\title{
Kristallstrukturen der C2B-Domäne von Rabphilin-3A und der PP2C-ähnlichen Phosphatase tPphA von Thermosynechococcus elongatus BP-1
}

\author{
Dissertation \\ zur Erlangung des Doktorgrades \\ der Mathematisch-Naturwissenschaftlichen Fakultäten \\ der Georg-August-Universität zu Göttingen
}

vorgelegt von

Christine Schlicker

aus Rotenburg

Göttingen 2006 
D 7

Referent: $\quad$ Prof. George M. Sheldrick, $\mathrm{PhD}$

Korreferent: Jun.-Prof. Dr. Oliver Einsle

Tag der mündlichen Prüfung: 5.7.06 


\section{Dank}

Für die Förderung dieser Arbeit sowie für die stete Gesprächsbereitschaft möchte ich mich recht herzlich bei Prof. George M. Sheldrick bedanken. Darüber hinaus möchte ich ihm besonders für meine Ausbildung im Bereich der Kleinmolekül- und Proteinkristallographie danken.

Für die Vergabe des interessanten Themas, für die Betreuung der Arbeit im biologischen Bereich und die stete Diskussionsbereitschaft möchte ich mich recht herzlich bei Dr. Stefan Becker bedanken. Bei Dr. Pierre Montaville möchte ich mich für die Einarbeitung in die Proteinreinigung der C2B-Domäne bedanken. Für die Einführung in die molekularbiologischen Arbeitstechniken und ihre Unterstützung im Labor gilt mein besonderer Dank Karin Giller.

Für die interessante Aufgabenstellung hinsichtlich der Phosphatase tPphA und für die stete Gesprächsbereitsschaft möchte ich recht herzlich Prof. Karl Forchhammer von der Universität Gießen danken. Außerdem möchte ich mich herzlich bei seiner Mitabeiterin Dr. Nicole Kloft bedanken, die mir das Thema der Phosphatase aus den Cyanobakterien näher gebracht hat.

Mein Dank geht auch an alle Mitarbeiter der Abteilung von Prof. G.M. Sheldrick. Für die stete Diskussionsbereitschaft möchte ich mich insbesondere bei Dr. Ina Dix und Dr. Tim Grüne bedanken.

Für das Korrekturlesen dieser Arbeit danke ich Dr. Stefan Becker, Dr. Ina Dix, Dr. Tim Grüne, Dipl. Chem. Kathrin Meindle, Prof. Dr. Isabel Usón und Dr. Anja Wieczarkowiecz.

Für die Hilfsbereitschaft in Sachen LATEX möchte ich sehr herzlich Dr. Rebekka von Benten danken.

Ganz besonders möchte ich meiner Familie und meinen Freunden danken, die in dieser Zeit für mich da waren. 


\section{Abkürzungsverzeichnis}

$\begin{array}{ll}\text { lac } & \text { Laktose } \\ p \text {-NP } & \text { para-Nitrophenol } \\ p \text {-NPP } & \text { para-Nitrophenylphosphat } \\ \text { ADP } & \text { Adenosindiphosphat } \\ \text { APS } & \text { Ammoniumperoxodiphosphat } \\ \text { ATP } & \text { Adenosintriphosphat } \\ \text { bp } & \text { Basenpaare } \\ \text { CCD } & \text { charge coupled device } \\ \text { cDNS } & \text { komplementäre DNS } \\ \text { d } & \text { Tag } \\ \text { DESY } & \text { Deutsches Elektronen-Synchrotron } \\ \text { DNS } & \text { Desoxyribonukleinsäure } \\ \text { DTT } & \text { Dithiotreitol } \\ \text { EDTA } & \text { Ethylendiamintetraacetat } \\ \text { EGTA } & \text { Ethylenglykol-bis(aminoethylether)-N,N'-Tetraacetat } \\ \text { GAP } & \text { GTPase-aktivierendes Protein } \\ \text { GDI } & \text { GDP-Dissoziationsinhibitor Protein } \\ \text { GDP } & \text { Guanosindiphosphat } \\ \text { GEF } & \text { GDP/GTP-Austauschfaktor } \\ \text { GST } & \text { Glutathion-S-Transferase } \\ \text { GTP } & \text { Guanosintriphosphat } \\ \text { GTPase } & \text { Guanosintriphosphatase } \\ \text { h } & \text { Stunde } \\ \text { Hepes } & \text { N-(2-Hydroxyethyl)-piperazin-N'-2-ethansulfonsäure } \\ \text { IPTG } & \text { Isopropyl- } \beta \text {-D-thiogalaktopyranosid } \\ \text { kDa } & \text { Kilodalton } \\ \text { M } & \text { mol/l } \\ \text { MAD } & \text { multiple-wavelength anomalous dispersion } \\ \text { MAD } & \text { multiple-wavelength anomalous dispersion } \\ \text { min } & \text { Minute } \\ \text { MIR } & \text { multiple derivatives isomorphous replacement } \\ & \end{array}$


MPD

OD

$\mathrm{P}_{i}$

PBS

PCR

PEG

PP2C

PphA

PPM

PPP

REP

rpm

RT

SAD

SDS

sec

SIR

SLS

SNAP-25

SNARE

SVs

Syt

TEMED

tPphA

Tris

UV

VAMP
2-Methyl-2,4-pentandiol

optische Dichte

anorganisches Phosphat

Phosphat-gepufferte Kochsalzlösung

Polymerase-Ketten-Reaktion

Polyethylenglykol

Proteinphosphatase 2C

Protein-Phosphatase A

$\mathrm{Mg}^{2+} / \mathrm{Mn}^{2+}$-abhängige Proteinphosphatasen

Phosphoproteinphosphatasen

Rab-eskortierendes Protein

Umdrehungen pro Minute

Raumtemperatur

single-wavelength anomalous dispersion

Natriumdodecylsulfat

Sekunde

single derivative isomorphous replacement

Swiss Light Source

25 kDa Synaptosom-assoziiertes Protein

soluble NSF attachment protein receptors, NSF: $N$-ethyl-malaimidesensitive fusion protein

Synaptische Vesikel-Glykoproteine

Synaptotagmin

$\mathrm{N}, \mathrm{N}, \mathrm{N}^{\prime}, \mathrm{N}^{\prime}$-Tetramethylendiamin

Thermosynechococcus-Protein-Phosphatase A

Tris-(hydroxymethyl)-aminoethan

Ultraviolett

Vesikel-assoziiertes Membran-Protein 


\section{Inhaltsverzeichnis}

Dank

Zusammenfassung $\quad 1$

1 Einleitung $\quad 3$

1.1 C2B-Domäne von Rabphilin-3A . . . . . . . . . . . . . . 3

1.1.1 Synaptischer Vesikelzyklus . . . . . . . . . . . . . . 3

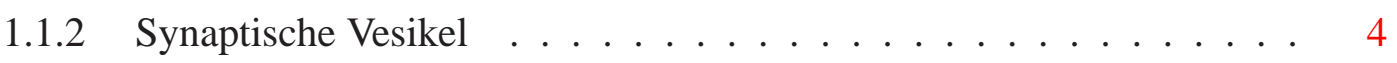

1.1.3 SNARE-Proteine .................... 5

1.1.4 Membranfusion während der Exocytose . . . . . . . . . . . 6

1.1.5 Rab-Proteine . . . . . . . . . . . . . . . . 8

1.1.6 Rabphilin-3A . . . . . . . . . . . . . . . . 9 9

1.1 .7 C2-Domänen . . . . . . . . . . . . . . . . 10

1.1.8 Struktur der C2-Domänen . . . . . . . . . . . . . . . 10

1.1 .9 Aufgabenstellung . . . . . . . . . . . . . . . . 11

1.2 PP2C-ähnliche Phosphatase tPphA . . . . . . . . . . . . . . 13

1.2.1 Cyanobakterien . . . . . . . . . . . . . . . 13

1.2.2 Die PII-Proteine . . . . . . . . . . . . . . . . . . 15

1.2.3 Wirkungsweise der PII-Proteine in Cyanobakterien . . . . . . . . . 16

1.2.4 Bedeutung der Phosphorylierung/Dephosphorylierung . . . . . . . . 17

1.2.5 Nomenklatur der Proteinphosphatasen . . . . . . . . . . . . . . 18

1.2.6 Sequenz-Vergleich der menschlichen und der bakteriellen Phosphatasen PP2C . . . . . . . . . . . . . . . . 18

1.2.7 Tertiärstruktur der menschlichen und der bakteriellen Phosphatasen PP2C . . . . . . . . . . . . . 20

1.2.8 Katalytischer Mechanismus der Phosphatase PP2C . . . . . . . . . . 20

1.2.9 Biologische Funktion der Phosphatase tPphA . . . . . . . . . . . . . 21

1.2.10 Aufgabenstellung . . . . . . . . . . . . . . . 22 
2 Material und Methoden $\quad 23$

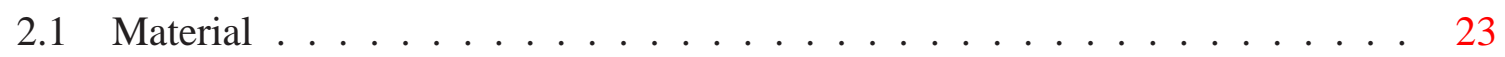

2.1.1 Bakterienstämme . . . . . . . . . . . . . 23

2.1.2 Primer und Restriktionsenzyme . . . . . . . . . . . . . . 23

2.1.3 Expressionsvektoren ..................... 23

2.1 .4 Nährmedien . . . . . . . . . . . . . . . . . . . . 24

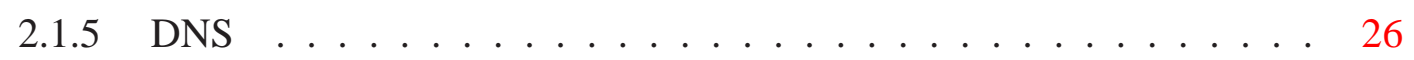

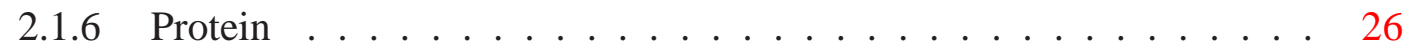

2.1.7 Pufferlösungen für die Reinigung der C2B-Domäne . . . . . . . . . . 27

2.1.8 Pufferlösungen für die Reinigung der

Phosphatase tPphA . . . . . . . . . . . . . . . 28

2.2 Molekularbiologische Methoden . . . . . . . . . . . . . . . . . . 29

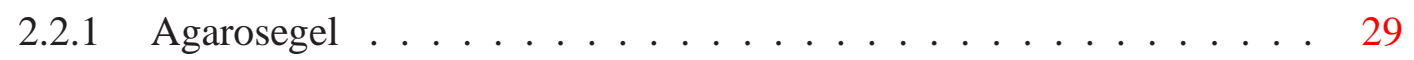

2.2.2 Transformation durch Hitzeschock . . . . . . . . . . . . . . . . 29

2.2.3 Vervielfältigung der Plasmid-DNS in E. coli . . . . . . . . . . . . . 30

2.2.4 Bestimmung der DNS-Konzentration . . . . . . . . . . . . . 30

2.2.5 Aufbewahrung der transformierten Konstrukte . . . . . . . . . . 30

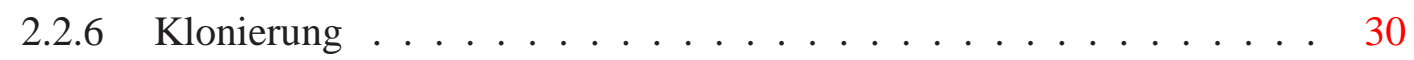

2.3 Biochemische Methoden . . . . . . . . . . . . . . . . 34

2.3.1 SDS-Polyacrylamid-Gelelektrophorese nach Laemmli . . . . . . . . 34

2.3.2 Ammoniumsulfatfällung . . . . . . . . . . . . . . 35

2.3.3 Glutathion-S-Transferase-Fusionsprotein Reinigung . . . . . . . . 35

2.3.4 Ionenaustauscher-Chromatographie . . . . . . . . . . . . . 36

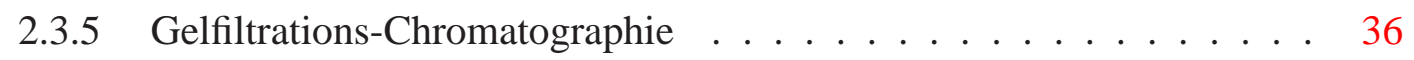

2.3.6 Bestimmung der Proteinkonzentration . . . . . . . . . . . . . . 37

2.3.7 Aktivitätstest für tPphA . . . . . . . . . . . . . . 37

2.4 Kristallographische Methoden . . . . . . . . . . . . . . . 38

2.4 .1 Kristallisation . . . . . . . . . . . . . . . . . . 38

2.4.2 Datensammlung und -prozessierung ............... 40

2.4 .3 Strukturlösung . . . . . . . . . . . . . . . . . . 42

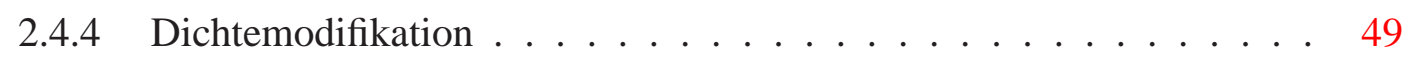

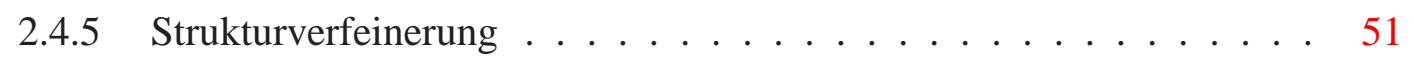

3 Strukturbestimmung der C2B-Domäne $\mathbf{5 2}$

3.1 Expression und Reinigung . . . . . . . . . . . . . . . . . . . . 52

3.1 .1 Natives Protein . . . . . . . . . . . . . . . 52

3.1 .2 Se-Met Protein . . . . . . . . . . . . . . . . . . 54

3.2 Kristallisation und Datensammlung . . . . . . . . . . . . . 57 
$3.2 .1 \quad$ Kristallisation . . . . . . . . . . . . . . . . . . 57

3.2 .2 Datensammlung . . . . . . . . . . . . . . . . 59

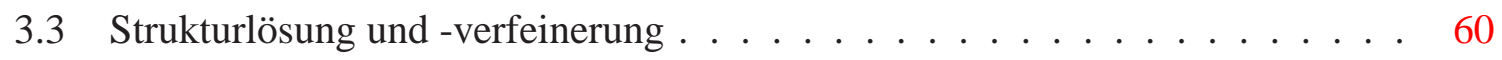

3.3.1 Die C2B-Struktur in der Raumgruppe $\mathrm{P}_{2} 2_{1} 2 \ldots \ldots \ldots \ldots$

3.3.2 Die C2B-Struktur in der Raumgruppe $\mathrm{P} 2$. . . . . . . . . . . 63

4 Ergebnisse $\quad 66$

4.1 Struktur der C2B-Domäne in $\mathrm{P} 2{ }_{1} 2_{1} 2 \ldots \ldots \ldots \ldots \ldots \ldots$

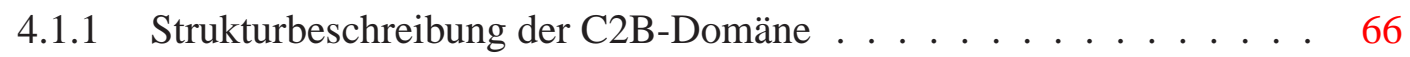

4.1.2 Die $\mathrm{Ca}^{2+}$-Bindungsstelle in $\mathrm{P}_{2}{ }_{2} 2_{2} \ldots \ldots \ldots \ldots \ldots$

4.2 Struktur der C2B-Domäne in $\mathrm{P} 2{ }_{1} \ldots \ldots \ldots \ldots \ldots$

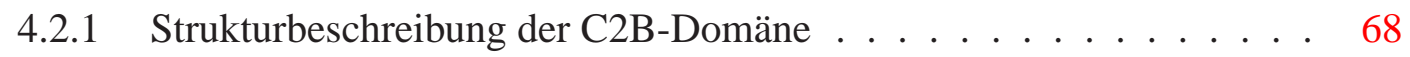

4.2.2 Vergleich der beiden Monomere . . . . . . . . . . . . . 68

4.2.3 Die $\mathrm{Ca}^{2+}$-Bindungsstelle in $\mathrm{P} 2{ }_{1} \ldots \ldots \ldots \ldots \ldots$

5 Diskussion 71

5.1 Vergleich der C2B-Strukturen in den unterschiedlichen

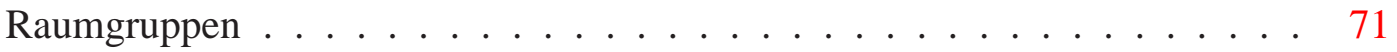

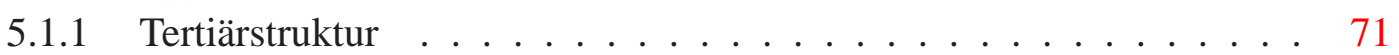

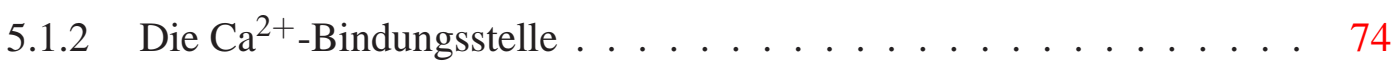

5.1.3 Der N-Terminus oberhalb der Kalziumbindungsstelle . . . . . . . . 75

5.2 Vergleich der Kristallstrukturen mit der NMR-Struktur $\ldots \ldots \ldots \ldots$

5.2.1 Elektrostatische Oberfläche im Vergleich . . . . . . . . . . . 79

5.3 Vergleich mit anderen C2B-Domänen $\ldots \ldots \ldots \ldots \ldots$

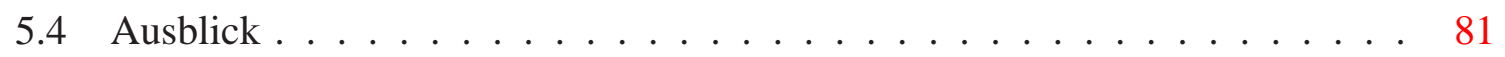

6 Strukturbestimmung der Phosphatase tPphA 83

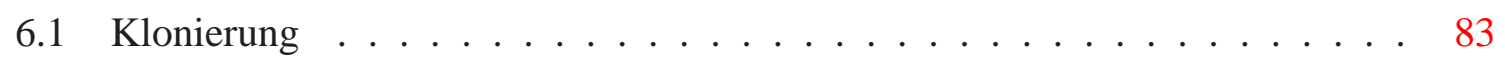

6.1 .1 Polymerase-Kettenreaktion . . . . . . . . . . . . . . 83

6.1 .2 Restriktionsverdau . . . . . . . . . . . . . 83

6.1 .3 Ligation . . . . . . . . . . . . . . . . . . . . . . . . . . 84

6.1 .4 Hot $\operatorname{Star} T a q$ PCR . . . . . . . . . . . . . . . . . . . . . . . . 84

6.2 Expression und Reinigung . . . . . . . . . . . . . . . 85

6.2 .1 Natives Protein . . . . . . . . . . . . . . . . . . . . . 85

6.2 .2 Se-Met Protein . . . . . . . . . . . . . . . . . . . . . . 90

6.3 Kristallisation und Datensammlung $\ldots \ldots \ldots \ldots$

6.3.1 Kristallisation . . . . . . . . . . . . . . . . . . . . . . . . . 94 94

6.3 .2 Datensammlung . . . . . . . . . . . . . 96

6.4 Strukturlösung und -verfeinerung . . . . . . . . . . . . . . . . . . . . 99 
6.4.1 Die tPphA-Struktur in der Raumgruppe C222 $\ldots$. . . . . . . . . . . 99

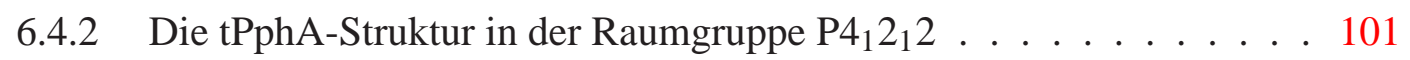

7 Ergebnisse $\quad 103$

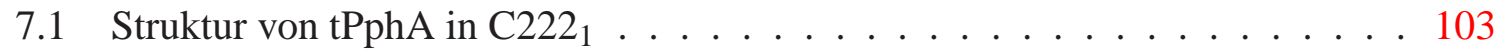

7.1 .1 Strukturbeschreibung von $\mathrm{tPphA} \ldots \ldots \ldots$. . . . . . . . . . . . . . . . . . . . 103

7.1.2 Das aktive Zentrum . . . . . . . . . . . . . . . . . . . . . 104

7.2 Struktur von tPphA in $\mathrm{P}_{4}{ }_{1}{ }_{1} 2 \ldots \ldots \ldots \ldots \ldots$

7.2.1 Strukturbeschreibung von tPphA . . . . . . . . . . . . . 105

7.2 .2 Das aktive Zentrum . . . . . . . . . . . . . . . . . 106

8 Diskussion $\quad 108$

8.1 Vergleich von tPphA in den verschiedenen

Raumgruppen . . . . . . . . . . . . . . . . . . . 108

8.1 .1 Tertiärstruktur . . . . . . . . . . . . . . . . 108

8.1.2 Das aktive Zentrum im Vergleich . . . . . . . . . . . . . . . 109

8.2 Vergleich von tPphA mit anderen

PP2C-Phosphatasen . . . . . . . . . . . . . . . . 110

8.2.1 Tertiärstruktur . . . . . . . . . . . . . . 110

8.2.2 Das aktive Zentrum im Vergleich . . . . . . . . . . . . . . . 112

8.2.3 Die elektrostatischen Oberflächen im Vergleich . . . . . . . . . . . 115

8.3 Ausblick . . . . . . . . . . . . . . . . . . 116

$\begin{array}{ll}\text { Anhang } & 118\end{array}$

$\begin{array}{ll}\text { Abbildungsverzeichnis } & 122\end{array}$

$\begin{array}{ll}\text { Tabellenverzeichnis } & 125\end{array}$

$\begin{array}{ll}\text { Literaturverzeichnis } & 126\end{array}$ 



\section{Zusammenfassung}

Die vorliegende Arbeit befaßt sich mit den Röntgenkristallstrukturen der C2B-Domäne von Rabphilin-3A und der PP2C-ähnlichen Phosphatase tPphA von Thermosynechococcus elongatus BP-1. Im ersten Teil der Arbeit wird die Struktur der C2B-Domäne (Typ I) von Rabphilin3A besprochen. Die C2-Domänen sind intrazelluläre, ca. 130 Aminosäuren umfassende Proteinmodule, welche als charakteristisches Strukturmerkmal ein viersträngiges, antiparalleles $\beta$-Sandwich aufweisen und zumeist eine hohe Kalziumionen-Affinität zeigen.

C2-Domänen sind sowohl an der Exocytose, als auch an der Regulierung der Neurotransmitterfreisetzung im synaptischen Vesikelzyklus beteiligt; als Beispiel für die Beteiligung an der Exocytose lassen sich die C2-Domänen des Synaptotagmins anführen, welche nach dem Einströmen von Kalziumionen in die synaptische Nervenendigung durch Wechselwirkungen mit den Phospholipiden der Plasmamembran die Freisetzung der Neurotransmitter durch Öffnung der Pore forcieren. Die Regulierung der Neurotransmitterfreisetzung hingegen wird unter anderem von den Rab-Proteinen übernommen, welche bei diesem Vorgang als molekulare Schalter dienen. In ihrer aktiven, GTP-gebundenen Form können sie mit Effektoren interagieren, während die inaktive, GDP-gebundene Form hierzu nicht in der Lage ist. Ein Effektor der Rab3A und Rab27A-Proteine ist die Rab-Bindungsdomäne des Rabphilins-3A. Das Rabphilin-3A besitzt außer der Rab-Bindungsdomäne noch zwei weitere Domänen, die C2A- und C2B-Domänen. Deren Aufgaben sind jedoch noch unklar, da in knock-out-Mäusen keine sichtbare physiologische Beeinträchtigung beobachtet werden konnte.

In dieser Arbeit wurde die Struktur der C2B-Domäne, die auch einen Teil der linkerRegion zwischen der C2A- und der C2B-Domäne des Rabphilin-3A enthielt, mit Hilfe der Röntgenstrukturanalyse untersucht. Für die Strukturlösung wurde ein MAD-Datensatz von Se-Methionin-Kristallen, sowie Datensätze von nativen Kristallen aufgenommen, die teilweise mit, teilweise ohne Kalziumionen kristallisiert wurden. Die C2B-Struktur konnte in zwei verschiedenen Raumgruppen $\left(\mathrm{P} 2{ }_{1} 2_{1} 2\right.$ und $\left.\mathrm{P} 2{ }_{1}\right)$ bestimmt werden. Dabei zeigten sich überraschende Einblicke in die Kalziumionenbindung: Aufgrund der geordneten N-terminalen Region oberhalb der Kalziumbindungsstelle, ausgehend von der linker-Region, liegt für die Kalziumionen eine nahezu optimale Koordinationssphäre vor. Dies erklärt, warum die C2BDomäne von Rabphilin-3A im Vergleich zu anderen C2-Domänen eine der stärksten Affinitäten zu Kalziumionen aufweist (5 - $7 \mu \mathrm{M})$. 
Der zweite Teil der Arbeit befaßt sich mit der Struktur der PP2C-ähnlichen Phosphatase tPphA aus dem Cyanobakterium Thermosynechococcus elongatus BP-1. Cyanobakterien besitzen als photosynthetische Organismen die Fähigkeit, in einer Photosynthesereaktion aus Kohlendioxid mit Hilfe von Wasser als Elektronendonor organische Biomoleküle und Sauerstoff zu produzieren. Darüber hinaus sind sie dazu in der Lage, sowohl Nitrat, Nitrit oder Ammonium als Stickstoffquelle zu nutzen (Stickstoff-Assimilation), als auch aus molekularem Stickstoff $\left(\mathrm{N}_{2}\right)$ biologisch verwendbare Stickstoffverbindungen aufzubauen (StickstoffFixierung). Sowohl Stickstoff-Assimilation als auch Stickstoff-Fixierung führen zur Bildung von Ammonium, welches als zentrales Ausgangsprodukt für den GS/GOGAT-Zyklus dient. In dessen erstem Schritt wird Ammonium durch die Glutamin-Synthetase (GS) unter ATPHydrolyse auf Glutaminsäure übertragen und dabei Glutamin gebildet. Im zweiten Schritt erfolgt die Umsetzung von Glutamin mit $\alpha$-Ketoglutarat zu zwei Molekülen Glutaminsäure durch die Glutamat-2-Oxoglutarat-Amidotransferase (GOGAT). Dieser Zyklus wird über die Regulierung der Glutamin-Synthetase kontrolliert, welche von den PII-Proteinen übernommen wird. Die PII-Proteine werden dabei je nach Kohlenstoff-Stickstoffbilanz der Zelle entweder phosphoryliert oder dephosphoryliert, um in die Aktivität der Glutamin-Synthetase einzugreifen. Die Dephosphorylierung übernimmt eine PP2C-ähnliche Phosphatase (PIIPhosphatase). Die erste PII-Phosphatase, deren Funktion hinsichtlich des PII-Proteins genau untersucht wurde, war die Protein-Phosphatase A (PphA). Da die tPphA eine im Vergleich zur PphA sehr ähnliche Sequenz besitzt und mit Hilfe von in-vitro-Tests die Dephosphorylierung des PII-Proteins durch tPphA bestätigt wurde, lag die Vermutung nahe, daß sich die Funktionen der tPphA und der PphA ähneln. Die Aufgabe dieser Arbeit war es, die Struktur der tPphA mit anderen PP2C-Phosphatasen zu vergleichen - hierfür boten sich die menschliche Phosphatase PP2C und die bakterielle Phosphatase PstP an - und darüber hinaus Rückschlüsse auf den katalytischen Mechanismus zu ziehen.

Für die Strukturlösung der tPphA wurde, wie im Fall der C2B-Domäne, ein MADExperiment durchgeführt. Desweiteren wurden native Kristalle, die sowohl mit als auch ohne Metallionen kristallisiert worden waren, gemessen. Die tPphA-Struktur konnte in den beiden Raumgruppen $\mathrm{C} 222_{1}$ und $\mathrm{P} 4{ }_{1} 2_{1} 2$ bestimmt werden. Ein Vergleich der tPphA-Struktur mit der menschlichen Phosphatase PP2C und der bakteriellen Phosphatase PstP zeigt, daß die tPphA-Struktur größere Ähnlichkeit mit der bakteriellen Phosphatase PstP aufweist: Beide bakterielle Phosphatasen besitzen drei statt zwei Metallionen (wie im Fall der menschlichen Phosphatase PP2C) im aktiven Zentrum. Gemeinsam ist hingegen allen drei Phosphatasen das zweifach koordinierte Hydroxid-Ion, das in der menschlichen Phosphatase PP2C als Nucleophil das phosphorylierte Substrat angreift. Es ist daher durchaus denkbar, daß bei beiden bakteriellen Phosphatasen ein ähnlicher katalytischer Mechanismus wie bei der menschlichen Phosphatase PP2C vorliegt. 


\section{Einleitung}

In der vorliegenden Arbeit wird sowohl die Struktur der Rabphilin-3A C2B-Domäne als auch der thermophilen PP2C-ähnlichen Phosphatase tPphA untersucht.

\subsection{C2B-Domäne von Rabphilin-3A}

\subsubsection{Synaptischer Vesikelzyklus}

In der präsynaptischen Nervenendigung unterliegen die synaptischen Vesikel einem vielstufigen Zyklus (s. Abb. 1.1, S. 4). Die mit Neurotransmittern gefüllten Vesikel gelangen in die aktive Zone der präsynaptischen Nervenendigung und docken an die Plasmamembran an. Dort verschmelzen sie mit der Membran als Antwort auf den $\mathrm{Ca}^{2+}$-Zufluß, der das Aktionspotential darstellt. Während dieses Schrittes im synaptischen Vesikelzyklus - Exocytose - werden die Neurotransmitter in den synaptischen Spalt freigesetzt. Anschließend beginnt die Endocytose, wobei das Recycling der leeren Vesikel auf unterschiedlichen Wegen erfolgen kann. Zum einen können die leeren Vesikel nach dem Prinzip des ,,kiss-and-run“-Mechanismus wieder mit Neurotransmittern gefüllt werden, d.h. nach Aufbau eines Protonengradienten können Neurotransmitter in die Vesikel aufgenommen werden. Zum anderen kann nach der Neurotransmitterfreisetzung das endosomale Recycling stattfinden, wobei die leeren Vesikel direkt oder über die Endosome Clathrin-vermittelt mit Neurotransmittern gefüllt werden [1]. 


\section{Einleitung}

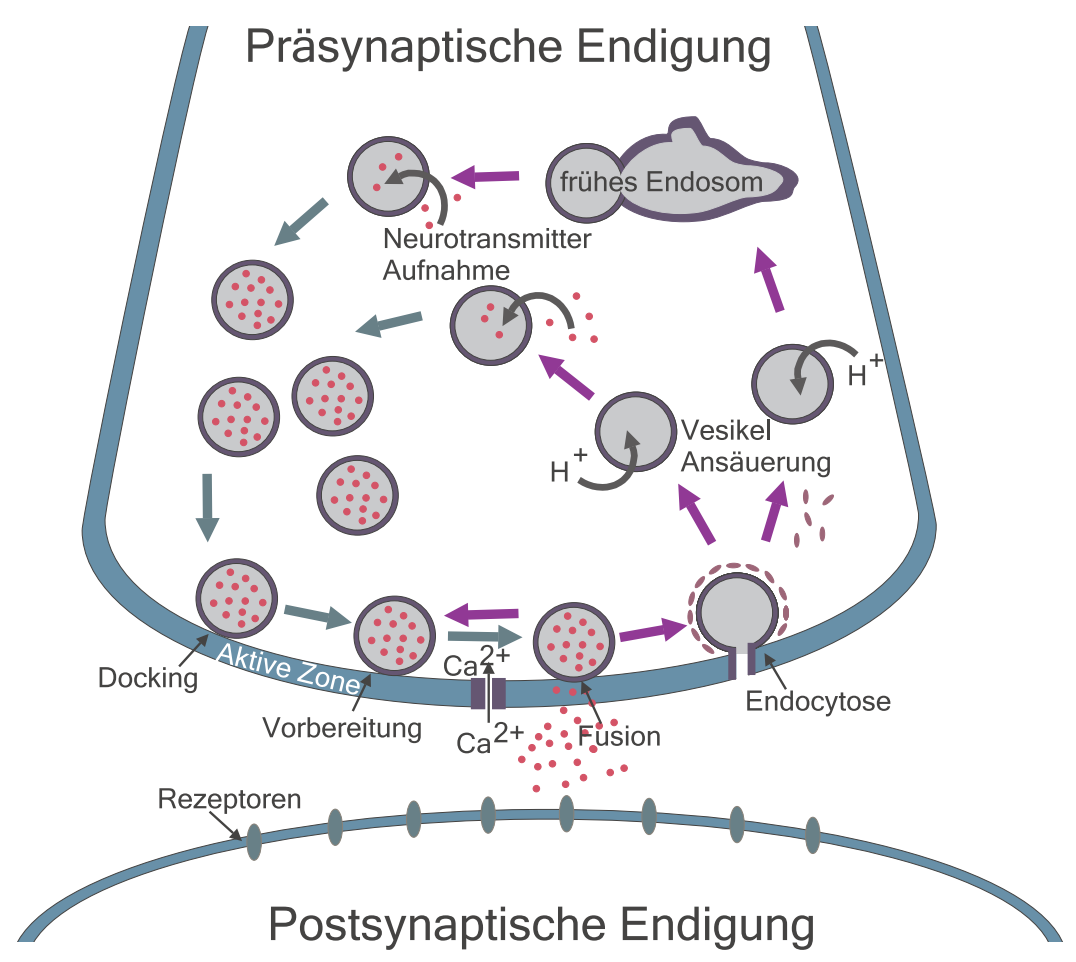

Abbildung 1.1: Der synaptische Vesikelzyklus; synaptische Vesikel, die mit Neurotransmittern gefüllt sind, gelangen in die aktive Zone der präsynaptischen Nervenendigung. Dort docken sie an die Plasmamembran an, verschmelzen mit ihr als Antwort auf $\mathrm{Ca}^{2+}-\mathrm{Zufluß}$ und setzen den Neurotransmitter in den synaptischen Spalt frei. Die leeren Vesikel werden auf unterschiedlichen Wegen wieder mit Neurotransmittern gefüllt.

\subsubsection{Synaptische Vesikel}

Die synaptischen Vesikel haben die Funktion, Neurotransmitter zu lagern und freizusetzen. Dazu besitzen sie zwei Arten von Proteinen in ihrer Membran. Zum einen sind das Transportproteine, die in die Neurotransmitteraufnahme involviert sind. Diese beinhalten Protonenpumpen, die einen elektrochemischen Gradienten aufbauen und somit die Aufnahme von Neurotransmittern ermöglichen [1]. Zum anderen sind Proteine beteiligt, die in das Recycling der Vesikel, der Exo- und Endocytose einbezogen sind [1]. Zu dieser Gruppe von Proteinen, die sehr unterschiedlich aufgebaute Membranproteine umfaßt, gehören unter anderem Rab-Proteine, Synaptotagmine, Synaptobrevine, Synaptische Vesikel-Glykoproteine (SV) und Synapsine [1]. In Abbildung 1.2 (S. 5) sind einige dieser Proteine, die in die Vesikelmembran eingelagert sind, dargestellt. 

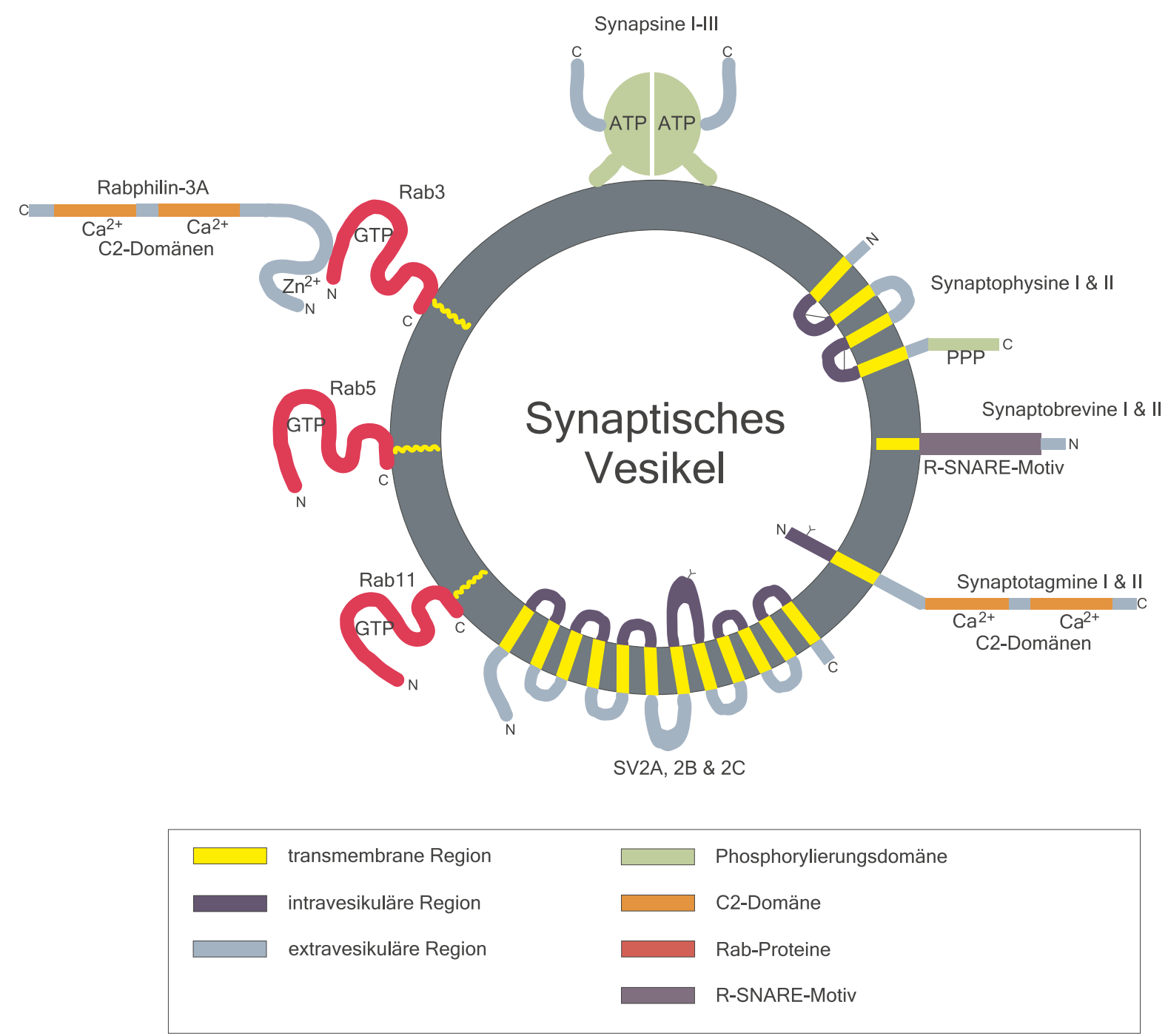

Abbildung 1.2: Das synaptische Vesikel mit den verschiedenen funktionellen Proteinen; dunkelblau: intravesikuläre Bereiche, gelb: transmembrane Regionen, hellgrün: Phosphorylierungsdomänen, lila: SNARE-Motive (s. Abschnitt 1.1.3 und 1.1.4, S. 5-6), hellblau: extrazelluläre Bereiche.

\subsubsection{SNARE-Proteine}

Die SNARE-Proteine spielen eine wichtige Rolle bei der intrazellulären Membranfusion. Der Begriff SNARE steht hierbei für soluble NSF attachment protein receptors, wobei NSF die Abkürzung für $N$-ethyl-malaimide-sensitive fusion protein ist. Zu den SNARE-Proteinen gehören Synaptobrevin - auch Vesikel-assoziiertes-Membran-Protein (VAMP) genannt - , Syntaxin und SNAP-25, welches ein 25 kDa Synaptosom-assoziiertes Protein darstellt [2]. Diese sind entweder an die Vesikelmembran (z.B. VAMP (s. Abb. 1.2, S. 5)), oder an die Ziel- 


\section{Einleitung}

membran (z.B. Syntaxin) gebunden. SNAREs sind in ihrer Größe und Struktur sehr unterschiedlich, sie besitzen aber eine gemeinsame homologe Sequenz, die als SNARE-Motiv bezeichnet wird [3]. Das SNARE-Motiv besteht aus 60-70 Aminosäuren, welche die für gewundene $\alpha$-helikale Strukturen (coiled-coils) typische Siebener-Wiederholungssequenz (heptad repeat) enthalten. Für diese ist charakteristisch, daß sich das Muster der SeitenkettenWechselwirkungen nach zwei Umrundungen der $\alpha$-Helix bzw. nach sieben Aminosäuren in der Sequenz wiederholt [4]. Dadurch entstehen hydrophobe Wechselwirkungen über die erste und vierte Aminosäure des Musters zur zweiten $\alpha$-Helix des coiled-coils. Im Fall der SNARE-Proteine wird bei der Membranfusion ein vier-helikales Bündel (four-helical bundle), bestehend aus vier SNARE-Motiven, gebildet (s. Abb. 1.3).

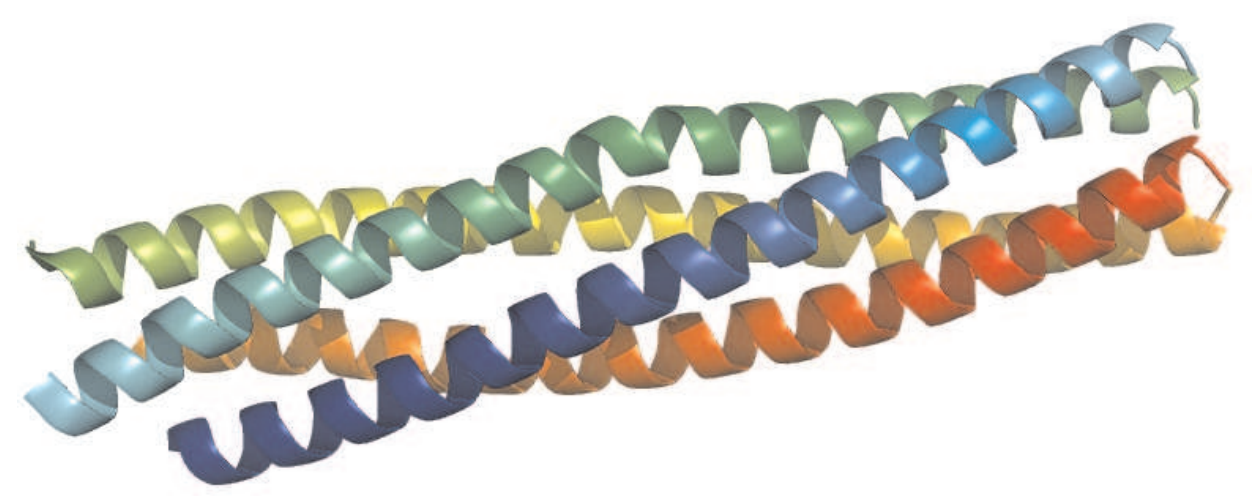

Abbildung 1.3: Struktur des endosomalen SNARE-Komplexes [5]

Aufgrund einer unterschiedlich konservierten Aminosäure in den SNARE-Motiven werden die SNARE-Proteine in zwei Gruppen unterteilt: die R-SNAREs, die als konservierte Aminosäure Arginin (R) enthalten (z.B. VAMP), und die Q-SNAREs, die als konservierte Aminosäure Glutamin (Q) enthalten [6]. Die Gruppe der Q-SNAREs kann weiterhin in die Untergruppen Qa (z.B. Syntaxin), Qb (z.B. SNAP-25, N-terminale Helix) und Qc (z.B. SNAP-25, C-terminale Helix) unterteilt werden [7]. Nur wenn aus jeder dieser Gruppen eine $\alpha$-Helix für das four-helical bundle zur Verfügung steht, entsteht der sehr starke Komplex der vier $\alpha$-Helices [3].

\subsubsection{Membranfusion während der Exocytose}

Bei der synaptischen Exocytose wird die Membranfusion über die drei SNARE-Proteine Syntaxin, Synaptobrevin und SNAP-25 vermittelt [1]. In dem Vorbereitungsschritt der Exocytose (s. Abb. 1.1, S. 4) formen diese drei SNARE-Proteine den SNARE-Komplex, der aus einem four-helical bundle besteht. Dieser Komplex bewirkt, daß die Plasmamembran und die 
Vesikelmembran sich einander nähern (s. Abb. 1.4 b, S. 7), wodurch sich ein instabiler Übergangszustand bildet, der jedoch noch nicht zur Öffnung der Pore führt. Durch das Zuströmen von $\mathrm{Ca}^{2+}$-Ionen in die Zelle, können die C2-Domänen des Synaptotagmins zusätzliche Wechselwirkungen mit den Phospholipiden der Plasmamembran eingehen [8] (s. Abb. 1.5 c, S. 8), die Instabilität des Übergangszustandes wird erhöht, die Pore öffnet sich, und der Neurotransmitter wird freigesetzt [1].

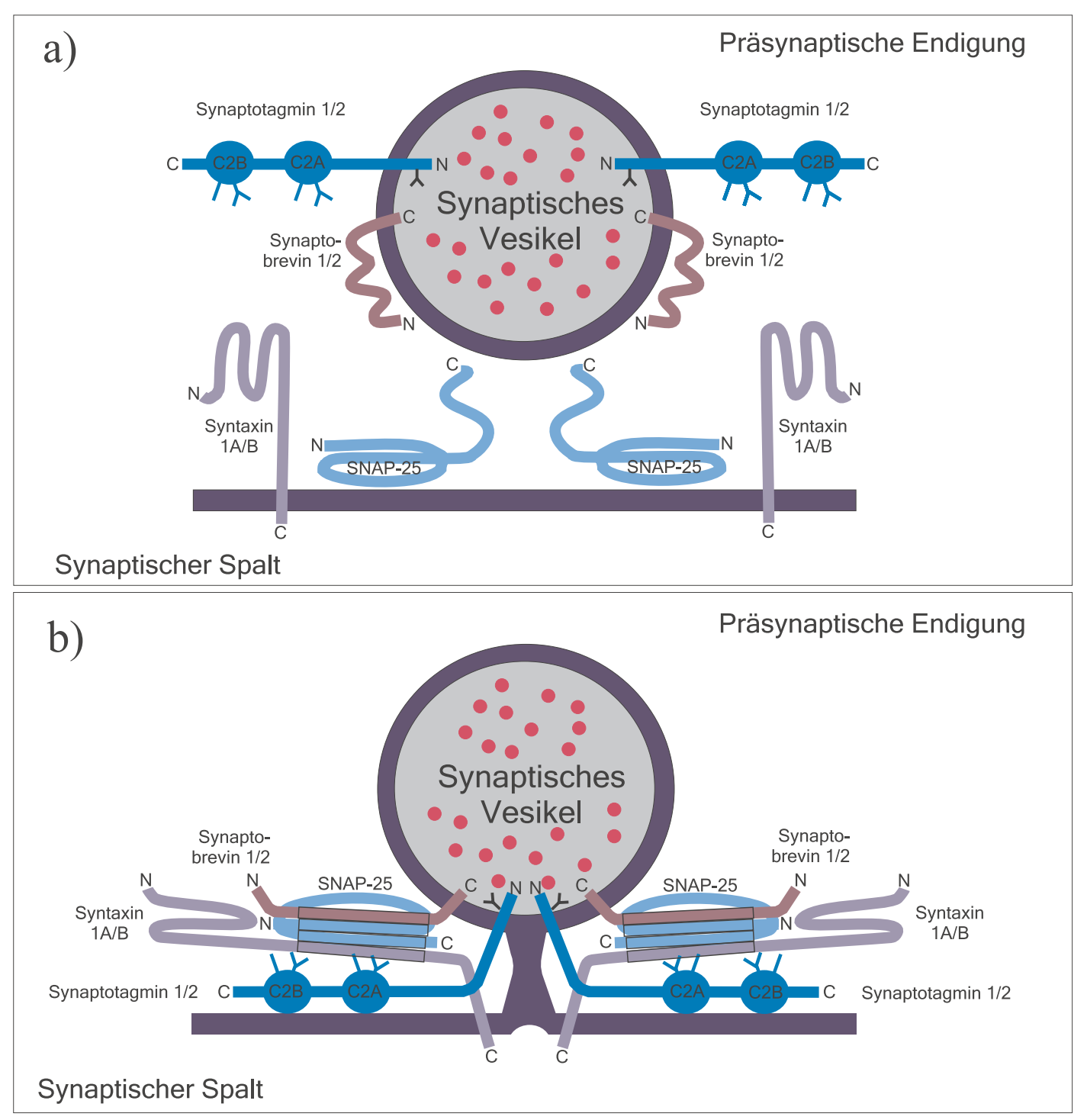

Abbildung 1.4: Modell für die Funktion der SNARE-Proteine: a) Docking-Phase, b) Vorbereitungsphase, in der sich der SNARE-Komplex bildet und die Vesikelmembran mit der Plasmamembran verschmilzt. 


\section{Einleitung}

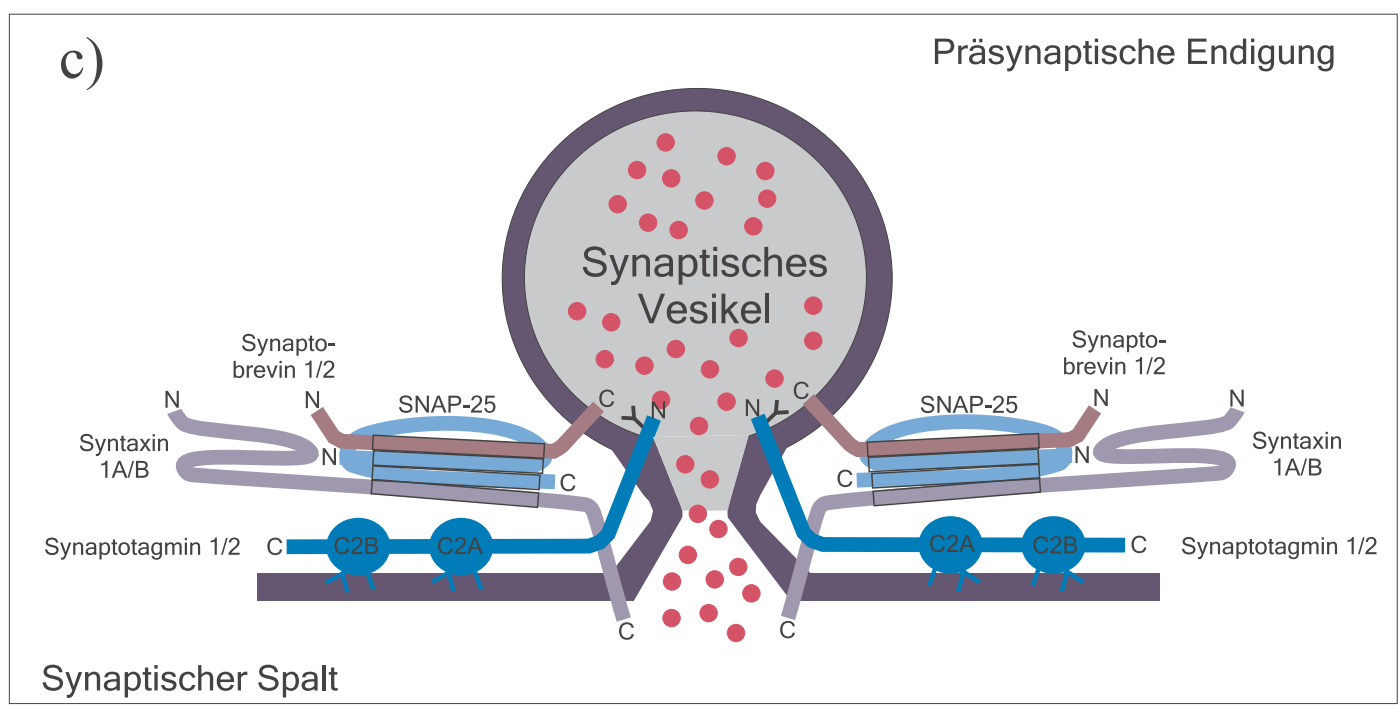

Abbildung 1.5: Modell für die Funktion der SNARE-Proteine: c) Fusionsphase, in der der Neurotransmitter (rot) freigesetzt wird.

\subsubsection{Rab-Proteine}

Die Rab-Proteine bilden eine Untergruppe der großen Familie der regulatorischen GTPHydrolasen (G-Proteine), die sich in insgesamt drei Gruppen aufteilen [9]: die kleinen monomerischen G-Proteine, die G-Proteine, die in ribosomale Proteinsynthese involviert sind und die $\alpha$-Untereinheit der heterotrimeren G-Proteine. Die Rab-Proteine gehören zu der Gruppe der kleinen monomerischen G-Proteine und sind an der Regulierung der Neurotransmitterfreisetzung beteiligt. Hierbei dienen sie als molekularer Schalter, d.h., daß sie entweder in ihrer aktiven Form, der GTP-gebundenen Form, mit Effektoren interagieren oder in ihrer inaktiven Form, der GDP-gebundenen Form, keine Reaktionen mit Effektoren eingehen. Dabei unterliegen sie einem funktionellen Zyklus, der mit der GTP-Hydrolase gekoppelt ist.

In Abbildung 1.6 (S. 9) ist der Zyklus der Rab-Proteine schematisch dargestellt [10]. Das GDP-gebundene Rab-Protein (z.B. Rab3A) ist im Cytosol an das Rab-eskortierende-Protein (REP) und an das GDP-Dissoziationsinhibitor Protein (GDI) gebunden. Gelangt es an die Membran des Vesikels, löst sich die Bindung zu GDI bzw. REP und es bindet an die Membran. Hier kann es mit Hilfe des GDP/GTP-Austauschfaktors (GEF) in seine aktive Form, die GTPgebundene Form, überführt werden. In seiner aktiven Form können Effektoren, wie z.B. Rabphilin-3A, an das Rab-Protein binden, und es kann die Neurotransmitterfreisetzung regulieren [9]. Anschließend wird das Rab-Protein mit Hilfe des GTPase-aktivierenden Proteins (GAP) wieder in seine inaktive, GDP-gebundene Form überführt, indem anorganisches Phosphat $\left(\mathrm{P}_{i}\right)$ abgespalten wird. 


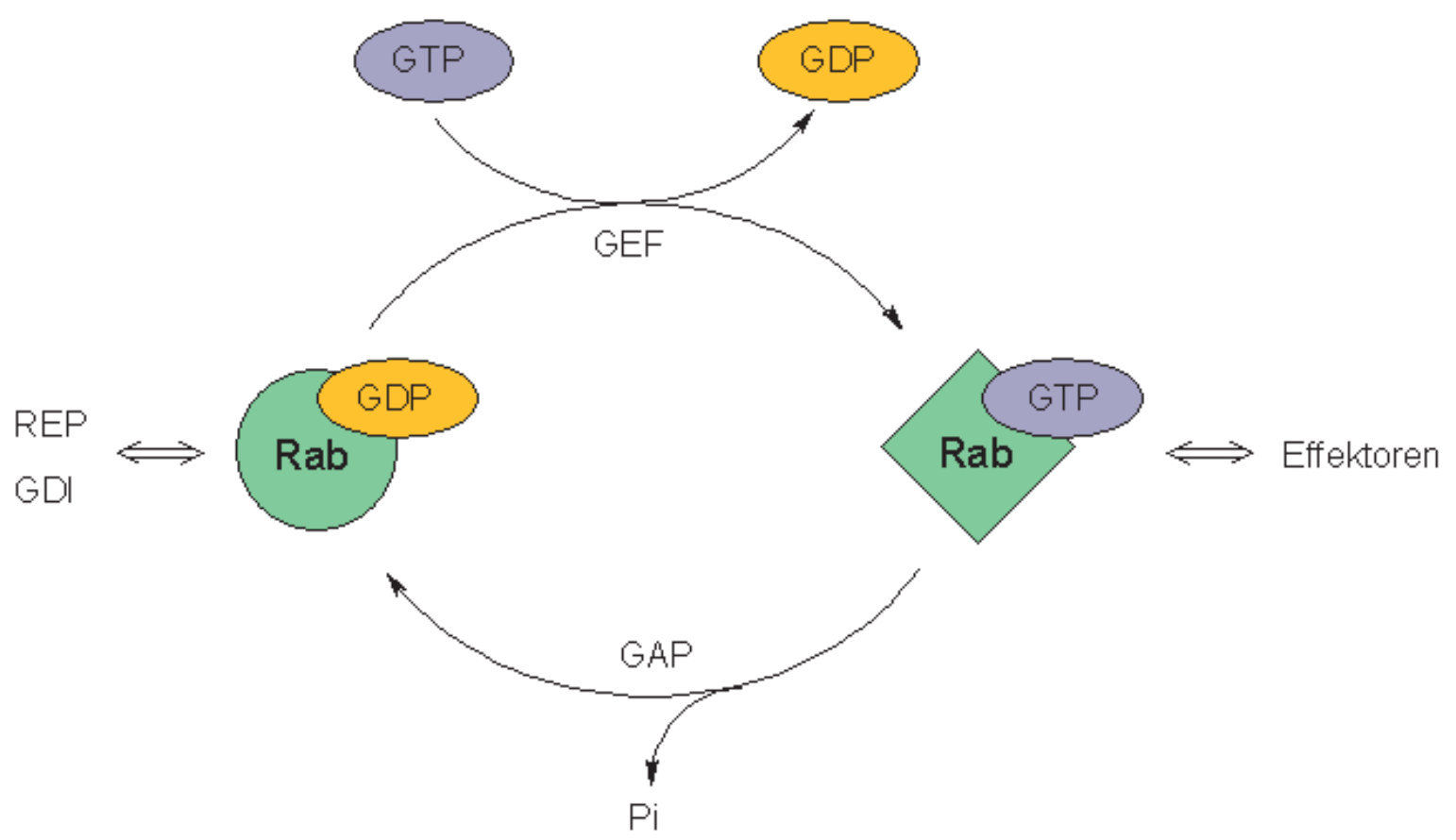

Abbildung 1.6: Der Rab Zyklus. Die Rab-GTPase wechselt zwischen der GDP-gebundenen inaktiven Form und der GTP-gebundenen aktiven Form.

\subsubsection{Rabphilin-3A}

Das Protein Rabphilin-3A ist ein 78 kDa cytosolisches Protein, das in Neuronen und endokrinen Zellen exprimiert wird [11]. Es beinhaltet N-terminal eine Rab-Bindungsdomäne, eine Prolin-reiche linker-Region und C-terminal zwei C2-Domänen, schematisch dargestellt in Abbildung 1.7 [12].

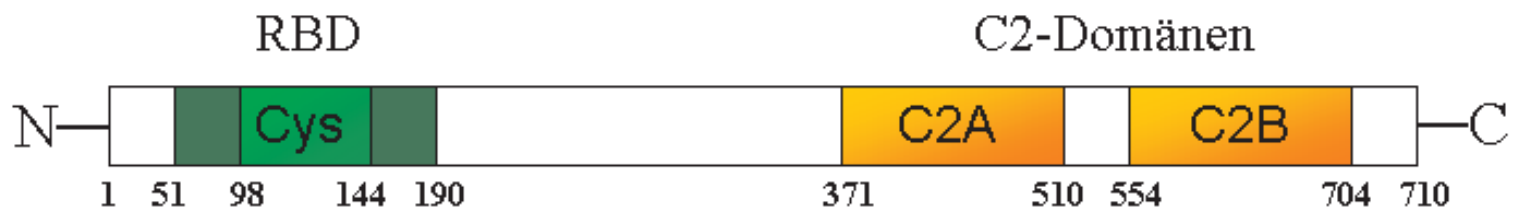

Abbildung 1.7: Rabphilin-3A

Rabphilin-3A besitzt multifunktionelle Aufgaben im synaptischen Vesikelzyklus, wobei es nicht wie andere Vesikel-assoziierte Proteine eine Membranbindungs-Domäne enthält [13]. Die N-terminale Rab-Bindungsdomäne (RBD) beinhaltet neun Cys-Reste, die zwei Zinkfinger ausbilden. Diese kann an verschiedene Rab-Proteine binden und agiert somit als Effektor 


\section{Einleitung}

im Rab Zyklus. Anfänglich war nur eine Bindung von Rabphilin-3A an die Isoformen von Rab3 bekannt. Mittlerweile weiß man jedoch, daß Rabphilin-3A an viele verschiedene RabProteine binden kann, unter anderem an Rab3A [14] und Rab27A [15]. Aufgrund der damit wohl einhergehenden funktionellen Redundanz ist verständlich, daß bei knock-out Mäusen, bei denen Rabphilin ausgeschaltet wurde, keine sichtbare physiologische Beeinträchtigung beobachtet werden konnte [16].

In der Abwesenheit von Rab-Proteinen kann die Rab-Bindungsdomäne von Rabphilin-3A an $\alpha$-Aktinin binden [17], eine Komponente des Aktin Cytoskeletts, das Aktinfilamente zu einem Bündel quervernetzt [11]. Durch die Bindung der Rab-Bindungsdomäne an $\alpha$-Aktinin wird die Aktivität von $\alpha$-Aktinin stimuliert, wodurch die Quervernetzung der Aktinfilamente forciert wird [17]. Diese Reorganisation der Aktinfilamente ist in die $\mathrm{Ca}^{2+}$-abhängige Exocytose involviert. Die Wechselwirkung der Rab-Bindungsdomäne mit $\alpha$-Aktinin wird durch anwesendes Rab3A inhibiert, da sich bei anwesendem Rab3A der Rabphilin-3A/Rab3AKomplex bildet.

\subsubsection{C2-Domänen}

C2-Domänen sind intrazelluläre Proteinmodule, die ca. 130 Aminosäuren umfassen [18]. Die erste C2-Domäne, die entdeckt wurde, war die Proteinkinase C. Im Jahr 1998 waren schon über 100 C2-Domänen bekannt [19]. Die beiden C2-Domänen des Rabphilin-3A sind homolog zu denen, die in der Proteinkinase C und Synaptotagmin entdeckt wurden [14]. C2-Domänen, wie diejenigen von Rabphilin-3A, besitzen sehr charakteristische Eigenschaften: sie binden $\mathrm{Ca}^{2+}$, Inositol Polyphosphate und Phospholipide [19], wobei die Bindung von Phospholipiden und Inositol Polyphosphaten $\mathrm{Ca}^{2+}$-abhängig ist [12]. Zusätzlich zu ihrer $\mathrm{Ca}^{2+}$-abhängigen Funktion besitzen sie auch $\mathrm{Ca}^{2+}$-unabhängige Funktionen, wie z.B. die Bindung zum Clathrin-aufbauenden Protein AP-2 [20], zu $\beta$-SNAP [21] und zu Ca ${ }^{2+}$ Kanälen [22]. Diese $\mathrm{Ca}^{2+}$-unabhängigen Funktionen konnten bei der C2B-Domäne von Synaptotagmin I (SytI) [19] und bei der C2B-Domäne von Rabphilin-3A [12] festgestellt werden.

\subsubsection{Struktur der C2-Domänen}

Die erste Kristallstruktur einer C2-Domäne war die der C2A-Domäne von SytI [23]. Sie enthält ein kompaktes $\beta$-Sandwich, das aus zwei viersträngigen, antiparallelen $\beta$-Faltblättern zusammengesetzt ist. Ein Vergleich mit der NMR-Struktur [24] zeigte, daß die Struktur im Kristall mit der Struktur in Lösung übereinstimmte. Ein Sequenz-Vergleich der C2A-Struktur mit anderen C2-Domänen - darunter die beiden C2-Domänen von Rabphilin - ergab Hinweise auf einen konservierten Kern von ca. 60 Aminosäure-Resten. Diese bilden eine kompakte Sekundärstruktur, die als C2-Schlüsselmotiv bezeichnet wurde [23]. In diesen Aminosäure- 
Resten sind auch die vier an der Kalziumbindung beteiligten Asp-Reste enthalten. Bei einem Vergleich der C2A-Domäne von SytI mit der C2-Domäne der Phosphoinositid-spezifischen Phospholipase PLC $\delta 1$ wurde deutlich, daß zwar die Faltung der C2-Domänen gleich ist, jedoch die Topologie der unterschiedlichen C2-Domänen verschieden ist.

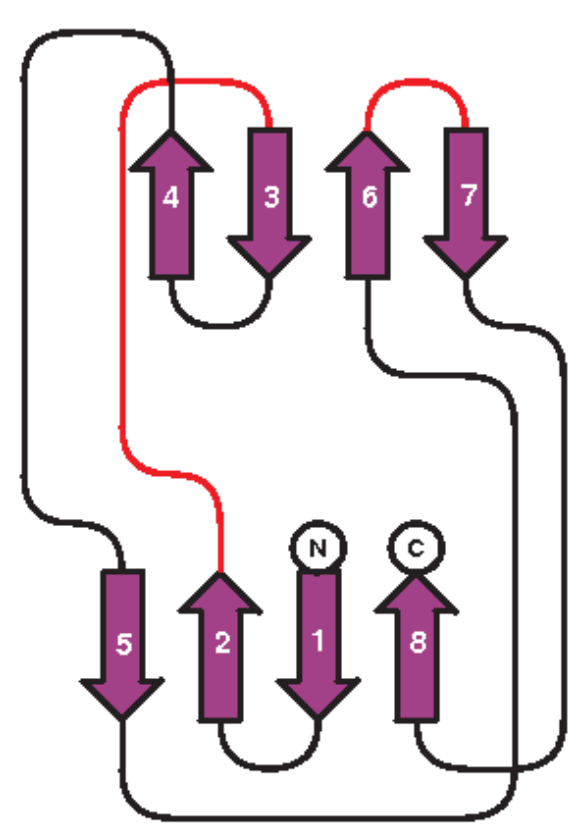

a)

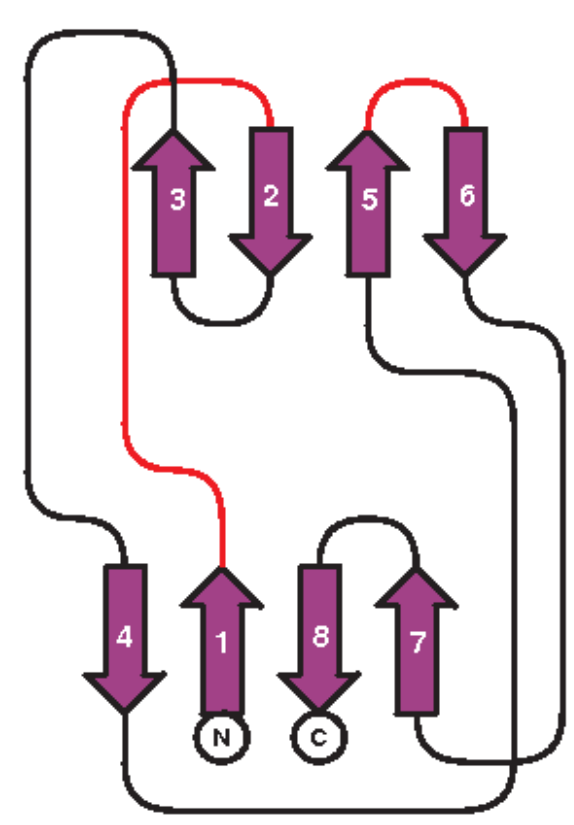

b)

Abbildung 1.8: Topologie der C2-Domänen: a) Typ I, b) Typ II; in rot sind die an der Kalziumbindung beteiligten loops dargestellt.

Die C2A-Domäne von SytI liegt in Form des Typ I vor (s. Abb. 1.8 a, S. 11), bei dem sich der N- und der C-Terminus der Struktur auf der Seite der Kalziumbindungsstelle befinden. In der C2-Domäne von PLC $\delta 1$, die in Form des Typ II auftritt (s. Abb. 1.8 b, S. 11), befinden sich der N- und der C-Terminus der Struktur auf der gegenüberliegenden Seite der Kalziumbindungsstelle $[18,19]$.

\subsubsection{Aufgabenstellung}

Von Rabphilin-3A lagen die Kristallstrukturen der RBD- und der C2A-Domäne [25] vor. Desweiteren war für die C2B-Domäne eine NMR-Struktur vorhanden, die jedoch für weitere NMR-Untersuchungen hinsichtlich des C2A-C2B Tandems zu ungenau bestimmt war. Um also weitere Dynamik-Untersuchungen mit der NMR-Spektroskopie durchführen zu können, sollte die Kristallstruktur der C2B-Domäne bestimmt werden. Hierbei war Bedingung, daß 


\section{Einleitung}

die Struktur möglichst hochaufgelöst sein sollte, um ein genaues Modell für weitere NMRExperimente vorliegen zu haben. 


\subsection{PP2C-ähnliche Phosphatase tPphA}

\subsubsection{Cyanobakterien}

Cyanobakterien, die früher mißverständlich auch als Blaualgen bezeichnet wurden, können fast jedes Ökosystem der Erde bewohnen [26]. Der Cyanobakterienstamm Thermosynechococcus elongatus BP-1 (s. Abb. 1.9, S. 13), aus dem die untersuchte Phosphatase (tPphA) stammt, lebt zum Beispiel in heißen Quellen und hat eine optimale Wachstumstemperatur von ca. $55^{\circ} \mathrm{C}[27]$.

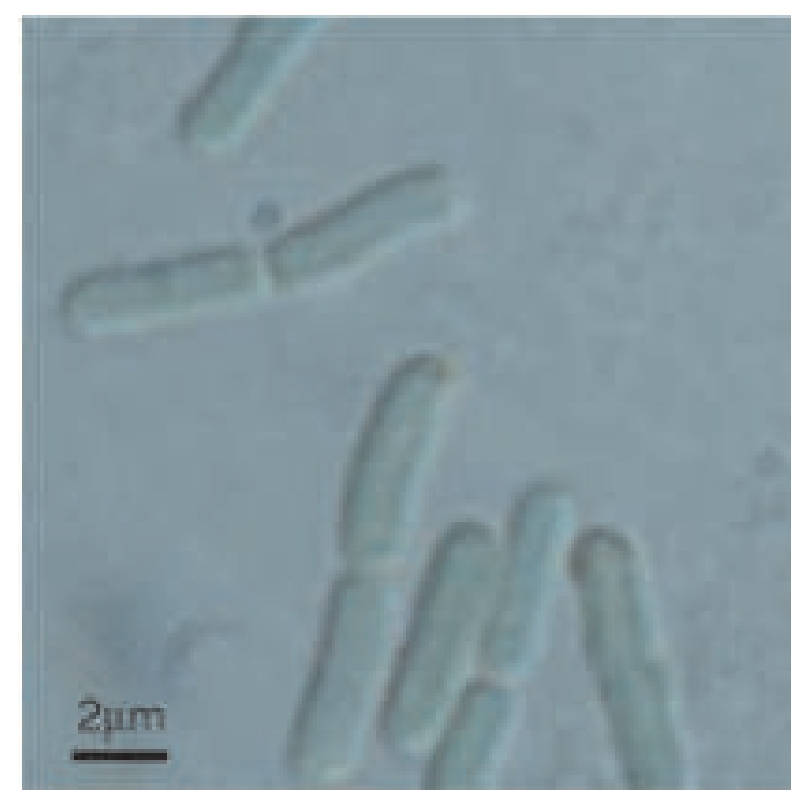

Abbildung 1.9: Thermosynechococcus elongatus BP-1

Unsere heutige aerobe Erdatmosphäre ist im Wesentlichen den Cyanobakterien zu verdanken. Sie besitzen als photosynthetische Organismen die Fähigkeit, aus Kohlendioxid mit Hilfe von Wasser als Elektronendonor organische Biomoleküle und Sauerstoff in einer Photosynthesereaktion herzustellen [28]. Die für diese Vorgänge benötigte Energie gewinnen sie über Photopigmente (z.B. Chlorophyll a, Carotinoid und Phycocyanobilin [27]), die durch verschiedene Wellenlängen des sichtbaren Lichts (Sonnenlicht) angeregt werden. Diese Art der Energie- und Brennstoffgewinnung bezeichnet man als photoautotroph [28]. Die heutigen pflanzlichen Chloroplasten arbeiten nach demselben Prinzip. Sie sind laut der Endosymbiontentheorie aus den Cyanobakterien entstanden [28]. Cyanobakterien sind allerdings nicht nur wegen der Produktion von Sauerstoff für das heutige Leben wichtig. Sie besitzen ferner die Fähigkeit, aus molekularem Stickstoff $\left(\mathrm{N}_{2}\right)$ biologisch verwendbare Stickstoffverbindungen herzustellen. Dieser Vorgang wird als Stickstoff-Fixierung bezeichnet [28]. Dabei wird Stick- 


\section{Einleitung}

stoff in Ammonium mit Hilfe von ATP und des Nitrogenasekomplexes umgewandelt [29]. Dieser besteht aus einer Reduktase, die die Elektronen liefert, und einer Nitrogenase, die die Reduktion von Stickstoff zu Ammonium vorantreibt (s. Abb. 1.10, S. 14).

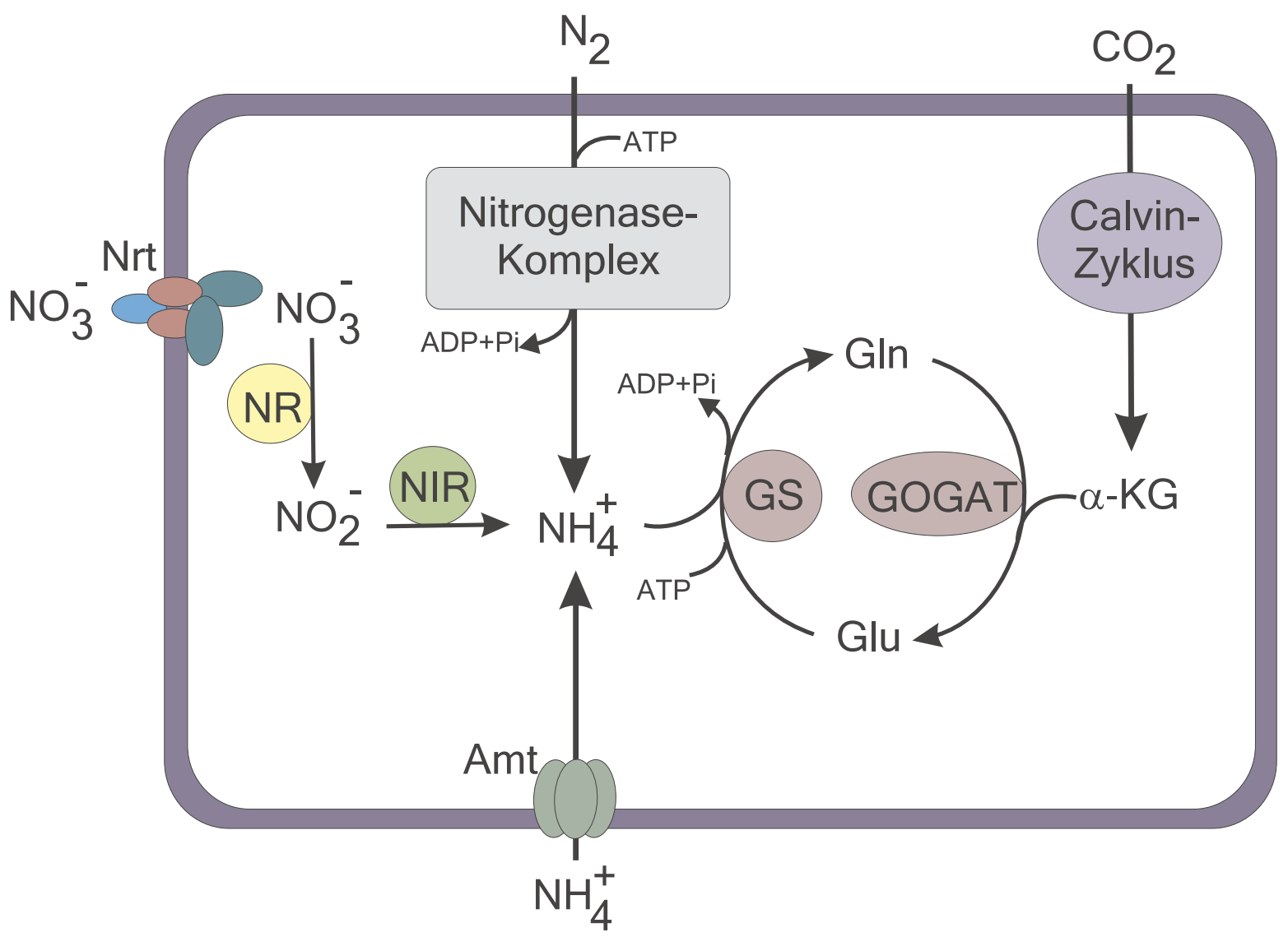

Abbildung 1.10: Schematische Darstellung der Stickstoff-Assimilation von Cyanobakterien; Nrt: Nitrat/Nitrit Permease, Amt: Ammonium Permease, NR: Nitratreduktase, NIR: Nitritreduktase, GS: Glutamin-Synthetase, GOGAT: Glutamat-2-Oxoglutarat-Amidotransferase, $\alpha$-KG: $\alpha$-Ketoglutarat, Gln: Glutamin, Glu: Glutamat

Als Elektronendonor fungiert reduziertes Ferredoxin, ein lösliches Protein mit einem [2Fe2S]-Cluster [29]. Cyanobakterien können auch Nitrat, Nitrit und Ammonium als Stickstoffquelle nutzen (Stickstoff-Assimilation), wobei sich die Präferenzen aufgrund der Energiegewinnung wie folgt ergeben: Ammonium > Nitrat/Nitrit > Stickstoff [30]. Für die Reduktion von Nitrat zu Ammonium werden zwei Enzyme benötigt: die Nitratreduktase (NR) und die Nitritreduktase (NIR), die ebenso wie der Nitrogenasekomplex Ferredoxin-abhängig arbeiten [31] (s. Abb. 1.10, S. 14). Anschließend kann Ammonium mit Hilfe des GS/GOGAT-Zyklus weiterverarbeitet werden. Dabei wird zunächst Ammonium durch die Glutamin-Synthetase (GS) unter ATP-Hydrolyse auf Glutaminsäure übertragen und Glutamin gebildet. In einem 
zweiten Schritt wird Glutamin von der Glutamat-2-Oxoglutarat-Amidotransferase (GOGAT), auch Glutamat-Synthase genannt, mit $\alpha$-Ketoglutarat zu zwei Moleküle Glutaminsäure umgesetzt, die für eine erneute Aufnahme von Ammonium zur Verfügung [31] stehen. Dieser Zyklus wird über die Regulierung der Glutamin-Synthetase kontrolliert. Diese Kontrolle übernehmen die PII-Proteine.

\subsubsection{Die PII-Proteine}

Die Familie der signalübertragenden PII-Proteine ist bei Bakterien, Archaea und Pflanzen weit verbreitet [32], wobei die PII-Proteine in Pflanzen in den Chloroplasten zu finden sind. Sie stellen die am besten konservierten Signalübertragungsproteine im Bereich der Bakterien dar. Ihre Funktion besteht darin, im Kohlenstoff- und Stickstoffmetabolismus der Bakterien Signale wahrzunehmen und zu übertragen, d.h., unter anderem die Transkription und Aktivität der Glutamin-Synthetase zu regulieren. Dies geschieht über die Messung der zellulären Konzentration an $\alpha$-Ketoglutarat (s. Abschnitt 1.2.3, S. 16). Die PII-Proteine können in drei Gruppen unterteilt werden: GlnB, GlnK und NifI [32], wobei die dritte Gruppe (NifI) nur in Archaea und einigen anaeroben Bakterien vorkommt [26].

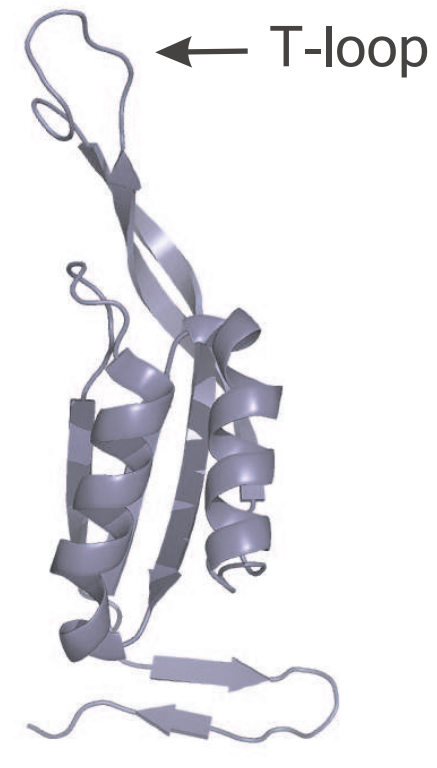

a)

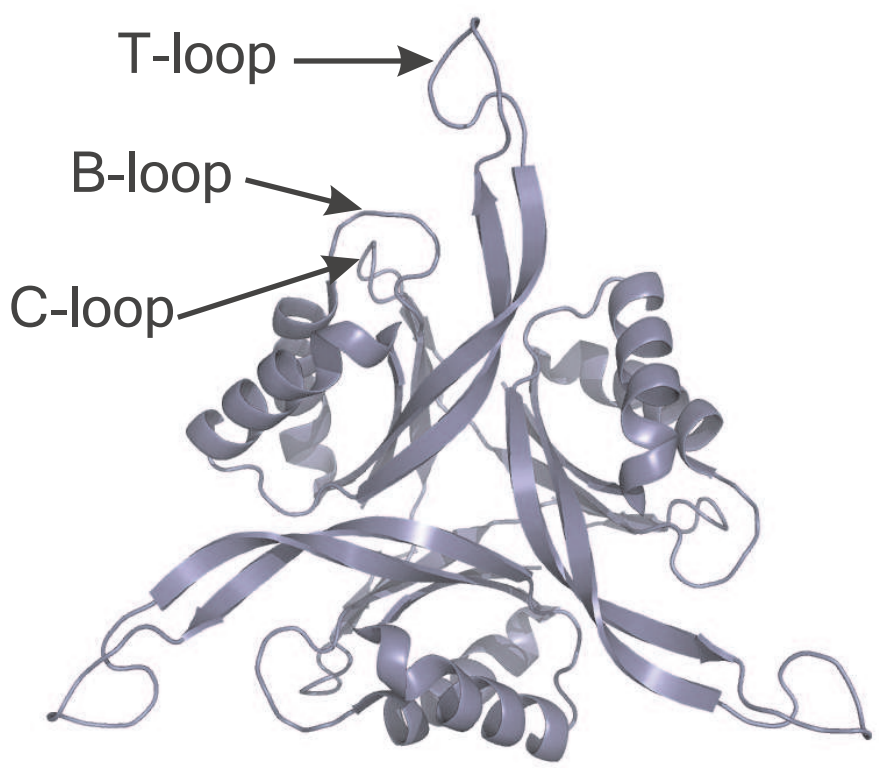

b)

Abbildung 1.11: Das erste identifizierte PII-Protein stammt aus dem Cyanobakterium Synechococcus sp. PCC 7942; a) Monomer, b) Trimer

Die PII-Proteine mit einer Größe von 12-13 kDa bilden in vivo Homotrimere aus, welche die drei loop-Regionen B, C und T beinhalten (s. Abb. 1.11, S. 15). Für die regulatorische 


\section{Einleitung}

Funktion ist eine Modifikation in der T-loop-Region entscheidend [32]. Diese verläuft entweder über eine Uridylierung/Deuridylierung (z.B. bei GlnB aus E. coli an der Aminosäure Tyr51 [33]) oder über eine Phosphorylierung/Dephosphorylierung (z.B. bei GlnB aus Synechococcus PCC 7942 an der Aminosäure Ser49 [34]).

\subsubsection{Wirkungsweise der PII-Proteine in Cyanobakterien}

In Cyanobakterien hält das PII-Protein die Kohlenstoff-Stickstoffbilanz der Zelle stabil $[35,36]$. Hierbei wird die Stickstoff-Fixierung auf die Kohlenstoff-Assimilation abgestimmt. Liegt viel Stickstoff und wenig Kohlenstoff in der Zelle vor, ist das PII-Protein vollständig dephosphoryliert $\left(\mathrm{PII}^{0}\right)$ [30,36]. Bei einem Stickstoffmangel und einem Kohlenstoffüberschuß hingegen wird das PII-Protein phosphoryliert und zwar einfach, zweifach oder dreifach phosphoryliert $\left(\mathrm{PII}^{1-3}\right)[30,36]$. Der Grad der Phosphorylierung hängt auch von der Stickstoff-

\section{N-Überschuß, C-Mangel (wenig $\alpha-K G$ )}
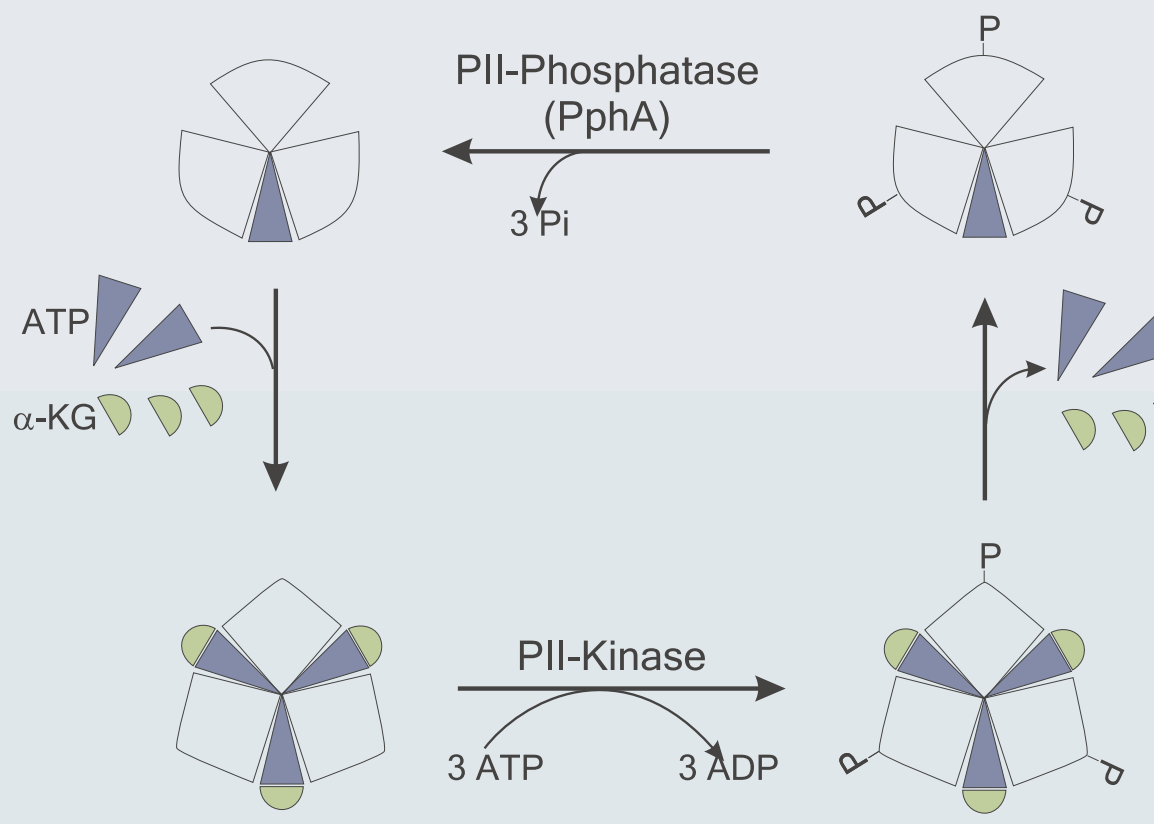

\section{N-Mangel, C-Überschuß (viel $\alpha-K G$ )}

Abbildung 1.12: Schematische Darstellung des PII-Phosphorylierungs-Zyklus; $\alpha$-KG steht für $\alpha$ Ketoglutarat [26]

quelle ab. Steht Ammonium zur Verfügung, liegt das PII-Protein vollständig dephosphory- 
liert vor. Ist die Stickstoffquelle hingegen Nitrat, ist das PII-Protein teilweise phosphoryliert. Steht den Bakterien nur molekularer Stickstoff zur Verfügung, ist das PII-Protein maximal phosphoryliert $[26,30,36,37]$. Weiterhin hängt der Grad der Phosphorylierung von der Konzentration von ATP und $\alpha$-Ketoglutarat in der Zelle ab. Nur in Anwesenheit von ATP und $\alpha$ Ketoglutarat kann das PII-Protein von der PII-Kinase phosphoryliert werden, da die Bindung von ATP und $\alpha$-Ketoglutarat eine Konformationsänderung des PII-Proteins bewirkt [26,38]. Erst in der ATP- $\alpha$-Ketoglutarat-gebundenen Form wird es von der PII-Kinase erkannt (s. Abb. 1.12, S. 16). Sinkt die Konzentration von $\alpha$-Ketoglutarat in der Zelle, lösen sich ATP und $\alpha$-Ketoglutarat von dem phosphorylierten PII-Protein und bewirken dadurch eine erneute Konformationsänderung, so daß nun das phosphorylierte PII-Protein von der PII-Phosphatase erkannt wird [26]. Die erste PII-Phosphatase, deren Funktion hinsichtlich des PII-Proteins genau untersucht wurde, war die Protein-Phosphatase A (PphA) (s. Abb. 1.12, S. 16).

\subsubsection{Bedeutung der Phosphorylierung/Dephosphorylierung}

Die Phosphorylierung bzw. Dephosphorylierung stellt sowohl in Eukaryonten als auch Prokaryonten einen bedeutenden Weg für die Übertragung von Signalen und Regulierung von Zellprozessen dar [39]. In Prokaryonten sind Proteinphosphorylierungsprozesse unter anderem an der Regulierung folgender Prozesse beteiligt [40]:

- Sporenbildung

- Expression von streßbeantwortenden Genen

- Koordination von Stickstoff- und Kohlenstoff-Metabolismus

- vegetatives Wachstum

- Zellteilung

Die Proteinphosphorylierung wurde zuerst in Eukaryonten entdeckt, wo sie die Grundlage des signalübertragenden Netzwerks bildet [39]. Die eukaryontischen Phosphatasen arbeiten stark substratspezifisch, wohingegen prokaryontische Phosphatasen in höherem Maß multifunktionelle Varianten ausbilden [41]. Dies läßt sich damit erklären, daß im Gegensatz zu eukaryontischen Phosphatasen nur wenige prokaryontische Phosphatasen vorliegen. Trotzdem können Parallelen zwischen prokaryontischen und eukaryontischen Phosphatasen und Kinasen gezogen werden. Untersuchungen an prokaryontischen Phosphatasen könnten helfen, Ursprung und Entwicklung der Proteinphosphorylierung als einen globalen biologischen Regulierungsmechanismus aufzuklären [41]. Dazu stellt die Erforschung der Phosphatasen aus Cyanobakterien einen guten Weg dar, da sich die zur Gruppe der Bakterien gehörigen Cyanobakterien 


\section{Einleitung}

schon früh von den Eukaryonten getrennt haben [41] und somit dem ursprünglichen Prokaryonten sehr ähnlich sind.

\subsubsection{Nomenklatur der Proteinphosphatasen}

Die Proteinphosphatasen lassen sich in zwei Gruppen unterteilen: die Serin/ThreoninPhosphatasen und die Tyrosin-Phosphatasen. Die Gruppe der Serin/Threonin Phosphatasen beinhaltet die Phosphoproteinphosphatasen (PPP) und die $\mathrm{Mg}^{2+} / \mathrm{Mn}^{2+}$-abhängigen Proteinphosphatasen (PPM). $\mathrm{Zu}$ der PPP-Familie gehören die PP1, PP2A und die $\mathrm{Ca}^{2+}$-abhängige PP2B [42], die Holoenzyme mit unterschiedlichen Untereinheiten, aber gemeinsamer katalytischer Domäne, sind. Sie besitzen drei konservierte Motive (Abb. 1.13, S. 18) [39].

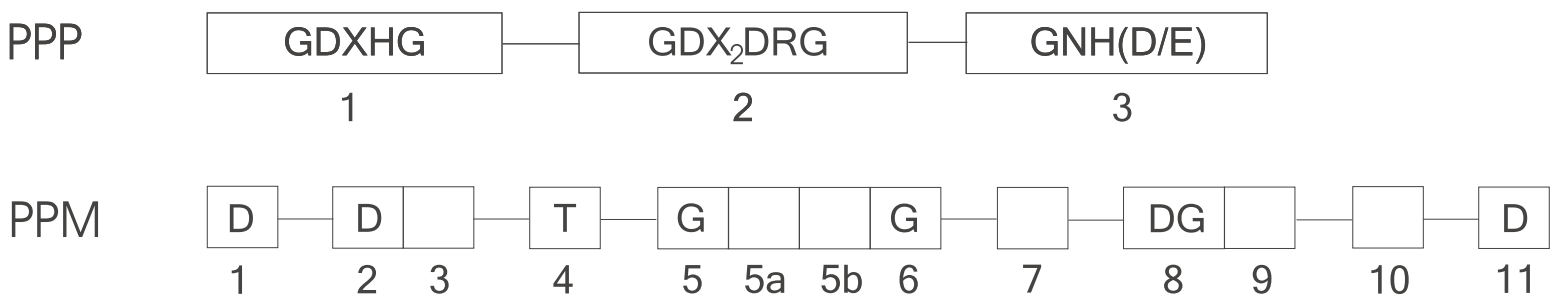

Abbildung 1.13: Genfamilie mit den zugehörigen charakteristischen Motiven. Die Buchstaben stehen für Aminosäure-Reste (Einbuchstaben-Code).

Die PPM-Familie umfaßt die PP2C-Domäne, die z.B. auch in der mitochondrialen PyruvatDehydrogenase-Phosphatase vorliegt [42]. Die PP2C-Domäne ist sowohl in Eukaryonten als auch in Prokaryonten präsent [41]. Sie weist elf Motive [43] (s. Abb. 1.13, S. 18) mit acht konservierten Aminosäuren auf, wobei vier der acht konservierten Aminosäuren an der Koordination der Metallionen im aktiven Zentrum der Phosphatasen beteiligt sind [40]. Die elf Motive enthalten sehr ähnliche Aminosäuren, die in ihren Eigenschaften (hydrophob, aliphatisch, polar, geladen) übereinstimmen [43]. Die Motive 5a und 5b existieren nicht in allen bakteriellen PPM Phosphatasen [40]. Trotzdem besitzen diese Phosphatasen die vollen Funktionalitäten der Serin/Threonin-Phosphatasen. Beispiele hierfür sind: SpoIIE/RsbWXIP von Bacillus subtilis und Icfg von Synechocystis sp. PCC 6803 [44]. Die prokaryontischen PPMs werden aufgrund der Motive 5a und 5b auch in die Gruppe der Motiv 5a und 5b enthaltenden PPMs und in die Gruppe der Motiv 5a und 5b nicht enthaltenden PPMs unterteilt [40].

\subsubsection{Sequenz-Vergleich der menschlichen und der bakteriellen Phosphatasen PP2C}

In Abbildung 1.14 (S. 19) ist der Aminosäure-Sequenz-Vergleich (ermittelt mit dem Programm MAFFT [45]) der folgenden Protein-Sequenzen dargestellt: der bakteriellen Phospha- 
tase tPphA aus Thermosynechococcus elongatus BP-1, der bakteriellen Phosphatase PphA aus Synechocystis sp. PCC 6803, der bakteriellen Phosphatase PstP aus M. tuberculosis und der menschlichen Phosphatase PP2C. Die für PPM-Phosphatasen typischen elf Motive [43] sind dabei farbig unterlegt. Die konservierten Aminosäuren, die unter anderem an der Bindung der Metallionen beteiligt sind, sind in rot hervorgehoben. Es fällt auf, daß eine konservierte Aminosäure (Gly) nicht in der Sequenz der PstP vorkommt. Beim Vergleich der vier Sequenzen wird deutlich, daß tPphA der Phosphatase PphA aus Synechocystis sp. PCC 6803 stark ähnelt. Ein Vergleich dieser beiden Phosphatasen mit CLUSTALW [46] bestätigt eine starke Übereinstimmung der Sequenzen (s. Abschnitt A.3 im Anhang, S. 120): identisch = $47.67 \%$, sehr ähnlich $=22.48 \%$, weniger stark ähnlich $=6.59 \%$, unterschiedlich $=23.26 \%$. Dagegen wird im Vergleich der tPphA mit PstP aus M. tuberculosis deutlich, daß diese beiden bakteriellen Phosphatasen größere Differenzen aufweisen (s. Abschnitt A.4 im Anhang, S. 121): identisch $=35.77 \%$, sehr ähnlich $=18.70 \%$, weniger stark ähnlich $=11.38 \%$, unterschiedlich $=34.15 \%$.

tPphA
PphA
PstP
Humane PP2C
tPphA
PphA
PstP
Humane PP2C
tPphA
PphA
PstP
Humane PP2C
tPphA
PphA
PstP
Humane PP2C
tPphA
PphA
PstP
Humane PP2C

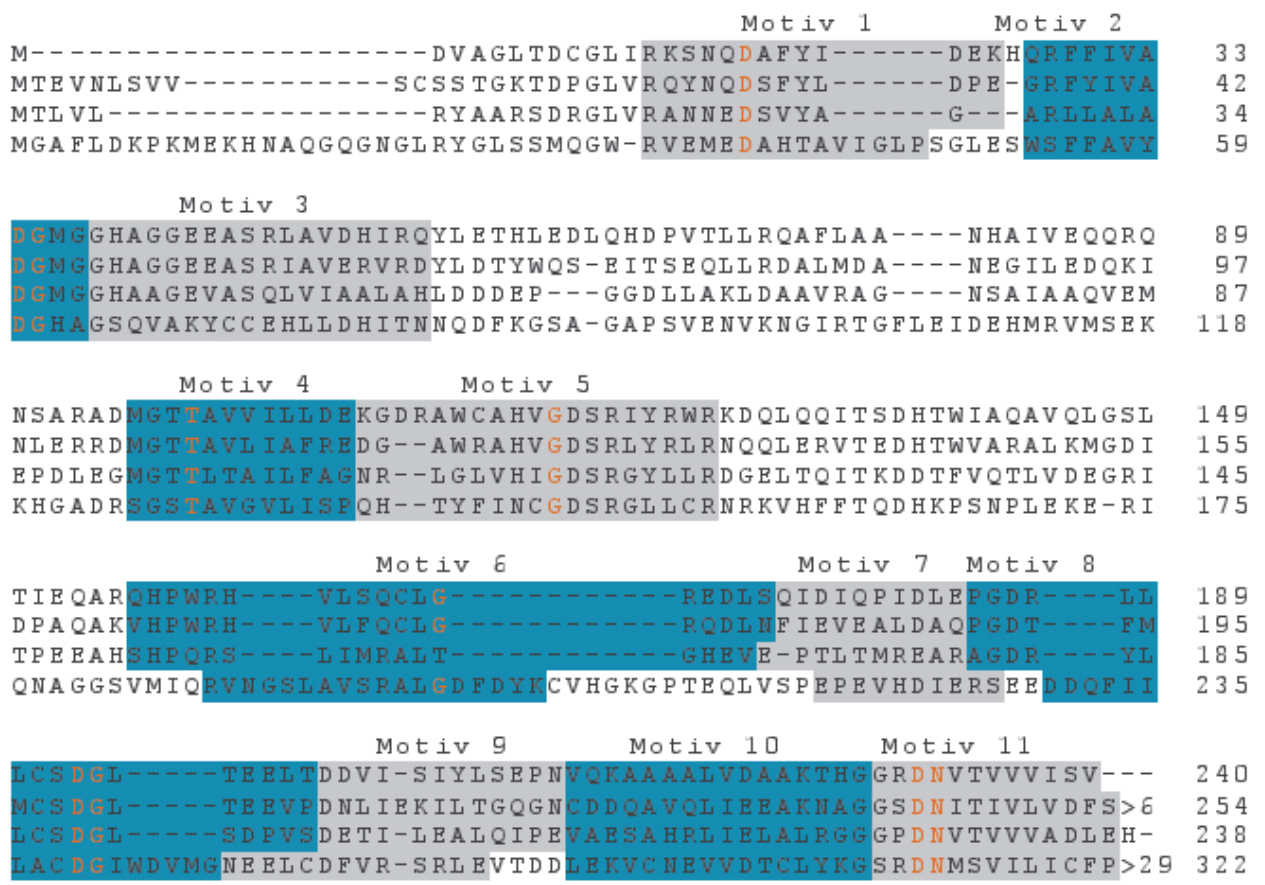

Abbildung 1.14: Aminosäure-Sequenz-Abgleich der tPphA, PphA, PstP und humanen PP2C; die elf Motive sind abwechselnd in grau und türkis markiert, die konservierten Aminosäuren sind in rot markiert. 


\section{Einleitung}

\subsubsection{Tertiärstruktur der menschlichen und der bakteriellen Phosphatasen PP2C}

Die Struktur der menschlichen Phosphatase PP2C beinhaltet sowohl die N-terminale katalytische Domäne, bestehend aus sechs $\alpha$-Helices und elf $\beta$-Faltblättern, als auch eine C-terminale Region, bestehend aus drei $\alpha$-Helices, die typisch für die menschliche PP2C sind [47]. Die katalytische Domäne besteht aus einem zentralen $\beta$-Sandwich, welches sich aus verknüpften $\beta$-Faltblättern zusammensetzt. Dabei sind jeweils zwei antiparallele $\beta$-Faltblätter in der Reihenfolge $1,2,11,10,7,8$, und 3, 4, 5, 6, 9 verbunden. Die $\beta$-Faltblätter sind an beiden Seiten von einem Paar antiparalleler $\alpha$-Helices umgeben. Die Struktur der bakteriellen PP2C-Domäne aus $M$. tuberculosis - PstP - zeigt eine der menschlichen PP2C-Domäne sehr ähnliche Tertiärstruktur. Allerdings fehlen im Gegensatz zur menschlichen Phosphatase PP2C das erste $\beta$-Faltblatt und die aus drei $\alpha$-Helices bestehende C-terminale helikale Region [48]. Ein weiterer großer Unterschied zur menschlichen Phosphatase PP2C liegt in der Gegenwart eines dritten Metallzentrums, welches für die Reorientierung der FLAP-Region (s. Abb. 1.15, S. 20), einer sehr flexiblen Region, bestehend aus ca. 20 Aminosäuren, verantwortlich sein könnte.

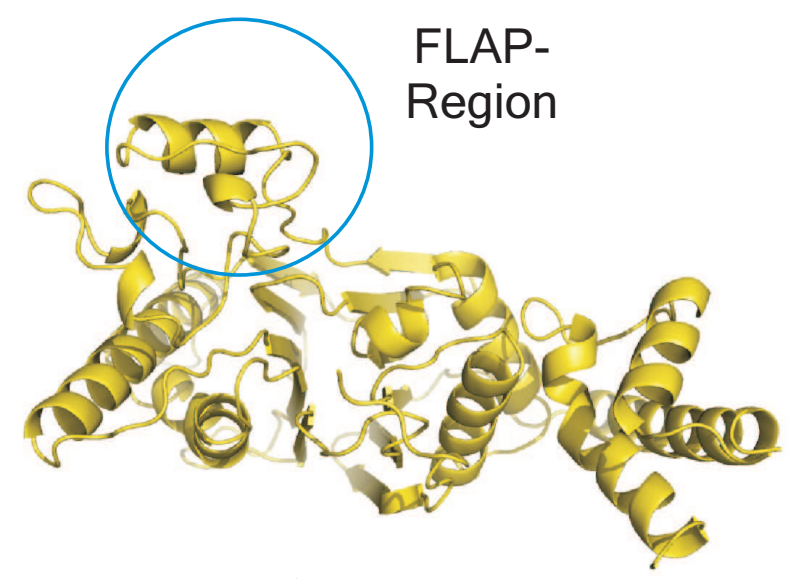

a)

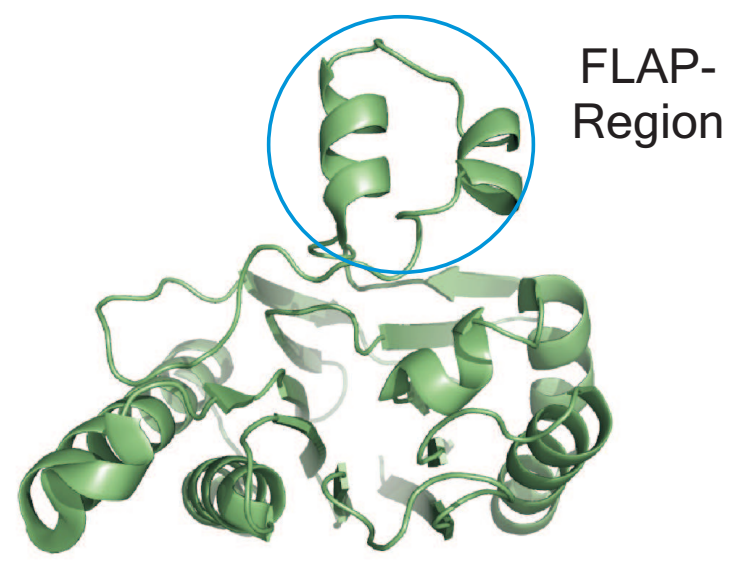

b)

Abbildung 1.15: Die FLAP-Region (mit einem blauen Kreis markiert) in den Strukturen a) der menschlichen PP2C und b) der bakteriellen Phosphatase PstP.

\subsubsection{Katalytischer Mechanismus der Phosphatase PP2C}

Das aktive Zentrum der menschlichen Phosphatase PP2C enthält zwei $\mathrm{Mn}^{2+}$-Ionen, die wie folgt koordiniert sind: 
- vier konservierte Asparaginsäure-Seitenketten

- eine nicht-konservierte Glutaminsäure

- sechs Wassermoleküle

Ein Hydroxid-Ion agiert - ganz ähnlich wie bei dem katalytischen Mechanismus der PPPPhosphatasen [40] als Metall-aktiviertes Nucleophil, welches die Phosphorgruppe in einem $\mathrm{S}_{N}$ 2-Mechanismus angreift (s. Abb. 1.16, S. 21). Anschließend protoniert ein Wassermolekül

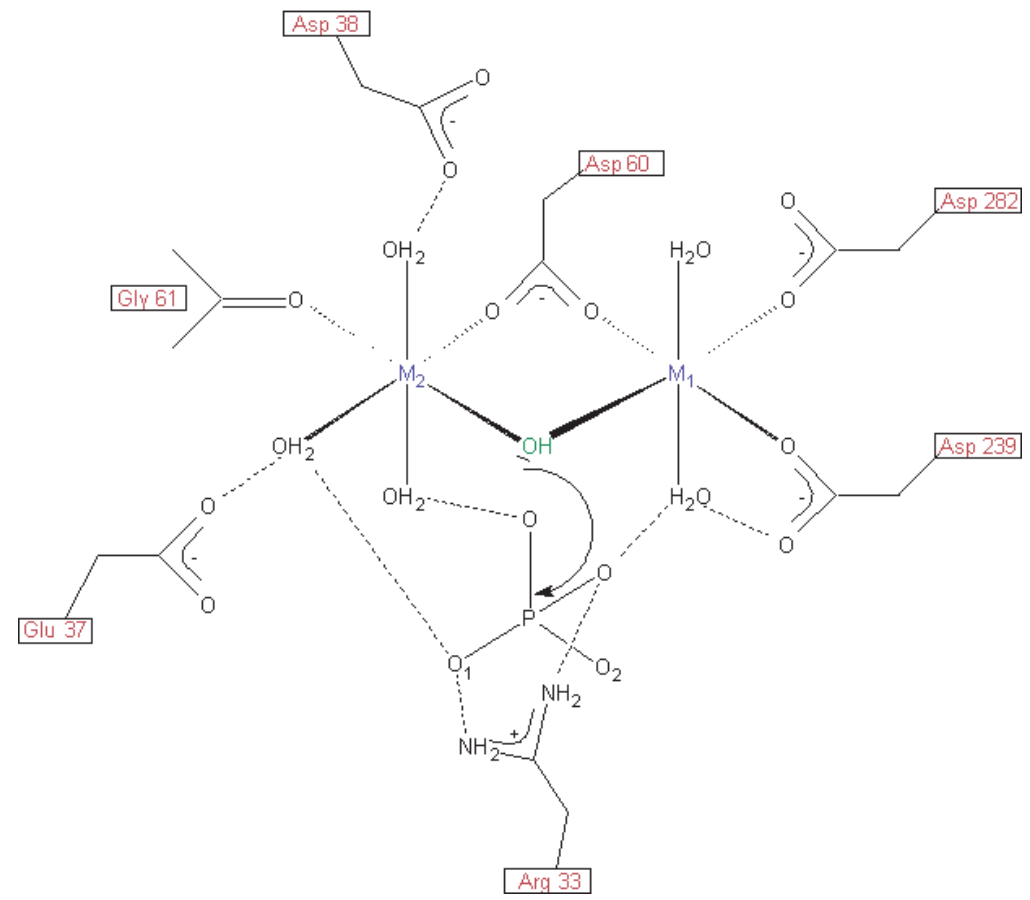

Abbildung 1.16: Katalytischer Mechanismus der menschlichen PP2C, in blau sind die beiden Metallionen M 1 und M 2 gekennzeichnet, in grün ist das aktivierte Hydroxid-Ion dargestellt.

den Sauerstoff der dephosphorylierten Aminosäure (Serin/Threonin) [48].

\subsubsection{Biologische Funktion der Phosphatase tPphA}

Die biologische Funktion der Phosphatase tPphA könnte der Funktion von PphA [40] ähneln. Dafür spricht, daß sich einerseits die Aminosäure-Sequenzen von PphA und tPphA sehr ähnlich sind. Andererseits konnte in in vitro Tests die Dephosphorylierung des PII-Proteins [49] gezeigt werden. Dabei ist, ebenso wie bei PphA, die Konzentration an $\alpha$-Ketoglutarat und ATP entscheidend. Liegen viel $\alpha$-Ketoglutarat und ATP in der Zelle vor, wird die Desphosphorylierungsreaktion gehemmt. 


\subsubsection{Aufgabenstellung}

Die Aufgabe war es, die Struktur der Phosphatase tPphA zu bestimmen und Vergleiche mit der menschlichen PP2C-Phosphatase und der bakteriellen PP2C-ähnlichen Phosphatase PstP aus M. tuberculosis aufzuzeigen. Dabei sollte geklärt werden, wo sich die Position der FLAPRegion in der tPphA-Struktur befindet und wie viele Metallionen im aktiven Zentrum der Struktur vorhanden sind. Zudem stellte sich die Frage, ob die Anzahl der Metallionen in bakteriellen PP2C-ähnlichen Phosphatasen immer drei anstatt zwei beträgt, wie in der menschlichen PP2C-Phosphatase. Durch die Untersuchung von einer aus einem Cyanobakterium stammenden PP2C-ähnlichen Phosphatase sollte diese Frage nach den Metallionen geklärt werden, da die Cyanobakterien sich sehr früh von den Eukaryonten abgespalten haben und somit die ursprüngliche Form der Phosphatasen widerspiegeln können. 


\section{Material und Methoden}

\subsection{Material}

\subsubsection{Bakterienstämme}

- XL2blue: Bakterienstamm für die Kultivierung eines neuen Plasmids

- BL21 DE3/BL21: Expressionsstämme

- B843 DE3: auxotropher Bakterienstamm; Expression von Se-Met Protein

\subsubsection{Primer und Restriktionsenzyme}

Für die Amplifizierung der DNS von tPphA wurden folgende Primer verwendet:

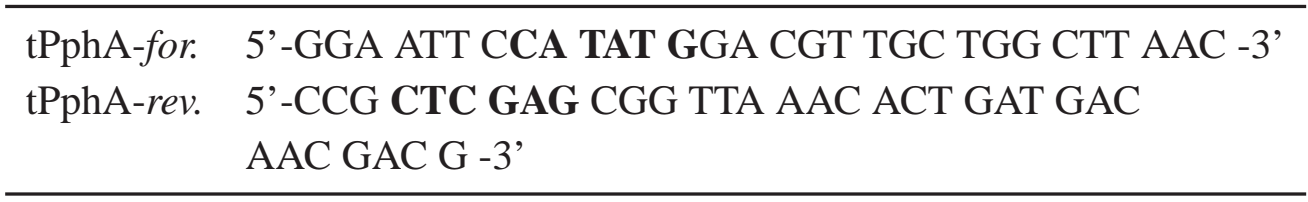

Tabelle 2.1: Primer für tPphA, die Restriktionsenzyms-Schnittstellen sind mit dickeren Buchstaben markiert; for: forward, rev.: reverse.

Beide Primer lagen in einer Konzentration von jeweils $100 \mu \mathrm{M}$ vor. Der forward Primer enthielt eine Nde I Restriktionsenzym-Schnittstelle und einen Teil der kodierenden Sequenz von tPphA, der reverse Primer hingegen eine Xho I Restriktionsenzym-Schnittstelle (in der Tabelle 2.1 sind die Restriktionsenzyms-Schnittstellen mit dickeren Buchstaben markiert).

\subsubsection{Expressionsvektoren}

Das Expressionskonstrukt pET32a-tPphA (s. Abb. 2.1, S. 24) (pET32a von Novagen), das für die native Phosphatase tPphA kodiert, enthält sowohl eine Nde I Schnittstelle als auch eine Xho I Schnittstelle, in welche die für tPphA kodierende Sequenz einkloniert wurde. Mit Hilfe von Isopropyl- $\beta$-D-thiogalaktopyranosid (IPTG) wird die Expression induziert. IPTG bindet 
an den Laktose (lac)-Repressor und löst dadurch die Bindung des lac-Repressors an den lacRNA-Polymerase-Promotor (lacI-Gen), der wiederum den T7-RNA-Polymerase-Promotor (T7) kontrolliert [50].

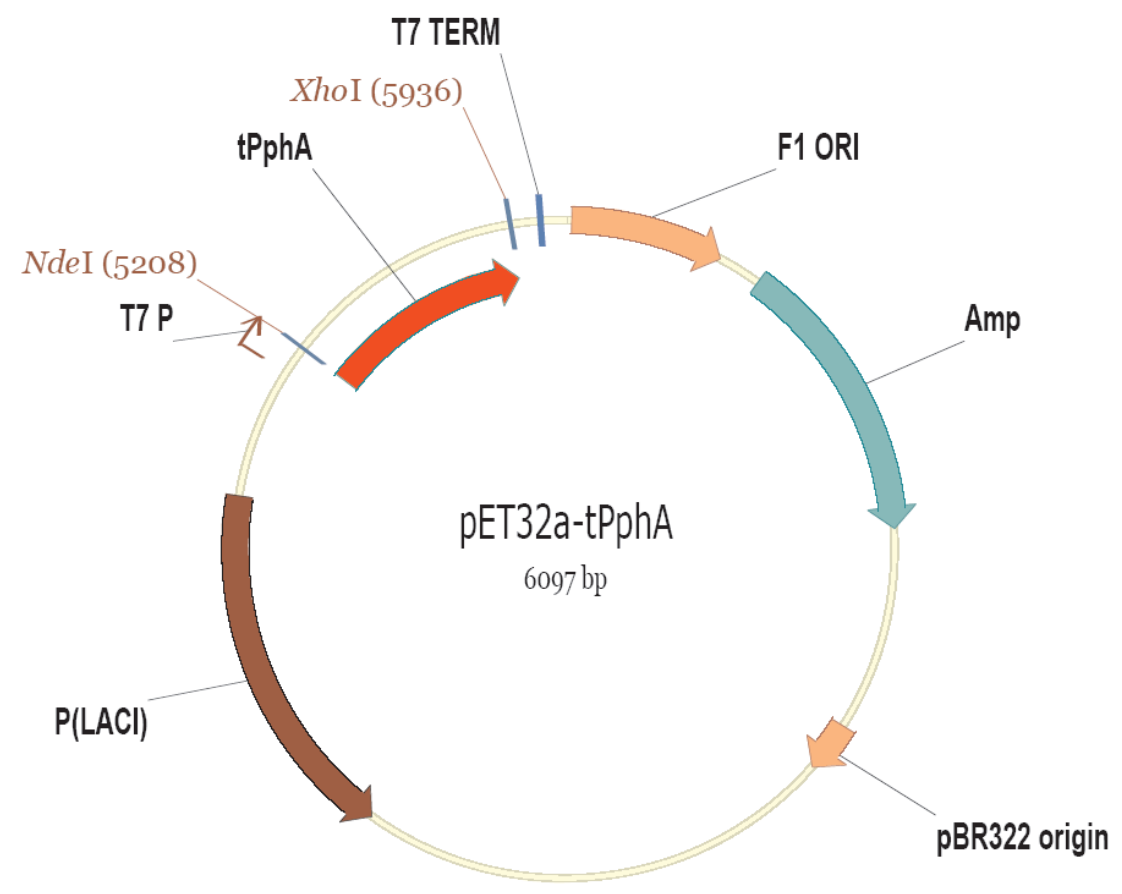

Abbildung 2.1: Vektorkarte des pET32a-Vektors mit dem tPphA insert; Amp bezeichnet das Gen für die Ampicillinresistenz, pBR322 origin steht für den Ursprung der Replikation des Plasmids.

Das Expressionskonstrukt für die C2B-Domäne wurde mit dem pGEX-2T-Vektor hergestellt. Es beinhaltet ein N-terminales Glutathion-S-Transferase(GST)-Fusionsprotein, wobei zwischen dem GST-Fusionsprotein und der C2B-Sequenz eine Thrombinschnittstelle mit der DNS-Sequenz CTG GTT CCG CGT GGA TCC (Aminosäuresequenz LVPRGS) vorliegt [51] (s. Abb. 2.2, S. 25). Die Induktion erfolgt über IPTG, welches an den lac-Repressor (lacIq-Gen) bindet und damit die Bindung des lac-Repressors an den lac-Operator des tacRNA-Polymerase-Promotor (mit optimierter RNA-Polymerase-Erkennungssequenz) unterbindet [50].

\subsubsection{Nährmedien}

\section{LB-Medium und Agarplatten}

$10 \mathrm{~g}$ Bactotrypton, $5 \mathrm{~g}$ Hefeextrakt und $10 \mathrm{~g}$ Natriumchlorid ad 11 Millipore Wasser, $\mathrm{pH}$ auf 7.2 mit $\mathrm{NaOH}$ eingestellt und autoklaviert. 


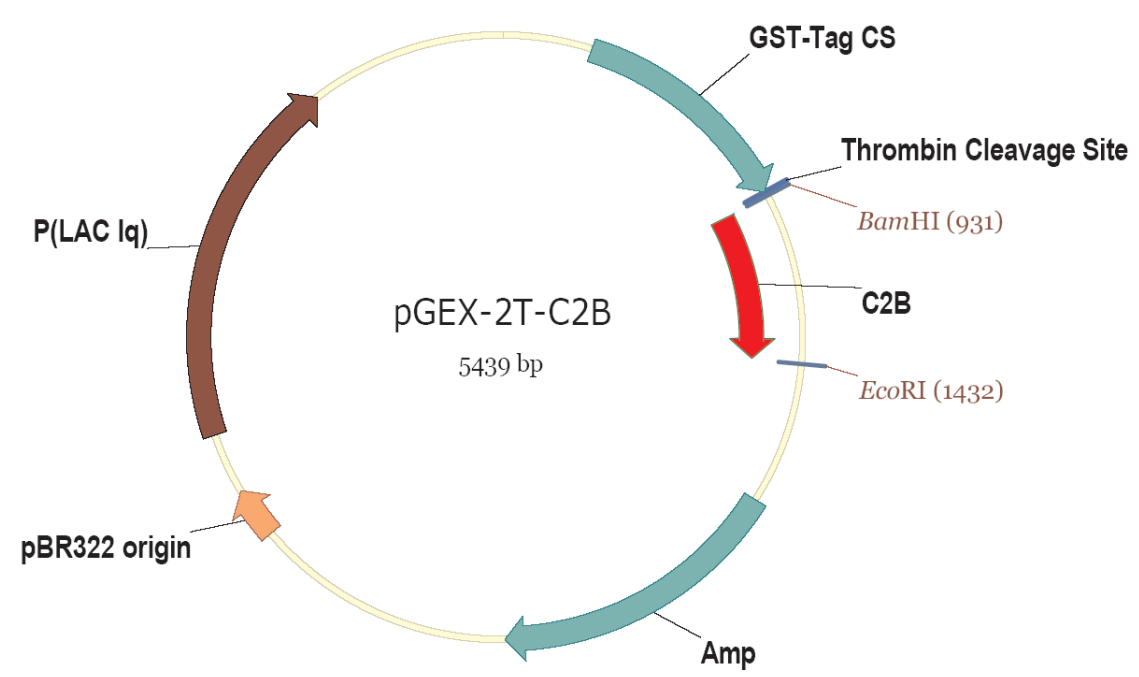

Abbildung 2.2: Vektorkarte des pGEX-2T-Vektors mit dem C2B insert; Amp bezeichnet das Gen für die Ampicillinresistenz, pBR322 origin steht für den Ursprung der Replikation des Plasmids.

Für die Agarplatten wurden $15 \mathrm{~g}$ Agar zu 11 LB-Medium gegeben und autoklaviert. Zu der abgekühlten Lösung konnte das verwendete Antibiotikum - in diesem Fall Ampicillin (auf $11 \mathrm{LB}$-Agarmedium $10 \mathrm{ml}$ steril-filtriertes Ampicillin $(10 \mathrm{mg} / \mathrm{ml})$ ) - zugegeben und die Amp-Agarplatten gegossen werden.

\section{$2 \times$ YT-Medium}

$16 \mathrm{~g}$ Trypton, $10 \mathrm{~g}$ Hefeextrakt und $5 \mathrm{~g}$ Natriumchlorid ad 11 Millipore Wasser, $\mathrm{pH}$ auf $7.2 \mathrm{mit}$ $\mathrm{NaOH}$ eingestellt und autoklaviert.

\section{Minimal-Medium}

- M9 Medium $(\mathbf{1 0} \times)$ : $80 \mathrm{~g} \mathrm{Na}_{2} \mathrm{HPO}_{4}, 40 \mathrm{~g} \mathrm{KH}_{2} \mathrm{PO}_{4}, 5 \mathrm{~g} \mathrm{NaCl}$ und $5 \mathrm{~g} \mathrm{NH} 4 \mathrm{Cl}$ ad 11 Millipore Wasser

- Spurenelemente $(\mathbf{1 0 0} \times)$ : Substanzen in der angegebenen Reihenfolge nacheinander in $100 \mathrm{ml}$ Millipore Wasser gelöst:

$$
\begin{aligned}
& 0.6 \mathrm{~g} \mathrm{FeSO}_{4} \times 7 \mathrm{H}_{2} \mathrm{O} \\
& 0.115 \mathrm{~g} \mathrm{MnCl}_{2} \times 4 \mathrm{H}_{2} \mathrm{O} \\
& 0.08 \mathrm{~g} \mathrm{CoCl}_{2} \times 6 \mathrm{H}_{2} \mathrm{O} \\
& 0.07 \mathrm{~g} \mathrm{ZnSO}_{4} \times 7 \mathrm{H}_{2} \mathrm{O} \\
& 0.03 \mathrm{~g} \mathrm{CuCl}_{2} \times 2 \mathrm{H}_{2} \mathrm{O}
\end{aligned}
$$




$$
\begin{aligned}
& 0.002 \mathrm{~g} \mathrm{H}_{3} \mathrm{BO}_{3} \\
& 0.025 \mathrm{~g}\left(\mathrm{NH}_{4}\right)_{6} \mathrm{Mo}_{7} \mathrm{O}_{24} \times 4 \mathrm{H}_{2} \mathrm{O}
\end{aligned}
$$

Die Lösung wurde 10 min gerührt. Anschließend wurden $0.5 \mathrm{~g}$ EDTA zugefügt und die Lösung für einige Stunden rühren gelassen, bis sie eine goldgelbe Farbe erreicht hatte. Behielt die Lösung hingegen die anfängliche grüne Farbe, mußte sie über Nacht gerührt werden. Anschließend wurde die Lösung steril filtriert.

- Medium A: $100 \mathrm{ml}$ M9 Medium (10×), $10 \mathrm{ml}$ Spurenelemente $(100 \times), 20 \mathrm{ml} 20 \%$ ige Glukoselösung, $1 \mathrm{ml} 1 \mathrm{M} \mathrm{MgSO}_{4}, 0.3 \mathrm{ml} 1 \mathrm{M} \mathrm{CaCl}_{2}, 1 \mathrm{ml}$ Thiaminlösung ( $\left.1 \mathrm{mg} / \mathrm{ml}\right)$ und $2 \mathrm{ml}$ Ampicillin $(25 \mathrm{mg} / \mathrm{ml})$ ad 11 steriles $\mathrm{H}_{2} \mathrm{O}$

\subsubsection{DNS}

\section{Molekulargewichtsmarker}

Als DNS Marker kamen der Lambda DNS/HindIII Marker (M1) und der $\Phi X 174 D N S /$ BsuRI (HaeIII) Marker (M2) der Firma Fermentas zum Einsatz.

\section{DNS-Probenpuffer $(5 \times)$}

$25 \%$ Ficoll 400, 25 mM EDTA pH 8.0, 1 \% SDS, $0.05 \%$ Bromphenolblau und $0.05 \%$ Xylen Cyanol

\section{Agarosegel Laufpuffer $(10 \times)$}

(entspricht TBE-Puffer) $108 \mathrm{~g} / \mathrm{l}$ Tris Base, $55 \mathrm{~g} / 1$ Borsäure und $40 \mathrm{ml} / 1$ 0.5 M EDTA Lösung pH 8.0 ad 11 Millipore Wasser

\subsubsection{Protein}

\section{Molekulargewichtsmarker}

Für die SDS-Polyacrylamidgele wurde der BenchMark ${ }^{\mathrm{TM}}$ Protein Ladder von der Firma Invitrogen verwendet.

\section{Laemmli Probenpuffer $(4 \times)$}

$17 \mathrm{ml} 10 \%$ SDS, $7.5 \mathrm{ml} 1 \mathrm{M}$ Tris $\cdot \mathrm{HCl} \mathrm{pH}$ 6.8, $23 \mathrm{ml}$ Glycerin, $50 \mathrm{mg}$ Bromphenolblau ad $50 \mathrm{ml}$ Millipore Wasser. Zu $1 \mathrm{ml}(4 \times)$ Laemmli Probenpuffer $10 \mu 1 \beta$-Mercaptoethanol geben und bei $-20{ }^{\circ} \mathrm{C}$ lagern. 


\section{Coomassie Färbelösung}

2.2 g Coomassie blau G250, $650 \mathrm{ml}$ Millipore Wasser, $100 \mathrm{ml}$ Essigsäure und $250 \mathrm{ml}$ Isopropanol für 11 Coomassie Färbelösung

\section{Coomassie Entfärbelösung}

$100 \mathrm{ml}$ Essigsäure (10 \%) ad 11 Millipore Wasser

Coomassie Laufpuffer $(10 \times)$

60.4 g Tris-Base, $288 \mathrm{~g}$ Glycin und $20 \mathrm{~g}$ SDS ad 21 Millipore Wasser

\subsubsection{Pufferlösungen für die Reinigung der C2B-Domäne}

\section{Zusammensetzung des PBS-Puffers für C2B:}

\begin{tabular}{l}
\hline $10 \times$ PBS-Puffer \\
\hline $80 \mathrm{~g} \mathrm{NaCl}$ \\
$2 \mathrm{~g} \mathrm{KCl}$ \\
$14.4 \mathrm{~g} \mathrm{Na}_{2} \mathrm{HPO}_{4}$ \\
$2.4 \mathrm{~g} \mathrm{KH}_{2} \mathrm{PO}_{4}$ \\
ad 11, auf $\mathrm{pH} 7.4$ equilibrieren \\
\hline
\end{tabular}

Zusammensetzung des Lysepuffers (Puffer 1) für C2B:

$1 \times$ PBS- Puffer pH 7.4
$1 \mathrm{mM}$ PMSF
$1 \mathrm{mM}$ EGTA
$1 \%$ Triton $\mathrm{X}-100$

\section{Kationensäulenpuffer A und B für C2B:}

\begin{tabular}{ll}
\hline Puffer A & Puffer B \\
\hline $20 \mathrm{mM} \mathrm{NaOAc} / \mathrm{HAc}$ pH 5.8 & $20 \mathrm{mM} \mathrm{NaOAc/HOAc} \mathrm{pH} \mathrm{5.8}$ \\
$100 \mathrm{mM} \mathrm{NaCl}$ & $1 \mathrm{M} \mathrm{NaCl}$ \\
\hline
\end{tabular}


2 Material und Methoden

Gelfiltrationschromatographiepuffer (Puffer 2) für C2B:

$10 \mathrm{mM}$ Hepes pH 7.0

$150 \mathrm{mM} \mathrm{NaCl}$

\subsubsection{Pufferlösungen für die Reinigung der}

Phosphatase tPphA

Lyse- und Ammoniumsulfatfällungspuffer (Puffer1) für tPphA:

$20 \mathrm{mM}$ Hepes $\mathrm{pH} 7.4$

$50 \mathrm{mM} \mathrm{KCl}$

$5 \mathrm{mM} \mathrm{MgCl}_{2}$

$0.5 \mathrm{mM}$ EDTA

$0.2 \mathrm{mM}$ PMSF

$3 \mathrm{mM}$ DTT

Anionensäulenpuffer A und B für tPphA:

\begin{tabular}{ll}
\hline Puffer A & Puffer B \\
\hline $20 \mathrm{mM} \mathrm{Hepes} \mathrm{pH} \mathrm{7.4}$ & $20 \mathrm{mM}$ Hepes pH 7.4 \\
$50 \mathrm{mM} \mathrm{KCl}$ & $600 \mathrm{mM} \mathrm{KCl}$ \\
$5 \mathrm{mM} \mathrm{MgCl}_{2}$ & $5 \mathrm{mM} \mathrm{MgCl}_{2}$ \\
$0.5 \mathrm{mM} \mathrm{EDTA}$ & $0.5 \mathrm{mM}$ EDTA \\
$0.2 \mathrm{mM} \mathrm{PMSF}$ & $0.2 \mathrm{mM} \mathrm{PMSF}$ \\
$3 \mathrm{mM}$ DTT & $3 \mathrm{mM} \mathrm{DTT}$ \\
\hline
\end{tabular}

Gelfiltrationschromatographiepuffer (Puffer 2) für tPphA:

\begin{tabular}{l}
$150 \mathrm{mM} \mathrm{NaCl}$ \\
$20 \mathrm{mM} \mathrm{Hepes} \mathrm{pH} 7.4$ \\
$50 \mathrm{mM} \mathrm{KCl}$ \\
$5 \mathrm{mM} \mathrm{MgCl}_{2}$ \\
$0.5 \mathrm{mM}$ EDTA \\
$3 \mathrm{mM}$ DTT \\
\hline
\end{tabular}




\subsection{Molekularbiologische Methoden}

\subsubsection{Agarosegel}

Anhand eines Agarosegels konnten Größe und Reinheit des DNS-Fragments und des geschnittenen Vektors überprüft werden. Desweiteren konnte die DNS über das Agarosegel gereinigt werden. Zur Überprüfung der DNS-Reinheit wurden $3 \mu$ 1 Probe (insert oder Vektor) zu $2 \mu 1$ DNS-Probenpuffer und $5 \mu \mathrm{l}$ sterilem $\mathrm{H}_{2} \mathrm{O}$ gegeben und auf ein 1 \%iges Agarosegel aufgetragen. Für die Reinigung der DNS wurde zur gesamten DNS-Lösung DNS-Probenpuffer im Verhältnis 1:5 gegeben und die gesamte Lösung auf ein Agarosegel aufgetragen. Die Trennung der unterschiedlich großen DNS-Fragmente auf dem Agarosegel erfolgte bei $80 \mathrm{~V}$ innerhalb von 2 h. Nach der Trennung der DNS konnte die Bande der zu reinigenden DNS aus dem Gel ausgeschnitten und mit einem kommerziell erhältlichen Gelreinigungskit (Qiagen) gereinigt werden. Die auf dem Agarosegel befindliche DNS wurde mit Hilfe des Ethidiumbromids markiert, welches sich durch Bestrahlung mit UV-Licht anschließend sichtbar machen ließ.

\section{Agarosegel $1 \%$ ig}

$0.4 \mathrm{~g}$ Agarose wurde in $40 \mathrm{ml}$ TBE-Puffer suspendiert und unter Hitze in der Mikrowelle gelöst. Nachdem die Lösung etwas abgekühlt war (ca. $40^{\circ} \mathrm{C}$ ), wurde $1 \mu$ l Ethidiumbromid zugegeben und die Mischung in eine Agarosegelkammer gegossen. Nach Erkalten des Agarosegels konnten die DNS-Proben aufgetragen werden.

\subsubsection{Transformation durch Hitzeschock}

\section{BL21 DE3, BL21 und XL2blue}

Zu $50 \mu$ 1 Bakterienzellen (BL21 DE3, BL21 und XL2blue) wurden 0.5 bis $1 \mu 1$ des Plasmids (zwischen 300-500 $\mu \mathrm{g} / \mathrm{ml}$ ) gegeben und das Ganze $30 \mathrm{~min}$ auf Eis gestellt. Anschließend wurden die Zellen bei $42^{\circ} \mathrm{C}$ für $45 \mathrm{sec}$ erhitzt und erneut 2 min auf Eis gestellt. Nun wurden $950 \mu \mathrm{l} 2 \times$ YT-Medium zugefügt und $1 \mathrm{~h}$ bei $37{ }^{\circ} \mathrm{C}$ inkubiert. Dann wurde 5 min bei $6000 \mathrm{rpm}$ abzentrifugiert, der Überstand bis auf $100 \mu \mathrm{l}$ abgenommen und das in den verbleibenden $100 \mu \mathrm{l}$ resuspendierte Zellpellet auf einer Amp-Agarplatte ausgestrichen. Die Platte wurde über Nacht bei $37^{\circ} \mathrm{C}$ inkubiert.

\section{B834 DE3}

$\mathrm{Zu} 20 \mu \mathrm{l}$ B834 DE3-Zellen wurden $0.5 \mu 1$ des Plasmids (zwischen 300-500 $\mu \mathrm{g} / \mathrm{ml}$ ) gegeben. Die Bakterienzellen wurden $5 \mathrm{~min}$ auf Eis gestellt, dann $30 \mathrm{sec}$ bei $42{ }^{\circ} \mathrm{C}$ erhitzt und wiederum 2 min auf Eis abgekühlt. Nach Zugabe von $980 \mu 12 \times$ YT-Medium wurden sie $1 \mathrm{~h}$ bei 


\section{Material und Methoden}

$250 \mathrm{rpm}$ bei $37{ }^{\circ} \mathrm{C}$ inkubiert. Anschließend wurde $5 \mathrm{~min}$ bei $6000 \mathrm{rpm}$ abzentrifugiert und der Überstand bis auf $100 \mu \mathrm{l}$ abgenommen. Das Zellpellet wurde in den verbleibenden $100 \mu 1$ resuspendiert und auf eine Agarplatte, die Ampicillin enthielt, ausplattiert. Die Inkubation erfolgte $10 \mathrm{~h}$ bei $37^{\circ} \mathrm{C}$.

\subsubsection{Vervielfältigung der Plasmid-DNS in E. coli}

Die Plasmidpräparation wurde mittels kommerziell erhältlicher Plasmid Mini/Midi Kits (Qiagen) durchgeführt.

\subsubsection{Bestimmung der DNS-Konzentration}

Bei einer Wellenlänge von 260 nm zeigen Nukleinsäuren ein Maximum im Absorptionsspektrum. Die Konzentration der gereinigten DNS wurde somit mittels des Absorptionsspektrums bei $260 \mathrm{~nm}$ in einer $2 \mathrm{~mm}$ Quarzküvette (1) gemessen und anhand des Extinktionskoeffizienten $(\varepsilon)$ mit Hilfe des Lambert-Beerschen Gesetzes [52] bestimmt:

$$
c=\frac{\log _{10} \frac{I_{0}}{I}}{\varepsilon \cdot l}=\frac{A b s(260 \mathrm{~nm})}{\varepsilon \cdot l}
$$

Außerdem wurde das DNS/Protein-Verhältnis betrachtet, welches bei einem Wert von 1.9 und höher liegen sollte. Bei diesem Wert gilt DNS als proteinfrei und somit als rein. Als Referenz diente $10 \mathrm{mM}$ Tris Puffer.

\subsubsection{Aufbewahrung der transformierten Konstrukte [50]}

Für die Aufbewahrung der transformierten Konstrukte wurden $150 \mu 150 \%$ iges Glycerin mit $350 \mu \mathrm{l}$ Vorkultur vermischt und bei $-80^{\circ} \mathrm{C}$ gelagert.

\subsubsection{Klonierung}

Für die Klonierung eines inserts (DNS-Abschnitt, der ein bestimmtes Protein kodiert) in einen Vektor mußten nacheinander folgende Arbeitsschritte durchgeführt werden:

1. Polymerase-Ketten-Reaktion mittels $P f u$-DNS-Polymerase zur Vervielfältigung des inserts

2. Restriktionsverdau zur Herstellung ,klebriger“ Enden am insert und am Vektor

3. Ligation zum Zusammenfügen von insert und Vektor 
4. Transformation des Konstrukts in XL2blue-Zellen

5. Polymerase-Ketten-Reaktion mittels Hot Star Taq-DNS-Polymerase zur Überprüfung der Klone

\title{
Polymerase-Ketten-Reaktion (PCR)
}

Zuerst mußte der vorliegende DNS-Abschnitt mittels Polymerase-Ketten-Reaktion (PCR) vervielfältigt werden. Hierzu wurden die Primer aus Abschnitt 2.1.2 (S. 23) verwendet, die eigens für den DNS-Abschnitt ermittelt wurden. Die Primersequenzen mußten in einer bestimmten Basenanzahl mit dem DNS-Abschnitt übereinstimmen, um eine Schmelztemperatur von 61 bis $63{ }^{\circ} \mathrm{C}$ zu erreichen. Am 3' bzw. 5' Ende beinhalteten die Primer eine Schnittstelle für ein spezifisches Restriktionsenzym. Im Fall von tPphA wurden die Schnittstellen Nde I und Xho I mittels der Primer eingeführt. Für die Amplifizierung der DNS für tPphA wurde die PCR mit Hilfe der $P f u$-DNS-Polymerase durchgeführt. Die $P f u$-DNS-Polymerase, gewonnen aus dem thermophilen Archaebakterium Pyrococcus furiosus, zeichnet sich durch eine sehr hohe Lesegenauigkeit aus [53], da sie eine $3^{\prime}-5^{\prime}$-Exonukleaseaktivität besitzt. Diese bewirkt eine Überprüfung des zuletzt eingebauten Nukleotids. Ist dieses falsch, wird es entfernt [54]. Durch diese proofreading-Funktion werden weniger fehlerbehaftete DNS-Ketten amplifiziert [55]. Daher wird die Pfu-DNS-Polymerase immer dann verwendet, wenn es auf die exakte Herstellung der DNS-Fragmente ankommt. Die Ansätze für die Amplifizierung wurden wie folgt zusammengegeben:

\author{
$2.5 \mu 1 P f u$-Puffer \\ $0.3 \mu 1 \mathrm{dNTP}$ 's (100 mmol, pro dNTP $25 \mathrm{mmol}$ ) \\ $1 \mu 1$ forward Primer $10 \mu \mathrm{M}$ \\ $1 \mu \mathrm{l}$ reverse Primer $10 \mu \mathrm{M}$ \\ $0.7 \mu$ l Pfu-DNS-Polymerase \\ $1 \mu \mathrm{l}$ insert $100 \mu \mathrm{M}$ \\ $18.5 \mu 1$ steriles Wasser
}

Das folgende Programm wurde für die $P f u$-DNS-Polymerase PCR verwendet:

\begin{tabular}{lll}
\hline Auftrennen des DNS-Doppelstrangs & $95^{\circ} \mathrm{C} 15 \mathrm{~min}$ & ein Zyklus \\
Denaturierung & $94^{\circ} \mathrm{C} 30 \mathrm{sec}$ & \\
Annealing & $55^{\circ} \mathrm{C} 1 \mathrm{~min}$ & $20-25$ Zyklen \\
Elongation (für 1 kb 2min) & $72^{\circ} \mathrm{C} 2 \mathrm{~min}$ & \\
Termination: PCR-Produkte vervollständigen & $72^{\circ} \mathrm{C} 10 \mathrm{~min}$ & ein Zyklus \\
\hline
\end{tabular}




\section{Material und Methoden}

\section{Restriktionsverdau}

Nach der Vervielfältigung der DNS wurden sowohl das insert als auch der Vektor (pET32a) mit den Restriktionsenzymen Nde I und Xho I verdaut. Es bildeten sich sogenannte „,klebrige“ Enden, die in der anschließenden Ligation zusammengefügt wurden. Der Restriktionsverdau mit Nde I und Xho I wurde in folgenden Teilschritten durchgeführt:

- Zuerst wurden insert und Vektor, wie in der folgenden Tabelle aufgeführt, angesetzt:

\begin{tabular}{ll}
\hline insert & Vektor pET32a \\
\hline $10 \mu 1 \mathrm{tPphA}$ & $2 \mu 1$ Vektor von Miniprep \\
$0.3 \mu 1$ Nde I & $0.3 \mu 1$ Nde I \\
$0.4 \mu 1$ Xho I & $0.4 \mu 1$ Xho I \\
$5 \mu 1$ Redpuffer & $5 \mu 1$ Redpuffer \\
ad $50 \mu 1$ steriles Wasser & ad $50 \mu 1$ steriles Wasser \\
\hline
\end{tabular}

Die Ansätze wurden über Nacht bei $37^{\circ} \mathrm{C}$ inkubiert, wobei nur das Restriktionsenzym Nde I über Nacht zugegeben wurde.

- Anschließend wurden zu den beiden Ansätzen jeweis $0.4 \mu 1$ Xho I gegeben und für $4 \mathrm{~h}$ bei $37^{\circ} \mathrm{C}$ inkubiert.

\section{Ligation}

Nach dem Verdau mußte der Vektor $\frac{1}{2} \mathrm{~h}$ bei $37^{\circ} \mathrm{C}$ mit alkalischer Phosphatase (CIAP) inkubiert werden, um das 5'-Ende der DNS zu hydrolysieren. Dadurch konnte die Religation des Vektors verhindert werden. Anschließend wurde der Vektor über das Agarosegel mit Hilfe eines kommerziellen Gelreinigungskit (Qiagen) und das DNS-Fragment mit Hilfe eines kommerziellen DNS-Reinigungskit (Qiagen) gereinigt. Danach konnte die Ligation anhand des folgenden Ligationsansatzes durchgeführt werden:

$$
\begin{aligned}
& 0.7 \mu 1 \text { Ligase }(\mathrm{T} 7) \\
& 1.5 \mu 1 \text { Ligasepuffer } \\
& 5 \mu 1 \text { Vektor } \\
& 3 \mu 1 \text { insert } \\
& 4.8 \mu 1 \text { steriles Wasser }
\end{aligned}
$$

Die Ligation erfolgte über Nacht bei $14^{\circ} \mathrm{C}$ im Wasserbad. 


\title{
Transformation in XL2blue-Zellen
}

Nach der Ligation konnte das Konstrukt in XL2blue-Zellen transformiert (wie in Abschnitt 2.2.2, S. 29 beschrieben) und auf Amp-Agarplatten ausgestrichen werden.

\section{Hot Star Taq Polymerase-Ketten-Reaktion}

Die Klone auf der Agarplatte wurden auf das richtige insert hin überprüft, indem eine Hot Star Taq PCR mit den oben beschriebenen Primern (s. Abschnitt 2.1.2, S. 23) durchgeführt wurde und die Größen des PCR-Produkts auf einem Agarosegel mit der Größe des ursprünglichen inserts verglichen wurden. Für die PCR wurde hierbei die Hot Star Taq-DNS-Polymerase verwendet, die erst nach 15 minütigem Erhitzen auf $95{ }^{\circ} \mathrm{C}$ aktiviert wird [56]. Dadurch wird die Bildung von falschen DNS-Fragmenten bei niedrigen Temperaturen aufgrund unspezifischer Primerbindung an die DNS verhindert [56]. Ein zusätzlicher Aspekt ist, daß die Zellen bei 15 minütigem Erhitzen auf $95^{\circ} \mathrm{C}$ lysiert werden und die Plasmid-DNS freigesetzt wird. Die Hot Star Taq-DNS-Polymerase weist nur eine geringe Lesegenauigkeit auf, da sie keine 3'-5'-Exonukleaseaktivität besitzt [57]. Daher werden häufiger falsche Nukleotide in die DNS-Sequenz eingebaut [54,57]. Bei der Überprüfung der Klone ist die hohe Lesegenauigkeit, wie sie von der Pfu-DNS-Polymerase bekannt, nicht notwendig.

- Für die Hot Star Taq PCR wurden sechs Klone von der Agarplatte entnommen und in der folgenden Lösung aufgenommen:

\author{
$17.5 \mu 110 \times$ PCR-Puffer \\ $1.4 \mu 1$ dNTP's (100 mmol, 25 mmol pro dNTP) \\ $7 \mu \mathrm{l}$ forward Primer $10 \mu \mathrm{M}$ \\ $7 \mu 1$ reverse Primer $10 \mu \mathrm{M}$ \\ $0.875 \mu 1$ Hot Star Taq \\ $141.4 \mu 1$ steriles Wasser
}

- Für die Hot Star Taq PCR wurde folgendes Programm verwendet:

\begin{tabular}{lll}
\hline Auftrennen des DNS-Doppelstrangs & $95^{\circ} \mathrm{C} 15 \mathrm{~min}$ & ein Zyklus \\
Denaturierung & $94^{\circ} \mathrm{C} 30 \mathrm{sec}$ & \\
Annealing & $55^{\circ} \mathrm{C} 1 \mathrm{~min}$ & $20-25$ Zyklen \\
Elongation (für $1 \mathrm{~kb} 2 \mathrm{~min})$ & $72^{\circ} \mathrm{C} 2 \mathrm{~min}$ & \\
Termination: PCR-Produkte & & \\
vervollständigen & $72^{\circ} \mathrm{C} 10 \mathrm{~min}$ & ein Zyklus \\
\hline
\end{tabular}




\subsection{Biochemische Methoden}

\subsubsection{SDS-Polyacrylamid-Gelelektrophorese nach Laemmli [58]}

Mit Hilfe der SDS-Polyacrylamid-Gelelektrophorese konnte das Molekulargewicht und die Reinheit des Proteins überprüft werden. Hierzu wurde zunächst Laemmli Probenpuffer (s. Abschnitt 2.1.6, S. 26) zur Proteinlösung gegeben. Dieser enthält SDS, welches sowohl die Quartär-, Tertiär- und zum Teil auch die Sekundärstruktur des Proteins zerstört. Das Protein liegt somit denaturiert vor. Außerdem wird aufgrund der Bindung von SDS an die vorliegenden Proteine eine starke negative Ladung eingefügt, welche das Verhalten in einem elektrischen Feld für alle Proteine vereinheitlicht. Die unterschiedlichen Proteine wandern somit nach Anlegen eines elektrischen Feldes alle in der gleichen Zeitspanne zur Anode, was dazu führt, daß die verschiedenen Proteine anhand ihrer Größe und nicht aufgrund ihrer unterschiedlichen Ladungen auf dem SDS-Gel getrennt werden können.

Die Proteinlösung wurde anschließend ca. 5 min bei $95{ }^{\circ} \mathrm{C}$ erhitzt und dann auf das SDSGel aufgetragen. Als Standard wurde der BenchMark ${ }^{\mathrm{TM}}$ Protein Marker aufgetragen. Die Gelelektrophorese-Kammer wurde mit dem Laufpuffer (s. S. 27) gefüllt. Die Elektrophorese erfolgte bei $25 \mathrm{~mA}$ für ein SDS-Gel bzw. $50 \mathrm{~mA}$ für zwei SDS-Gele.

Zur Färbung der Proteinbanden wurde das SDS-Gel zuerst in die Coomassie Färbelösung (s. S. 27) gegeben und für einige Minuten im Mikrowellengerät erhitzt. Anschließend wurde die Entfärbelösung (s. S. 27) auf das Gel gegeben, einige Minuten erhitzt und das Gel schütteln gelassen. Nach wenigen Minuten waren die Proteinbanden sichtbar.

\section{SDS-Gel (15\% ig)}

Für ein $15 \%$ iges SDS-Gel wurden folgende Substanzen für das Trenn- und das Sammelgel benötigt:

\begin{tabular}{lcc}
\hline Substanzen & $\begin{array}{c}\text { Trenngel } \\
(15 \% \text { ig, 5ml })\end{array}$ & $\begin{array}{c}\text { Sammelgel } \\
(3 \% \text { ig, 2.5 ml })\end{array}$ \\
\hline 30 \%ige Acrylamid-Lösung & $2.5 \mathrm{ml}$ & $250 \mu \mathrm{l}$ \\
$1 \mathrm{M}$ Tris $\cdot \mathrm{HCl}, \mathrm{pH} 8.8$ & $1.88 \mathrm{ml}$ & - \\
\hline
\end{tabular}




\begin{tabular}{lcc}
\hline Substanzen & $\begin{array}{c}\text { Trenngel } \\
(15 \% \text { ig, 5ml })\end{array}$ & $\begin{array}{c}\text { Sammelgel } \\
(3 \% \text { ig, } 2.5 \mathrm{ml})\end{array}$ \\
\hline 1 M Tris·HCl, pH 6.8 & - & $313 \mu \mathrm{l}$ \\
Millipore Wasser & $0.53 \mathrm{ml}$ & $1.88 \mathrm{ml}$ \\
$10 \%$ ige SDS-Lösung & $50 \mu \mathrm{l}$ & $25 \mu \mathrm{l}$ \\
$10 \%$ ige APS-Lösung & $50 \mu \mathrm{l}$ & $25 \mu \mathrm{l}$ \\
TEMED & $2.5 \mu \mathrm{l}$ & $2 \mu \mathrm{l}$ \\
\hline
\end{tabular}

\subsubsection{Ammoniumsulfatfällung}

Bei Zugabe von Ammoniumsulfat zu einer Proteinlösung werden die Lösungsmittelmoleküle, die das Protein umgeben, für die Hydrathülle der Salzionen benötigt und stehen dem Protein nicht mehr zur Verfügung. Dadurch liegen die hydrophoben Bereiche an der Oberfläche des Proteins frei und die Proteinmoleküle aggregieren. Sie sind jedoch nicht denaturiert und können bei Zugabe von Lösungsmittel wieder in ihre lösliche Form überführt werden. Diese Prozedur wird Aussalzen (salting out) genannt. Im Fall von tPphA wurde die Ammoniumsulfatfällung zur Konzentrierung des Proteins und als erster Reinigungsschritt durchgeführt. Dazu wurde nach der Zentrifugation des Zellaufschlusses tPphA aus dem Überstand im Eisbad mit Ammoniumsulfat der folgenden Konzentrationen gefällt: $35 \%, 50 \%, 55 \%$ und $60 \%$. Das Präzipitat wurde 10 min bei 20.000 rpm zentrifugiert. Das Pellet der einzelnen Ammoniumsulfat-Fällungen wurde jeweils in möglichst wenig Puffer 1 (s. S. 28) aufgenommen und über Nacht gegen 21 Puffer 1 bei $4{ }^{\circ} \mathrm{C}$ dialysiert.

\subsubsection{Glutathion-S-Transferase-Fusionsprotein Reinigung [51,59]}

Bei der Glutathion-S-Transferase (GST)-Fusionsprotein Reinigung handelt es sich um eine Affinitäts-Chromatographie. Die Glutathion-S-Transferase ist ein 26 kDa Protein von Schistosoma japonicum [59], das eine starke Affinität zu Glutathion besitzt. Das GST-Fusionsprotein enthält zwischen dem N-terminalen GST und dem eigentlichen Zielprotein eine Proteaseschnittstelle für Thrombin, den Blutgerinnungsfaktor Xa oder eine andere spezifische Protease. Für die Thrombinschnittstelle ist die Aminosäure-Sequenz LVPRGS verantwortlich, wobei die Spaltung zwischen der Aminosäure Arginin (R) und Glycin (G) erfolgt [50]. Nach dem Zellaufschluß und Abtrennen der unlöslichen Zellbestandteile durch Zentrifugation kann das lösliche GST-Fusionsprotein an das Glutathion des Säulenmaterials (GlutathionSepharose) binden. Alle anderen Proteine in der Zellsuspension besitzen die GST-Fusion nicht und werden beim Waschen von der Säule gespült. Zurück bleibt das gewünschte Protein, wel- 


\section{Material und Methoden}

ches bei der GST-Reinigung entweder mit freiem Glutathion oder mit Hilfe einer Protease (z.B. Thrombin) von der Säule entfernt werden kann. Die Proteasespaltung auf der Säule hat den Vorteil, daß nur ein Reinigungsschritt über die Säule nötig ist, um das Protein in sehr reiner Form zu erhalten, da das GST auf der Säule gebunden bleibt. Diese Reinigungsmethode wurde im Fall der C2B-Domäne angewendet.

\subsubsection{Ionenaustauscher-Chromatographie}

Die Ionenaustauscher-Chromatographie kann für Proteine genutzt werden, da diese aufgrund ihrer positiv und negativ geladenen Aminosäuren bei unterschiedlichen $\mathrm{pH}$-Werten elektrisch geladen sind. Sie liegen bei einem bestimmten $\mathrm{pH}$-Wert in einem elektrischen Feld ungeladen vor, d.h., ihre negativen und positiven Ladungen heben sich gegenseitig auf. Dieser pH-Wert wird auch als isoelektrischer $\mathrm{pH}$-Wert oder isoelektrischer Punkt ( $\mathrm{pI}$ ) des spezifischen Proteins bezeichnet. Liegt dieser bei einem niedrigen $\mathrm{pH}$-Wert, wie im Fall von tPphA (pI = 5.18), kann für die Trennung des Proteins von Verunreinigungen bei neutralem $\mathrm{pH}-$ Wert eine Anionenaustauschersäule verwendet werden, da das Protein bei einem $\mathrm{pH}-$ Wert ungefähr 7 negativ geladen ist. Liegt er hingegen bei einem hohen pH-Wert, wie im Fall der C2B-Domäne (pI = 7.85), sollte für die Reinigung des Proteins bei neutralem pH-Wert eine Kationenaustauschersäule verwendet werden, da das Protein bei einem $\mathrm{pH}$-Wert ungefähr 7 positiv geladen ist $[60,61]$.

Prinzipiell wird für die Equilibration vor der Reinigung auf einer Ionenaustauschersäule ein Puffer mit einer niedrigen Salzionenkonzentration benötigt, um einerseits die Verdrängung der an das Säulenmaterial koordinierten Salzionen durch das Protein zu gewährleisten und andererseits die Bindung von Verunreinigungen zu verhindern. Ist das Protein an das Säulenmaterial gebunden, kann es mit Hilfe einer hohen Salzionenkonzentration wieder von der Säule eluiert werden, da hierbei die Salzionen wieder an das Säulenmaterial binden und das Protein verdrängen.

\subsubsection{Gelfiltrations-Chromatographie [62]}

Das Prinzip der Gelfiltrations-Chromatographie beruht auf der Trennung der Proteine nach ihrer Größe. In der Gelfiltrationssäule liegt als Säulenmaterial ein quervernetzendes Polymer vor, in welches kleine Proteine eindringen können. Größere Proteine hingegen passen nicht in dessen Poren und können daher schneller durch die Säule gelangen. Diese Chromatographiemethode wird meist am Ende einer Proteinreinigung vorgenommen. Auch im Fall der tPphAund der C2B-Reinigung schloß sich als letzter Reinigungsschritt eine Gelfiltrationssäule an. 


\subsubsection{Bestimmung der Proteinkonzentration}

Die Proteinkonzentration wurde mit Hilfe einer photometrischen Messung bei einer Wellenlänge von $280 \mathrm{~nm}$ in einer $2 \mathrm{~mm}$ Quarzküvette (l) gegen den Gelfiltrationspuffer als Referenz bestimmt. Die Proteinkonzentration konnte anhand des Extinktionskoeffizienten $(\varepsilon)$ mit Hilfe des Lambert-Beerschen Gesetzes [52] ebenso wie die DNS-Konzentration (s. Abschnitt 2.2.4, S. 30) berechnet werden.

\subsubsection{Aktivitätstest für tPphA [63]}

Die Aktivität der Phosphatase tPphA konnte mit Hilfe des Reagenz para-Nitrophenylphosphat ( $p$-NPP) überprüft werden. Dazu mußte $p$-NPP entweder zu der Proteinlösung oder später zu den Kristallen gegeben werden. Liegt das Protein in seiner aktiven Form vor, kann es Phosphat von $p$-NPP abspalten und freies $p$-NP wird sichtbar. Nach der Reaktion zeigt die Lösung die gelbe Farbe des freiwerdenden para-Nitrophenols ( $p$-NPs).

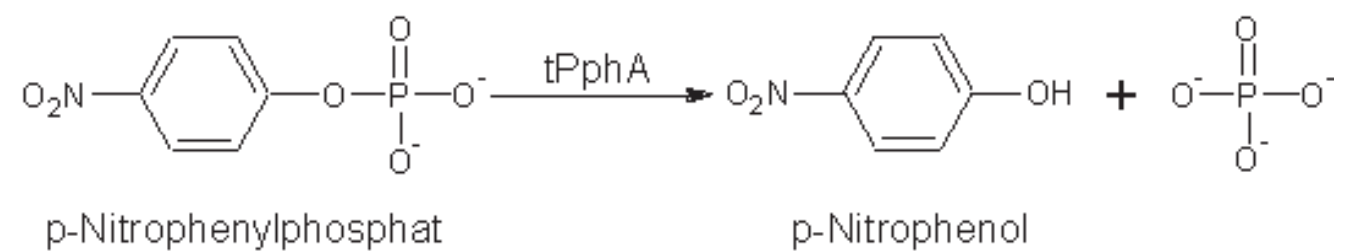

Abbildung 2.3: Reaktionsgleichung des p-NPPs

Für eine erfolgreiche Reaktion mußten sowohl $\mathrm{Mg}^{2+}$ - oder $\mathrm{Mn}^{2+}$-Ionen als auch ein $\mathrm{pH}-$ Wert von $\geq 8.0$ vorliegen. 


\subsection{Kristallographische Methoden}

\subsubsection{Kristallisation}

\section{Voraussetzung der Kristallisation}

Voraussetzung für die Kristallisation eines Proteins ist, daß es in Lösung stabil ist, d.h. nicht in Lösung aggregiert, und daß es einen hohen Reinheitsgrad (> $90 \%$ ) hat. Wenn diese Voraussetzungen erfüllt sind, können Kristallisationsversuche mit guten Chancen auf Kristalle angesetzt werden.

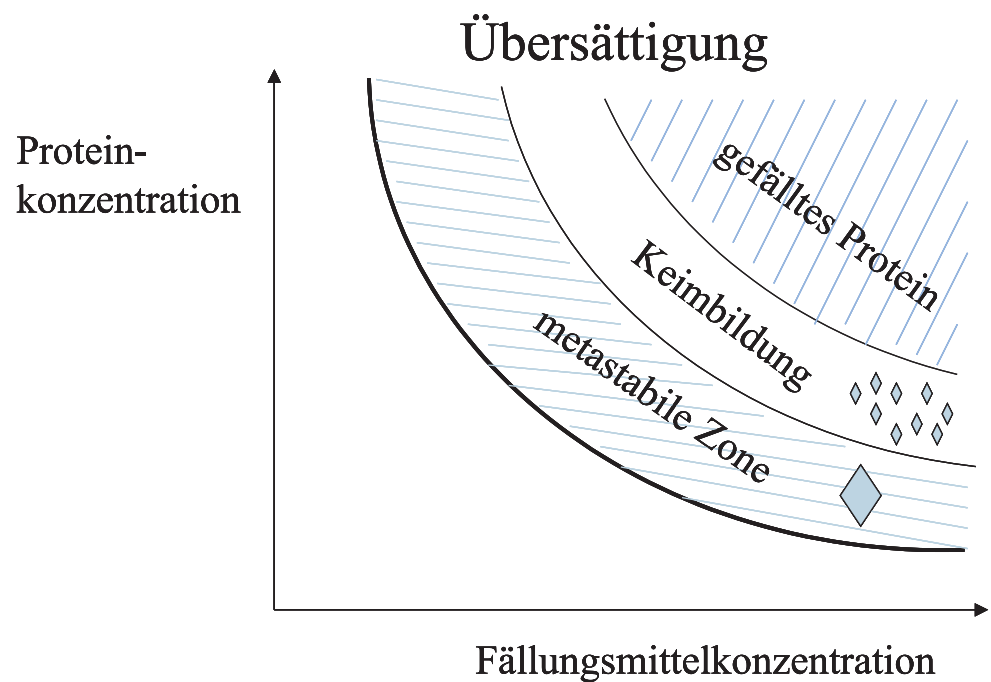

Abbildung 2.4: Phasendiagramm für die Kristallisation

Bei der Kristallisation versucht man, wie in Abbildung 2.4 gezeigt, die Proteinlösung in den Übersättigungszustand zu bringen. Ist dieser erreicht, können sich in der Keimbildungszone kleine Kristalle bilden. In der metastabilen Zone hingegen können sich nur mit bereits vorhandenen Keimen größere Kristalle bilden. Ansonsten ist keine Kristallisation in diesem Bereich möglich. Die Kunst der Kristallisation besteht nun darin, langsam in den Übersättigungsbereich und damit in die Keimbildungszone zu gelangen, um erste Kristallisationskeime zu formen. Liegen einzelne Keime vor, sollte die Proteinkonzentration in Lösung aufgrund der gebildeten Proteinkristalle geringer werden. Dadurch erreicht die Kristallisationslösung anschließend den Bereich der metastabilen Zone, wo die Keime zu großen Kristallen heranwachsen können [64]. Wurde die Proteinlösung hingegen in den Bereich des gefällten Proteins gebracht, tendiert das Protein zum Aggregieren und kann schlechter Kristalle ausbilden. 


\section{Hanging und sitting drop Methode}

Für die Kristallisation eines Proteins haben sich mehrere Methoden bewährt, darunter vor allem die hanging drop und die sitting drop Methode, die auch in dieser Arbeit verwendet wurden. Bei diesen beiden Methoden macht man sich das Prinzip der Gasphasendiffusion zunutze. Die Proteinlösung, die sich in einer abgeschlossenen Kammer in einem Tropfen befindet, wird mit der Zeit langsam aufkonzentriert. Irgendwann ist dann der Übersättigungsbereich der Lösung erreicht, und es können sich Kristalle ausbilden (s. Abb. 2.4, S. 38). Sowohl bei der hanging drop als auch bei der sitting drop Methode wird zuerst die Reservoirlösung, die aus der spezifischen Kristallisationsbedingung besteht, in das Kristallisationsgefäß gegeben.

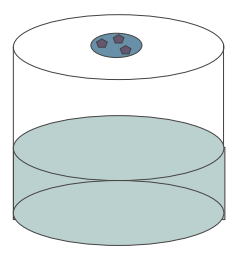

a)

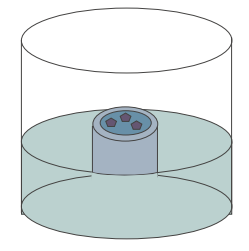

b)

Abbildung 2.5: Kristallisation nach a) der hanging drop Methode, b) der sitting drop Methode

Bei der hanging drop Methode wird, z.B. auf einem silikonisierten Objektträger, ein Tropfen der Reservoirlösung mit einem Tropfen der Proteinlösung gemischt und das Kristallisationsgefäß, wie in Abbildung 2.5 (S. 39) gezeigt, verschlossen. Im Gegensatz dazu gibt man bei der sitting drop Methode die Tropfen von Reservoir- und Proteinlösung auf eine Brücke, die in dem Kristallisationsgefäß, wie in Abbildung 2.5 (S. 39) gezeigt, angebracht wird. Ein Vorteil der sitting drop Methode liegt darin, daß bei Lösungen, die eine geringe Oberflächenspannung aufweisen, der Tropfen nicht in die Reservoirlösung fallen kann, wie im Fall der hanging drop Methode, sondern auf der Brücke verbleibt.

\section{Streak seeding $[65,66]$}

Liegen nach der Kristallisation zu viele kleine Kristalle vor, können mit Hilfe der streak seeding Methode wenige große Kristalle gezüchtet werden. Dazu müssen neue Kristallisationbedingungen mit einer niedrigeren Proteinkonzentration - z.B. die ursprüngliche Konzentration auf die Hälfte verdünnen - oder niedrigeren Fällungsmittelkonzentrationen angesetzt werden [67]. Die ursprünglich kleinen Kristalle werden als Kristallisationskeime für die neuen Bedingungen verwendet. Sie werden z.B. mit einem Katzen- oder Pferdehaar [67] in die neuen Bedingungen überführt, wie in Abbildung 2.6 dargestellt ist. Bei dieser Methode werden Kristallisationskeime in die metastabile Zone des Übersättigungsbereichs transferiert, so daß große Kristalle wachsen können. Diese Methode wurde in dieser Arbeit für die Kristallisation 
1) Keime für das seeding produzieren

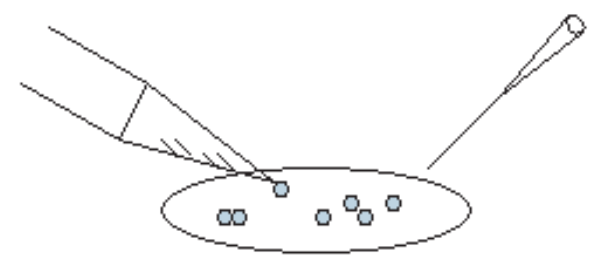

2) Tranfer der Keime in eine neue Bedingung

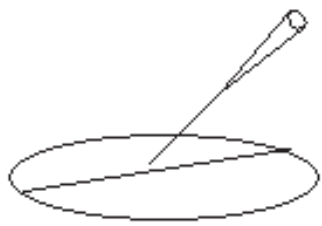

3) Kristalle entlang einer seeding Linie

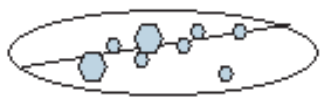

Abbildung 2.6: Anleitung für streak seeding [65]

der Se-Met Proteinlösungen für tPphA und C2B und für die C2B-Kristallisation mit Kalziumionen angewendet.

\subsubsection{Datensammlung und -prozessierung}

\section{Datensammlung}

Für die Tieftemperatur-Datensammlung werden die gezüchteten Kristalle in flüssigem Stickstoff eingefroren, wobei sie vorher jedoch in eine Cryolösung überführt werden müssen. Proteinkristalle enthalten zu einem großen Anteil Wasser, welches sich beim Schockgefrieren schlagartig ausdehnt. Um zu verhindern, daß der Kristall zerstört wird, werden die Kristalle vor dem Einfrieren in eine Lösung transferiert, die zusätzliche Lösungsmittel wie Glycerin, MPD, 2,3-Butandiol oder PEGs etc. als Gefierschutz enthalten sollte [68,69]. Erst dann kann der Kristall in einer Schlaufe montiert und in flüssigem Stickstoff eingefroren werden $[68,69]$. Die Cryolösung für die Kristalle der C2B-Domäne beinhaltete $10 \%$ Glycerin, die für die Kristalle von tPphA $15 \%$ 2,3-Butandiol. Die ersten Diffraktionstests der C2B- und tPphA-Kristalle wurden an einem Einkreis-Diffraktometer mit einem MAR345 image plate Detektor vorgenommen, wobei als Röntgenquelle eine $\mathrm{Cu}$-Drehanode vorlag. Die eigentliche Aufnahme der Datensätze erfolgte im Falle der C2B-Domäne am Synchrotron SLS an der beamline PX 6, die mit einem MAR CCD Detektor ausgestattet ist. Die Kristalle wurden bei der Messung auf 89.5 K gekühlt. Im Falle von tPphA wurden die Daten am Synchrotron DESY in Hamburg an der beamline BW 6 gemessen, die ebenfalls einen MAR CCD Detektor 
beinhaltete. Bei der Messung betrug die Kühltemperatur der Kristalle $100 \mathrm{~K}$. In beiden Fällen wurden sowohl Daten von nativen als auch von Se-Methionin Kristallen aufgenommen. Die Strategie der Datensammlung der Se-Methionin Kristalle für ein MAD-Experiment wird im folgenden Abschnitt genauer erläutert (MAD = multiple-wavelength anomalous dispersion).

MAD-Datensammlung Für eine MAD-Datensammlung wird zunächst ein FluoreszenzScan aufgenommen, um das anomale Signal zu überprüfen und die Wellenlängen für den peak (f" maximal, Differenz zwischen f' und f" maximal), high energy remote und inflection (f' maximal) Datensatz festzulegen [70]. Dann wird zuerst der peak Datensatz mit einer

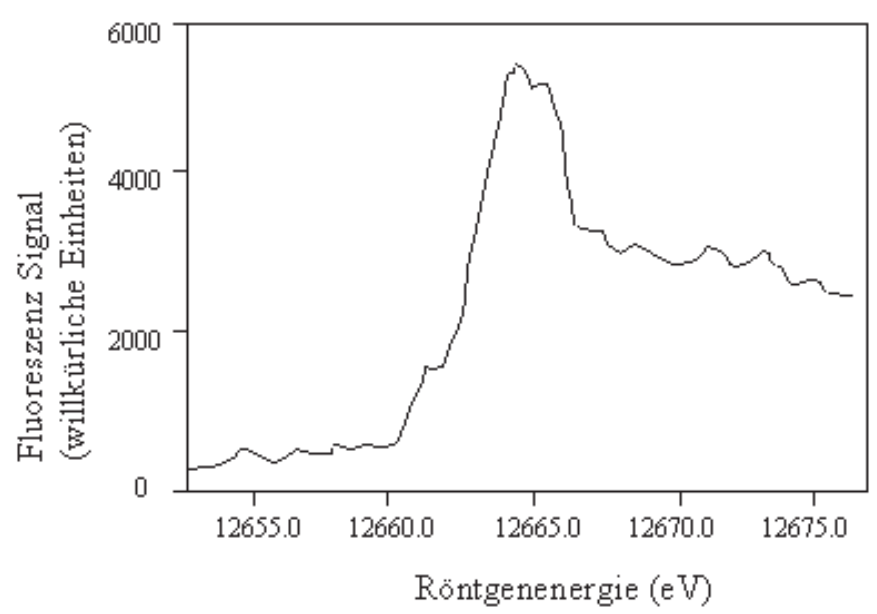

a)

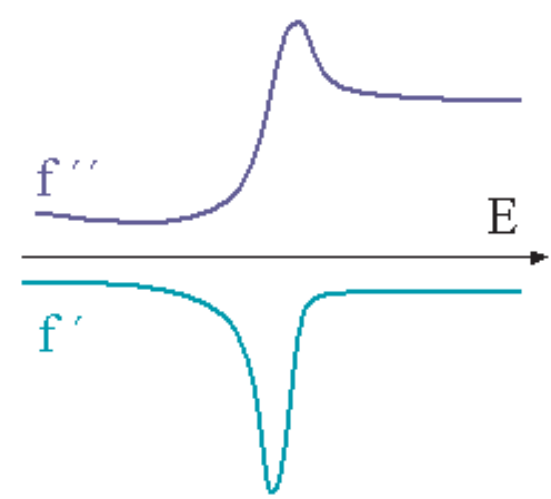

b)

Abbildung 2.7: a) Fluoreszenz-Scan von Se-Met Protein, b) Korrelation von $f^{\prime}(\lambda)$ zu $f^{\prime \prime}(\lambda)$ im Falle von Se-Met Kristallen [70]

hohen Redundanz gemessen. Solange danach kein Strahlenschaden vorliegt, sollte nach dem peak Datensatz der high energy remote Datensatz aufgenommen werden und am Ende des MAD-Experiments der inflection Datensatz. Andernfalls wird nach dem peak Datensatz der inflection Datensatz gemessen und mit einem zweiten Kristall der high energy remote Datensatz aufgenommen [71]. Für eine gute Elektronendichtekarte sollte mindestens ein Datensatz zu höherer Auflösung gemessen worden sein, entweder der high energy remote Datensatz oder ein Datensatz eines nativen Kristalls. Die Meßzeit (und damit verbunden die Auflösung) des MAD-Experiments sollte nicht zu hoch gewählt werden, da sonst das Risiko des Strahlenschadens besonders groß ist [71]. 


\section{Material und Methoden}

\section{Datenprozessierung}

Die Integration der Daten von der C2B-Domäne und von tPphA erfolgte mit Hilfe des Programms HKL2000 [72] (Denzo). Für die Skalierung der Daten wurde ebenfalls HKL2000 [72] (Scalepack) oder wahlweise X2SAD [73] in Kombination mit SADABS [74] verwendet. Nach Bestimmung der Raumgruppe bzw. Überprüfung der Datenqualität mittels XPREP [74] konnten die beiden Strukturen mit Hilfe des anomalen Signals von Selen gelöst werden.

\subsubsection{Strukturlösung}

Die gemessenen Beugungsbilder enthalten die Intensität der gebeugten Röntgenstrahlung, die proportional dem Quadrat der Amplituden der Strukturfaktoren ist. Allerdings kann aus dem Röntgenexperiment nur der Absolutwert der Strukturamplitude $\left|F_{h k l}\right|$ ermittelt werden, da die Intensität $I_{h k l}$ dem Wert $\left|F_{h k l}\right|^{2}$ entspricht. Die Information über den Phasenwinkel $\phi_{h k l}$ geht verloren $[75,76]$ :

$$
\begin{aligned}
F_{h k l} & =\left|F_{h k l}\right| \cdot \exp \left[i \phi_{h k l}\right] \\
& =V \int_{0}^{1} \int_{0}^{1} \int_{0}^{1} \rho(x, y, z) \exp [2 \pi i(h x+k y+l z)] \mathrm{d} x \mathrm{~d} y \mathrm{~d} z .
\end{aligned}
$$

Nur mit beiden Informationen von Phase und Strukturfaktoramplitude $\left(\left|F_{h k l}\right|\right)$ kann mit Hilfe der inversen Fourier-Transformation die Elektronendichte der Struktur bestimmt werden [75]:

$$
\rho(x, y, z)=\frac{1}{V} \sum_{h k l} F_{h k l} \exp [-2 \pi i(h x+k y+l z)],
$$

wobei x y z die Koordinaten in der Elementarzelle darstellen.

Für Proteinstrukturen können die Phasen mit den folgenden Methoden ermittelt werden:

- Isomorpher Ersatz (MIR/SIR)

- Anomale Dispersion (MAD/SAD)

- Kombination aus isomorphem Ersatz und anomaler Dispersion (MIRAS/SIRAS)

- Molekularer Ersatz (MR)

- Direkte Methoden, die jedoch auf relativ kleine Proteinstrukturen (ca. 3000 Atome) begrenzt sind. 
In den Methoden des isomorphen Ersatzes und der anomalen Dispersion werden zur Ermittlung der Phasen Schweratomderivate verwendet. In einem ersten Schritt werden die Schweratompositionen und anhand derer die Phasen der Schweratome bestimmt. Anschließend können aus diesen die Phasen des gesamten Proteins berechnet und mittels Dichtemodifikation verbessert werden.

\section{Isomorpher Ersatz (MIR/SIR)}

Bei der Methode des isomorphen Ersatzes benötigt man verschiedene Schweratomderivate und native Kristalle, die isomorph zueinander sind, d. h., daß die Kristalle die gleichen Zellkonstanten und die gleiche Symmetrie aufweisen müssen. Nur wenn die Kristalle isomorph sind, können die Unterschiede in den Intensitäten zwischen Schweratomderivat und nativem Kristall zur Phasenbestimmung und damit zur Strukturklärung führen. Die Idee des isomorphen Ersatzes ist, anhand der Strukturfaktoramplituden des Schweratomderivats und des nativen Kristalls die Strukturfaktoramplituden der Schweratome zu bestimmen und daraus die Phase des Schweratoms abzuleiten. Dazu ist der Zusammenhang zwischen den Strukturfaktoren des nativen Kristalls $(\mathrm{P})$, des Schweratomderivats $(\mathrm{PH})$ und der Schweratome $(\mathrm{H})$ wichtig [77]:

$$
F_{P H}=F_{P}+F_{H} \quad \text { bzw. } \quad F_{H}=F_{P H}-F_{P}
$$

Der Strukturfaktor von $F_{H}$ ist gegenüber den Strukturfaktoren von $F_{P}$ und $F_{P H}$ klein, so daß $\left|F_{P}\right|$ und $\left|F_{P H}\right|$ in die gleiche Richtung zeigen (s. Abb. 2.8, S. 44). In einem ersten Schritt werden die Amplituden der Schweratome aus der Differenz der Amplituden des nativen Kristalls und des Schweratomderivats anhand der Gleichung für den isomorphen Ersatz ermittelt [75]:

$$
\left|F_{H}\right|=\Delta\left|F_{i s o}\right| \approx\left|F_{P H}\right|-\left|F_{P}\right| .
$$

Diese Gleichung ergibt nur für zentrosymmetrische Raumgruppen einen genauen Wert für die Amplitude von $F_{H}$ (s. Abb. 2.8a, S. 44). In nicht-zentrosymmetrischen Raumgruppen ist der tatsächliche Wert für $\left|F_{H}\right|$ größer als der errechnete Wert, da das $\left|F_{i s o}\right|$ den minimalen Wert angibt (s. Abb. 2.8 b und c, S. 44). Anschließend können mittels direkter Methoden oder der Patterson-Methode [78] die Phasen der Schweratome mit Hilfe der Amplitude bestimmt werden. In der Patterson-Methode werden die Quadrate der Amplituden für die Berechnung der Schweratomsubstruktur verwendet [75]:

$$
P(u, v, w)=\frac{1}{V} \sum_{h k l}\left|F_{h k l}\right|^{2} \exp [-2 \pi i(h u+k v+l w)] .
$$

Um die Schweratompositionen zu erhalten, müssen die höchsten Maxima in der PattersonFunktion ermittelt werden. Anschließend können anhand der Phaseninformation der Schweratomsubstruktur die Phasen der gesamten Struktur ermittelt werden. 


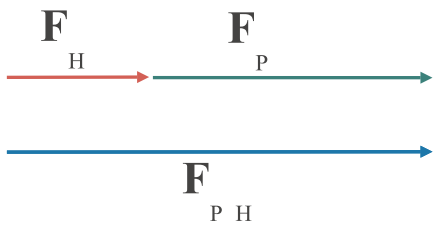

a)

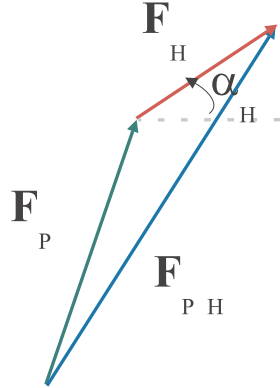

b)

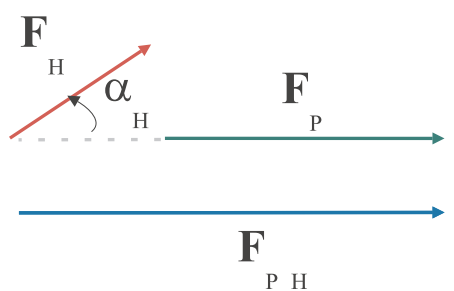

c)

Abbildung 2.8: Der Zusammenhang der Amplituden des nativen Kristalls $\left(F_{P}\right)$, des Schweratomderivatkristalls $\left(F_{P H}\right)$ und der Schweratome $\left(F_{H}\right)$ für a) zentrosymmetrische, b) und c) nichtzentrosymmetrische Raumgruppen.

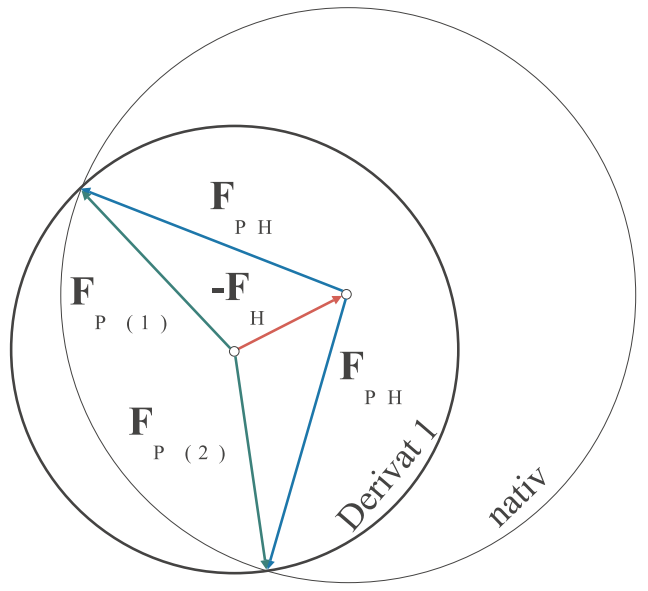

a)

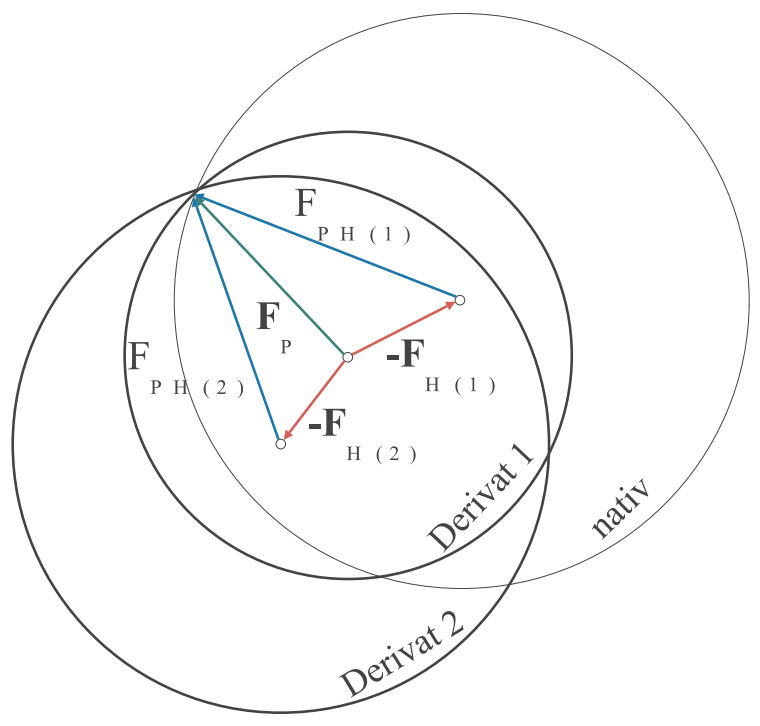

b)

Abbildung 2.9: Die Harker Konstruktion für den isomorphen Ersatz: a) SIR (single isomorphous replacement), die Lösung für die Phase von $F_{P}$ ist zweideutig, b) MIR (multiple isomorphous replacement), die Lösung für die Phase von $F_{P}$ ist eindeutig 
Wird für die Strukturlösung mittels isomorphen Ersatzes nur ein Schweratomderivat verwendet (SIR = single derivative isomorphous replacement), ist die Lösung zweideutig, d.h., es kann nicht zwischen zwei Lösungen für die Phase von $F_{P}$ entschieden werden (s. Abb. 2.9a, S. 44). Daher ist es ratsam, verschiedene Schweratomderivate zu messen und somit die Zweideutigkeit des SIR-Experiments mittels verschiedener Derivate in einem MIR-Experiment (MIR = multiple derivatives isomorphous replacement) zu lösen (s. Abb. 2.9b, S. 44).

\section{Anomale Dispersion (MAD/SAD)}

Besonders ausgeprägte anomale Dispersion kann beobachtet werden, wenn Schweratome nahe ihrer Absorptionskante mit Röntgenstrahlen bestrahlt werden. Schon Elemente ab Sauerstoff zeigen anomale Dispersion, wobei bei den „leichteren“ Schweratomen wie Sauerstoff und Schwefel sehr exakte Messungen notwendig sind, um das anomale Signal für die Phasenbestimmung nutzen zu können.

Bei der normalen Beugung von Röntgenstrahlen (leichte Elemente wie Kohlenstoff und Stickstoff) entspricht die einfallende Strahlung der austretenden Strahlung. Im Gegensatz dazu verändert sich bei der anomalen Beugung die Amplitude und die Phase der austretenden Strahlung (s. Abb. 2.10, S. 45). In einer Vektorgraphik dargestellt (s. Abb. 2.11, S. 46) wird

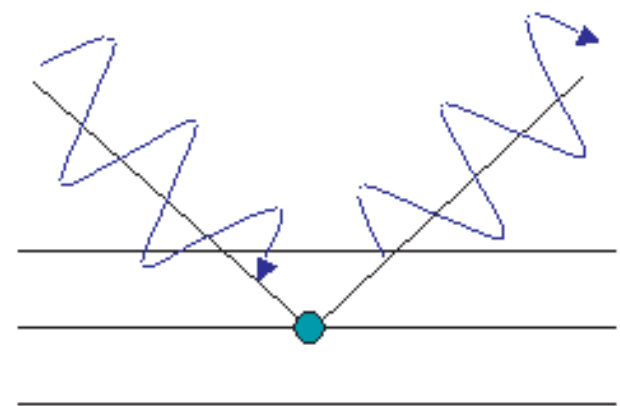

a)

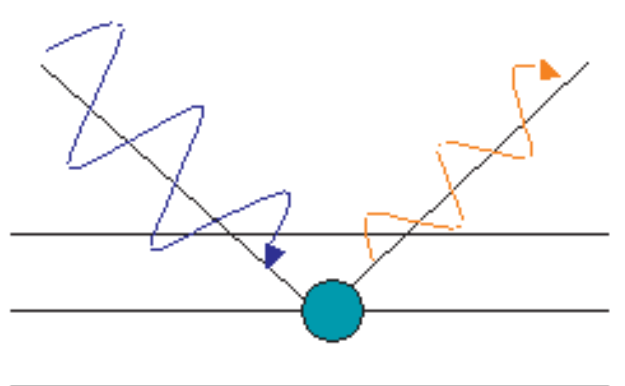

b)

Abbildung 2.10: Beugung des einfallenden Röntgenstrahls: a) normale Beugung, b) anomale Beugung, bei der sich die Amplitude und Phase ändert, die Wellenlänge jedoch nicht.

deutlich, daß bei normaler Beugung die Amplitude des Strukturfaktors $\mathrm{F}_{\text {total }}$ des gesamten Proteins inklusive Schweratomen der Amplitude des negativen Strukturfaktors $-\mathrm{F}_{\text {total }}$ entspricht $\left(F_{\text {total }}(h k l)=-F_{\text {total }}(\overline{h k l})\right)$. Somit ist die Phase von $\mathrm{F}_{\text {total }}$ identisch mit der negativen Phase von $-\mathrm{F}_{\text {total }}\left(\phi_{\text {total }}(h k l)=\phi_{\text {total }}(\overline{h k l})\right)$. Dies ist als Friedelsches Gesetz bekannt [75]. Im Fall der anomalen Streuung hingegen sind sowohl die Amplitude als auch die Phase der beiden Strukturfaktoren unterschiedlich. 

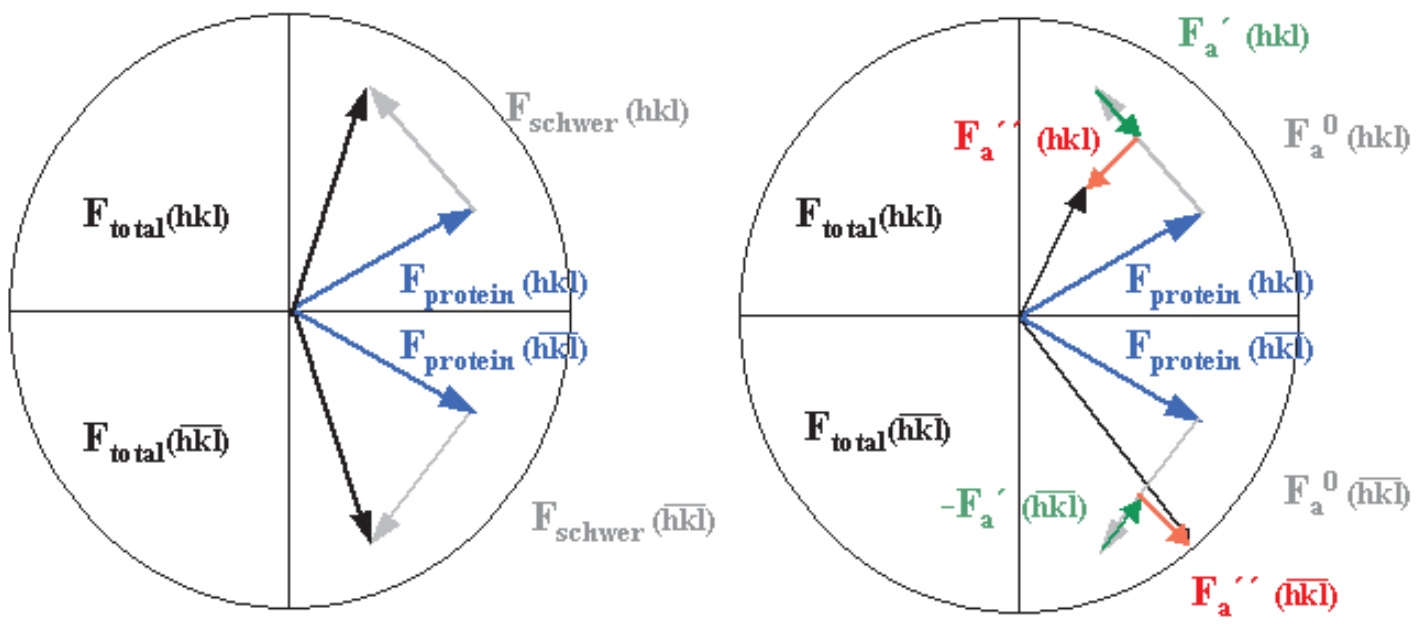

Abbildung 2.11: Friedelsches Gesetz für a) normale und b) anomale Beugung

Daraus folgt, daß das Friedel Gesetz für normale Beugung erfüllt ist, also $\left|F_{h k l}\right|=\left|F_{\overline{h k l}}\right|$ gilt, daß das Friedel Gesetz für anomale Beugung hingegen nicht mehr zutrifft:

$$
\left|F_{h k l}\right| \neq\left|F_{\overline{h k l}}\right| \text {. }
$$

Dieser Unterschied tritt nur bei nicht-zentrosymmetrischen Raumgruppen auf, bei zentrosymmetrischen Raumgruppen sind aufgrund der Zentrosymmetrie (Inversion) die Intensitäten der Reflexe $I_{h k l}$ und $I_{\overline{h k l}}$ gleich ( $F_{h k l}$ und $F_{\overline{h k l}}$ entsprechen sich).

Nahe der Absorptionskante des Schweratoms ist der anomale Anteil der Streuung maximal. Dieser verändert den Strukturfaktor des gesamten Proteins inklusive Schweratomen wie in Abbildung 2.11 (s. S. 46) gezeigt ist, wobei der Strukturfaktor des Proteins ( $\left.\mathrm{F}_{\text {protein }}\right)$ unverändert bleibt. Der Anteil des Strukturfaktors der Schweratome setzt sich aus mehreren Faktoren zusammen: dem normalen Strukturfaktoranteil (in Abbildung $2.11 F_{a}^{0}$ für $f^{0}$ ) und den anomalen Strukturfaktoranteilen (in Abbildung 2.11 $F_{a}^{\prime}$ für $f^{\prime}(\lambda)$ und $F_{a}^{\prime \prime}$ für $i f^{\prime \prime}(\lambda)$ ) [79]:

$$
f(\lambda)=f^{0}+f^{\prime}(\lambda)+i f^{\prime \prime}(\lambda) .
$$

Der Anteil $f^{0}$ umfaßt normale Beugung ohne Phasenverschiebung. $\operatorname{Im} f^{\prime}(\lambda)$-Anteil ist der Beitrag von Absorption und sofortige Emission enthalten. Der $f^{\prime \prime}(\lambda)$-Anteil beinhaltet den Beitrag der Absorption und verzögerten Emission, welcher zu einer Phasenverschiebung um $90^{\circ}$ führt. Der $f^{\prime \prime}(\lambda)$ Anteil kann mit Hilfe eines Röntgen-Fluoreszenz-Scans ermittelt werden (s. Abb. 2.7, S. 41). Aus dem $f^{\prime \prime}(\lambda)$-Anteil kann anschließend der $f^{\prime}(\lambda)$-Anteil mit der Kramers-Kronig Gleichung berechnet werden, wenn $f^{\prime \prime}(\lambda)$ bekannt ist [79]:

$$
f^{\prime}(E)=\left(\frac{2}{\pi}\right) P \int_{0}^{\infty} \frac{E^{\prime} f^{\prime \prime}\left(E^{\prime}\right)}{E^{2}-E^{\prime 2}} d E^{\prime}
$$


Voraussetzung für die Messung der anomalen Dispersion ist mindestens ein Schweratomderivat. Hierbei können unter anderem die Elemente Se, S, Halogenide (Br, I), Ca, Co und Mn verwendet werden.

SAD Für die Strukturlösung mit Hilfe der SAD-Methode (SAD = single-wavelength anomalous dispersion) muß ein Datensatz eines Schweratomderivats (PH) nahe der Absorptionskante des Schweratoms (peak-Wellenlänge) aufgenommen werden, um die größtmögliche anomale Differenz in $f^{\prime \prime}(\lambda)$ zu erhalten [80]. Aus der anomalen Differenz in $f^{\prime \prime}(\lambda)$ erhält man das Bijvoet-Paar $\left|{ }^{\lambda} F_{\text {obs }}(+h)\right|^{2}$ und $\left|{ }^{\lambda} F_{o b s}(-h)\right|^{2}$, aus dem man anhand der MAD-Gleichung die Phasen ermitteln kann:

$$
\begin{aligned}
\left|{ }^{\lambda} F_{o b s}( \pm h)\right|^{2}= & \left|{ }^{0} F_{T}\right|^{2}+\left.\left.a_{\lambda}\right|^{0} F_{A}\right|^{2} \\
& +\left.b_{\lambda}\right|^{0} F_{T}||^{0} F_{A} \mid \cos \left(\varphi_{T}-\varphi_{A}\right) \\
& \pm\left. c_{\lambda}\right|^{0} F_{T}||^{0} F_{A} \mid \sin \left(\varphi_{T}-\varphi_{A}\right), \\
& \left.\left.a_{\lambda}=\left(f_{\lambda}^{\prime \prime 2}+f_{\lambda}^{\prime 2}\right) /\left(f^{0}\right)^{2}, b_{\lambda}=2 f_{\lambda}^{\prime}\right) / f^{0} \quad \text { und } \quad c_{\lambda}=2 f_{\lambda}^{\prime \prime}\right) / f^{0}
\end{aligned}
$$

Die Lösung der Gleichung ist allerdings nicht eindeutig, da anhand von zwei bekannten GröBen $\left(\left|{ }^{\lambda} F_{\text {obs }}(+h)\right|^{2}\right.$ und $\left.\left|{ }^{\lambda} F_{\text {obs }}(-h)\right|^{2}\right)$ drei Unbekannte $\left(\left|{ }^{0} F_{T}\right|,\left|{ }^{0} F_{T}\right|\right.$ und $\left.\varphi_{T}-\varphi_{A}\right)$ gelöst werden müssen. Dieses Problem ist als Zweideutigkeit des SAD-Experiments bekannt. Es kann gelöst werden, indem der Mittelwert zwischen den beiden Phasen als Startwert verwendet wird und der mittlere Phasenfehler nicht zu groß ist.

MAD In dieser Arbeit wurden die Strukturen der C2B-Domäne und von tPphA mit Se-Met Kristallen mit Hilfe von MAD-Experimenten gelöst. Die Vorteile von Se als Schweratomderivat sind folgende:

1. K-Kante von Se nahe $\lambda=0.98 \AA$ und damit im Bereich von Synchrotronstrahlung [79]

2. Präparation des Se-Met ${ }^{1}$ gekennzeichneten Proteins mit Hilfe von auxotrophen Zellen ist gut handhabbar

3. Se-Met-Einheiten sind innerhalb des Proteins gut geordnet [79] (Ausnahme: am N- und C-Terminus sind sie jedoch flexibel.)

4. Proteinstabilität und -funktion wird nicht beeinflußt von Se

5. Gutes MAD-Signal (4 - $6 \%$ ) erhältlich, wenn ein Methionin innerhalb von 50 Aminosäuren im Protein vorliegt [79]

\footnotetext{
${ }^{1}$ Aminosäuren werden im Folgenden anhand der üblichen Drei-Buchstaben-Abkürzungen bezeichnet.
} 


\section{Material und Methoden}

In einem MAD-Experiment werden von einem Schweratomderivat mehrere Datensätze bei verschiedenen Wellenlängen nahe der Absorptionskante des enthaltenen Schweratoms aufgenommen. Zuerst wird mit Hilfe eines Fluoreszenz-Scans die genaue Position der Absorptionskante (Maximum von $f^{\prime \prime}(\lambda)$ ) bestimmt. Anschließend kann $f^{\prime}(\lambda)$, wie oben beschrieben, berechnet werden. Dadurch können die Wellenlängen für die peak (Maximum von $f^{\prime \prime}(\lambda)$ ), inflection (Minimum von $f^{\prime}(\lambda)$ ) und high remote (mittlere Werte für $f^{\prime}(\lambda)$ und $f^{\prime \prime}(\lambda)$ ) Datensätze festgelegt werden, wie in Abbildung 2.12 a dargestellt ist. Bei der MAD-Messung wer-

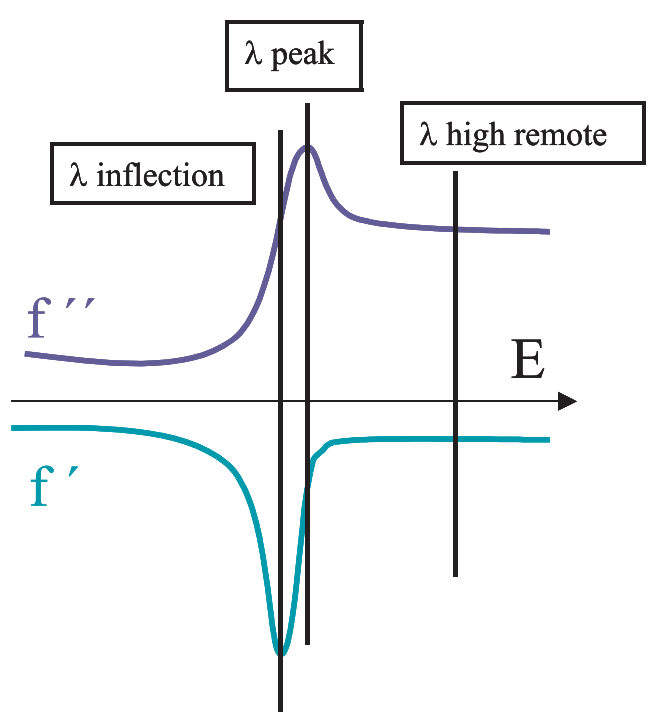

a)

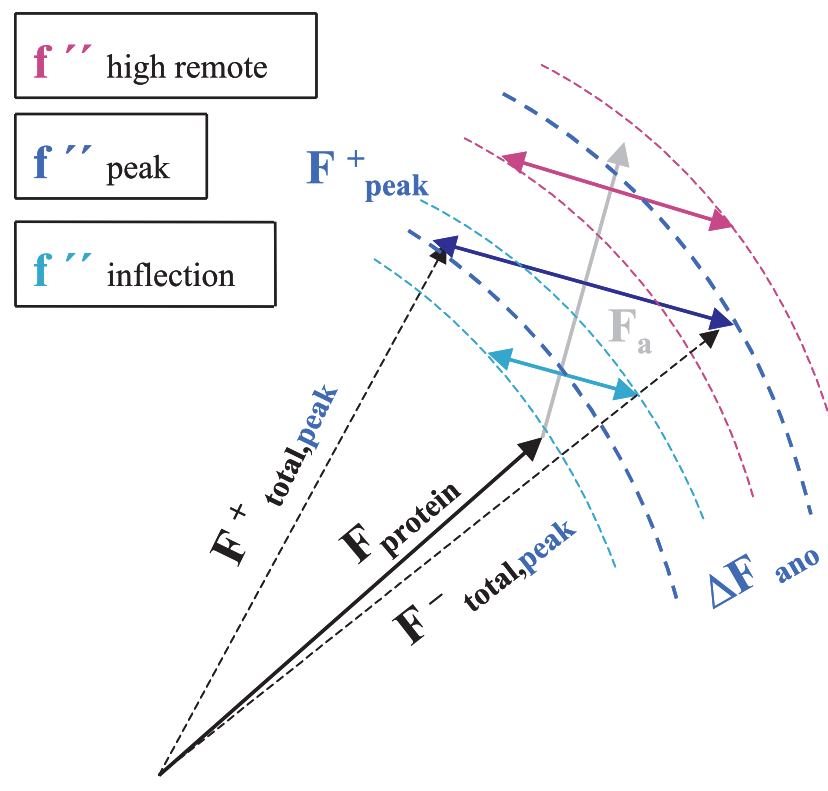

b)

Abbildung 2.12: a) Datensätze eines MAD-Experiments, b) Korrelation zur Theorie des MADExperiments

den die unterschiedlichen Bijvoet-Paare $\left(\mathrm{F}_{\text {total }}^{+}\right.$und $\left.\mathrm{F}_{\text {total }}^{-}\right)$aufgenommen [79], wobei für den peak Datensatz die größte Differenz vorliegt (s. Abb. 2.12b). Die zweitgrößte Differenz tritt je nach Wahl der Wellenlänge bei dem high remote Datensatz oder dem inflection Datensatz auf (s. Abb. 2.12a und b). Anhand der Differenzen in den Bijvoet-Paaren kann eine eindeutige Lösung für das Phasenproblem gefunden werden - im Gegensatz zum SAD-Experiment -. Dafür müssen mindestens zwei Datensätze bei verschiedenen Wellenlängen aufgenommen werden. Dann liegen für jede Wellenlänge $\left|{ }^{\lambda} F_{o b s}(+h)\right|^{2}$ und $\left|{ }^{\lambda} F_{o b s}(-h)\right|^{2}$ vor. Nach Einsetzen in die MAD-Gleichung [79] erhält man insgesamt 2n Gleichungen, wobei n die Anzahl der verschiedenen Wellenlängen angibt. Bei zwei verschiedenen Wellenlängen ergeben sich vier Gleichungen mit drei Unbekannten $\left(\left|{ }^{0} F_{T}\right|,\left|{ }^{0} F_{T}\right|\right.$ und $\left.\varphi_{T}-\varphi_{A}\right)$, aus denen die Phasen der Struktur mit Hilfe von direkten Methoden ermitteln werden können. 


\section{Molekularer Ersatz (MR)}

Notwendig für den molekularen Ersatz ist eine verwandte Struktur, die für die Strukturlösung verwendet werden kann. Hierzu sollte das Modell zu mindestens $40 \%$ mit der zu lösenden Struktur übereinstimmen. Bei der Methode des molekularen Ersatzes wird die exakte Position des Suchfragments in der Elementarzelle ermittelt. Dazu gibt es zum einen die Rotationssuche, bei der es um die Berechnung der richtigen Orientierung des Suchmodells (drei Rotationsvariablen) geht. Zum anderen gibt es die Translationssuche, um die exakte Position des Suchmodells (drei Translationsvariablen) zu ermitteln. Die sechs zu ermittelnden Variablen können entweder in einem Schritt simultan oder in zwei Schritten ermittelt werden, wobei die sechs-dimensionale Suche sehr viel Rechenleistung erfordert. In beiden Fällen wird im ersten Schritt die Rotationssuche mit Hilfe der Patterson-Funktion (s. Absatz 2.4.3, S. 43) durchgeführt, wobei in diesem Fall die Patterson-Funktion des bekannten Fragments über der aus den Daten gewonnenen rotiert wird. Um die richtige Orientierung des Suchfragments zu erhalten, müssen die intramolekularen Vektoren (self-vectors) betrachtet werden. Eine maximale Überlappung der self-vectors indiziert die richtige Orientierung des gesuchten Fragments. Ist die richtige Orientierung des Suchfragments bekannt, muß die absolute Position des Fragments in der Elementarzelle ermittelt werden. Für die Raumgruppe P1 ist die Frage der Translation einfach, da der Ursprung der Zelle willkürlich mit Rücksicht auf die Zellachsen gewählt werden kann [77]. Für alle übrigen Raumgruppen muß die exakte Position des Fragments mit Hilfe der intermolekularen Vektoren (cross-vectors) der Patterson-Funktion ermittelt werden. Auch hier zeigt ein maximaler Wert die genaue Position des Suchfragments an. Die Methode des molekularen Ersatzes kann aufgrund der verbesserten Rechenleistung auch in einer sechs-dimensionalen Suche z.B. über die maximum likelihood Methode, wie in dem Programm PHASER [81], angewandt werden.

\subsubsection{Dichtemodifikation}

Die verschiedenen Methoden der Dichtemodifikation werden nach Erhalt der Phasen angewandt, um die ursprünglich für einen begrenzten Bereich erhaltenen Phasen zu verbessern und zu erweitern. Dadurch wird die Elektronendichtekarte besser interpretierbar, so daß die Modellierung der Proteinstruktur vereinfacht wird. Die Methoden der Dichtemodifikation basieren auf den Eigenschaften der Elektronendichtekarten von Makromolekülen [82]. Zwei wichtige Dichtemodifikationen sind zum einen die unterschiedliche Behandlung von Lösungsmittel- und Proteinbereichen im Kristall (solvent flattening, histogram matching und sphere of influence), zum anderen die Einbeziehung von nicht-kristallographischer Symmetrie $(N C S)$. 


\section{Solvent flattening}

Bei der Methode des solvent flattenings wird die Elektronendichte der Lösungsmittelregionen auf einen konstanten Wert gesetzt, während die Proteinbereiche unverändert bleiben [75]. Dadurch wird das Rauschen in der Elektronendichtekarte, welches von den ungeordneten Lösungmittelbereichen verursacht wird, unterdrückt. Dies führt zu einer Verbesserung in den Phasen und damit der Elektronendichtekarte [82].

\section{Histogram matching}

Die Methode des histogram matchings gleicht die Elektronendichte-Verteilung der gemessenen Elektronendichtekarte an eine ideale Elektronendichte-Verteilung an. Dazu wird der vorhandenen Elektronendichte ein neuer Wert zugewiesen, der mit der idealen Dichteverteilung bei einer bestimmten Auflösung konsistent ist.

\section{Sphere of influence}

In dem in dieser Arbeit verwendeten Programm SHELXE [83] wird die Dichtemodifikation mit Hilfe der Methode des sphere of influence ermittelt. Dabei wird um jeden Pixel der Elektronendichtekarte eine Kugel mit einem Radius von $2.42 \AA$ konstruiert, was einem typischen 1,3-Abstand in allen organischen und makromolekularen Strukturen entspricht, und die Unterschiede der Elektronendichte auf der Oberfläche der Kugel untersucht. Bei großen Varianzen wird der Bereich der Proteinregion zugeteilt, bei kleinen Varianzen der Lösungsmittelregion. Mittlere Varianzen werden entweder wie Proteinregionen oder Lösungsmittelregionen behandelt. In den Proteinregionen wird die negative Elektronendichte auf Null gesetzt und die positive Elektronendichte verstärkt, in der Lösungsmittelregion wird ebenfalls die negative Elektronendichte auf Null gesetzt und zusätzlich die positive Elektronendichte negiert. Dadurch erhöht sich der Kontrast zwischen der Protein- und der Lösungsmittelregion.

\section{Nicht-kristallographische Symmetrie}

Beinhaltet die Proteinstruktur mehr als ein Molekül in der asymmetrischen Einheit, welche nur über lokale Symmetrie-Operatoren ineinander überführbar sind, spricht man von nichtkristallographischer Symmetrie. Diese kann für die Dichtemodifikation verwendet werden, indem die verschiedenen Kopien der Struktur gemittelt werden und somit das Signal-zuRausch-Verhältnis verbessert wird. 


\subsubsection{Strukturverfeinerung}

Die Strukturverfeinerung hat das Ziel, die berechnete Struktur bestmöglich an die beobachteten Daten anzupassen. Dazu wechseln sich Zyklen des Modellierens der Struktur in einem Graphikprogramm (z.B. COOT [84]) mit der Verfeinerung der modellierten Struktur in einem Strukturverfeinerungsprogramm (z.B. REFMAC5 [85] für eine mittlere Auflösung (2-3 $⿱$ ) oder SHELXL [86] für eine hohe Auflösung (bis ca. $2.5 \AA$ A)) ab. Für die Strukturverfeinerung gibt es verschiedene Methoden, unter anderem die Methode der kleinsten Fehlerquadrate (least-squares), die davon abgeleitete Methode des conjugate-gradient und die maximum likelihood Methode [87]. Die Strukturverfeinerung kann entweder auf Basis der Strukturfaktoramplituden $\left(\left|F_{h k l}\right|\right)$ oder den gemessenen Intensitäten $\left(I_{h k l}\right)$ (das Quadrat der Strukturfaktoramplituden $\left|F_{h k l}\right|^{2}$ ) durchgeführt werden. Ein Vorteil bei der Verfeinerung gegen Intensitäten ist, daß alle Daten inklusive negativer Meßwerte in die Verfeinerung mit einfließen. In allen Strukturverfeinerungsmethoden geht es letztendlich darum, die Übereinstimmung der beobachteten Strukturfaktoramplituden $\left(\left|F_{o b s}\right|\right)$ mit den kalkulierten Strukturfaktoramplituden $\left(\left|F_{\text {calc }}\right|\right)$ zu verbessern. Für die Überprüfung der Übereinstimmung zwischen $\left|F_{\text {obs }}\right|$ und $\left|F_{\text {calc }}\right|$ wird der R-Wert betrachtet [75]:

$$
R=\frac{\sum_{h k l}|| F_{o b s}|-| F_{c a l c}||}{\sum_{h k l}\left|F_{o b s}\right|} .
$$

Bei der Betrachtung des R-Werts als Gütekriterium für die Struktur besteht das Problem, daß durch die Verfeinerung model bias in die Struktur eingeht. Das bedeutet, daß die Dichte an das Modell angepaßt wird, so daß Fehler im Modell in der Dichte nicht mehr sichtbar sind. Als ein unabhängiges Gütekriterium für die Struktur wird daher zusätzlich zum R-Wert der $\mathrm{R}_{\text {free }}$-Wert berechnet. Dieser wird aus einem zufällig ausgewählten Satz von Reflexen (üblicherweise 5-10 \% der Daten), der vor der Verfeinerung gewählt wurde, analog der Gleichung für den R-Wert bestimmt [88]. Da bei Proteinstrukturen üblicherweise die gemessenen Daten nicht für die unabhängige Verfeinerung aller Atompositionen ausreichen, werden zusätzliche Informationen in Form von constraints oder restraints in die Verfeinerung einbezogen. Diese basieren auf chemischen Informationen. Constraints, die als exakte mathematische Beziehungen eingehen, verringern die Zahl der Parameter, während restraints, die als zusätzliche Beobachtungen eingehen, die Anzahl der Daten erhöhen. 


\section{Strukturbestimmung der C2B-Domäne}

\subsection{Expression und Reinigung}

\subsubsection{Natives Protein}

\section{Expression des rekombinanten Fusionsproteins}

Das Expressionskonstrukt beinhaltete sowohl die C2B-Domäne als auch einen Teil der linker Region (s. Abb. 1.7, S. 9) zwischen der C2A- und der C2B-Domäne des Rabphilin-3A aus der Ratte (rattus norvegicus). Insgesamt bestand die cDNS Sequenz aus dem kodierenden Fragment für die Aminosäuren 519 bis 684. Außerdem war im Vektor pGEX-2T (GE Lifesciences) am N-Terminus ein GST-Fusionsprotein angefügt, welches für den ersten Reinigungsschritt benötigt wurde. Die Induktion der Expression erfolgte über den IPTG-induzierbaren tac-Promotor.

Zunächst wurde eine Tageskultur von $2 \mathrm{ml}$ LB-Medium (s. S. 24) und $4 \mu 1$ Ampicillinlösung $(25 \mathrm{mg} / \mathrm{ml})$ über ca. 5 bis $6 \mathrm{~h}$ bei $37^{\circ} \mathrm{C}$ kultiviert. Anschließend wurde eine Vorkultur, bestehend aus $25 \mathrm{ml}$ LB-Medium, $50 \mu \mathrm{l}$ Ampicillinlösung und $15 \mu \mathrm{l}$ der Tageskultur, über Nacht bei $37^{\circ} \mathrm{C}$ inkubiert. Dann wurde die Hauptkultur, bestehend aus $750 \mathrm{ml}$ LB-Medium und $1.5 \mathrm{ml}$ Ampicillinlösung, mit $25 \mathrm{ml}$ Vorkultur angeimpft und bis zu einer $\mathrm{OD}_{600}$ von 0.9 bei $37^{\circ} \mathrm{C}$ kultiviert. Die Bakterien wurden auf $15^{\circ} \mathrm{C}$ abgekühlt und bei einer $\mathrm{OD}_{600}$ von 1.0 mit $1 \mathrm{mM}$ IPTG induziert. Die Expression erfolgte über Nacht bei $15^{\circ} \mathrm{C}$, um die Löslichkeit des Fusionsproteins zu gewährleisten (s. Abb. 3.1, S. 53). Für die Aufbewahrung des Zellpellets wurde die Kultur $20 \mathrm{~min}$ bei $8000 \mathrm{rpm}$ zentrifugiert und das Zellpellet bei $-80^{\circ} \mathrm{C}$ gelagert.

\section{Reinigung}

Die pelletierten Bakterien wurden in $30 \mathrm{ml}$ Lysispuffer (s. Tab. 2.1.7, S. 27), der mit einer Protease-Inhibitor-Tablette (COMPLETE ${ }^{\mathrm{TM}}$ von Roche) und einer Spatelspitze Lysozym (Roth) versetzt wurde, vollständig resuspendiert. Das Lysat wurde mittels Ultraschall aufgeschlossen und die löslichen Zellbestandteile von den unlöslichen Zellbestandteilen mit einer Zentrifugation bei $20000 \mathrm{rpm}$ (Rotor TA 30-50 Ti) für $1 \mathrm{~h}$ bei $4^{\circ} \mathrm{C}$ getrennt. Für die Affinitätsreinigung des GST-Fusionsproteins wurden $2 \mathrm{ml}$ Glutathion-Sepharose in eine $10 \mathrm{ml}$ 


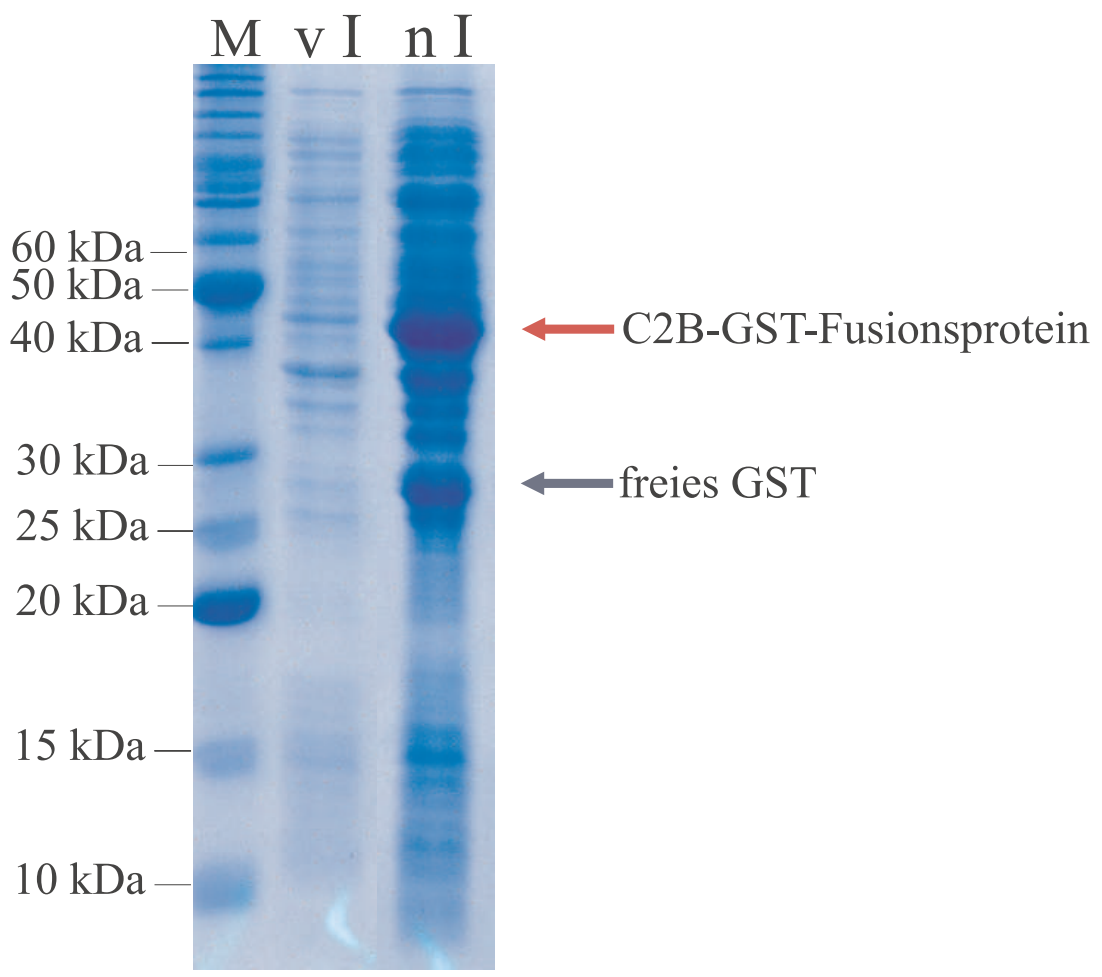

Abbildung 3.1: SDS-Gel der Expression des GST-C2B-Fusionsproteins; vI: vor Induktion, nI: nach Induktion. 


\section{Strukturbestimmung der C2B-Domäne}

Pierce Säule gegeben und mit $20 \mathrm{ml} 1 \times$ PBS-Puffer (s. Tab. 2.1.7, S. 27) gewaschen. Zur gewaschenen Glutathion-Sepharose wurde der Überstand der Zentrifugation hinzugefügt und $1 \mathrm{~h}$ bei RT mit dem Ziel inkubiert, das GST-Fusionsprotein an das Glutathion des Säulenmaterials zu binden. Anschließend wurde der Überstand der Lösung in einem Falcon-Röhrchen aufgefangen. Die Säule wurde mit $50 \mathrm{ml} 1 \times$ PBS-Puffer (s. Tab. 2.1.7, S. 27) gewaschen, um die meisten Verunreinigungen von der Säule zu spülen. Dann wurden $8 \mathrm{ml} 1 \times$ PBS-Puffer und $80 \mu 1$ Thrombin (10 U/ $\mu 1$, GE Lifescience) auf die Säule gegeben, diese verschlossen und über Nacht bei RT inkubiert, wobei die Suspension leicht geschüttelt wurde. Das Thrombin spaltete über Nacht das GST-Fusionsprotein ab, so daß die C2B-Domäne nun nicht mehr an die Glutathion-Sepharose gebunden war. Der Durchlauf der Säule wurde in einem FalconRöhrchen aufgefangen (s. Abb. 3.2, S. 55, Fraktion D für Durchlauf und S für Glutathion-Sepharose). Anschließend wurde die Säule mit $20 \mathrm{ml} 1 \times$ PBS-Puffer (s. Tab. 2.1.7, S. 27) gewaschen und der Duchlauf erneut aufgefangen. Die aufgefangenen Fraktionen nach Abspaltung des GSTs wurden mit einem 10000 MW cutoff Dialyseschlauch 6-8 h gegen 51 Puffer A (s. Tab. 2.1.7, S. 27) bei $4{ }^{\circ} \mathrm{C}$ dialysiert. Dann wurden die Fraktionen auf die HiTrap SP XL Kationenaustauschersäule ( $5 \mathrm{ml}$, GE Lifescience) aufgetragen, die zuvor mit vier Säulenvolumina Puffer B (s.Tab. 2.1.7, S. 27) und anschließend mit vier Säulenvolumina Puffer A äquilibriert worden war. Vorhandene Verunreinigungen wurden mit vier Säulenvolumina Puffer A von der Säule gewaschen. Anschließend wurde das Protein mit einem linearen Gradienten von sechs Säulenvolumina und einer Flußrate von $1 \mathrm{ml} / \mathrm{min}$ eluiert. Es wurden 1 ml-Fraktionen gesammelt. Das SDS-Gel der Kationenaustauschersäule ist in Abbildung 3.2 dargestellt.

Die Proteinfraktionen wurden vereinigt und gegen 51 Gelfiltrationspuffer (s. Tab. 2.1.7, S. 28) über Nacht bei $4{ }^{\circ} \mathrm{C}$ dialysiert. Vor der Gelfiltrationssäule wurde die Proteinlösung auf ca. $1 \mathrm{ml}$ mit einem Centricon $10000 \mathrm{MW}$ cutoff mit $3000 \mathrm{rpm}$ bei $4^{\circ} \mathrm{C}$ eingeengt. Für die Gelfiltration wurde eine Superdex75 16/60 (GE Lifescience) verwendet. Die Eluierung erfolgte mit 1.5 Säulenvolumina des Gelfiltrationspuffers (s. Tab. 2.1.7, S. 28) und einer Flußrate von $0.5 \mathrm{ml} / \mathrm{min}$. Die Proteinfraktionen 64 bis 70 (s. Abb. 3.3) wurden vereinigt und auf $21.8 \mathrm{mg} / \mathrm{ml}$ eingeengt.

\subsubsection{Se-Met Protein}

\section{Transformation und Vorkultur}

Die Transformation wurde mit $1 \mu \mathrm{l}$ des Plasmids aus einer Mini Prep und $20 \mu 1$ B834 DE3Zellen laut Protokoll (S. 29) durchgeführt. Die Amp-Agarplatte wurde über Nacht bei $37^{\circ} \mathrm{C}$ inkubiert. Anschließend wurde die Vorkultur, bestehend aus $5 \mathrm{ml}$ Medium A (S. 25), $5 \mu 1$ Methionin $(50 \mathrm{mg} / \mathrm{ml})$ und einem Klon von der Amp-Agarplatte, angesetzt. Sie inkubierte über Nacht bei $37^{\circ} \mathrm{C}$ und $200 \mathrm{rpm}$. 


\section{Thrombin}

Verdau

$\mathrm{M} \overbrace{\mathrm{D} \text { S vor } 13 \longrightarrow 23}$

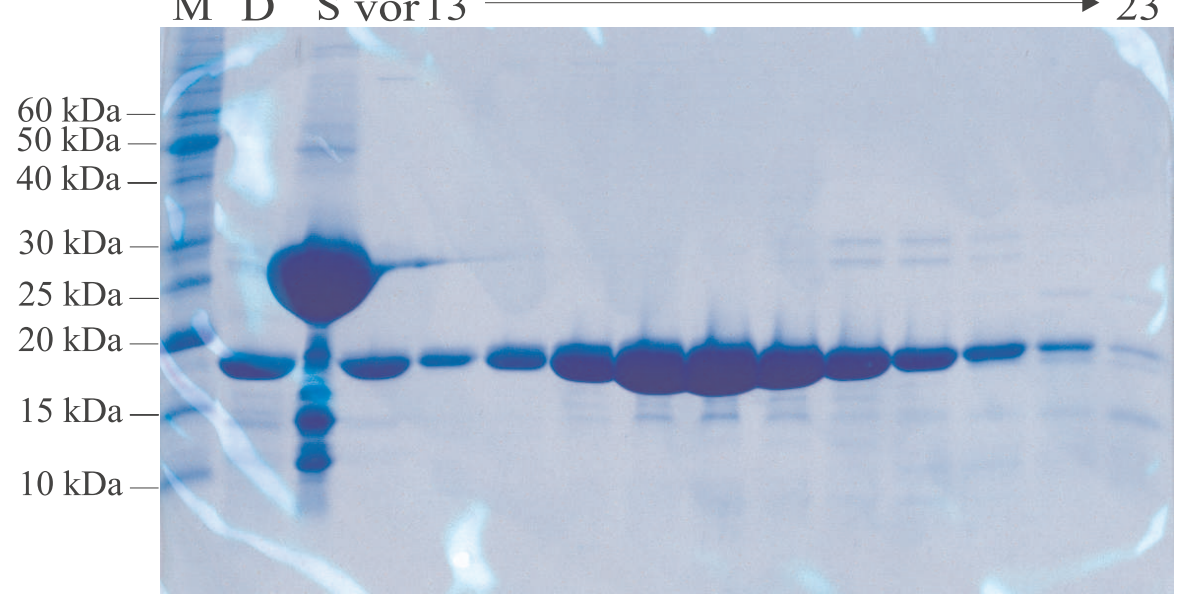

Abbildung 3.2: Reinigung des nativen C2B: SDS-Gel des Thrombinverdaus und der Kationenaustauschersäule; die Fraktion „D“ steht für Durchlauf und „S“ für an Glutathion-Sepharose gebundene Proteine, d.h. Proteine, die nach Verdau auf der Säule bleiben; die Fraktion „vor“ steht für die Proteinlösung vor der Kationenaustauschersäule und die nummerierten Fraktionen stehen für die peakFraktionen der Kationenaustauschersäule.

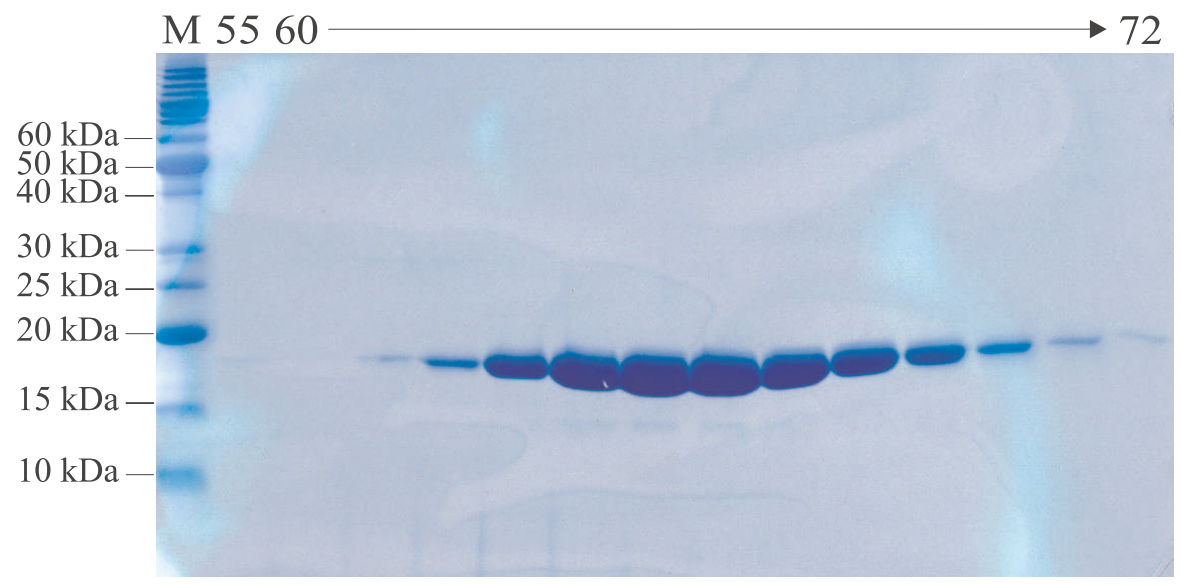

Abbildung 3.3: Reinigung des nativen C2B: SDS-Gel der Gelfiltration, die peak-Fraktionen 60 bis 72 sind aufgetragen. 


\section{Strukturbestimmung der C2B-Domäne}

\section{Expression}

Zu 11 Medium A (s. S. 25) wurden $1 \mathrm{ml}$ Methionin $(50 \mathrm{mg} / \mathrm{ml})$ und die gesamte Vorkultur von $5 \mathrm{ml}$ gegeben. Die Kultur wurde bei $37^{\circ} \mathrm{C}$ und $120 \mathrm{rpm}$ bis zu einer $\mathrm{OD}_{600}$ von 1.0 inkubiert. Dann wurde die Lösung $10 \mathrm{~min}$ bei $6000 \mathrm{rpm}$ bei $4^{\circ} \mathrm{C}$ zentrifugiert, der Überstand verworfen und das Zellpellet in 11 Medium A ohne Methionin aufgenommen. Die Kultur wurde $4 \mathrm{~h}$ bei $24{ }^{\circ} \mathrm{C}$ und $120 \mathrm{rpm}$ inkubiert. Anschließend wurde $1 \mathrm{ml} \mathrm{Se}-\mathrm{Met}(50 \mathrm{mg} / \mathrm{ml})$ hinzugegeben und für $\frac{1}{2} \mathrm{~h}$ inkubiert. Dann wurde die Expression mit $1 \mathrm{mM}$ IPTG induziert. Die Expression erfolgte über Nacht bei $24^{\circ} \mathrm{C}$.

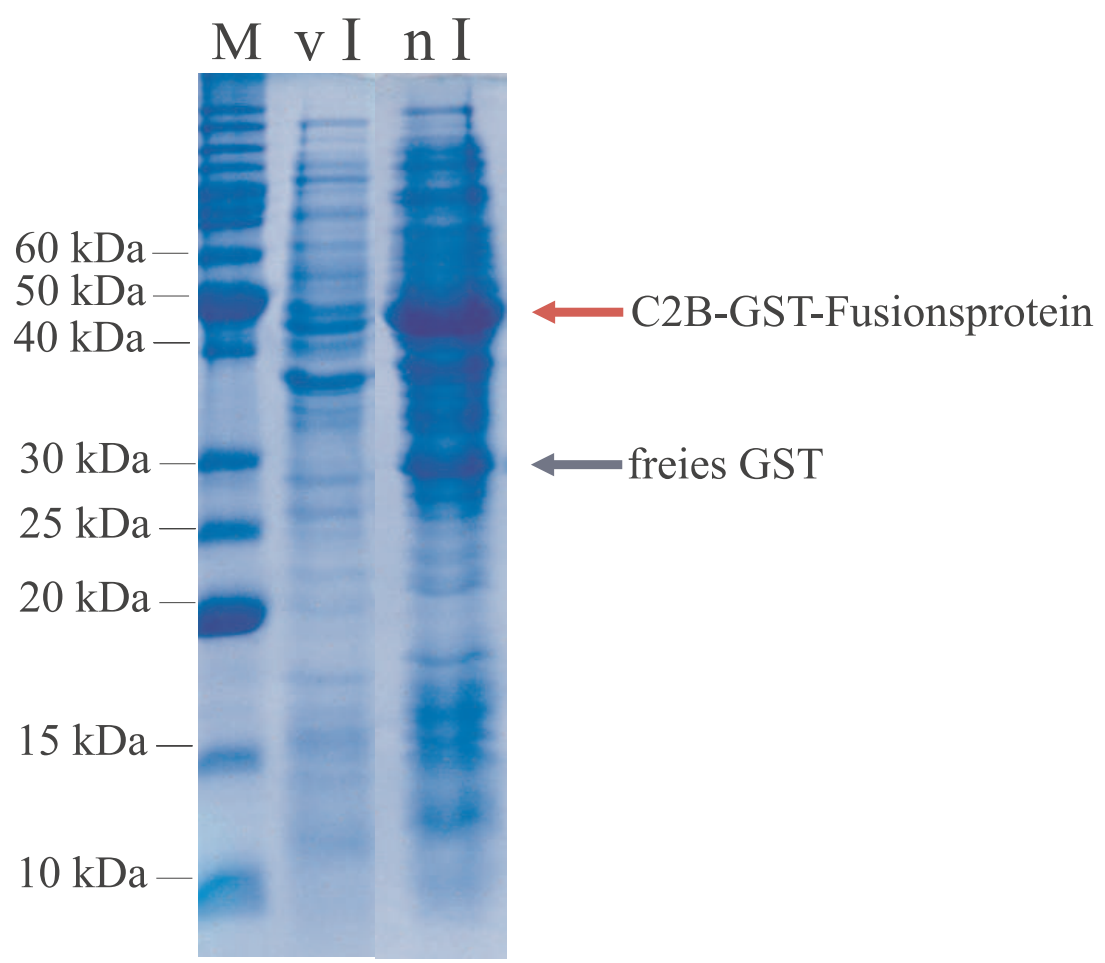

Abbildung 3.4: SDS-Gel der Expression des Se-Met Proteins; vI: vor Induktion, nI: nach Induktion.

\section{Reinigung}

Die Reinigung des Se-Met Proteins wurde analog zur Reinigung des nativen Proteins durchgeführt:

1. Glutathion-Sepharose Affinitäts-Chromatographie

2. Kationenaustauscher-Chromatographie

3. Gelfiltrations-Chromatographie 
Da die Reinigung für das Se-Met Protein identisch mit der des nativen Proteins war, sind hier keine SDS-Gele der Reinigung des Se-Met Proteins dargestellt. Das Se-Met Protein konnte auf $20.6 \mathrm{mg} / \mathrm{ml}$ eingeengt werden.

\subsection{Kristallisation und Datensammlung}

\subsubsection{Kristallisation}

Erste Kristallisationsversuche mit dem Kristallisationsroboter (Mosquito, TTP Labtech) mit einer Proteinkonzentration von $17 \mathrm{mg} / \mathrm{ml}$ zeigten, daß die C2B-Domäne bevorzugt mit PEG mittlerer Größe und mit 0.1 M Hepes bei pH 6-8 kristallisierte. Daher wurde eine $4 \times 6 \mathrm{Ma}-$ trix aufgestellt, bei der einerseits die Größe der verwendeten PEGs, andererseits der pH-Wert der Lösung variiert wurde. Die unterschiedlichen PEGs und die eingesetzten Konzentrationen waren: 20 \% PEG MME 2000, 20 \% PEG 8 000, 30 \% PEG 3 350, 30 \% PEG $1000,30 \%$ PEG 400 und $20 \%$ PEG MME 5 000. Die Kristallisationsansätze wurden sowohl bei $20^{\circ} \mathrm{C}$ als auch bei $12{ }^{\circ} \mathrm{C}$ mit einer Tropfengröße von $2 \mu 1(1 \mu$ l Proteinlösung $+1 \mu$ l Reservoirlösung) angesetzt. Nachdem nach $6 \mathrm{~d}$ keine Kristalle zu sehen waren, wurde streak seeding mit den ursprünglich mittels Roboters erhaltenen nativen Kristallen mit Hilfe eines Pferdehaares durchgeführt. Zwei Tage nach dem seeding zeigten sich die ersten Kristalle in den Tropfen mit PEG MME 2000, PEG 8000 und PEG 3350. Um ihre vollständige Größe zu erreichen, wuchsen die Kristalle ein bis zwei Wochen. Die größten Kristalle $\left(15 \times 15 \times 100 \mu \mathrm{m}^{3}\right)$ wurden in Tropfen mit $20 \%$ PEG MME 2000 und $20 \%$ PEG 8000 sowohl bei $12{ }^{\circ} \mathrm{C}$ als auch $20^{\circ} \mathrm{C}$ erhalten (s. Tab. 3.1, S. 57 und Abb. 3.5, S. 58). Für die Messung bei $100 \mathrm{~K}$ wurden die Kristalle in eine Cryolösung, bestehend aus Reservoirlösung und $10 \%$ Glycerin, überführt, dann in einer Schlaufe montiert und anschließend in flüssigem Stickstoff schockgefroren. Die Messung erfolgte am Deutschen Elektronen-Synchrotron (DESY) in Hamburg. Dort beugten die Kristalle bis 1.6 Å. Für die Kristallisation der C2B-Domäne mit Kalzium wurde die Proteinlö-

\begin{tabular}{l|l}
\hline Bedingung 1 & Bedingung 2 \\
\hline 20\% PEG MME 2 000 & 20 \% PEG 8 000 \\
0.1 M Hepes pH 8.5 & 0.1 M Hepes pH 8.5 \\
\hline
\end{tabular}

Tabelle 3.1: Kristallisationsbedingungen der nativen C2B-Domäne

sung, die ursprünglich auf $21.8 \mathrm{mg} / \mathrm{ml}$ eingeengt worden war, mit dem Puffer der Gelfiltration (s. S. 28) und 0.1 bzw. 0.2 $\mathrm{M} \mathrm{CaCl}_{2}$-Lösung auf $17 \mathrm{mg} / \mathrm{ml}$ verdünnt. Mit dieser Proteinlösung wurden Kristallisationsansätze um die Bedingungen (s. Tab. 3.1, S. 57) bei $12^{\circ} \mathrm{C}$ angesetzt. Nach $4 \mathrm{~d}$ wurde mit den nativen Kristallen, die ohne $\mathrm{Ca}^{2+}$ gewachsen waren (Raumgruppe 

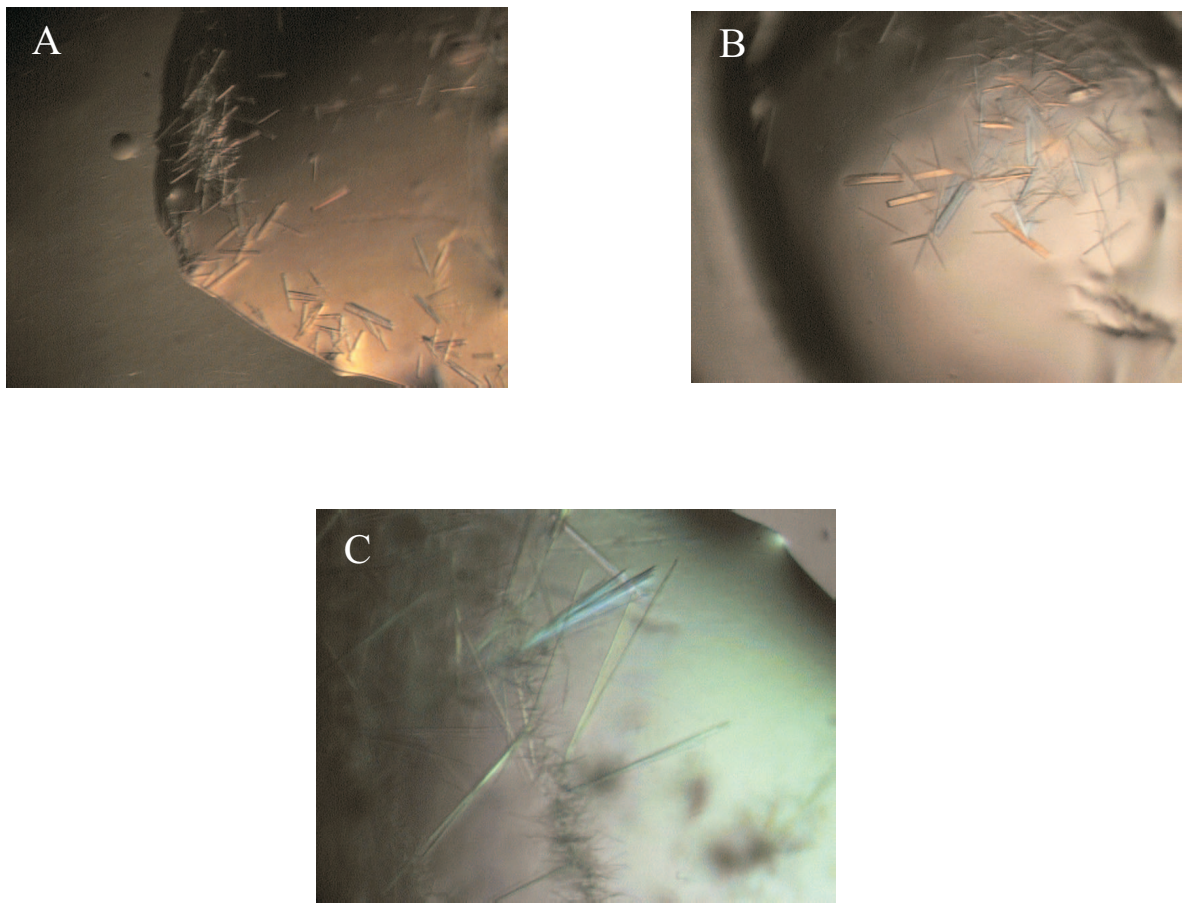

Abbildung 3.5: Kristalle der C2B-Domäne: a) native Kristalle $\left(15 \times 15 \times 100 \mu \mathrm{m}^{3}\right)$, b) Se-Met Kristalle $\left(25 \times 25 \times 100 \mu \mathrm{m}^{3}\right)$ und c) Kristalle mit $\mathrm{Ca}^{2+}\left(15 \times 15 \times 200 \mu \mathrm{m}^{3}\right)$

$\mathrm{P} 2{ }_{1} 2_{1} 2$ ), streak seeding durchgeführt. Die Kristalle wuchsen innerhalb einer Woche zu ihrer vollen Größe heran. In Tabelle 3.2 (S. 58) sind die Kristallisationsbedingungen aufgeführt, die zu den besten Kristallen führten.

Auch diese Kristalle wurden vor der Messung in eine Cryolösung, bestehend aus Reservoirlösung mit $10 \%$ Glycerin, überführt, bevor sie in flüssigem Stickstoff gefroren wurden. Die

\begin{tabular}{l|l}
\hline Bedingung mit PEG MME 2000 & Bedingung mit PEG 8000 \\
\hline $30 \%$ PEG MME 2000 & $25 \%$ PEG 8000 \\
$0.1 \mathrm{M}$ Hepes pH 8.0 & $0.1 \mathrm{M} \mathrm{Hepes} \mathrm{pH} \mathrm{7.6}$ \\
$0.2 \mathrm{M} \mathrm{CaCl}_{2}$ in der Proteinlösung & $0.2 \mathrm{M} \mathrm{CaCl}_{2}$ in der Proteinlösung \\
\hline
\end{tabular}

Tabelle 3.2: Kristallisationsbedingungen der nativen C2B-Domäne mit $\mathrm{Ca}^{2+}$

Kristallisation des Se-Met Proteins wurde analog zum nativen Protein durchgeführt, wobei für die Kristallisationsansätze eine Proteinkonzentration von $20.6 \mathrm{mg} / \mathrm{ml}$ verwendet wurde. Nach 2 d wurden die Tropfen mit ursprünglich mittels Roboters erhaltenen Kristallen mit einem Pferdehaar geseedet. Die Kristalle wuchsen innerhalb einer Woche bis zu einer Größe von $25 \times 25 \times 100 \mu \mathrm{m}^{3}$. Die Kristalle aus Bedingung 2 (s. Tab. 3.1, S. 57) streuten am Syn- 
chrotron Swiss Light Source (SLS) in Brugg bis 1.2 $\AA$. Vor der Messung wurden sie in eine Cryolösung, die aus Reservoirlösung und $10 \%$ Glycerin bestand, transferiert und in flüssigem Stickstoff gefroren.

\subsubsection{Datensammlung}

Zuerst wurde für die Messung der Se-Met Kristalle ein Fluoreszenz-Scan durchgeführt (s. Anhang S. 118), damit die Wellenlängen für den peak und inflection Datensatz festgelegt werden konnten.

Dann wurden erst die peak Daten und anschließend die inflection Daten mit einem SeMet Kristall gesammelt. Mit einem zweiten Se-Met Kristall wurden hochaufgelöste Daten bei einer Wellenlänge im high energy remote Bereich erhalten. Die Daten der MADDatensammlung sind in Tabelle 3.3 (S. 59) aufgeführt.

\begin{tabular}{llll}
\hline Datensatz & peak & inflection & high remote \\
\hline beamline & & SLS & \\
& & PX 6 & \\
Wellenlänge $(\AA)$ & 0.9792 & 0.9796 & 0.9500 \\
Detektor & MAR CCD & MAR CCD & MAR CCD \\
Raumgruppe & $\mathrm{P} 2{ }_{1} 2{ }_{1} 2$ & $\mathrm{P} 2{ }_{1} 2{ }_{1} 2$ & $\mathrm{P} 2{ }_{1} 2{ }_{1} 2$ \\
Zellparameter $(\AA)$ & & $\mathrm{a}=53.898$ & \\
& & $\mathrm{~b}=60.043$ & \\
& & $\mathrm{c}=41.928$ & \\
Auflösungsgrenze $(\AA)$ & $1.91(2.01-1.91)$ & $1.92(2.02-1.92)$ & $1.28(1.38-1.28)$ \\
Unabhängige Reflexe & 10738 & 10524 & 33387 \\
Redundanz & $7.07(6.71)$ & $6.17(3.90)$ & $1.72(1.16)$ \\
Vollständigkeit $(\%)$ & $98.6(96.9)$ & $96.9(87.9)$ & $94.2(72.7)$ \\
mittleres I / $\sigma(\mathrm{I})$ & $18.62(12.89)$ & $15.69(7.74)$ & $14.38(2.84)$ \\
$\mathrm{R}_{\text {int }}(\%)$ & $7.07(12.90)$ & $8.32(14.84)$ & $2.92(21.00)$ \\
\hline
\end{tabular}

Tabelle 3.3: Datensammlung der Se-Met Kristalle der C2B-Domäne

Auch konnte ein Datensatz eines nativen Kristalls ohne $\mathrm{Ca}^{2+}$ in der Kristallisationsbedingung aufgenommen werden (Raumgruppe P2 ${ }_{1}{ }_{1} 2$ ). Dieser war jedoch im Gegensatz zu dem Se-Met Datensatz schlechter, so daß er im Nachhinein für weitere Berechnungen keine Verwendung fand. Desweiteren wurden Daten eines nativen Kristalls, der in Kristallisationsbedingungen mit $\mathrm{Ca}^{2+}$ gewachsen war, gesammelt (Raumgruppe P2 1 ). Die Daten der nativen Kristalle sind in Tabelle 3.4 (S. 60) aufgelistet. 


\begin{tabular}{lll}
\hline Datensatz & nativ ohne $\mathrm{Ca}^{2+}$ & nativ mit Ca \\
\hline beamline & DESY Hamburg, & SLS, \\
& BW 6 & PX 6 \\
Wellenlänge $(\AA)$ & 1.0500 & 0.9536 \\
Detektor & MAR CCD & MAR CCD \\
Raumgruppe & P2 ${ }_{1} 212$ & $\mathrm{P} 21$ \\
Zellparameter $(\AA)$ & $\mathrm{a}=53.898$ & $\mathrm{a}=40.069$ \\
& $\mathrm{~b}=60.043$ & $\mathrm{~b}=59.606$ \\
& $\mathrm{c}=41.928$ & $\mathrm{c}=66.385$ \\
& & $\beta=103.89$ \\
Auflösungsgrenze $(\AA)$ & $1.58(1.67-1.58)$ & $1.85(1.94-1.85)$ \\
Unabhängige Reflexe & 18693 & 25345 \\
Redundanz & $5.88(2.22)$ & $6.44(4.43)$ \\
Vollständigkeit $(\%)$ & $96.5(80.7)$ & $97.2(93.9)$ \\
mittleres I / $\sigma(\mathrm{I})$ & $14.53(2.33)$ & $12.50(3.07)$ \\
$\mathrm{R}_{\text {int }}(\%)$ & $7.83(39.37)$ & $8.86(40.06)$ \\
\hline
\end{tabular}

Tabelle 3.4: Datensammlung der nativen Kristalle der C2B-Domäne

\subsection{Strukturlösung und -verfeinerung}

\subsubsection{Die C2B-Struktur in der Raumgruppe $P 2_{1} 2_{1} 2$}

Die Struktur von C2B konnte anhand der C2B Kristalle, die ohne $\mathrm{Ca}^{2+}$ gewachsen waren, mit Hilfe des anomalen Signals der Selenatome gelöst werden. Allerdings lag in den einzelnen Datensätzen bei den Wellenlängen des peaks, der inflection und der high energy remote nur ein schwaches aber signifikantes anomales Signal vor (s. Auszüge des Programms XPREP [74], S. 61), so daß alle drei Datensätze in XPREP [74] korreliert werden mußten, um das Signal vom Rauschen der Daten zu extrahieren (s. S. 61). Ein gutes anomales Signal, welches sich durch einen anomalen Korrelationskoeffizienten von $>30 \%$ auszeichnet [89], war bis $2.4 \AA$ A vorhanden.

Da trotz ausreichendem, anomalem Signal keine Strukturlösung erhalten werden konnte, wurden zuerst die Datensätze der Se-Met Kristalle in XPREP [74] eingelesen und gemittelt, wobei die Friedel Paare nicht gemittelt wurden. Als Referenzdatensatz diente der high energy remote Datensatz, so daß die Zellachsenaufstellung des high energy remote Datensatz auf die beiden anderen Datensätze übertragen werden konnte. Der $\mathrm{R}_{\text {int }}$ betrug $12.70 \%$. Die Schweratompositionen wurden mit Hilfe der Se-SAD Methode mit dem Programm SHELXD $[90,91]$ bestimmt. Hierbei zeigte sich, daß von den vier erwarteten Selenatomen nur zwei fast 


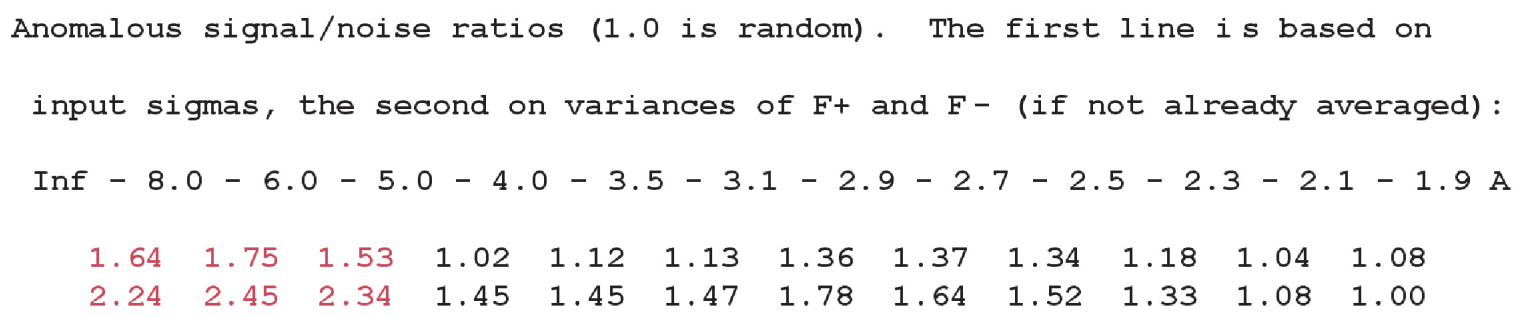

Abbildung 3.6: Anomales I/sigma für den peak Datensatz

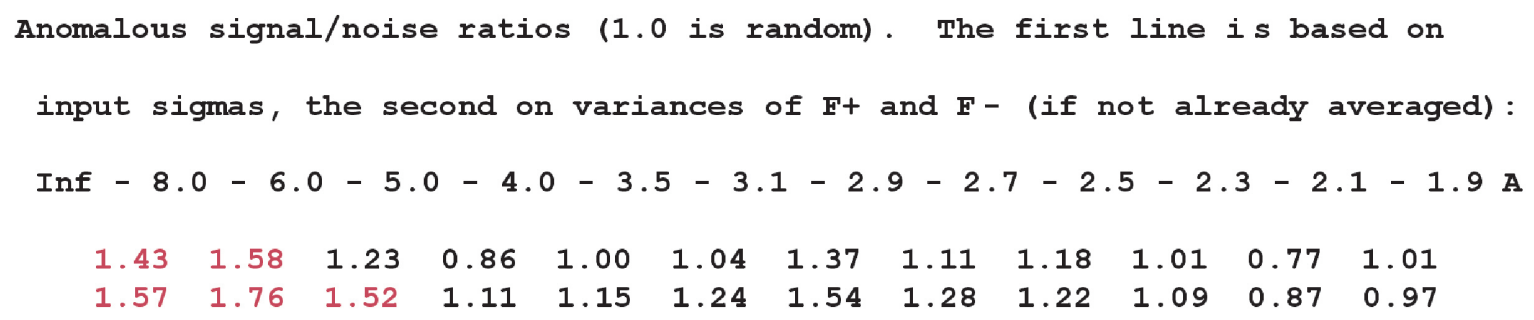

Abbildung 3.7: Anomales I/sigma für den inflection Datensatz

\begin{abstract}
Anomalous signal/noise ratios (1.0 is random). The first line $i s$ based on input sigmas, the second on variances of $F+$ and $F-$ (if not already averaged): Inf $-8.0-6.0-5.0-4.0-3.5-3.0-2.5-2.0-1.8-1.6-1.4-1.2 \mathrm{~A}$ $\begin{array}{llllllllllll}1.68 & 1.42 & 1.32 & 1.07 & 0.97 & 1.00 & 1.09 & 1.07 & 1.10 & 1.09 & 1.04 & 1.10\end{array}$
\end{abstract}

Abbildung 3.8: Anomales I/sigma für den high remote Datensatz

\begin{tabular}{|c|c|c|c|c|c|c|c|c|c|c|c|}
\hline Inf -8 & $0-6$. & $0-5$. & $0-4$ & $0-3$ & $5-3$ & $1-2$. & $9-2$ & $7-2$ & $5-2$ & $3-2$ & $1-1.9 \mathrm{~A}$ \\
\hline 42.7 & 68.6 & 70.5 & 35.0 & 42.4 & 47.1 & 49.1 & 45.6 & 37.7 & 22.7 & 13.1 & 10.3 \\
\hline 81.3 & 92.5 & 86.8 & 74.4 & 69.0 & 66.2 & 67.8 & 60.8 & 43.1 & 29.8 & 16.5 & 17.1 \\
\hline 64.6 & 70.9 & 76.9 & 40.9 & 57.2 & 54.5 & 62.7 & 60.7 & 57.7 & 48.4 & 33.0 & 27.7 \\
\hline
\end{tabular}

Abbildung 3.9: Korrelation zwischen peak, inflection und high remote Datensatz 


\section{Strukturbestimmung der C2B-Domäne}

vollständig besetzte Selenatome gefunden wurden. Wie sich im Nachhinein herausstellte, waren die übrigen zwei Selenatome in flexiblen Regionen des Proteins lokalisiert. Anschließend wurde die Händigkeit der Elektronendichtekarte mit SHELXE [83] bestimmt.

Außerdem wurden die Se-MAD Datensätze in hkl2map [92] eingelesen, wobei hier darauf geachtet werden mußte, daß im Vorfeld in XPREP [74] die richtige Zellachsenaufstellung gewählt worden war. Da der Se-Met Kristall, von dem die peak und inflection Daten aufgenommen wurden, entlang seiner 2-zähligen Achse in der Schlaufe montiert worden war und somit die 2-zählige Achse nicht mehr von einer $21_{1}$-Achse unterschieden werden konnte, war die Bestimmung der Zellachsenaufstellung schwierig. Bei der Zellbestimmung des high energy remote Datensatzes war die Zellachsenaufstellung eindeutig, da dieser Kristall nicht entlang der 2-zähligen Achse montiert worden war. Daher mußte darauf geachtet werden, daß die Zellachsenaufstellung des high energy remote Datensatzes für den peak und den inflection Datensatz übernommen worden war. Nur bei der richtigen Zellachsenaufstellung von $\mathrm{a}=53.898 \AA, \mathrm{b}=60.043 \AA$ und $\mathrm{c}=41.928 \AA$ konnte eine interpretierbare Elektronendichtekarte anhand der Se-MAD Methode mit einem guten anomalen Signal über $30 \%$ bis $2.4 \AA$ A bestimmt werden. Auch in diesem Fall wurden eindeutig zwei Schweratompositionen gefunden.

Desweiteren wurde das Modell von C2B in ARP/wARP [93] mit Hilfe der Elektronendichte und der Aminosäure-Sequenz der Struktur mit je 10 Zyklen des automatischen Modellbauens, die mit je 5 Verfeinerungszyklen alterniert wurden, gebaut. Hierbei konnten nach 50 Zyklen 80.6 \% der Sequenz (gesamte Sequenz: 519 bis 684) - d.h. 131 Aminosäuren - modelliert werden. Folgende Bereiche des Proteins fehlten in dem anfänglichen Modell:

- Aminosäuren 519-538

- Aminosäuren 585-592

- Aminosäuren 678-684

Der R-Wert betrug $22.9 \%$, der $\mathrm{R}_{\text {free }} 27.0 \%$. Das Modell aus ARP/wARP [93] wurde anschließend zunächst als starre Gruppe in REFMAC5 [85,94] mit 20 Zyklen verfeinert. Danach wurde eine Verfeinerung mit restraints in REFMAC5 [85,94] mit 10 Verfeinerungszyklen durchgeführt. Die Struktur konnte mit Hilfe von REFMAC5 [85,94] und COOT [84] soweit vervollständigt werden, daß nur noch die flexiblen Bereiche, die von Aminosäuren 519 bis 523, 532 bis 537 und 678 bis 684 reichten, fehlten. Diese Bereiche waren in der Elektronendichte nicht zu sehen und wurden daher nicht modelliert. Anschließend wurde mit SHELXL [86] verfeinert. Hierbei wurde zuerst die Besetzung der Selenatome verfeinert, da sie aufgrund der starken Strahlung an der Absorptionskante von Se unter Strahlenschäden litten. Die Besetzung des Selenatoms in Se-Met549 betrug 65.5 \%, in Se-Met570 55.3 \% nach der Verfeinerung. Anschließend wurde die Besetzung des flexiblen Bereichs von Aminosäuren 587 
bis 590 mit verschiedenen Variablen berechnet. Es zeigte sich jedoch, daß dieser Bereich zu flexibel war und damit zu wenig Elektronendichte aufwies, so daß die Aminosäuren 587 bis 590 nicht in das endgültige Modell eingebaut werden konnten. Das endgültige Modell von C2B beinhaltete die Aminosäuren 524 bis 530, 538 bis 587 und 591 bis 677. Die Struktur konnte anisotrop verfeinert werden und $\mathrm{H}$-Atome eingefügt werden.

Ein Vergleich der Elektronendichtekarten nach der Strukturlösung mit SHELXE sowie nach der Strukturlösung mit SHELXE inklusive der free lunch Methode und nach der Verfeinerung mit SHELXL [86] ist in Abbildung 3.10 (S. 63) zu sehen. Bei der free lunch Methode wurden nicht gemessene Daten bis $1.0 \AA$ A extrapoliert.

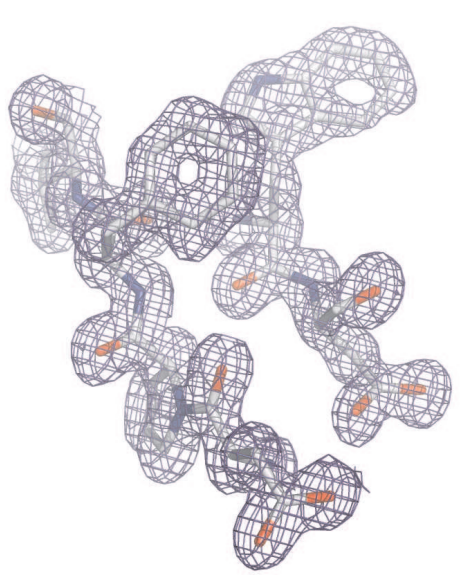

a)

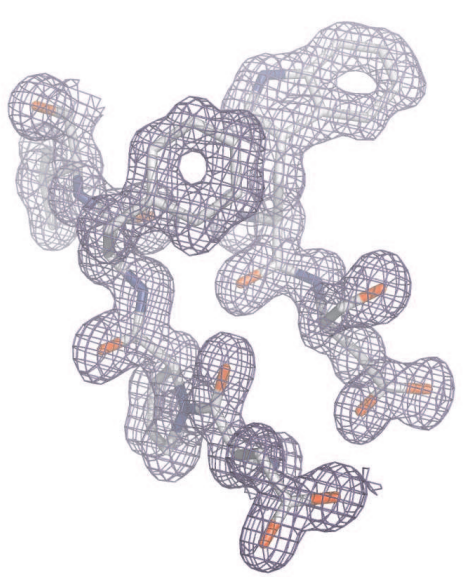

b)

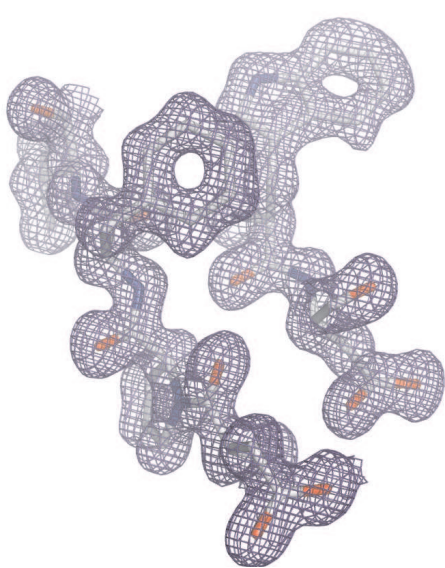

c)

Abbildung 3.10: Vergleich der Elektronendichtekarten: a) SHELXE, b) SHELXE mit der free lunch Methode und c) nach der Verfeinerung mit SHELXL [86]

Die verfeinerte C2B-Struktur der Se-Met Kristalle (in P2 ${ }_{1} 2{ }_{1}$ ) wurde mit der C2B-Struktur der nativen Kristalle (in P $22_{1} 2$ ), die ohne Kalziumionen kristallisiert worden waren, verglichen, um mögliche Veränderungen durch die Se-Methionine festzustellen. Da jedoch beide Strukturen strukturell identisch waren, entspricht die C2B-Struktur des Se-Met Kristalls der natürlichen Struktur der C2B-Domäne. Die Daten der Strukturverfeinerung des Se-Met Kristalls sind in Tabelle 3.5 (S. 64) zusammengefaßt.

\subsubsection{Die C2B-Struktur in der Raumgruppe $\mathbf{P} 2_{1}$}

Die C2B-Struktur in der monoklinen Raumgruppe P2 2 konnte mit der Methode des molekularen Ersatzes anhand der C2B-Struktur aus der orthorhombischen Raumgruppe P $2{ }_{1} 2{ }_{1} 2$ ermittelt werden. Hierzu wurde das Modell der orthorhombischen Struktur dahingehend modifiziert, daß die Kalziumionen, die Wassermoleküle und die Aminosäuren 524 bis 531 ent- 
3 Strukturbestimmung der C2B-Domäne

\begin{tabular}{ll}
\hline $\mathrm{R}_{\text {Kristall }}$ & 14.40 \\
$\mathrm{R}_{\text {Free }}$ & 19.37 \\
Anzahl der Proteinatome & 1123 \\
Anzahl der Heteroatome & 2 \\
Anzahl der Wasseratome & 68 (ein Wassermolekül nur halb besetzt) \\
Mittlerer B-Wert $\left(\AA^{2}\right)$ & 18.985 \\
der Hauptkette & 15.726 \\
der Seitenketten & 22.027 \\
Standardabweichung & \\
der Bindungslängen $(\AA)$ & 0.011 \\
der Bindungswinkelabstände $(\AA)$ & 0.030 \\
Ramachandran Analyse $(\%)$ & \\
am meisten favorisierte Region & 89.6 \\
erlaubte Region & 10.4 \\
generell erlaubte Region & 0 \\
unerlaubte Region & 0 \\
\hline
\end{tabular}

Tabelle 3.5: Verfeinerung der C2B-Struktur in der Raumgruppe $\mathrm{P} 2{ }_{1} 2{ }_{1} 2$

fernt wurden. Die Strukturlösung in der Raumgruppe P2 2 mit dem Programm PHASER [95] ergab zwei Moleküle der C2B-Domäne, vier Kalziumionen und ein Phosphatmolekül in der asymmetrischen Einheit. Zuerst wurden die zwei Moleküle der C2B-Domäne mit REFMAC5 [85,94] und COOT [84] komplettiert, wobei das erste Monomer aus den Aminosäuren 524 bis 535, 539 bis 586 und 590 bis 678 und das zweite Monomer aus den Aminosäuren 525 bis 532 und 539 bis 678 zusammengesetzt war. In der weiteren Verfeinerung mit SHELXL [86] wurden im ersten Monomer die Besetzungen folgender Aminosäuren verfeinert: Aminosäure 534 auf $50 \%$ und Aminosäure 540 auf 60 \%. Die Daten der Verfeinerung sind in Tabelle 3.6 (s. S. 65) zusammengestellt. 


\begin{tabular}{ll}
\hline $\mathrm{R}_{\text {Kristall }}$ & 19.48 \\
$\mathrm{R}_{\text {Free }}$ & 26.75 \\
Anzahl der Proteinatome & 2314 \\
Anzahl der Heteroatome & 9 \\
Anzahl der Wasseratome & 77 \\
Mittlerer B-Wert $\left(\AA^{2}\right)$ & 28.618 \\
der Hauptkette & 25.973 \\
der Seitenketten & 31.210 \\
Standardabweichung & \\
der Bindungslängen $(\AA)$ & 0.005 \\
der Bindungswinkelabstände $(\AA)$ & 0.021 \\
Ramachandran Analyse $(\%)$ & \\
am meisten favorisierte Region & 87.7 \\
erlaubte Region & 11.5 \\
generell erlaubte Region & 0.4 \\
unerlaubte Region & 0.4 \\
\hline
\end{tabular}

Tabelle 3.6: Verfeinerung der C2B-Struktur in der Raumgruppe $\mathrm{P}{ }_{1}$ 


\section{Ergebnisse}

\subsection{Struktur der C2B-Domäne in $P 2_{1} 2_{1} 2$}

\subsubsection{Strukturbeschreibung der C2B-Domäne}

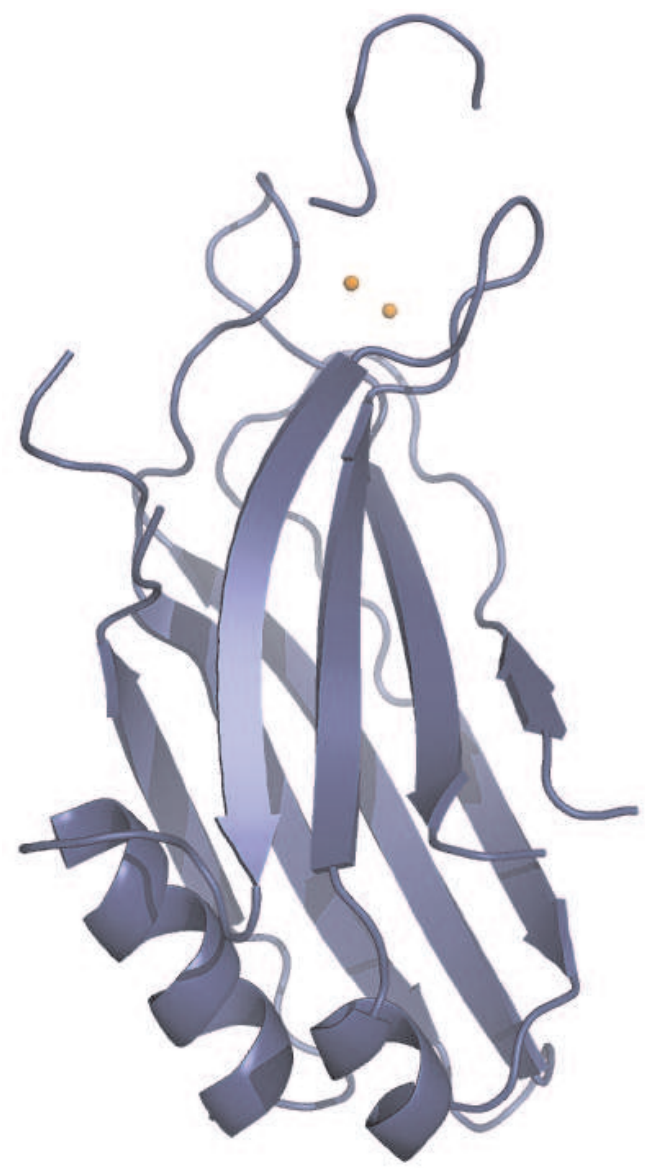

a)

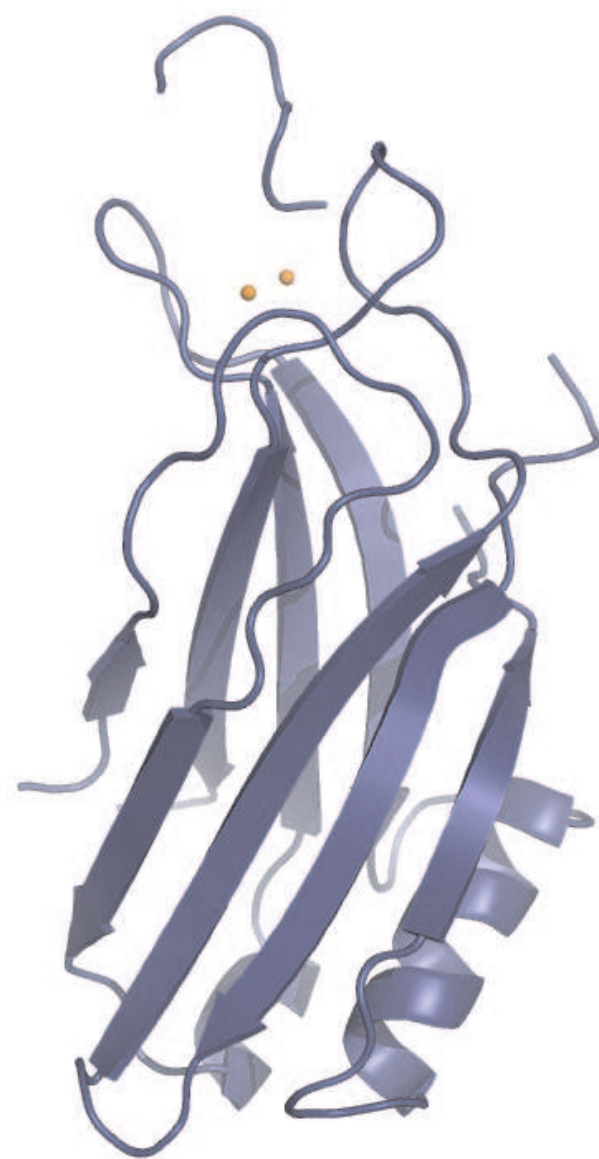

b)

Abbildung 4.1: Struktur der C2B-Domäne in $\mathrm{P} 2{ }_{1} 2{ }_{1} 2$; Darstellung b) ist um $180^{\circ}$ zu a) gedreht; die zwei Kalziumionen sind mit orange-farbenen Kugeln dargestellt. 
In der asymmetrischen Einheit in der Raumgruppe $\mathrm{P} 2{ }_{1} 2{ }_{1} 2$ liegen ein Monomer der C2B-Struktur, zwei Kalziumionen und 68 Wassermoleküle vor. Die Tertiärstruktur der C2B-Domäne besteht aus einer $\beta$-Faltblattstruktur, wobei sich jeweils vier antiparallele $\beta$ Faltblätter auf beiden Seiten befinden und ein $\beta$-Sandwich formen. An der entgegengesetzten Seite der Kalziumbindungsregion befinden sich zwei $\alpha$-Helices. Die kürzere $\alpha$-Helix verbindet $\beta$-Faltblatt fünf mit sechs, die lange $\alpha$-Helix verbindet $\beta$-Faltblatt sieben mit acht. Oberhalb der Kalziumbindungstasche bildet der N-Terminus der Sequenz eine Art „Deckel“ auf der Kalziumbindungsstelle und vervollständigt damit die Koordinationssphäre der Kalziumionen. Überraschenderweise konnten sogar in der Struktur, die ohne $\mathrm{Ca}^{2+}$-Ionen gereinigt und kristallisiert wurde, zwei $\mathrm{Ca}^{2+}$-Ionen lokalisiert werden. Der „Deckel“ in der C2B-Struktur in der Raumgruppe $\mathrm{P} 2{ }_{1} 2{ }_{1} 2$ besteht aus einer loop-Region.

\subsubsection{Die $\mathrm{Ca}^{2+}$-Bindungsstelle in $\mathrm{P}_{1} 2_{1} 2$}

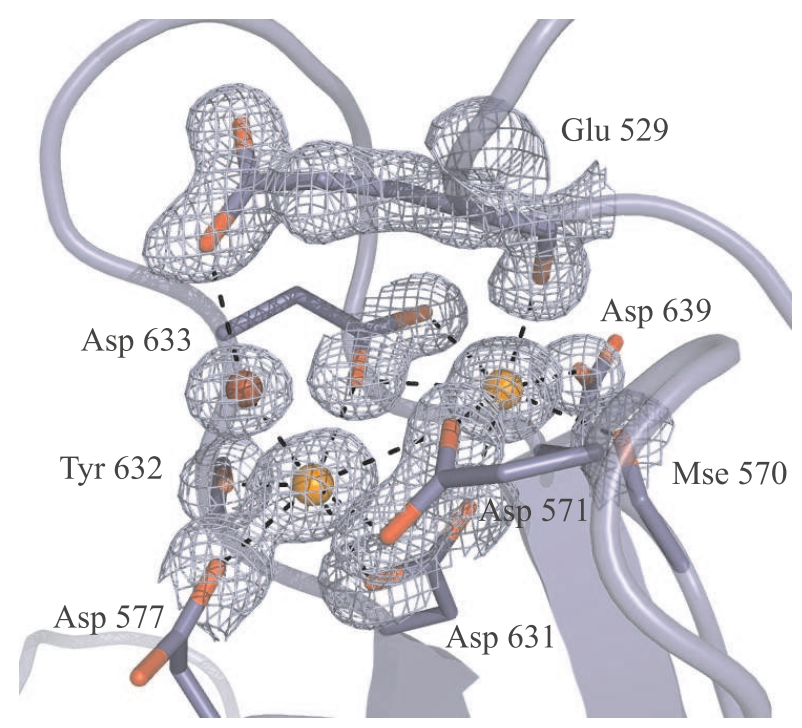

Abbildung 4.2: Kalzium-Bindungstasche der C2B-Struktur in $\mathrm{P} 2{ }_{1} 2_{1} 2$; die an der Koordination der beiden Kalziumionen beteiligten Aminosäuren sind gekennzeichnet, die beiden orange-farbenen Kugeln stellen die Kalziumionen dar, während die rote Kugel für das einzige koordinierende Wassermolekül steht.

Die beiden Kalziumionen sind von acht Aminosäuren und einem Wassermolekül umgeben. Das erste Kalziumion (Ca1) ist von einer Hauptketten-Carbonylgruppe der Aminosäuren Se-Met570 und Glu529 und den Sauerstoffatomen OD2 von Asp631, Asp633 und Asp639 und den Sauerstoffatomen OD1 von Asp571 und Asp633 umgeben. Die Umgebung des zweiten Kalziumions ( $\mathrm{Ca} 2$ ) besteht aus einem Wassermolekül, einer Hauptketten-Carbonylgruppe 
der Aminosäure Tyr632, den Sauerstoffatomen OD1 der Aminosäuren Asp571, Asp631 und Asp633 und den Sauerstoffatomen OD2 der Aminosäuren Asp571 und Asp577. Die beiden Kalziumionen sind somit pentagonal bipyramidal umgeben. Die $\mathrm{Ca}^{2+}$-Bindungsstelle ist in Abbildung 4.2 (S. 67) zu sehen. In dieser Abbildung wird deutlich, daß Glu529 in zweierlei Hinsicht wichtig für die Bindung von Kalziumionen ist. Einerseits geht es mit seiner Hauptketten-Carbonylgruppe eine direkte Bindung an das erste Kalziumion (Ca1) ein, andererseits koordiniert es zusätzlich mit seiner Seitenkette an das Wassermolekül, welches das zweite Kalziumion (Ca2) koordiniert.

\subsection{Struktur der C2B-Domäne in $\mathrm{P} 2_{1}$}

\subsubsection{Strukturbeschreibung der C2B-Domäne}

Die asymmetrische Einheit der C2B-Domäne in $\mathrm{P} 2{ }_{1}$ beinhaltet zwei Monomere der C2B Domäne, vier $\mathrm{Ca}^{2+}$-Ionen, ein Phosphatmolekül und 77 Wassermoleküle. Die Tertiärstruktur besteht wie die Struktur der C2B-Domäne in $\mathrm{P} 2{ }_{1} 2{ }_{1} 2$ aus einem antiparallelen, achtsträngigen $\beta$-Sandwich, welches sich aus je vier antiparallelen $\beta$-Faltblättern zusammensetzt. Der große Unterschied zu der Struktur in der Raumgruppe P $2_{1} 2_{1} 2$ ist, daß der N-Terminus oberhalb der Kalziumbindungsstelle eine $\alpha$-Helix bildet. Das Phosphatmolekül bildet zwei Wasserstoffbrücken aus, eine zu dem Hauptketten-NH von Phe612 mit einer Distanz von $2.68 \AA$ und eine zu einer Hauptketten-Carbonylgruppe von Gly652 eines symmetrieäquivalenten Monomers B mit einer Distanz von $3.03 \AA$.

\subsubsection{Vergleich der beiden Monomere}

Das Monomer A beinhaltet die Sequenz von Aminosäuren 524 bis 535, 539 bis 586 und 590 bis 678. Im Monomer B liegt die Sequenz von Aminosäuren 525 bis 532 und 539 bis 678 vor. Der loop der Aminosäuren 532 bis 540 ist sehr flexibel, daher konnte er in beiden Monomeren nicht in seiner vollen Länge modelliert werden. Im Monomer A konnte der loop 532 bis 539 bis auf drei Aminosäuren gebaut werden, es mußten jedoch die Besetzungen der Aminosäuren 534 und 540 mit SHELXL [86] verfeinert werden. Die beiden Monomere sind zum Vergleich in Abbildung 4.3 (S. 69) nebeneinander dargestellt.

Desweiteren fällt auf, daß in Monomer A der loop der Aminosäuren 587 bis 589 fehlt, da dort keine Elektronendichte vorhanden war. In Monomer B hingegen ist dieser loop vollständig in der Elektronendichte sichtbar und konnte ohne Lücken gebaut werden. Für C2BDomänen ist im Allgemeinen dieser loop nicht in der Elektronendichte sichtbar. Monomer B stellt in dieser Hinsicht eine Ausnahme zu den bekannten C2B Strukturen dar. 


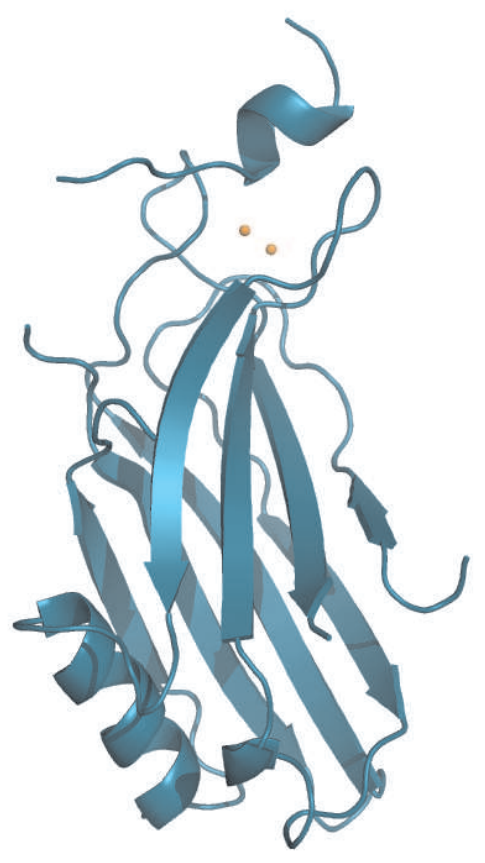

a)

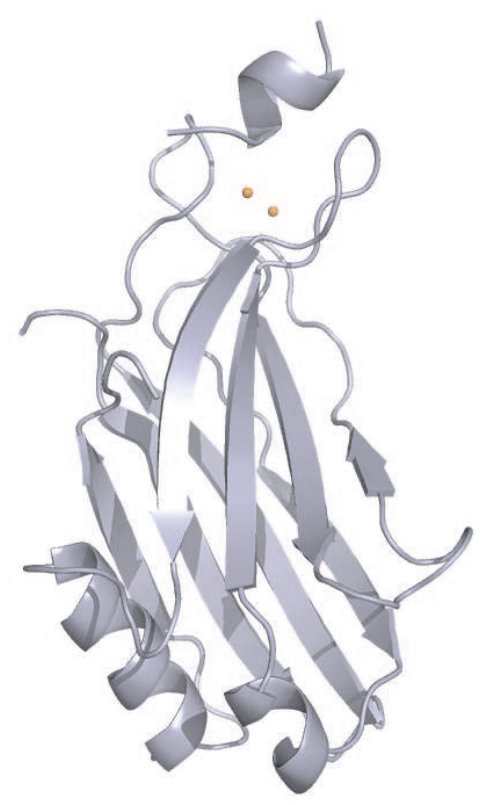

c)

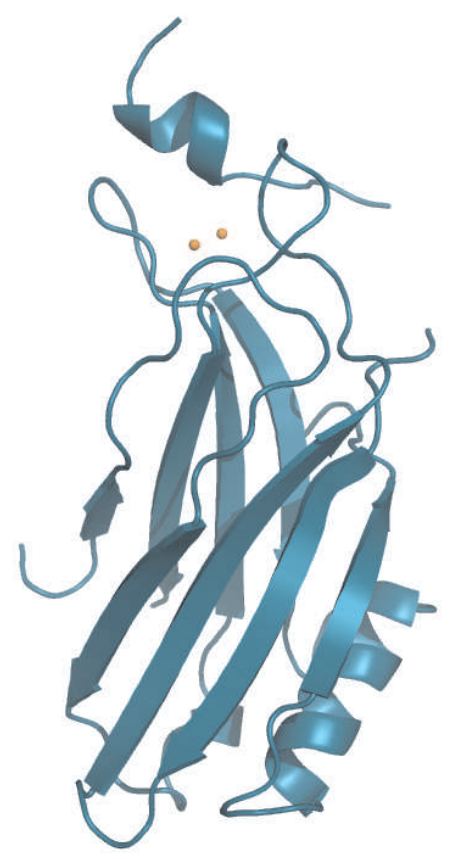

b)

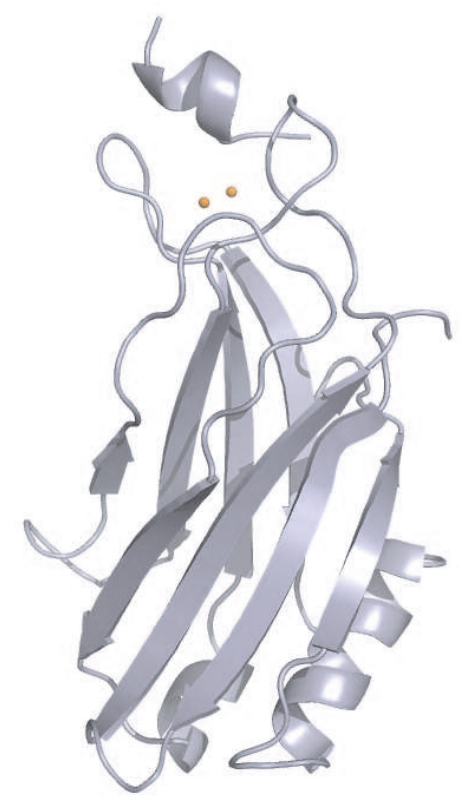

d)

Abbildung 4.3: Struktur von a) Monomer A und b) Monomer A um $180^{\circ}$ gedreht, c) Monomer B der C2B-Domäne und d) Monomer B um $180^{\circ}$ gedreht; die orange-farbenen Kugeln stehen für die Kalziumionen. 


\section{Ergebnisse}

Gemeinsam ist den beiden Monomeren, daß der N-Terminus oberhalb der Kalziumbindungstasche eine $\alpha$-Helix ausbildet. Diese Art Deckel ist in der Struktur mit $\mathrm{Ca}^{2+}$-Ionen in beiden Monomeren gut lokalisiert, wobei in Monomer B die Sequenz des N-Terminus erst ab Aminosäure 525 sichtbar ist.

\subsubsection{Die $\mathrm{Ca}^{2+}$-Bindungsstelle in $\mathrm{P}_{1}$}

Die beiden Kalziumionen werden in beiden Monomeren von den gleichen Aminosäuren koordinert. Das erste Kalziumion (Ca1) wird von der Hauptketten-Carbonylgruppe der Aminosäuren Met570 und Glu530, von OD1 von Asp571 und Asp633 und von OD2 von Asp631, Asp633 und Asp639 umgeben. Das zweite Kalziumion (Ca2) bildet Koordinationen zur Hauptketten-Carbonylgruppe von Tyr632, zu einem Wassermolekül, zu OD1 von Asp571, Asp631 und Asp633 und zu OD2 von Asp571 und Asp577 aus. Für beide Kalziumionen liegt somit eine pentagonal-bipyramidale Koordination vor. Die beiden Bindungstaschen sind in Abbildung 4.4 (S. 70) nebeneinander abgebildet. Wie in der Struktur der C2B-Domäne in $\mathrm{P} 2{ }_{1} 2{ }_{1} 2$ wird in der Abbildung deutlich, daß Glu530 sowohl direkt - via HauptkettenCarbonylgruppe an Ca1 - als auch indirekt - via Seitenkette an das an Ca2 koordinierte Wassermolekül - die Koordination der Kalziumionen beeinflußt.

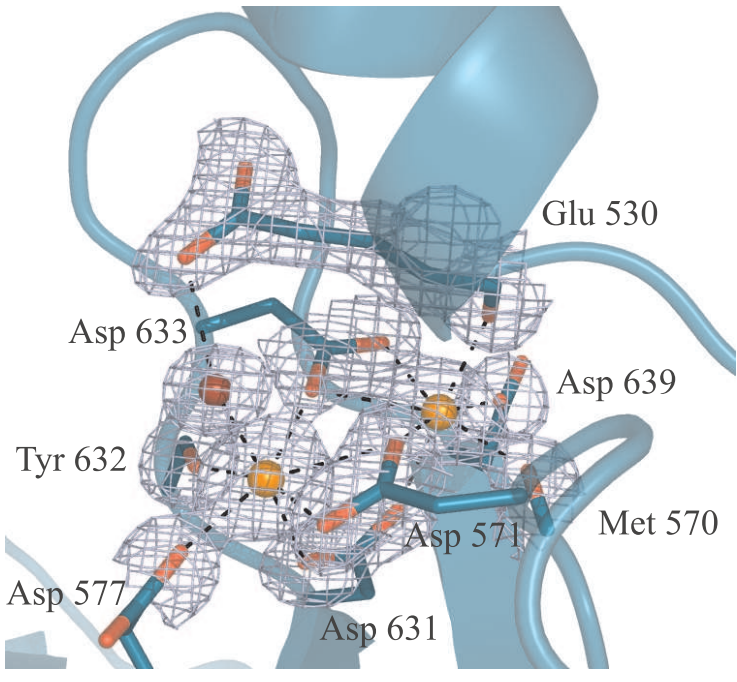

a)

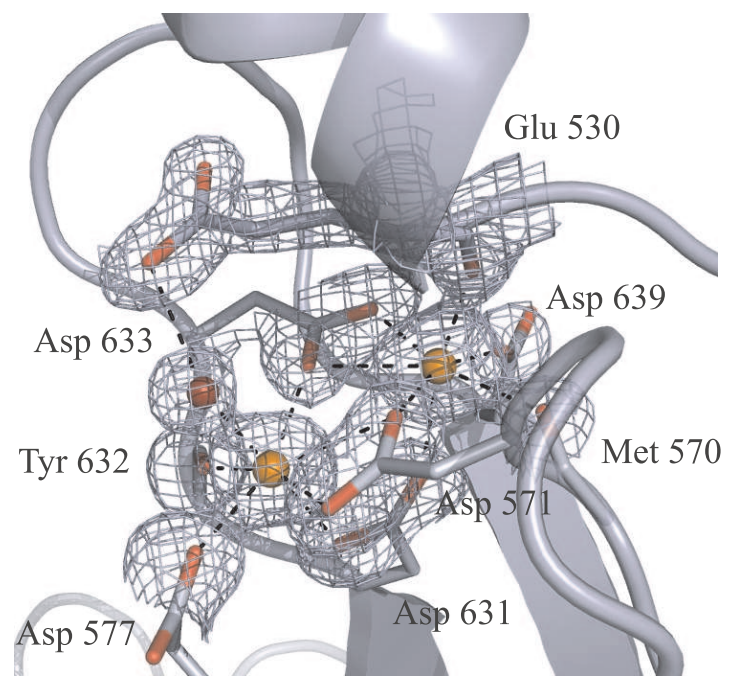

b)

Abbildung 4.4: Kalzium-Bindungstasche a) in Monomer A und b) in Monomer B; die an der Koordination der Kalziumionen beteiligten Aminosäuren sind gekennzeichnet, die beiden orange-farbenen Kugeln stellen die Kalziumionen dar, während die rote Kugel für das einzige koordinierende Wassermolekül steht. 


\section{Diskussion}

\subsection{Vergleich der C2B-Strukturen in den unterschiedlichen Raumgruppen}

\subsubsection{Tertiärstruktur}

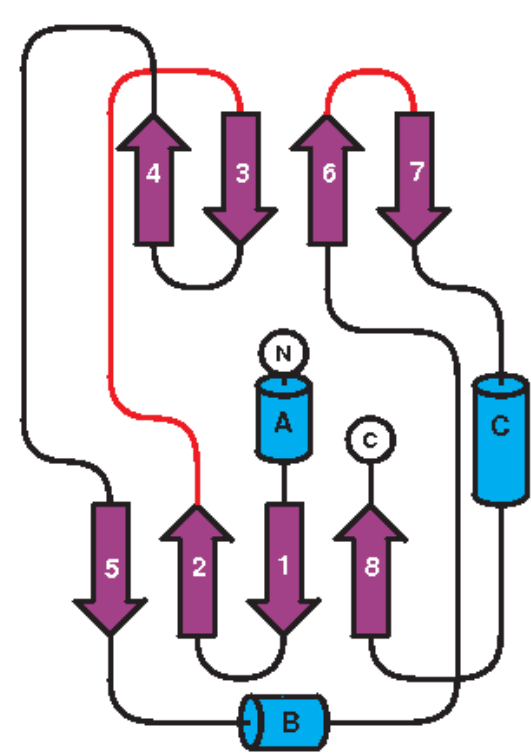

a)

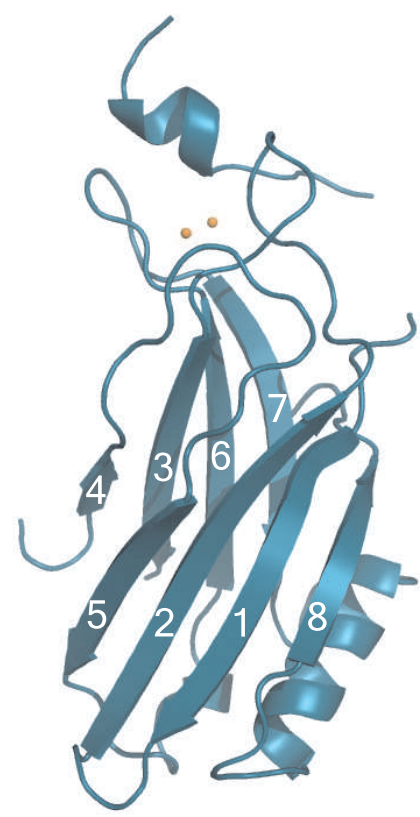

b)

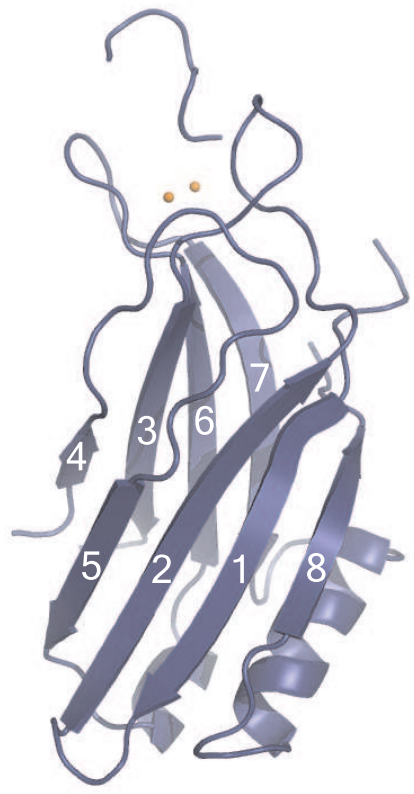

c)

Abbildung 5.1: a) Topologie der C2B-Domäne (rot dargestellte loops sind die beiden loops an der Kalziumbindungsstelle), b) Monomer A in P2 ${ }_{1}$, c) Struktur der C2B-Domäne in P2 ${ }_{1} 2_{1} 2$

Die Topologie der C2B-Domäne wurde mit Hilfe des Programms DSSP[96] erstellt und zusätzlich manuell überprüft (s. Abb. 5.1a, S. 71). In der Abbildung wird die achtsträngige, antiparallele $\beta$-Sandwich Struktur, die für C2-Domänen typisch ist, deutlich. Bei der C2BDomäne von Rabphilin-3A handelt es sich um eine C2-Domäne von Typ I, was bedeutet, daß sich der N- und der C-Terminus der Sequenz auf der Seite der Kalziumbindungsstelle 
befinden. Bei C2-Domänen des Typs II sind der N- und der C-Terminus der Sequenz auf der gegenüberliegenden Seite der Kalziumbindungsstelle anzutreffen (s. Abb. 1.8, S. 11).

Das Programm DSSP [96] gab für den N-Terminus in der C2B-Struktur in P2 ${ }_{1}$ eine $\alpha$ helikale Sekundärstruktur an (s. Abb. 5.1b, S. 71). Für die N-terminale Region der C2BStruktur in P2 ${ }_{1} 2{ }_{1} 2$ hingegen ermittelte DSSP [96] einen loop (s. Abb. 5.1c, S. 71), der entgegengesetzt gedreht ist. In Tabelle 5.1 (S. 72) sind die Wasserstoffbrücken der Aminosäuren des N-terminalen Bereiches 524 bis 534 für die Struktur in P2 $2_{1} 2$ und in Tabelle 5.2 (S. 73) die für die Struktur in $\mathrm{P} 2{ }_{1}$ aufgelistet. In der C2B-Struktur in $\mathrm{P} 2{ }_{1} 2{ }_{1} 2$ begünstigen die angegebenen Wasserstoffbrücken die Bildung des loops, während in der C2B-Struktur in $\mathrm{P} 2{ }_{1}$ die angegebenen Wasserstoffbrücken die Bildung der Helix begünstigen. Eine Erklärung dafür ist, daß in der C2B-Struktur in $\mathrm{P} 2{ }_{1} 2{ }_{1} 2$ insgesamt weniger Wasserstoffbrücken in diesem Bereich vorliegen. Es fällt z.B. in der C2B-Struktur in P2 1 auf, daß die Aminosäure Glu530 im Fall des Monomers A sechs und im Fall des Monomers B fünf Wasserstoffbrückenbindungen sowohl als Donor als auch als Akzeptor eingeht. Sie ist fest in der Struktur verankert. Im Gegensatz dazu liegt in der C2B-Struktur in $\mathrm{P} 2{ }_{1} 2{ }_{1} 2$ nur eine Wasserstoffbrücke von der Aminosäure Glu530 vor, die auch in der C2B-Struktur in P2 1 vorhanden ist: N-H0_530 zu O_527. Desweiteren sieht man, daß die Aminosäure Ala525 in der C2B-Struktur in P $2{ }_{1} 2{ }_{1} 2$ nur über die Wasserstoffbrücke zu N-H0_526 koordiniert ist, wohingegen in den beiden Monomeren in $\mathrm{P} 21$ von der Aminosäure Ala525 jeweils zwei Wasserstoffbrückenbindungen ausgehen: in Monomer A N-H0_525 an OE1_528 und N-H0_528 an O_525, in Monomer B N-H0_528 an O_525 und N-H0_529 an O_525.

\begin{tabular}{rlcl}
\hline Struktur in P2 1212 & Donor-H & Distanz (H...Akzeptor) $\AA$ & Akzeptor [Symmetrieoperator] \\
\hline N-H0_526 & 2.033 & OE1_528 \\
N-H0_526 & 2.319 & N_525 \\
N-H0_527 & 2.387 & N_526 \\
N-H0_530 & 2.173 & O_527 \\
N-H0_572 & 2.063 & O_528 \\
N-H0_585 & 1.622 & O_528 [x+1/2,-y+1/2, -z] \\
N-H0_634 & 1.969 & OE2_529 \\
N-H0_635 & 2.049 & OE1_529 \\
\hline
\end{tabular}

Tabelle 5.1: Wasserstoffbrücken im Bereich des N-Terminus in der Struktur in $\mathrm{P} 2{ }_{1} 2{ }_{1} 2$

Die Unterschiede in den C2B-Strukturen in den verschiedenen Raumgruppen werden nach der Berechnung der flexiblen Bereiche mit Escet [97] noch deutlicher (s. Abb. 5.2, S. 74). Natürlich werden auch hier die großen Differenzen in der N-terminalen Region deutlich. Hinzu kommen jedoch die Regionen 548 bis 549, 570, 587 bis 590 und 646 bis 650. Bei dem 


\begin{tabular}{|c|c|c|c|}
\hline Struktur in $\mathrm{P} 2{ }_{1}$ & Donor-H & Distanz (H...Akzeptor) & Akzeptor \\
\hline \multirow[t]{15}{*}{ Monomer A } & N-H0_525 & 2.394 & OE1_528 \\
\hline & N-H0_527 & 2.295 & OE1_670 [x+1, y, z] \\
\hline & N-H0_528 & 2.405 & O_525 \\
\hline & N-H0_529 & 2.129 & O_526 \\
\hline & N-H0_530 & 2.232 & O_527 \\
\hline & N-H0_530 & 2.240 & N_529 \\
\hline & N-H0_531 & 2.296 & N_530 \\
\hline & NH1-HH1A_534 & 2.092 & O_569 \\
\hline & NH1-HH2B_534 & 2.307 & O_569 \\
\hline & N-H0_572 & 2.113 & O_529 \\
\hline & N-H0_634 & 1.683 & OE2_530 \\
\hline & N-H0_634 & 2.299 & OE1_530 \\
\hline & N-H0_635 & 1.798 & OE1_530 \\
\hline & N-H0_672 & 2.223 & $\mathrm{OH} \_527[\mathrm{x}-1, \mathrm{y}, \mathrm{z}]$ \\
\hline & NE-HE1_672 & 2.274 & OE1_528 [x-1, y, z] \\
\hline \multirow[t]{12}{*}{ Monomer B } & N-H0_528 & 2.325 & O_525 \\
\hline & N-H0_529 & 2.244 & O_526 \\
\hline & N-H0_529 & 2.404 & O_525 \\
\hline & N-H0_530 & 2.201 & O_527 \\
\hline & N-H0_530 & 2.650 & O_526 \\
\hline & N-H0_531 & 2.608 & O_528 \\
\hline & N-H0_572 & 2.063 & O_529 \\
\hline & N-H0_634 & 1.907 & OE2_530 \\
\hline & N-H0_634 & 2.559 & OE1_530 \\
\hline & N-H0_635 & 2.013 & OE1_530 \\
\hline & N-H0_672 & 2.105 & OH_527 [x-1, y, z] \\
\hline & NE-HE1_672 & 2.332 & OE1_528 [x-1, y, z] \\
\hline
\end{tabular}

Tabelle 5.2: Wasserstoffbrücken im Bereich des N-Terminus in der Struktur in $\mathrm{P} 2{ }_{1}$ 


\section{Diskussion}

Bereich 587 bis 590 handelt es sich um eine sehr flexible loop-Region, die nur in Monomer $\mathrm{B}$ in der Raumgruppe $\mathrm{P} 21$ gebaut werden konnte. In den anderen beiden Monomeren war in diesem Bereich keine Elektronendichte zu sehen, was in C2B-Strukturen für gewöhnlich zu beobachten ist. Es ist daher nicht verwunderlich, daß diese Region in den drei Monomeren stark differiert. Desweiteren zeigen die drei Monomere in der flexiblen loop-Region von 646 bis 650 Unterschiede. Die Standardabweichungen der einzelnen Überlagerungen besitzen folgende Werte: $0.6271 \AA$ für $\mathrm{C} 2 \mathrm{~B}$ in $\mathrm{P} 2{ }_{1} 2{ }_{1} 2$ und Monomer $\mathrm{A}$ in $\mathrm{P} 2{ }_{1}, 0.7281 \AA$ für $\mathrm{C} 2 \mathrm{~B}$ in $\mathrm{P} 2{ }_{1} 2{ }_{1} 2$ und Monomer $\mathrm{B}$ in $\mathrm{P} 2{ }_{1}$ und $0.4892 \AA$ für Monomer $\mathrm{A}$ und $\mathrm{B}$ in $\mathrm{P} 2{ }_{1}$.

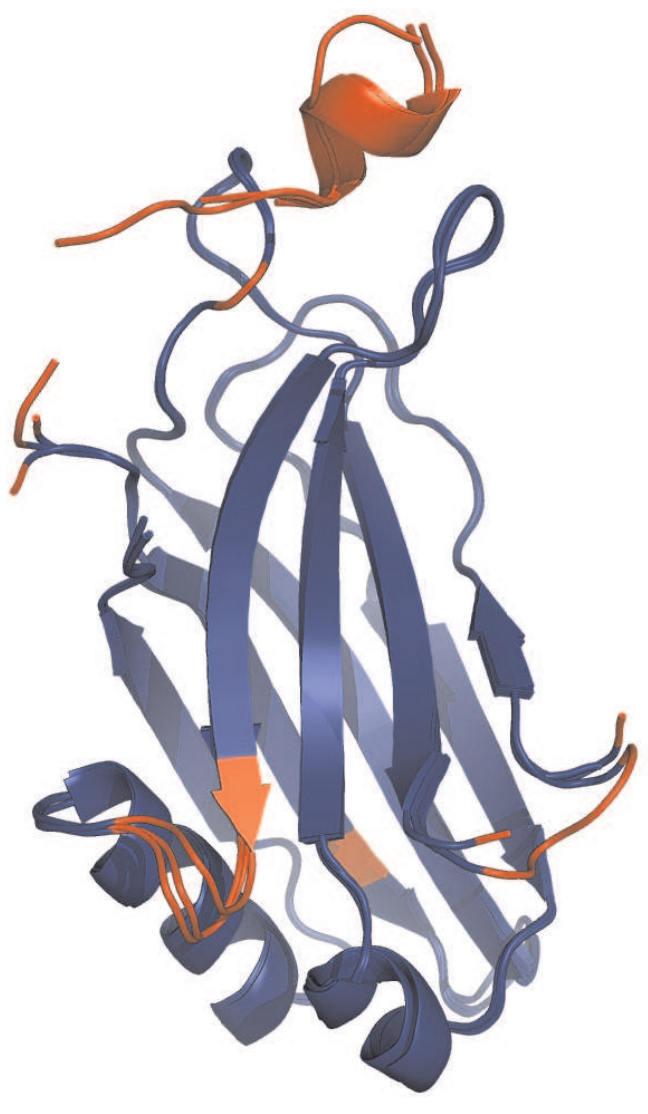

a)

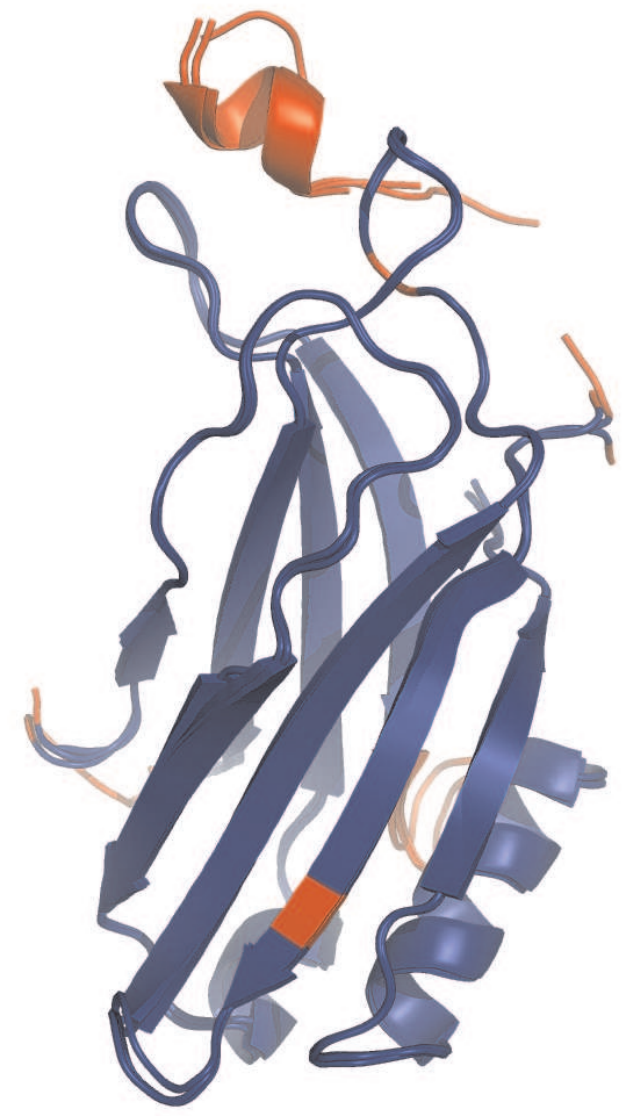

b)

Abbildung 5.2: Escet-Abbildung der Unterschiede in den drei Monomeren der C2B-Struktur; in blau sind die starren Bereiche gezeigt, in rot die flexiblen Bereiche

\subsubsection{Die $\mathrm{Ca}^{2+}$-Bindungsstelle}

Die $\mathrm{Ca}^{2+}$-Bindungsstelle unterscheidet sich in den beiden Raumgruppen kaum. Lediglich die Koordination der Hauptketten-Carbonylgruppe der Aminosäure Glu übernimmt im Falle 
der Raumgruppe $\mathrm{P} 2{ }_{1} 2{ }_{1} 2$ Glu529 und im Falle der Raumgruppe $\mathrm{P} 2{ }_{1}$ Glu530. Die Bindung der Kalziumionen ist demzufolge gewährleistet, obwohl der N-Terminus in den beiden Strukturen sehr unterschiedlich geformt ist. Desweiteren liegt in der Struktur in der Raumgruppe P2 1 kein Se-Met vor, was aber für die Koordination der Kalziumionen unbedeutend ist, da die Bindung von der Hauptketten-Carbonylgruppe ausgeht. Die beiden Kalziumionen sind somit in beiden Raumgruppen pentagonal-bipyramidal koordiniert. Eine Überlagerung aller drei Bindungstaschen macht deutlich, daß es keine großen Unterschiede in der Koordination der Metallionen in den drei Monomeren gibt (s. Abb. 5.3, S. 75).

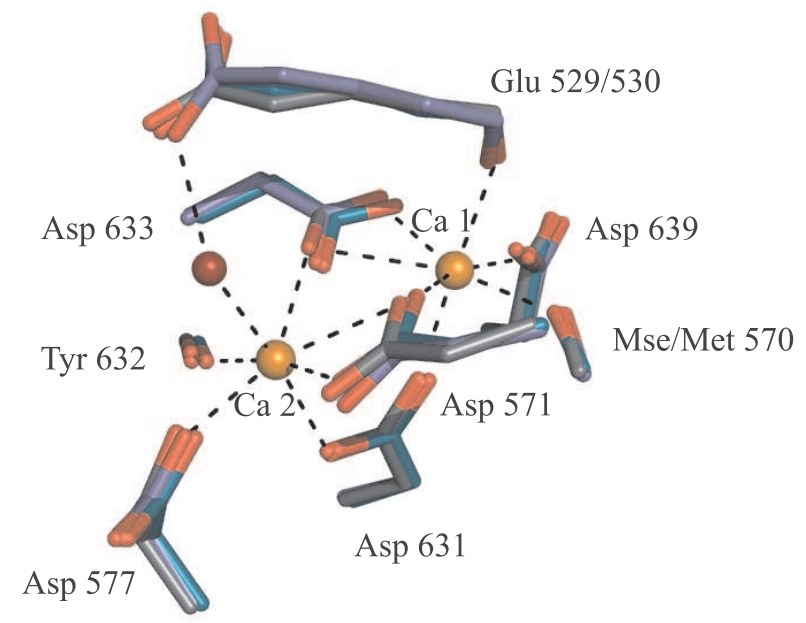

Abbildung 5.3: Überlagerung aller drei Kalziumbindungsstellen; in blau die Struktur in $P 2{ }_{1} 2{ }_{1} 2$, in türkis Monomer A in $\mathrm{P} 2_{1}$, in grau Monomer B in P2 1

\subsubsection{Der N-Terminus oberhalb der Kalziumbindungsstelle}

Beim Vergleich der N-Termini wird deutlich, daß der N-Terminus in der C2B-Struktur in der Raumgruppe $\mathrm{P} 2{ }_{1} 2{ }_{1} 2$ eine loop-Region ausbildet, in der C2B-Struktur in der Raumgruppe $\mathrm{P} 2{ }_{1}$ hingegen eine $\alpha$-Helix aufweist. In Abbildung 5.4 (s. S. 76) ist die N-terminale Region für alle drei Monomere mit der entsprechenden Elektronendichtekarte in diesem Bereich abgebildet.

Wie schon in Kapitel 5.1.1 (S. 71) angesprochen wurde, ist die N-terminale Region aufgrund der unterschiedlichen Wasserstoffbrücken strukturell sehr unterschiedlich in den beiden Raumgruppen. In der C2B-Struktur in P2 ${ }_{1} 2{ }_{1} 2$ gehen von der Aminosäure Glu530 fünf (Monomer B) bzw. sechs (Monomer A) Wasserstoffbrücken aus, die diese Aminosäure besonders fest in ihrer Position verankern. In der C2B-Struktur in $\mathrm{P} 2{ }_{1}$ ist diese Verankerung nicht gegeben, so daß zwar die N-terminale Region durch verschiedene Wasserstoffbrücken an ihrem Platz gehalten wird, jedoch keine Aminosäure besonders stark an ihre Position verankert wird. 


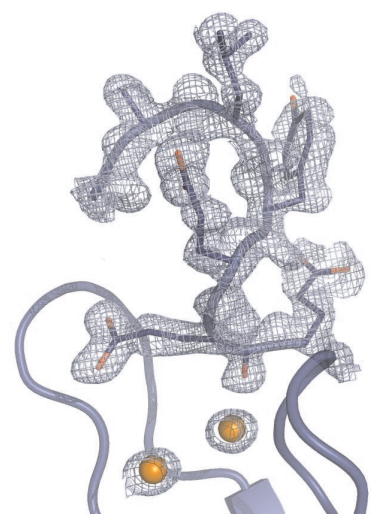

a)

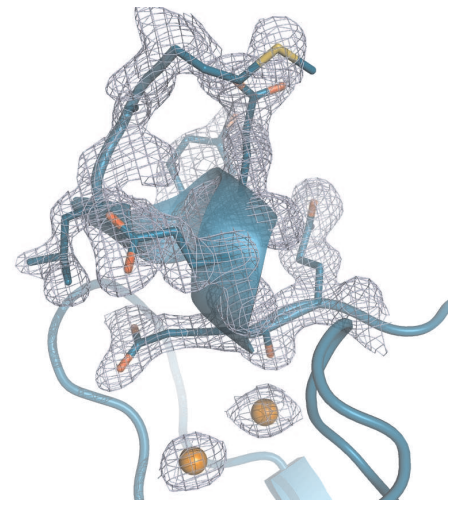

b)

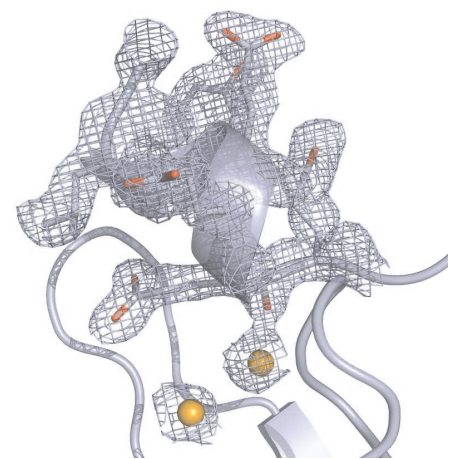

c)

Abbildung 5.4: N-Terminus-Region von a) $\mathrm{C} 2 \mathrm{~B}$ in der Raumgruppe $\mathrm{P} 2{ }_{1}{ }_{2} 2$, b) $\mathrm{C} 2 \mathrm{~B}$ Monomer $\mathrm{A}$ in $\mathrm{P} 2{ }_{1}$ und c) $\mathrm{C} 2 \mathrm{~B}$ Monomer $\mathrm{B}$ in $\mathrm{P} 2{ }_{1}$ jeweils mit der dazugehörigen Elektronendichte

\subsection{Vergleich der Kristallstrukturen mit der NMR-Struktur}

Das für die NMR-Struktur gewählte Fragment der C2B-Domäne von Rabphilin [98] war im Gegensatz zum Konstrukt für die Kristallstruktur um fünf Aminosäuren am N-Terminus kürzer, d.h. es enthielt die Aminosäuren 524 bis 684. Die NMR-Struktur enthält wie die Kristallstruktur die typische Typ I Faltung bestehend aus einem antiparallelen, achtsträngigen $\beta$ Sandwich, welches zwei $\alpha$-Helices enthält: eine kurze $\alpha$-Helix zwischen den $\beta$-Faltblättern fünf und sechs und eine lange $\alpha$-Helix zwischen den $\beta$-Faltblättern sieben und acht (Topologie s. Abb. 1.8, S. 11). Der große Unterschied zwischen der NMR-Struktur und den Kristallstrukturen der C2B-Domäne besteht in der N-terminalen Region. In der NMR-Struktur ist der N-Terminus kürzer und kann im NMR-Experiment nicht über der Kalziumbindungsstelle lokalisiert werden. Hingegen sind in den Kristallstrukturen zwei unterschiedliche Orientierungen der N-terminalen Region zu beobachten. Desweiteren wird bei einer genaueren Betrachtung der Kalziumbindungsstellen deutlich, daß die Koordination der beiden Kalziumionen in der NMR-Struktur auf keinen Fall pentagonal-bipyramidal sein kann. In der NMR-Struktur sind nur zwei Aminosäuren (Asp577 und Asp631) an der gleichen Position wie die Kalziumkoordinierenden Aminosäuren in den Kristallstrukturen. Ansonsten sind die Aminosäuren, die für die Bindung von Kalziumionen verantwortlich sind, zu weit von den Kalziumionen entfernt, als daß sie Bindungen mit Kalziumionen eingehen könnten. Außerdem fehlt die für die Bindung wichtige Aminosäure Glu529 bzw. Glu530, die sowohl direkt als auch indirekt die Bindung von Kalziumionen begünstigt. Eine Überlagerung der $\mathrm{Ca}^{2+}$-Bindungsstellen aller vier C2B-Domänen veranschaulicht die unterschiedliche Lage der kalziumbindenden Aminosäuren (s. Abb. 5.5, S. 77). 


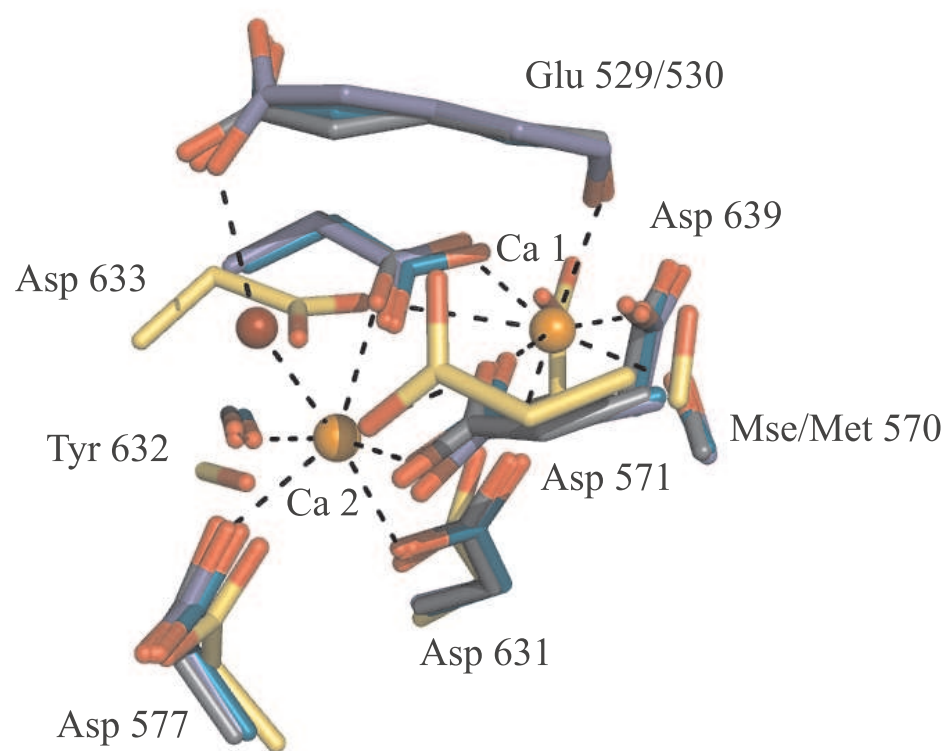

Abbildung 5.5: Überlagerung der NMR- und Kristallstrukturen; in blau die Strukur in $\mathrm{P} 2{ }_{1} 2_{1} 2$, in cyan Monomer A in P2 1 , in grau Monomer B in P2 ${ }_{1}$, in gelb die NMR-Struktur; die flexiblen loop-Regionen sind mit Kreisen markiert: in grün der Bereich 632 bis 638, in rot der Bereich von 587 bis 590.

Bei dem Vergleich der gesamten C2B-Struktur aus der NMR-Spektroskopie und der Kristallographie fällt auf, daß der eine in der $\mathrm{Ca}^{2+}$-Bindungsstelle gelegene loop (Aminosäure 587 bis 590) in der NMR-Struktur weiter nach außen geneigt ist als in den Kristallstrukturen (in Abb. 5.6, S. 78 in grün eingekreist). Dies deutet auch auf eine schlechtere Bindungsmöglichkeit der Kalziumionen in der NMR-Struktur hin. Ein weiterer Unterschied der NMRStruktur zur Kristallstruktur besteht in der flexiblen Region von Aminosäure 587 bis 590 (in Abb. 5.6, S. 78 in rot eingekreist). Dies ist jedoch nicht verwunderlich, da dieser Bereich des Proteins in allen bekannten C2B-Strukturen sehr flexibel ist. Die Standardabweichungen der in COOT erzeugten Überlagerung [99] von 1.2909 $\AA$ für C2B in P2 ${ }_{1} 2{ }_{1} 2$ mit der NMRStruktur, 1.2386 A für C2B Monomer A in P2 ${ }_{1}$ mit der NMR-Struktur und $1.2603 \AA$ für C2B Monomer B in P2 1 mit der NMR-Struktur zeigen, daß große Unterschiede in der Kristallstruktur verglichen mit der NMR-Struktur im N-terminalen Bereich und in der loop-Regionen von Aminosäure 587 bis 590 (in. Abb. 5.6, S. 78 mit einem roten Kreis markiert) bzw. 632 bis 638 (in. Abb. 5.6, S. 78 mit einem grünen Kreis markiert) vorliegen. 


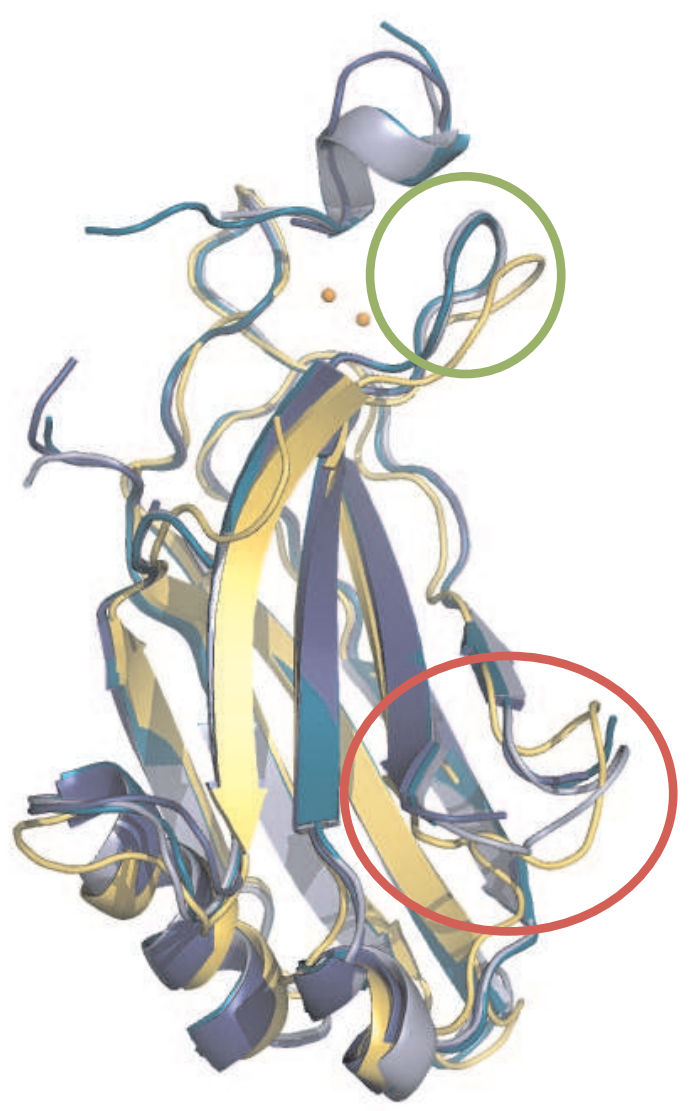

a)

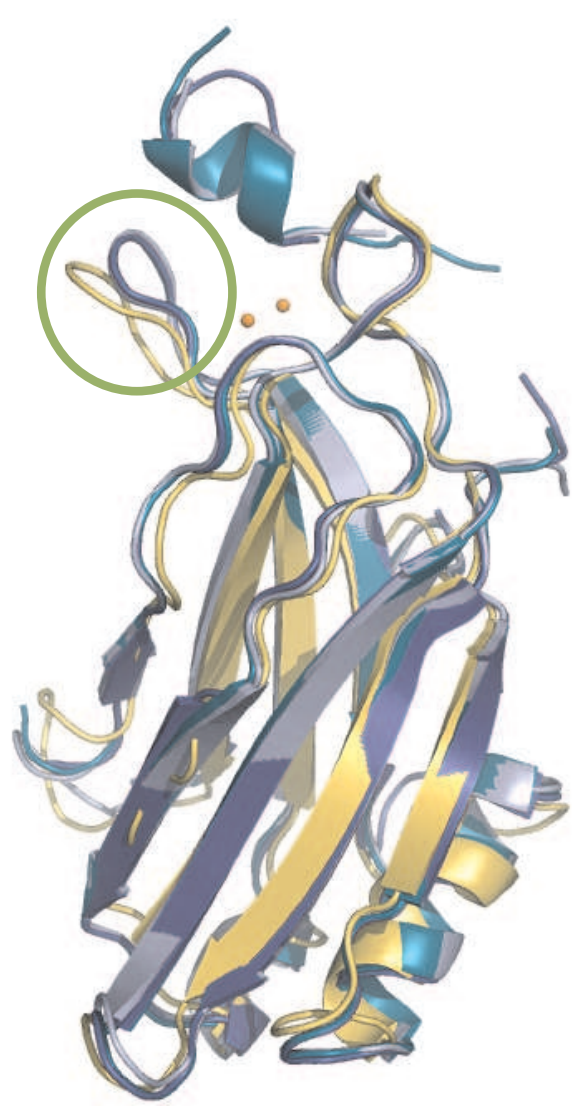

b)

Abbildung 5.6: Überlagerung der gesamten $\mathrm{C} 2 \mathrm{~B}-$ Struktur, b) ist um $180^{\circ}$ zu a) gedreht; in blau die Strukur in $\mathrm{P} 2{ }_{1} 2{ }_{1}$, in türkis Monomer A in $\mathrm{P} 2{ }_{1}$, in grau Monomer B in $\mathrm{P} 2{ }_{1}$, in gelb die NMR-Struktur; der grüne Kreis markiert die flexible loop-Region von 632 bis 638, der rote Kreis markiert die flexible loop-Region von 587 bis 590 . 


\subsubsection{Elektrostatische Oberfläche im Vergleich}

In Abbildung 5.7 (s. S. 79) ist die elektrostatische Oberfläche der C2B-Struktur in der Raumgruppe P2 1 (Monomer B) im Vergleich mit der NMR-Struktur abgebildet. Sowohl in der NMR-Struktur als auch der Kristallstruktur ist der Dipolcharakter der C2B-Domäne in Abb. 5.7 a und 5.7 c deutlich zu sehen. Dies könnte, wie für die NMR-Struktur der C2BDomäne [98] prognostiziert wurde, für die unterschiedlichen Funktionen und damit den „Janus-Charakter“ [98] der C2B-Domäne sprechen. Die Funktionen wären demnach zum einen $\mathrm{Ca}^{2+}$-abhängig und würden an der Kalziumbindungsstelle am oberen Teil der Struktur lokalisiert stattfinden, zum anderen wären sie $\mathrm{Ca}^{2+}$-unabhängig und würden dann auf der gegenüberliegenden Seite der Kalziumbindungsstelle am unteren Teil der Struktur stattfinden.

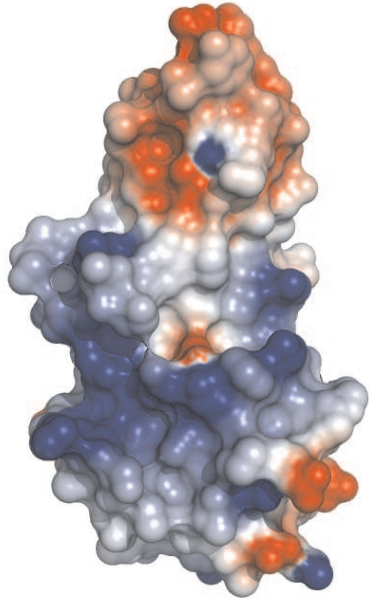

a)

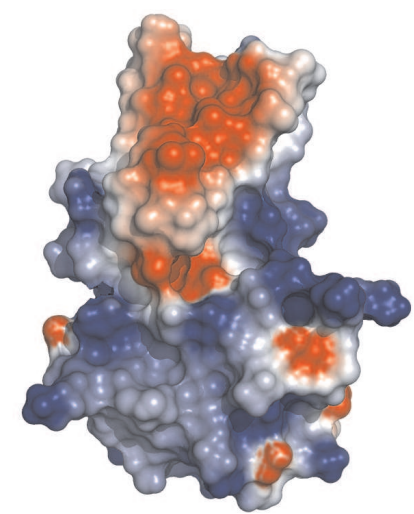

c)

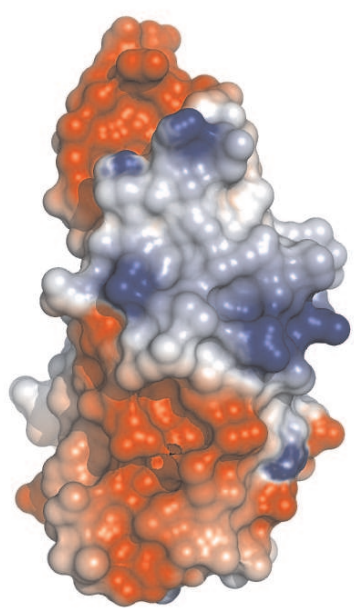

b)

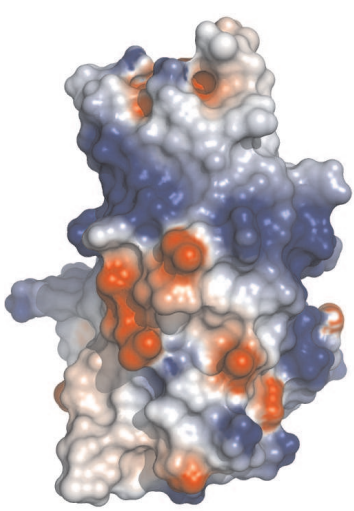

d)

Abbildung 5.7: Elektrostatische Oberfläche der C2B-Struktur a) und b) in der Raumgruppe $\mathrm{P} 2{ }_{1}$, wobei b) um $180^{\circ} \mathrm{zu}$ a) gedreht ist; c) und d) in der NMR-Struktur, wobei d) um $180^{\circ} \mathrm{zu}$ c) gedreht ist. 


\subsection{Vergleich mit anderen C2B-Domänen}

Für den Vergleich mit anderen C2B-Domänen wurden die Kristallstrukturen der drei C2BDomänen von Synaptotagmin I, III, und IV herangezogen. Der Vergleich wurde sowohl mit der C2B-Struktur in P $2{ }_{1} 2{ }_{1} 2$ als auch mit dem Monomer B der C2B-Struktur in P2 1 vorgenommen. In einer Überlagerung der fünf $\mathrm{C} 2 \mathrm{~B}$-Domänen fällt auf, daß keine der C2B-Strukturen von Synaptotagmin einen N-terminalen Bereich auf der Kalziumbindungsstelle aufweisen. Desweiteren ist deutlich, daß der flexible Bereich (in Abb. 5.8, S. 80 in gelb eingekreist), der in der C2B-Struktur von Rabphilin-3A die Aminosäuren 587 bis 590 umfaßt, in allen C2B-Strukturen des Synaptotagmins anders geformt ist als in der C2B-Struktur des Rabphilins. Ein weiterer wichtiger Unterschied der C2B-Struktur des Rabphilins ist der loop-Bereich (632-638) an der Kalziumbindungsstelle (in Abb. 5.8, S. 80 in grün eingekreist). Dieser loop ist in der C2B-Struktur des Rabphilins viel näher an der Kalziumbindungsstelle lokalisiert.

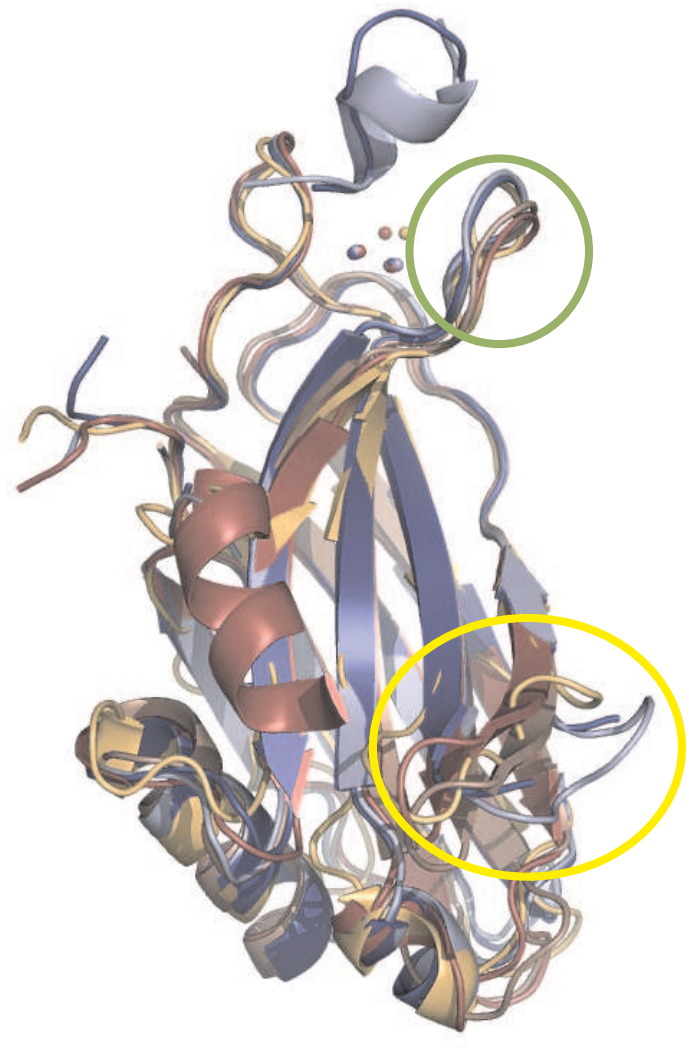

a)

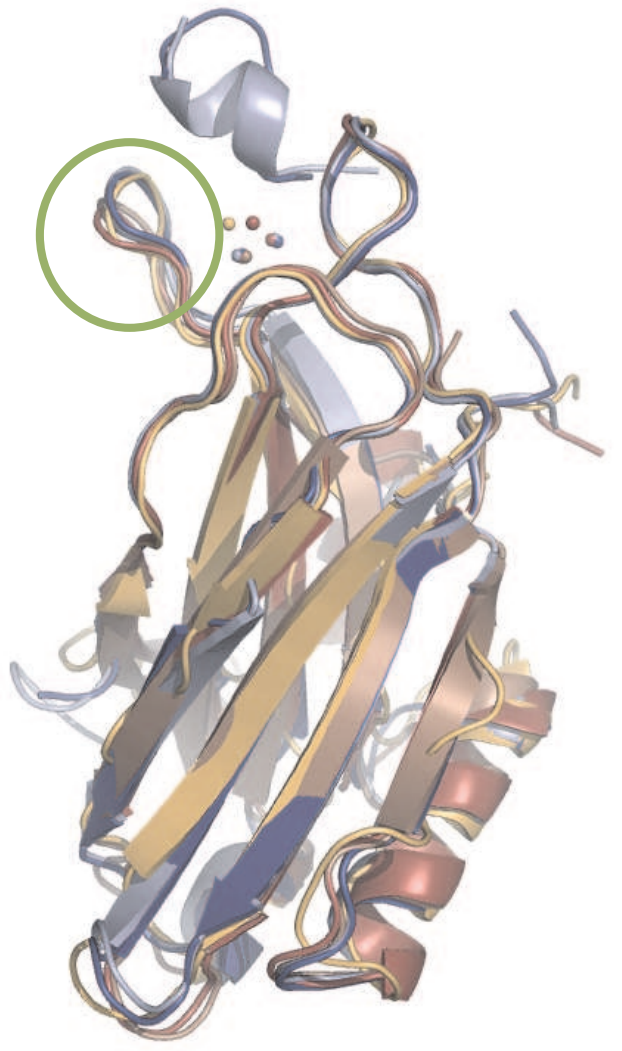

b)

Abbildung 5.8: Überlagerung der C2B-Strukturen von Synaptotagmin I (rot), III (gelb), IV (sandfarben), Rabphilin-3A in P2 ${ }_{1} 22$ (blau) und Rabphilin-3A in P2 (hellblau); die flexiblen loop-Regionen sind mit Kreisen markiert: in grün der Bereich von 632 bis 638, in gelb der Bereich von 587 bis 590. 
Im Vergleich der Standardabweichungen der in COOT erzeugten Überlagerung [99] wird deutlich, daß die C2B-Struktur des Rabphilins am ehesten mit der C2B-Struktur des Synaptotagmins I verglichen werden kann (s. Tab. 5.3, S. 81). Die C2B-Struktur von Synaptotagmin III weicht von allen drei Monomeren der C2B-Struktur von Rabphilin-3A am weitesten ab.

\begin{tabular}{llll}
\hline & C2B in P2 ${ }_{1}{ }_{1} 2$ & $\begin{array}{l}\text { C2B in P2 } \\
\text { Monomer A }\end{array}$ & $\begin{array}{l}\text { C2bB in } \mathrm{P} 2{ }_{1} \\
\text { Monomer B }\end{array}$ \\
\hline $\mathrm{C} 2 \mathrm{~B}$ von Syt. I & $1.0522 \AA$ & $1.1289 \AA$ & $0.9957 \AA$ \\
$\mathrm{C} 2 \mathrm{~B}$ von Syt. III & $1.4175 \AA$ & $1.4551 \AA$ & $1.5556 \AA$ \\
$\mathrm{C} 2 \mathrm{~B}$ von Syt. IV & $1.1854 \AA$ & $1.0225 \AA$ & $1.1200 \AA$ \\
\hline
\end{tabular}

Tabelle 5.3: Standardabweichungen der Überlagerung von C2B Rabphilin-3A mit C2B-Domänen aus Synaptotagmin I, III und IV

\subsection{Ausblick}

Das Ziel der Arbeit war es, ein gutes Modell der C2B-Struktur zu erhalten, welches für weitere NMR-Untersuchungen verwendet werden kann. Die mittels Röntgenstrukturanalyse bestimmte C2B-Struktur liefert ein sehr gutes Modell für weitere Dynamikuntersuchungen hinsichtlich des C2A-C2B-Tandems mittels NMR.

Außerdem sind mit der geordneten N-terminalen Region oberhalb der Kalziumbindungsstelle überraschende Einblicke in die Kalziumbindung gewonnen worden. Es ist bekannt, daß die C2B-Domäne von Rabphilin-3A im Vergleich zu anderen C2-Domänen eine der stärksten Affinitäten zu Kalziumionen aufweist $(5-7 \mu \mathrm{M})$. Anhand der in dieser Arbeit untersuchten Struktur der C2B-Domäne konnte gezeigt werden, daß für die Kalziumionen eine nahezu optimale Koordinationssphäre vorliegt (s. Abb. 5.9).

Diese wird durch die Aminosäure Glu 529 bzw. Glu 530, die aus der linker-Region zwischen der C2A- und C2B-Domäne stammt, vervollständigt. Die hohe Affinität zu Kalziumionen kann somit aufgrund der vorliegenden optimalen Koordinationssphäre der beiden Kalziumionen verstanden werden. 


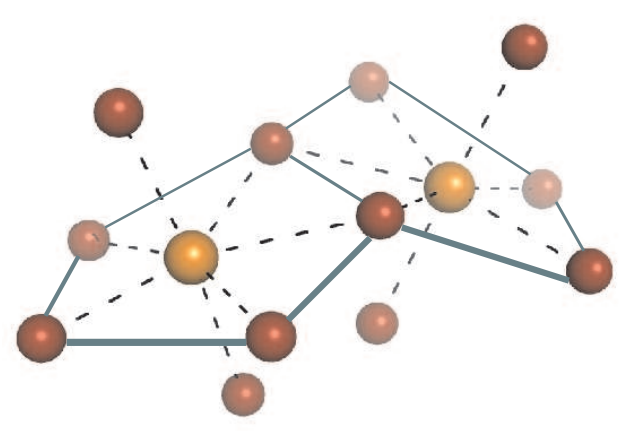

a)

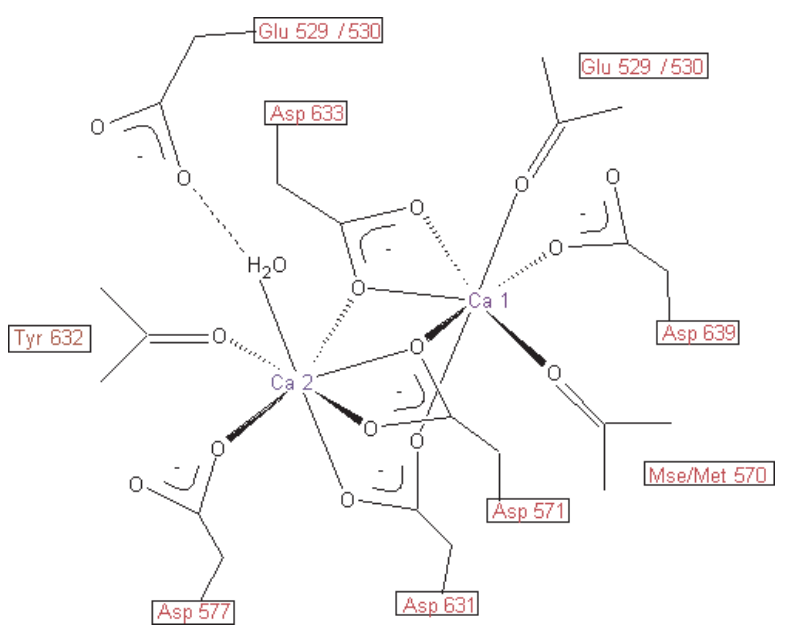

b)

Abbildung 5.9: Koordination der beiden Kalziumionen: a) Darstellung der Kalziumionen umgeben von jeweils sieben Sauerstoffatomen, b) schematische Darstellung der Koordination der Kalziumionen mit Angabe der Aminosäuren. 


\section{Strukturbestimmung der Phosphatase tPphA}

\subsection{Klonierung}

Ein Plasmid, das für den Vollängenklon von tPphA kodierte, wurde von der Arbeitsgruppe von Prof. Karl Forchhammer (Gießen), bereitgestellt. Mittels PCR wurde die tPphA-kodierende Sequenz amplifiziert und über Nde I und Xho I Restriktionsschnittstellen in den Expressionsvektor pET32a kloniert. Das insert enthielt die cDNS Sequenz, welche für die Aminosäuren 1 bis 240 von tPphA kodierte. Das Expressionskonstrukt ermöglichte die Expression des freien tPphA ohne jegliches Fusionsprotein.

\subsubsection{Polymerase-Kettenreaktion}

Die für tPphA-kodierende Sequenz wurde zuerst mittels $P f u$-DNS-Polymerase-PCR amplifiziert. Dazu wurde $1 \mu \mathrm{l}$ des Plasmids für den PCR-Ansatz (s. Abschnitt 2.2.6, S. 31) verwendet. Die Durchführung erfolgte gemäß dem in Abschnitt 2.2.6 (S. 31) aufgeführten Protokolls.

\subsubsection{Restriktionsverdau}

Der Restriktionsverdau wurde mit $10 \mu \mathrm{l}$ des PCR-Produkts und $2 \mu \mathrm{l}$ des Vektors pET32a durchgeführt (s. Tab. 2.2.6, S. 32). Die verwendeten Restriktionsenzyme waren Nde I und Xho I . Der Verdau mit Nde I wurde über Nacht bei $37^{\circ} \mathrm{C}$ durchgeführt. Im Anschluß daran wurde mit Xho I für $4 \mathrm{~h}$ bei $37^{\circ} \mathrm{C}$ verdaut. Zum Vektor pET32a wurde anschließend $1 \mu \mathrm{l} \mathrm{CIAP}$ gegeben und $\frac{1}{2} \mathrm{~h}$ bei $37^{\circ} \mathrm{C}$ inkubiert. Der Vektor wurde über ein Agarosegel gereinigt. Das PCR-Fragment wurde mit dem Mini Elute Purification Kit der Firma Qiagen gereinigt. Nach der Reinigung wurden sowohl das insert als auch der Vektor auf ein Agarosegel geladen, um die Reinheit zu überprüfen und die einzusetzenden Mengen für die Ligation zu ermitteln (s. Abb. 6.1). 
6 Strukturbestimmung der Phosphatase tPphA

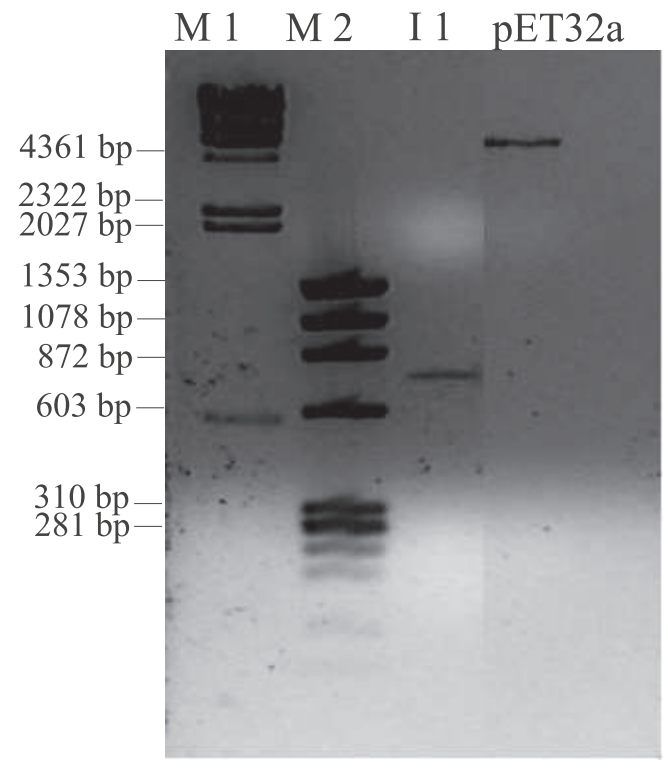

Abbildung 6.1: Agarosegel für das insert (I 1) und den verdauten Vektor pET32a nach dem Restriktionsverdau

\subsubsection{Ligation}

Die Ligation wurde, wie auf S. 32 angegeben, angesetzt. Die Lösung wurde über Nacht bei $14{ }^{\circ} \mathrm{C}$ im Wasserbad inkubiert. Anschließend konnte der Ligationsansatz transformiert werden. Dazu wurden $3 \mu 1$ des Ligationsansatzes in $50 \mu 1$ XL2blue Zellen entsprechend der Anleitung für BL21 DE3 (s. S. 29) transformiert und auf Amp-Agarplatten ausplattiert. Als Negativkontrolle wurde außerdem der in Abwesenheit des PCR-Fragments ligierte Vektor ohne insert auf Amp-Agarplatten ausplattiert. Die Agarplatten wurden über Nacht bei $37^{\circ} \mathrm{C}$ inkubiert.

\subsubsection{Hot Star Taq PCR}

Zur Überprüfung der Klone auf den Amp-Agarplatten wurde am nächsten Tag die Hot Star Taq PCR für sechs Klone durchgeführt (s. Abschnitt Hot Star Taq PCR, S. 33). Die Ansätze wurden anschließend auf ein Agarosegel aufgetragen, um die sechs Klone zu überprüfen. Die Klone zeigten alle das erwartete PCR-Fragment von tPphA. Im Anschluß daran wurde eine größere Menge zweier positiver Klone mittels Midiprep (Qiagen) hergestellt und ihre Sequenz mit Hilfe der DNS-Sequenzierung (SeqLab, Göttingen) verifiziert. 


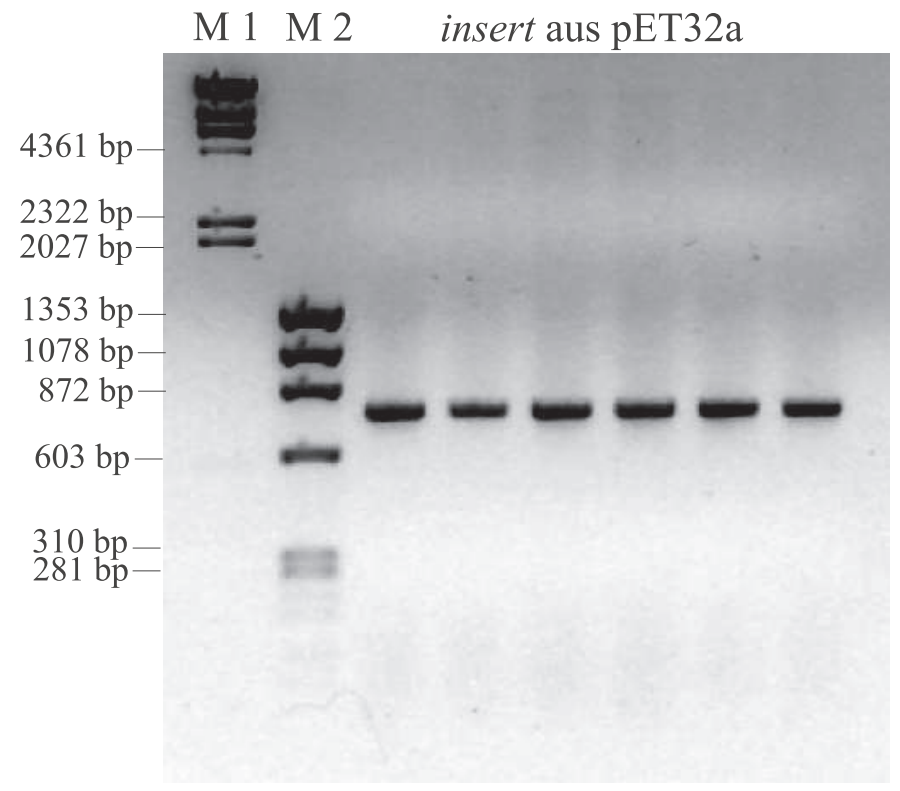

Abbildung 6.2: Agarosegel der Hot Star Taq PCR Produkte

\subsection{Expression und Reinigung}

\subsubsection{Natives Protein}

\section{Transformation und Vorkultur}

Das Expressionskonstrukt wurde in BL21 DE3-Zellen transformiert, wie in Abschnitt 2.2.2 (s. S. 29) beschrieben wurde. Die Amp-Agarplatten inkubierten über Nacht bei $37^{\circ} \mathrm{C}$. Dann wurde zunächst eine Tageskultur kultiviert, indem ein Klon von der Agarplatte zu $2 \mathrm{ml}$ LBMedium und $4 \mu \mathrm{l}$ Ampicillin $(25 \mathrm{mg} / \mathrm{ml})$ gegeben wurde und die Bakterien für ca. $7 \mathrm{~h}$ bei $37^{\circ} \mathrm{C}$ und $200 \mathrm{rpm}$ inkubierten. Im Anschluß daran wurde eine Vorkultur, bestehend aus $50 \mathrm{ml}$ LB-Medium und $100 \mu \mathrm{l}$ Ampicillin $(25 \mathrm{mg} / \mathrm{ml})$, mit $30 \mu \mathrm{l}$ der Tageskultur versetzt und über Nacht kultiviert.

\section{Expression des rekombinanten Proteins}

Am nächsten Tag wurde die Hauptkultur aus $750 \mathrm{ml}$ LB-Medium und $1.5 \mathrm{ml}$ Ampicillinlösung $(25 \mathrm{mg} / \mathrm{ml})$ mit $15 \mathrm{ml}$ der über Nacht hergestellten Vorkultur angeimpft. Die gemessene Anfangs-OD 600 betrug 0.11. Die Kultur wurde bei $37^{\circ} \mathrm{C}$ bis zu einer $\mathrm{OD}_{600}$ von 0.6 inkubiert. Dann wurden die Bakterien auf $15^{\circ} \mathrm{C}$ abgekühlt und die Expression nach 30 min mit $1 \mathrm{mM}$ IPTG induziert. Die Bakterien wurden über Nacht bei $15^{\circ} \mathrm{C}$ kultiviert, um die Löslichkeit 


\section{Strukturbestimmung der Phosphatase tPphA}

des Proteins sicherzustellen. Schon nach 6 h der Induktion war exprimiertes Protein auf dem SDS-Gel zu beobachten (s. Abb. 6.3).

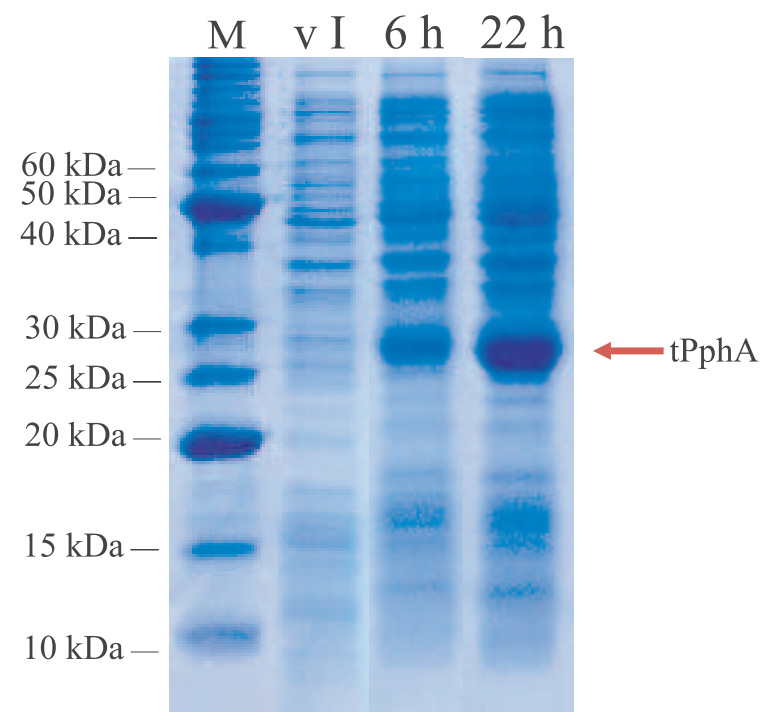

Abbildung 6.3: SDS-Gel der Induktion des nativen tPphA; vI: vor Induktion, 6 h: nach 6 h Induktion, $22 \mathrm{~h}$ : nach $22 \mathrm{~h}$ Induktion

Nach $22 \mathrm{~h}$ wurde die Kultur $20 \mathrm{~min}$ bei $8000 \mathrm{rpm}$ und $4{ }^{\circ} \mathrm{C}$ abzentrifugiert und das Zellpellet bei $-80^{\circ} \mathrm{C}$ eingefroren.

\section{Reinigung}

Das Zellpellet wurde in $40 \mathrm{ml}$ des Puffers 1 (s. Tab. 2.1.8, S. 28), dem eine Protease-Inhibitor Tablette (COMPLETE ${ }^{\mathrm{TM}}$ von Roche) und eine Spatelspitze DNAse zugegeben worden war, suspendiert.

Das Lysat wurde 7 x $20 \mathrm{sec}$ mit der Ultraschallsonotrode TT13 (Bandelin) bei maximaler Intensität aufgeschlossen. Zwischen dem Beschallen wurden zweiminütigen Pausen auf Eis eingelegt. Anschließend wurde die Zellsuspension $1 \mathrm{~h}$ bei $4{ }^{\circ} \mathrm{C}$ und $38000 \mathrm{rpm}$ (mit einem Ti 45-5 Rotor) abzentrifugiert. Sowohl das Pellet als auch der Überstand der einstündigen Zentrifugation sind auf dem SDS-Gel in Abbildung 6.4 zu sehen. Die löslichen Zellkomponenten wurden für die Ammoniumsulfatfällung verwendet. Dazu wurden sie auf Eis gekühlt, und es wurde langsam fein zermörsertes Ammoniumsulfat bis zu einer Sättigung von $35 \%$ dazugegeben. Nachdem sich das Ammoniumsulfat gelöst hatte, wurde die Lösung für 10 min bei $20000 \mathrm{rpm}$ und $4{ }^{\circ} \mathrm{C}$ abzentrifugiert und das Pellet in möglichst wenig Puffer 1 (s. Tab. 2.1.8, S. 28) aufgenommen. Zu dem Überstand wurde erneut Ammoniumsulfat gegeben. Dies wurde für die folgenden Ammoniumsulfatanteile wiederholt: $50 \%, 60 \%$ und $65 \%$. Die gelösten Pellets der Ammoniumsulfatfällung wurden in 10000 MW cutoff Dialyseschläuche gegeben 
und gegen 21 von Puffer 1 über Nacht bei $4{ }^{\circ} \mathrm{C}$ dialysiert. Die dialysierten Fraktionen sind auf dem SDS-Gel in Abbildung 6.4 zu sehen.

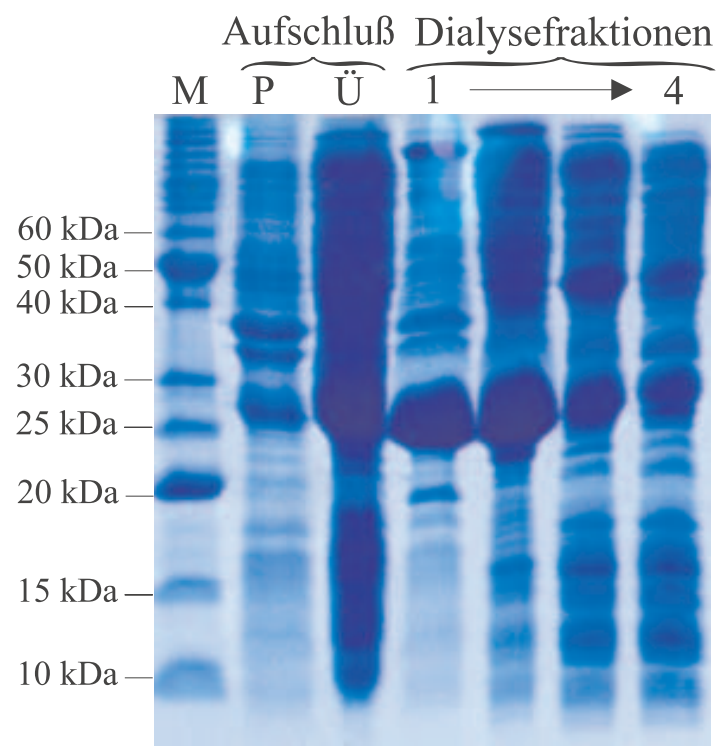

Abbildung 6.4: Reinigung der nativen tPphA: SDS-Gel des Aufschlusses und der Dialysefraktionen; Aufschluß P: Pellet, Ü: Überstand; Dialysefraktion 1: $35 \%$, 2: $50 \%$, 3: 60 \%, 4: 65 \% Ammoniumsulfat

Nachfolgend wurde das Protein auf eine mit Puffer A (s. Tab. 2.1.8, S. 28) äquilibrierten HiTrap Q XL Anionenaustauschersäule (5 ml, GE Lifesciences) geladen. Nach Waschen mit Puffer A wurde das Protein mit einem $30 \mathrm{ml}$ linearen Gradienten von Puffer A nach Puffer B (s. Tab. 2.1.8, S. 28) eluiert (s. Abb. 6.5).

Es wurden 1 ml-Fraktionen gesammelt. In Fraktion 17 bis 26 wurde das Protein mittels SDS-Gel detektiert (s. Abb. 6.6).

Anschließend wurden die Proteinfraktionen mit einem Vivaspin Centriprep mit 10000 MW cutoff auf $1.5 \mathrm{ml}$ eingeengt und auf eine Superdex 75 16/60 Gelfiltrationssäule (GE Lifesciences) aufgetragen. Hierbei wurde das Protein mit 1.5 Säulenvolumen des Gelfiltrationspuffers (s. Tab. 2.1.8, S. 28) und einer Flußrate von $0.5 \mathrm{ml} / \mathrm{min}$ eluiert. Das Chromatogramm der Gelfiltrationssäule ist in Abbildung 6.7 zu sehen. Es wurde aus den Fraktionen 73 bis 84 vereinigt (s. Abb. 6.8) und auf $52 \mathrm{mg} / \mathrm{ml}$ eingeengt. 


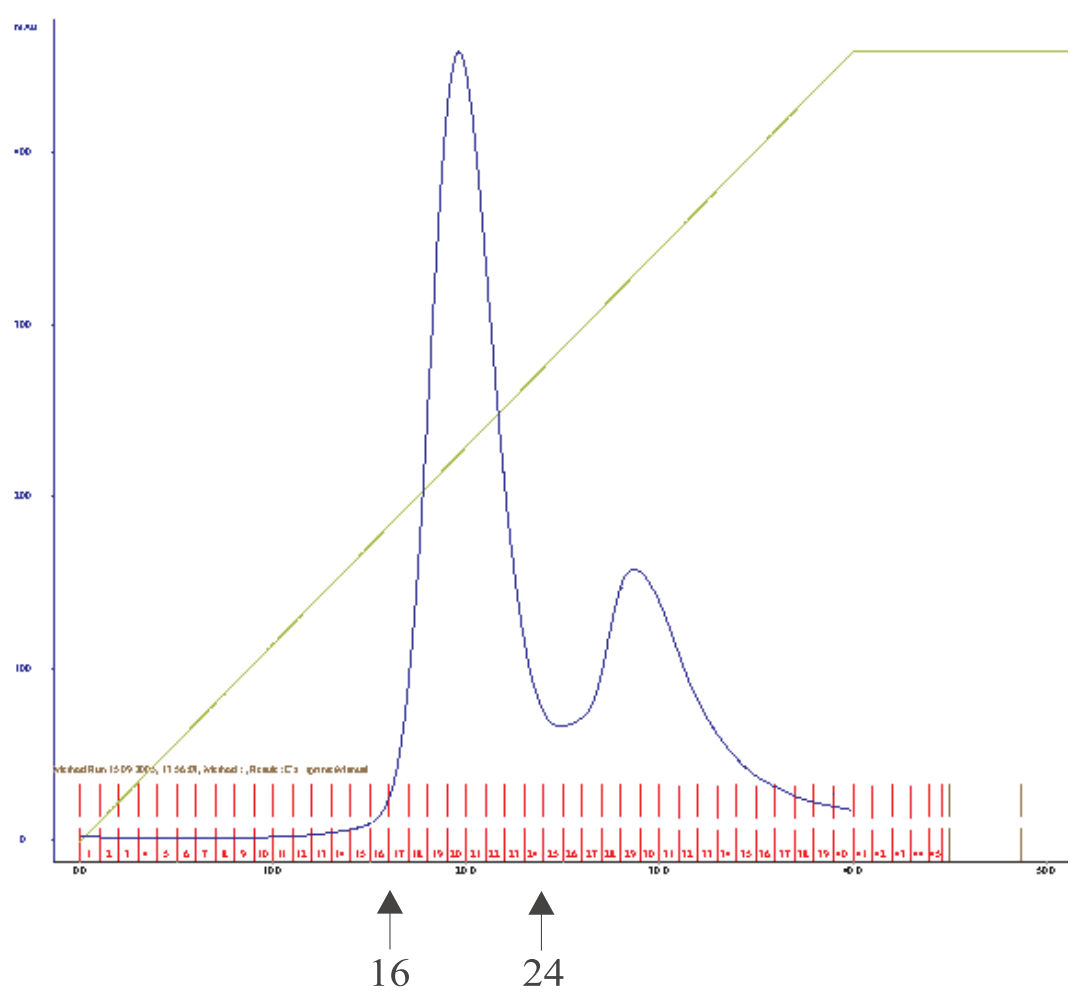

Abbildung 6.5: Reinigung der nativen tPphA: Chromatogramm der Anionenaustauschersäule

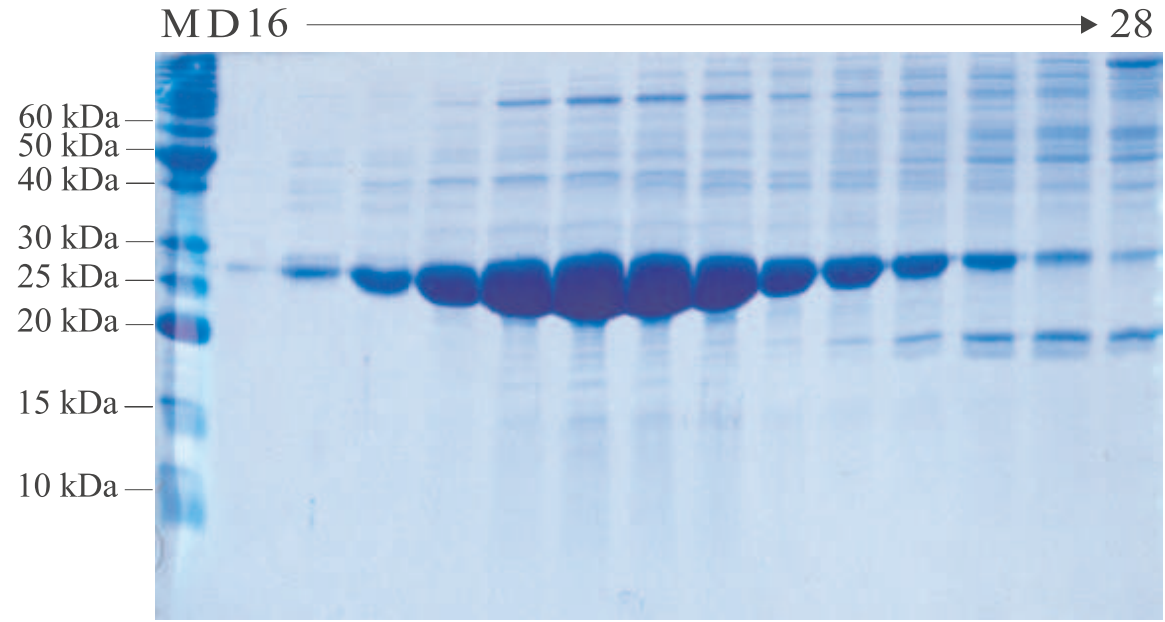

Abbildung 6.6: Reinigung der nativen tPphA: SDS-Gel der Anionenaustauschersäule, D: Durchlauf, 16-28: Fraktionen der Anionenaustauschersäule 


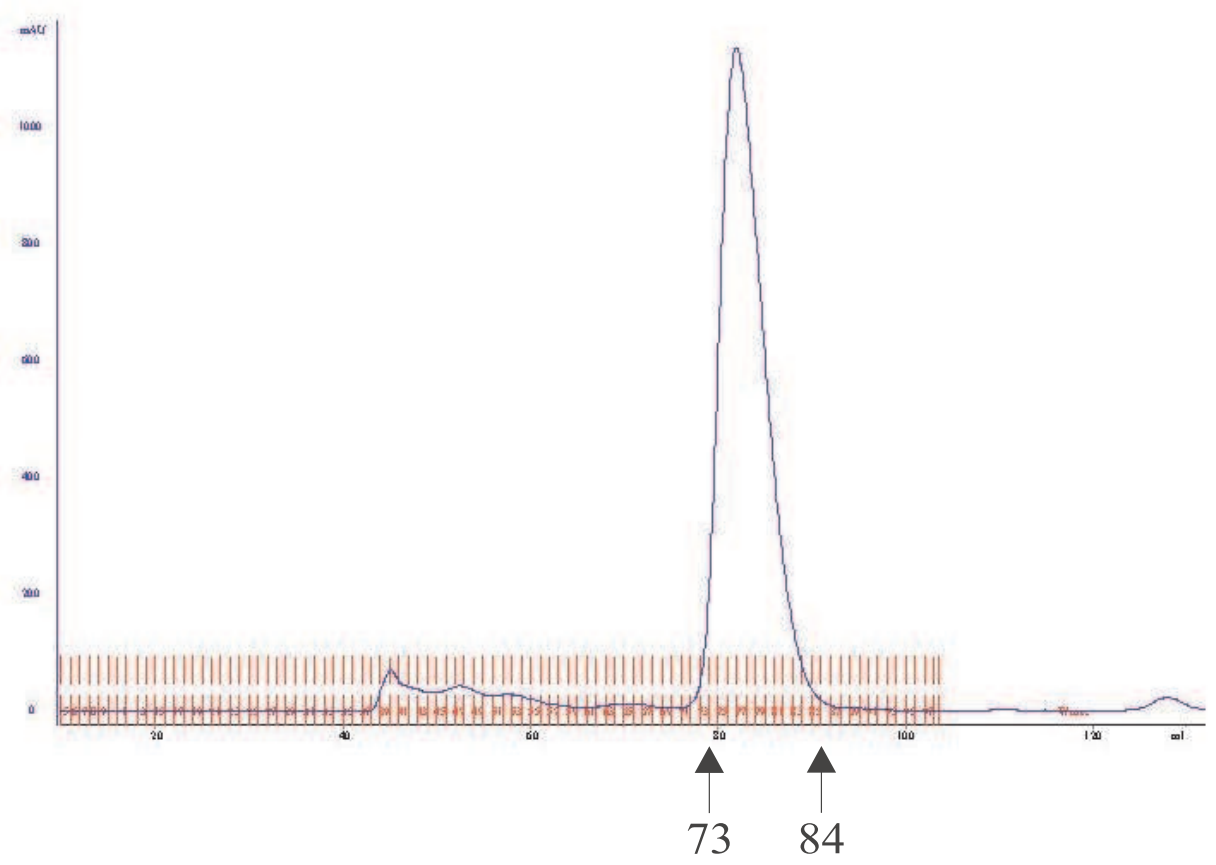

Abbildung 6.7: Reinigung der nativen tPphA: Chromatogramm der Gelfiltrationssäule

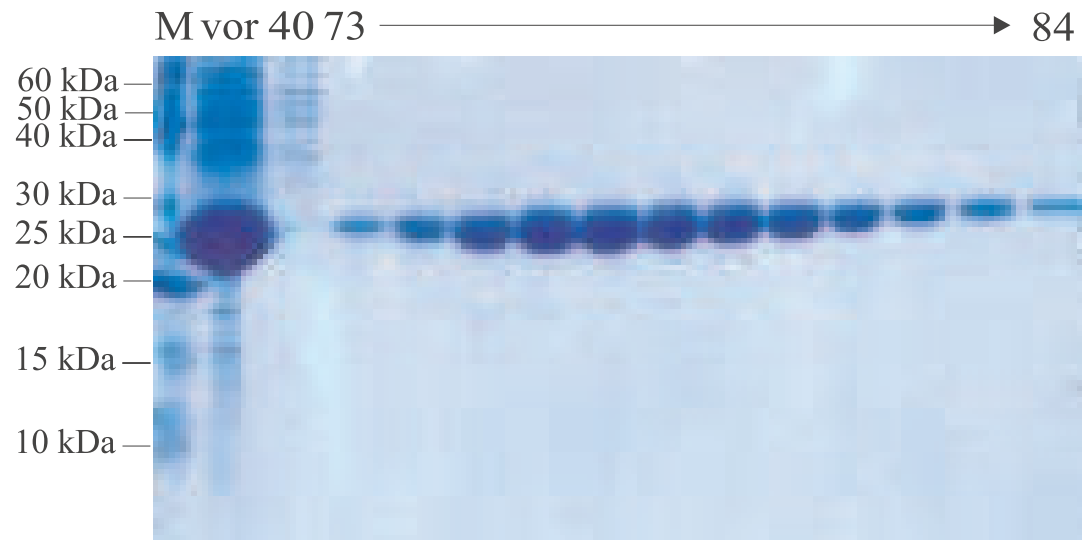

Abbildung 6.8: Reinigung der nativen tPphA: SDS-Gel der Gelfiltrationssäule; vor: vor der Gelfiltration, 40: Verunreinigung, 73-84: Fraktionen der nativen tPphA 


\section{Strukturbestimmung der Phosphatase tPphA}

\subsubsection{Se-Met Protein}

\section{Transformation und Vorkultur}

Die Transformation in auxotrophe B834 DE3-Zellen wurde, wie in Abschnitt 2.2.2 (s. S. 29) beschrieben, durchgeführt. Dazu wurden $0.5 \mu 1$ des Plasmids aus der Midi Prep zu $20 \mu 1$ B834 DE3-Zellen gegeben. Die Amp-Agarplatte wurde für ca. $10 \mathrm{~h}$ bei $37^{\circ} \mathrm{C}$ inkubiert. AnschlieBend wurde $5 \mathrm{ml}$ Medium A, welches $5 \mu \mathrm{l}$ Methionin $(50 \mathrm{mg} / \mathrm{ml})$ enthielt, mit einem Klon der Amp-Agarplatte angeimpft. Diese Vorkultur wurde über Nacht bei $37^{\circ} \mathrm{C}$ und $200 \mathrm{rpm}$ inkubiert.

\section{Expression des rekombinanten Proteins}

Das Expressionsmedium, bestehend aus 11 Medium A und $1 \mathrm{ml}$ Methionin (50 mg/ml), wurde mit $5 \mathrm{ml}$ Vorkultur versetzt. Die Anfangs-OD 600 betrug 0.015 . Die Kultur wurde bei $37^{\circ} \mathrm{C}$ und $120 \mathrm{rpm}$ bis zu einer $\mathrm{OD}_{600}$ von 1.0 inkubiert (Dauer ca. 6 h). Danach wurde die Kultur für $10 \mathrm{~min}$ bei $6000 \mathrm{rpm}$ und $4{ }^{\circ} \mathrm{C}$ abzentrifugiert und das Zellpellet in 11 Medium A ohne Methionin aufgenommen. Die Kultur wurde nun $4 \mathrm{~h}$ bei $15^{\circ} \mathrm{C}$ und $120 \mathrm{rpm}$ inkubiert. Anschließend wurden $50 \mathrm{mg}$ Se-Met, welches in $1 \mathrm{ml}$ Millipore Wasser gelöst und steril filtriert war, hinzugegeben und die Kultur nach $\frac{1}{2} \mathrm{~h}$ mit $1 \mathrm{mM}$ IPTG induziert. Die Expression erfolgte über Nacht bei $15^{\circ} \mathrm{C}$ und $120 \mathrm{rpm}$ (s. Abb. 6.9). Dann wurde die Kultur bei $8000 \mathrm{rpm} 20 \mathrm{~min}$ bei $4{ }^{\circ} \mathrm{C}$ abzentrifugiert und bei $-80^{\circ} \mathrm{C}$ gelagert.

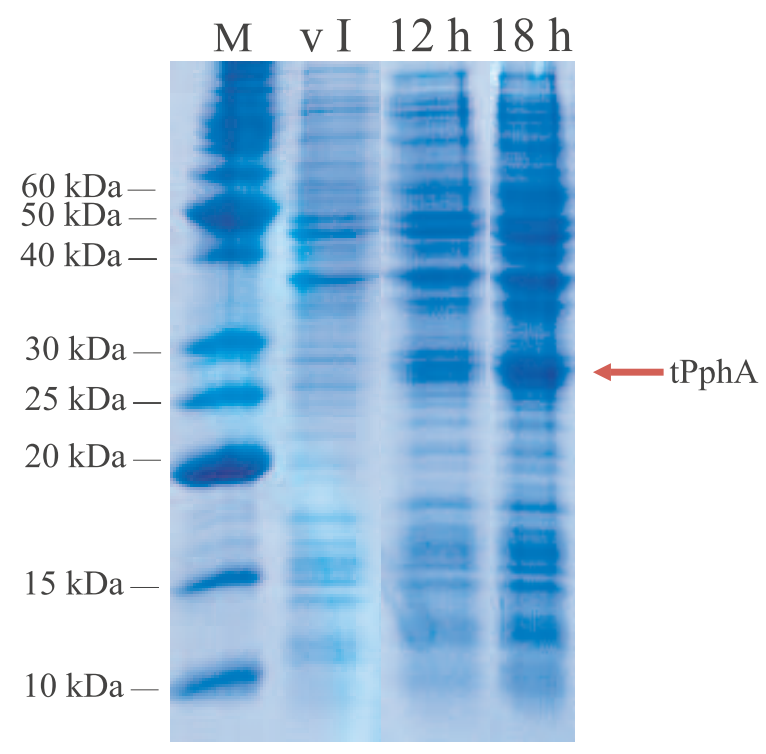

Abbildung 6.9: SDS-Gel der Induktion des Se-Met-tPphA; vI: vor Induktion, 12 h: nach 12 h Induktion, $18 \mathrm{~h}$ : nach $18 \mathrm{~h}$ Induktion 


\section{Reinigung}

Der Aufschluß und die Reinigung des Se-Met Proteins unterschieden sich nicht von der Reinigung des nativen Proteins, d.h.

1. Ammoniumsulfatfällung (mehr Zwischenschritte)

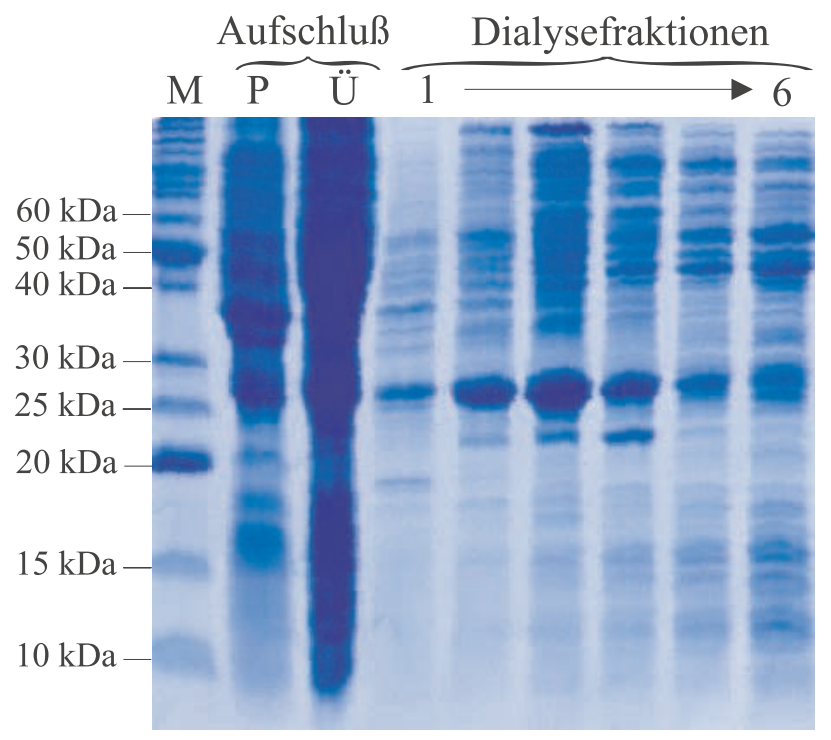

Abbildung 6.10: Reinigung der Se-Met tPphA: SDS-Gel des Aufschlusses und der Dialysefraktionen; Aufschluß P: Pellet, Ü: Überstand; Dialysefraktion 1: $35 \%, 2: 45 \%$, 3: $50 \%$, 4 : $55 \%, 5: 60 \%, 6: 65 \%$ Ammoniumsulfat

2. Anionenaustauscher-Chromatographie

3. Gelfiltrations-Chromatographie

In den Abbildungen 6.10 bis 6.14 sind die Chromatogramme und SDS-Gele der Reinigung des Se-Met Proteins abgebildet. Obwohl die Reinigung über die Anionenaustauschersäule ineffizient war, wie das Chromatogramm 6.11 zeigt, konnten mit Hilfe der Gelfiltrationssäule die Verunreinigungen äußerst effizient abgetrennt werden (s. Abb. 6.13). Das Se-Met Protein konnte auf $58.5 \mathrm{mg} / \mathrm{ml}$ eingeengt werden. 
6 Strukturbestimmung der Phosphatase tPphA

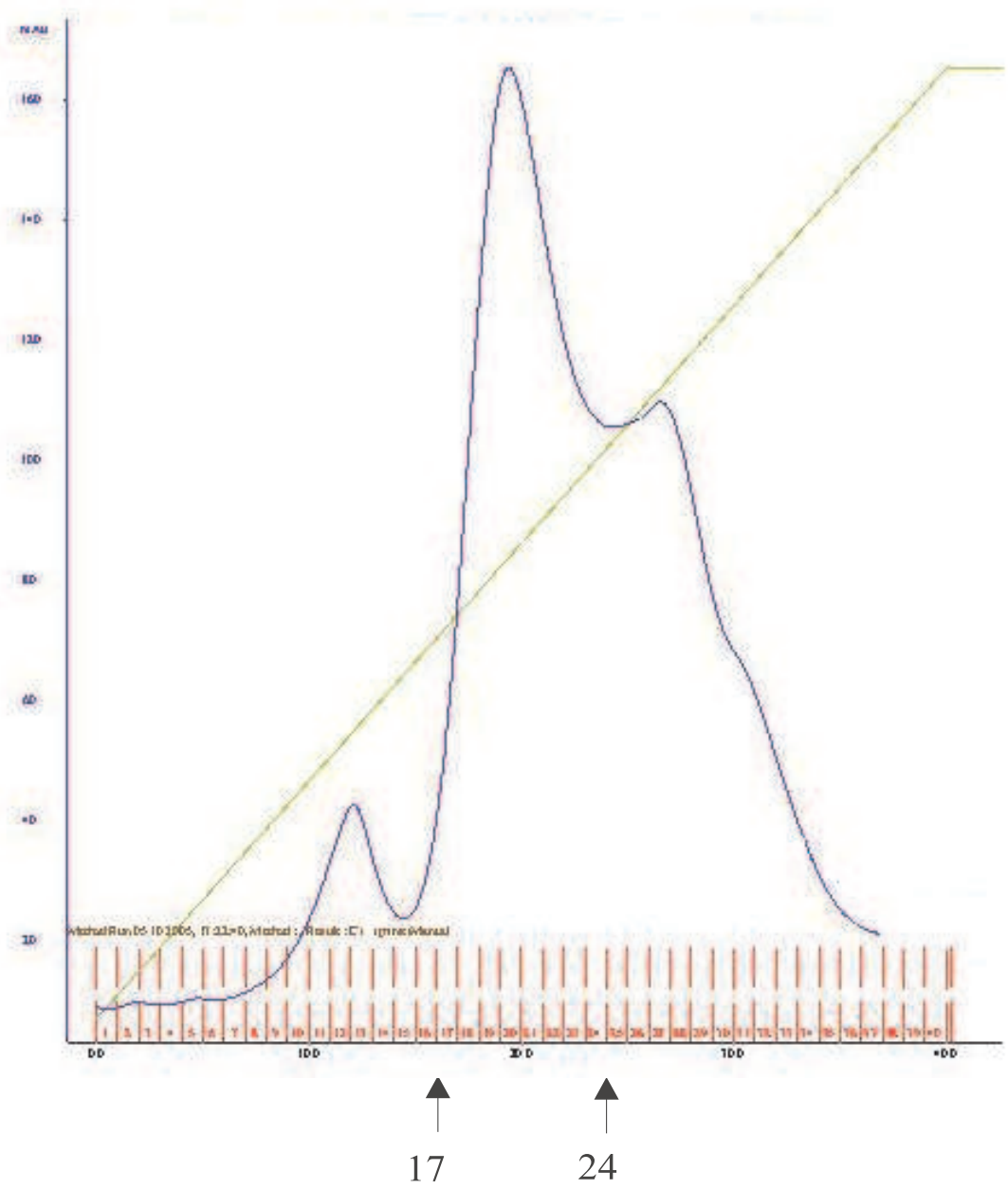

Abbildung 6.11: Reinigung der Se-Met-tPphA: Chromatogramm der Anionenaustauschersäule

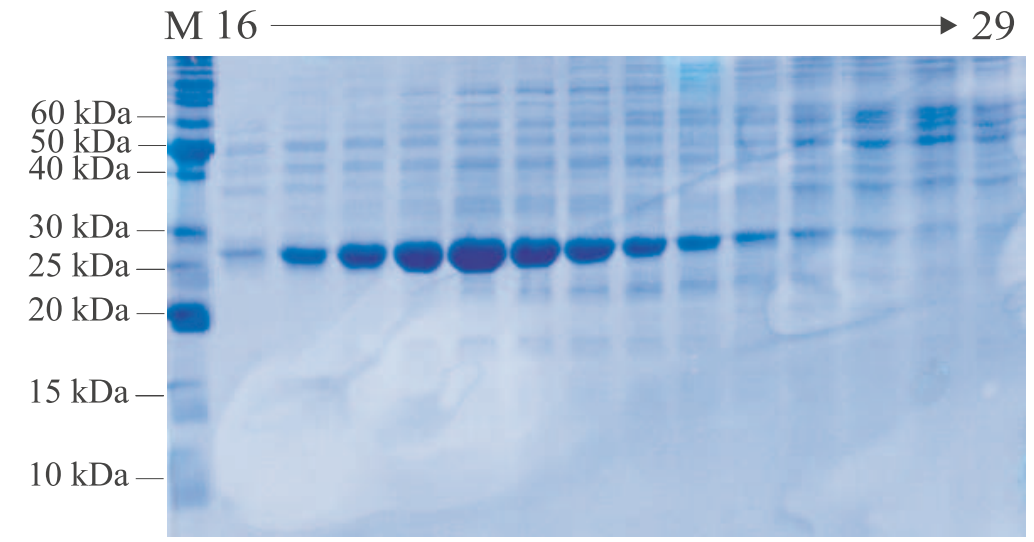

Abbildung 6.12: Reinigung der Se-Met-tPphA: SDS-Gel der Anionenaustauschersäule; 16-29: Fraktionen der Anionenaustauschersäule 


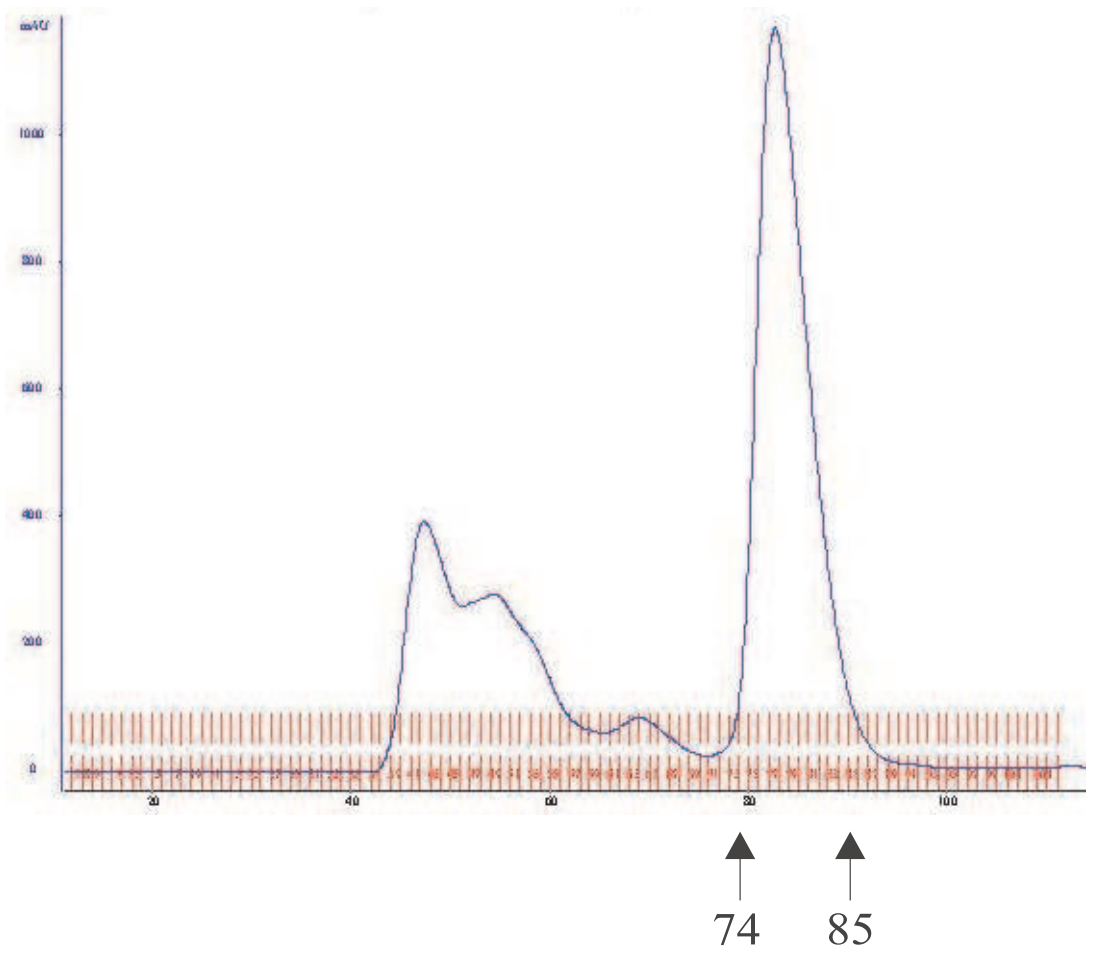

Abbildung 6.13: Reinigung der Se-Met-tPphA: Chromatogramm der Gelfiltrationssäule

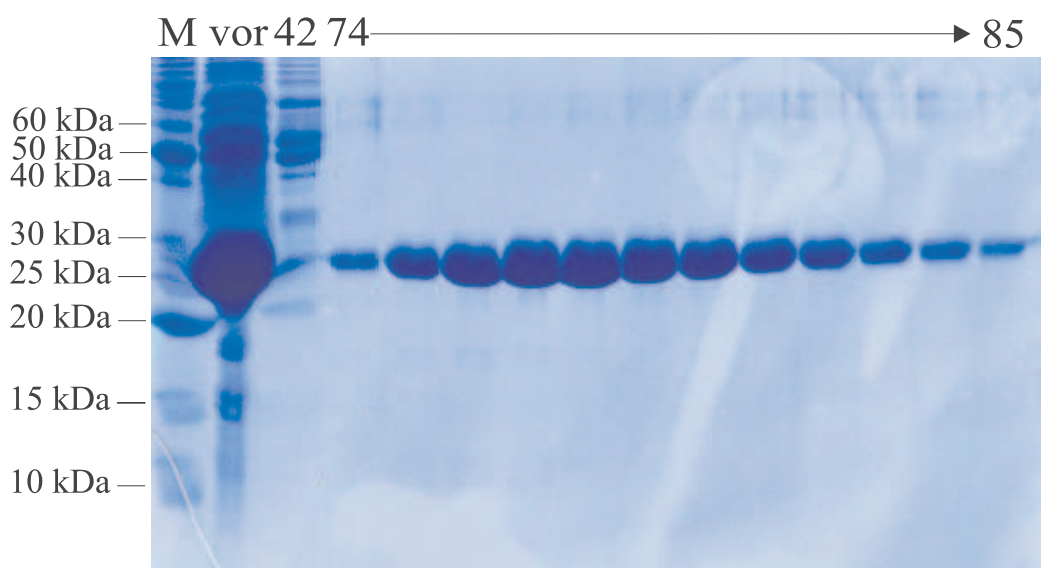

Abbildung 6.14: Reinigung der Se-Met-tPphA: SDS-Gel der Gelfiltrationssäule; vor: vor der Gelfiltration, 42: Verunreinigung, 74-85: Fraktionen der Se-Met-tPphA 


\subsection{Kristallisation und Datensammlung}

\subsubsection{Kristallisation}

Die ersten Kristallisationsansätze des nativen Proteins wurden mit Hilfe eines Roboters (Mosquito, TTP Labtech) angesetzt, wobei die Proteinkonzentration mit Puffer 2 (s. Tab. 2.1.8, S. 28) auf $36 \mathrm{mg} / \mathrm{ml}$ verdünnt wurde. Es wurden folgende Standardscreens verwendet:

- Hampton crystal screen 1 und 2

- Hampton PEG-Ion und Ammoniumsulfat screen

- Hampton Index screen

- Jena bioscience Wizard 1 und 2 screen

Die Tropfen wurden bei $20^{\circ} \mathrm{C}$ auf Greiner low profile 96 well Platten als sitting drops angesetzt. Nach einem Tag waren in fünf Bedingungen, die in den Tabellen 6.1 und 6.2 aufgeführt sind, Kristalle zu sehen.

\begin{tabular}{l|l|l}
\hline C4 (crystal screen 1+2) & G12 (Index screen) & F6 (Wizard screen 1+2) \\
\hline $0.2 \mathrm{M} \mathrm{NaAc}$ & $0.2 \mathrm{M} \mathrm{MgCl}_{2}$ & $0.2 \mathrm{M} \mathrm{CaAc}$ \\
$0.1 \mathrm{M}$ Na-Cacodylat pH 6.5 & $0.1 \mathrm{M}$ Hepes pH 7.5 & $0.1 \mathrm{M}$ Tris pH 7.0 \\
$30 \%$ PEG 8000 & $25 \%$ PEG 3 350 & $20 \%$ PEG 3000 \\
\hline
\end{tabular}

Tabelle 6.1: Kristallisationsbedingungen mit Metallionen

\begin{tabular}{l|l}
\hline D7 (Index screen) & D11 (Index screen) \\
\hline $\begin{array}{l}\text { 0.1 M bisTris pH 6.5 } \\
\text { 25\% PEG 3 350 }\end{array}$ & 28 \% PisTris pH 6.5 M MME 2 000 \\
\hline
\end{tabular}

Tabelle 6.2: Kristallisationsbedingungen ohne Metallionen

Die Kristalle ohne zusätzliche Metallionen in der Kristallisationslösung zeigten nur sehr schwache Beugungbilder ( 8 Å und schlechter), so daß vorerst für die Strukturlösung Kristallisationsansätze mit Metallionen verwendet wurden. Es wurde um Bedingung G12 des Index screens und um Bedingung F6 des Wizard screens variiert. Dabei wurden sowohl Greiner low profile 96 well Platten mit Hilfe des Roboters mit einer Tropfengröße von $200 \mathrm{nl}$ angesetzt als auch hanging drop 24 well Platten per Hand mit einer Tropfengröße von $1.6 \mu 1(0.8 \mu 1$ 

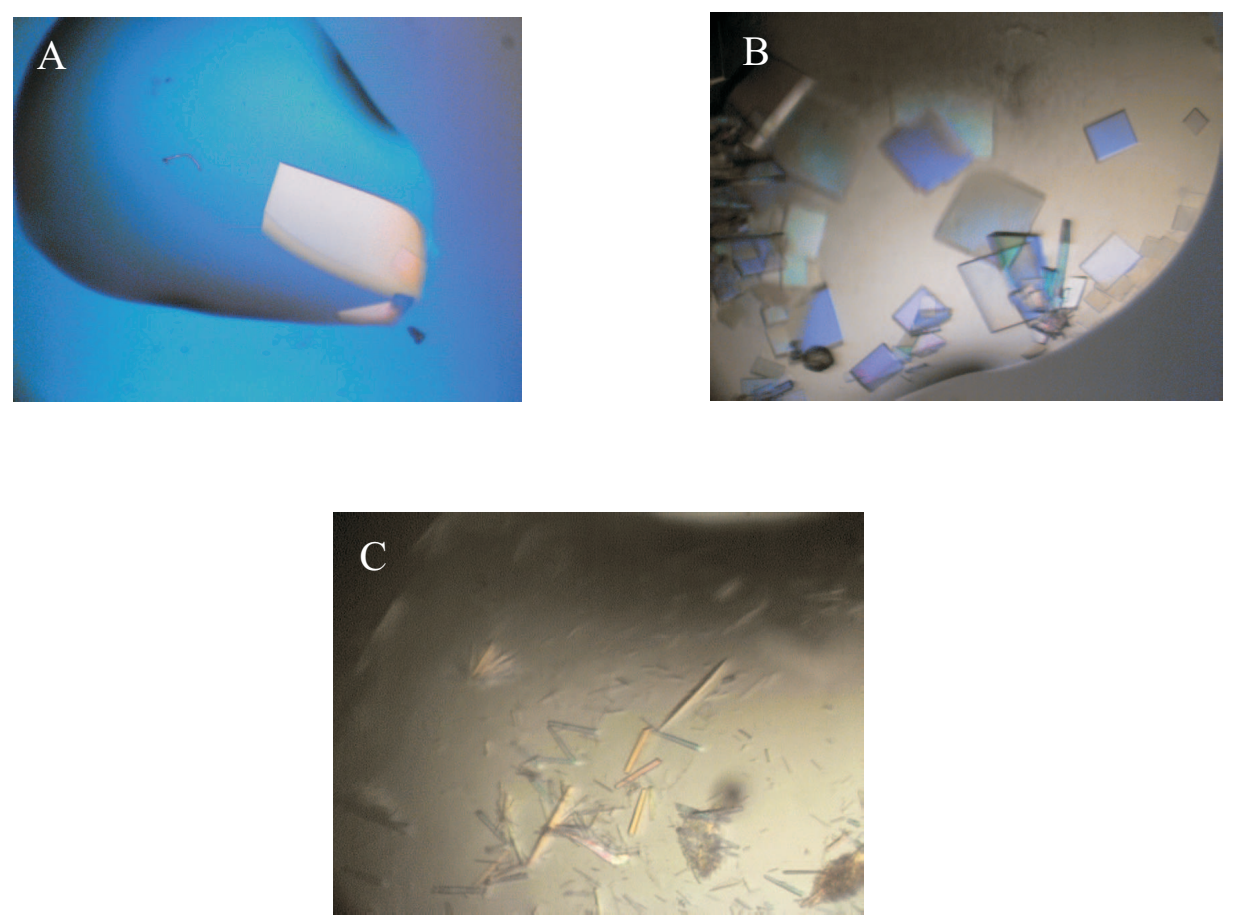

Abbildung 6.15: Kristalle der tPphA: a) native Kristalle $\left(200 \times 250 \times 50 \mu \mathrm{m}^{3}\right)$, b) Se-Met Kristalle $\left(200 \times 200 \times 50 \mu \mathrm{m}^{3}\right)$ und c) native Kristalle, die in $25 \mathrm{mM}$-NPP und $0.2 \mathrm{M} \mathrm{MgCl}_{2}$ gesoakt worden waren $\left(50 \times 50 \times 200 \mu \mathrm{m}^{3}\right)$.

Reservoir $+0.8 \mu$ l Protein). Alle weiteren Kristallisationsansätze wurden mit einer Proteinkonzentration von $36 \mathrm{mg} / \mathrm{ml}$ bei $20^{\circ} \mathrm{C}$ durchgeführt. Die verbesserten Kristallisationsansätze sind in Tabelle 6.3 (s. S. 95) aufgelistet. Hierbei wurde auch eine Bedingung ohne Metallionen für das native Protein verbessert. Die Kristalle sind in Abbildung 6.15 (s. S. 95) dargestellt.

\begin{tabular}{l|l|l}
\hline native Kristalle & Se-Met Kristalle & native Kristalle ohne Metallion \\
\hline $0.2 \mathrm{M} \mathrm{CaCl}_{2}$ & $0.2 \mathrm{M} \mathrm{CaCl}_{2}$ & - \\
$0.1 \mathrm{M}$ Tris pH 7.0 & $0.1 \mathrm{M}$ Hepes pH 8.0 & $0.1 \mathrm{M}$ Tris pH 7.0 \\
$23 \%$ PEG 3350 & $28 \%$ PEG 3350 & 25\% PEG 3 350 \\
\hline
\end{tabular}

Tabelle 6.3: Verbesserte Kristallisationsbedingungen

Für die Röntgenstrukturanalyse wurden sowohl die nativen als auch die Se-Met Kristalle in eine Lösung aus Reservoirlösung, die 15 \% 2,3-Butandiol enthielt, gegeben. Anschließend wurden sie in einer Schlaufe montiert und in flüssigem Stickstoff schockgefroren.

Um die Kristalle auf ihre Aktivität zu testen, wurden die nativen und die Se-Met Kristalle in eine Lösung, bestehend aus $25 \mathrm{mM}$-NPP, Reservoir und zusätzlich entweder $0.2 \mathrm{M} \mathrm{CaCl}_{2}$, 


\section{Strukturbestimmung der Phosphatase tPphA}

$0.2 \mathrm{M} \mathrm{MgCl}_{2}$ oder $0.2 \mathrm{M} \mathrm{MnCl}_{2}$, für ca. $1 \mathrm{~h}$ gegeben. Bei vorhandener Aktivität wurde Phosphat abgespalten, und es bildete sich gelbes $p$-Nitrophenol. Dies war im Fall des soakings mit $\mathrm{MgCl}_{2}$ und $\mathrm{MnCl}_{2} \mathrm{zu}$ sehen. Das Protein konnte somit also in seiner aktiven Form kristallisiert werden.

Die nativen Kristalle, die ohne Metallionen kristallisiert worden waren, zeigten nach dem soaking in $25 \mathrm{mM}$-NPP und $0.2 \mathrm{M} \mathrm{MgCl}_{2}$ an der in house Röntgenquelle ein Beugungsbild bis $3.5 \AA$ A. Sie wurden daraufhin in Reservoirlösung mit $15 \%$ 2,3-Butandiol transferiert, in flüssigem Stickstoff gefroren und sowohl am SLS an der beamline PX 6 (Diffraktion bis $2.75 \AA$ ) als auch am DESY an der beamline BW 6 (Diffraktion bis $3.00 \AA$ ) gemessen.

\subsubsection{Datensammlung}

Sowohl die hochaufgelösten nativen Daten (s. Tab. 6.4, S. 97) als auch die MAD-Daten wurden am DESY in Hamburg an der beamline BW 6 gesammelt (s. Tab. 6.5, S. 97). Für die nativen Daten wurden ein hoch aufgelöster Datensatz und ein niedrig aufgelöster Datensatz gesammelt, um Überbelichtungen bei niedrigen Beugungswinkeln zu vermeiden (s. Tab. 6.4, S. 97). Beide Datensätze wurden zusammen skaliert (mit X2SAD [73] und SADABS [74]). Außerdem wurden zwei Datensätze der nativen Kristalle, die ohne Metallionen kristallisiert und anschließend in eine $p$-NPP-Lösung gesoakt worden waren, gemessen. Ein Datensatz wurde am DESY an der beamline BW 6 aufgenommen, ein weiterer wurde am SLS an der beamline PX 6 gesammelt (s. Tab. 6.4, S. 97).

Für die Se-MAD-Daten wurde zuerst ein Fluoreszenz-Scan durchgeführt (s. Anhang S. 119), um die Wellenlängen für den peak und den inflection Datensatz zu ermitteln.

Anschließend wurden die Se-MAD Daten in folgender Reihenfolge gesammelt:

1. peak Datensatz

2. inflection Datensatz

3. high remote Datensatz (war in diesem Fall nicht mehr für die Lösung der Struktur nötig)

Die Datensätze wurden mit HKL2000 [72] integriert und mit X2SAD [73] und SADABS [74] skaliert. Anschließend wurden in XPREP [74] die Raumgruppe und das anomale Signal der Se-MAD-Daten überprüft. Das anomale Signal war in den peak Daten bis $2.2 \AA$ und in den inflection Daten bis 3.2 A vorhanden, wie in den Abbildungen 6.16 und 6.17 durch die rote Markierung verdeutlicht wird.

Die Korrelation der beiden Datensätze zeigte ein starkes anomales Signal bis $2.6 \AA$, so daß Daten bis 2.6 Å für die Strukturlösung verwendet werden konnten (s. Abb. 6.18).

Desweiteren konnten in XPREP [74] in der Harker Sektion y $=0$ der anomalen Elektronendichtekarte die drei Selenatome lokalisiert werden (s. Abb. 6.19,S. 98). 


\begin{tabular}{llll}
\hline Datensatz & nativ mit M & nativ ohne M & nativ ohne M \\
\hline beamline & DESY Hamburg, & DESY Hamburg, & SLS, \\
& BW 6 & BW 6 & PX 6 \\
Wellenlänge $(\AA)$ & 1.0500 & 1.0500 & 0.97629 \\
Detektor & MAR CCD & MAR CCD & MAR CCD \\
Raumgruppe & C222 1 & P4 $2{ }_{1} 2$ & P4 ${ }_{1} 2{ }_{1} 2$ \\
Zellparameter $(\AA)$ & $\mathrm{a}=38.941$, & $\mathrm{a}=113.418$ & $\mathrm{a}=113.291$ \\
& $\mathrm{~b}=152.128$, & $\mathrm{b}=113.418$ & $\mathrm{~b}=113.291$ \\
& $\mathrm{c}=82.437$ & $\mathrm{c}=88.579$ & $\mathrm{c}=88.610$ \\
Auflösungsgrenze $(\AA)$ & $1.22(1.32-1.22)$ & $3.00(3.10-3.00)$ & $2.75(2.84-2.75)$ \\
Unabhängige Reflexe & 72295 & 11141 & 14628 \\
Redundanz & $7.50(4.27)$ & $1.66(0.71)$ & $1.72(1.04)$ \\
Vollständigkeit $(\%)$ & $97.5(91.1)$ & $92.1(49.9)$ & $93.9(64.9)$ \\
mittleres I / $\sigma(\mathrm{I})$ & $14.72(2.10)$ & $7.31(1.44)$ & $13.08(2.87)$ \\
$\mathrm{R}_{\text {int }}(\%)$ & $6.44(52.45)$ & $7.88(31.58)$ & $4.22(21.82)$ \\
\hline
\end{tabular}

Tabelle 6.4: Datensammlung für die nativen tPphA Kristalle; M: Metallion

\begin{tabular}{llll}
\hline Datensatz & peak & inflection & high remote \\
\hline beamline & DESY Hamburg, & BW 6 & \\
Wellenlänge $(\AA)$ & 0.9792 & 0.9796 & 0.9500 \\
Detektor & MAR CCD & MAR CCD & MAR CCD \\
Raumgruppe & C222 1 & C222 1 & C222 1 \\
Zellparameter $(\AA)$ & & $\mathrm{a}=38.941$, & \\
& & $\mathrm{b}=152.128$, & \\
& & $\mathrm{c}=82.437$ & \\
Auflösungsgrenze $(\AA)$ & $2.06(2.16-2.06)$ & $2.06(2.16-2.06)$ & $2.06(2.16-2.06)$ \\
Unabhängige Reflexe & 13345 & 13330 & 15307 \\
Redundanz & $14.32(13.98)$ & $7.00(5.90)$ & $7.11(6.74)$ \\
Vollständigkeit $(\%)$ & $99.5(97.8)$ & $97.7(82.6)$ & $99.5(98.3)$ \\
mittleres I / $\sigma(\mathrm{I})$ & $42.33(20.37)$ & $31.54(14.22)$ & $28.58(12.01)$ \\
$\mathrm{R}_{\text {int }}(\%)$ & $4.94(14.22)$ & $4.12(13.53)$ & $4.02(15.06)$ \\
\hline
\end{tabular}

Tabelle 6.5: Datensammlung für Se-Met tPphA 
6 Strukturbestimmung der Phosphatase tPphA

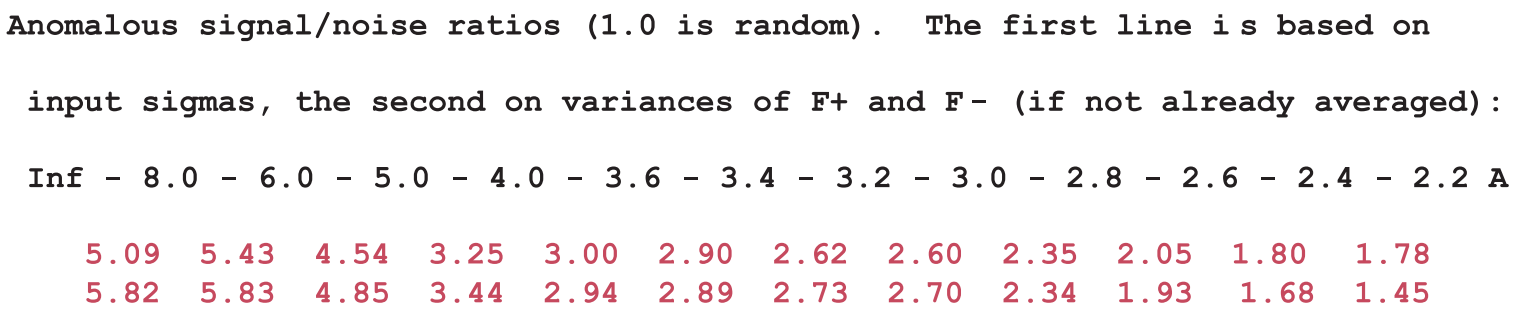

Abbildung 6.16: Anomales I/sigma für den peak Datensatz

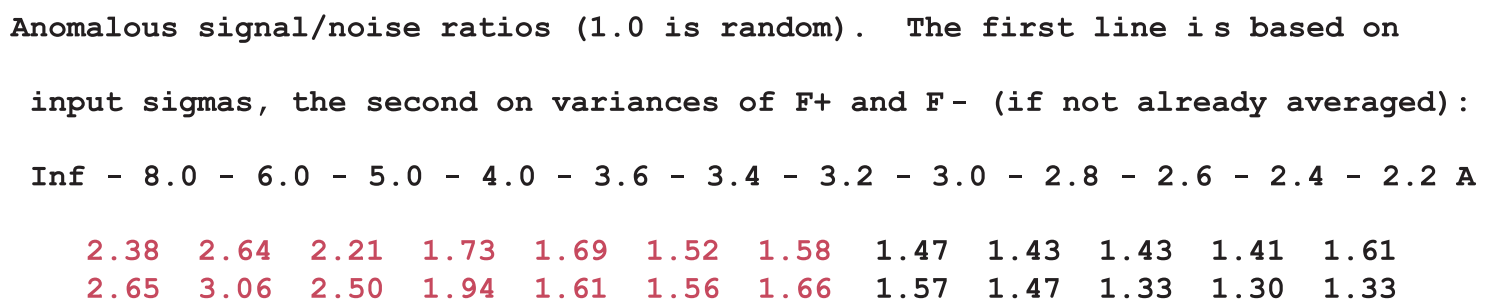

Abbildung 6.17: Anomales I/sigma für den inflection Datensatz

\section{Anomalous correlation coefficients (\%) against previous datasets}

Inf $-8.0-6.0-5.0-4.0-3.6-3.4-3.2-3.0-2.8-2.6-2.4-2.2 \mathrm{~A}$

$\begin{array}{llllllllllll}74.4 & 92.0 & 87.3 & 78.8 & 58.8 & 65.6 & 43.0 & 65.4 & 56.8 & 30.7 & 14.4 & 19.1\end{array}$

Abbildung 6.18: Korrelation zwischen peak und inflection Datensatz

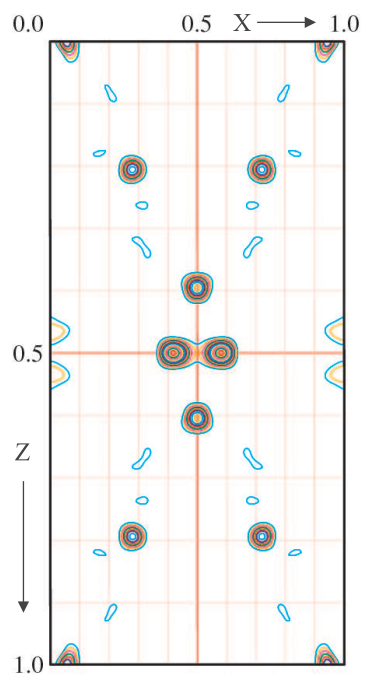

Abbildung 6.19: Harker Sektion entlang y $=0$; Kontourlevel liegt bei 1.0 sigma 


\subsection{Strukturlösung und -verfeinerung}

\subsubsection{Die tPphA-Struktur in der Raumgruppe C222}

Mit Hilfe des Programms hkl2map [92] konnten, wie erwartet, die drei Schweratompositionen der Se-Met aus dem Se-MAD Experiment ermittelt werden. Anschließend konnten aus den Schweratompositionen die Phasen und unter Zuhilfenahme der Dichtemodifikation eine interpretierbare Elektronendichtekarte der Proteinstruktur bestimmt werden.

In die Elektronendichte wurde mit Hilfe des Programms ARP/wARP [93] die Proteinstruktur modelliert, wobei $79.6 \%$ der Struktur anhand der vorgegebenen Sequenz gebaut werden konnten. Es fehlten jedoch einige loops, die in den weiteren Verfeinerungsschritten mit REFMAC5 [85,94] und COOT [84] vervollständigt wurden:

- Aminosäuren 37-40

- Aminosäuren 85-95

- Aminosäuren 142-175

- Aminosäuren 210-211

Die fehlenden loops, ausgehend von Aminosäure 144 bis 159 bzw. 37 bis 40, konnten nicht modelliert werden, da sie zu flexibel waren und daher nicht in der Elektronendichte zu sehen waren.

Nachdem das Modell vervollständigt worden war, wurde mit dem Programm SHELXL [86] anisotrop verfeinert, Wasserstoffatome gesetzt, Besetzungen neu berechnet und Fehlordnungen modelliert. Es konnten sechs Fehlordnungen an folgenden Aminosäuren verfeinert werden: Arg54, His81, Ser135, Cys166, Ile180 und His227 (s. Abb. 6.20, S. 100). Desweiteren konnte eine Fehlordnung an einem der drei Metallzentren ermittelt werden. Die Verhältnisse der Besetzungen der fehlgeordneten Reste sind in Tabelle 6.6 aufgeführt.

Außerdem wurden die Besetzungen einiger loops/Reste verfeinert. Für die Besetzung des loops der Aminosäuren 82 bis 94 ergab sich eine Besetzung von 85.2\%. Die Besetzung der Aminosäuren 142 bis 162 nahe der fehlenden loop-Region wurde auf $85.7 \%$ verfeinert.

Das endgültige Modell enthielt ein Monomer von $\mathrm{tPphA}$, drei Metallionen $\left(\mathrm{Ca}^{2+} / \mathrm{Mg}^{2+}\right)$ und 136 Wassermoleküle in der asymmetrischen Einheit. Die endgültigen Verfeinerungsdaten sind in Tabelle 6.7 (s. S. 101) aufgeführt. Die Proteinstruktur wurde mit Hilfe des Programmes PROCHECK [100] auf seine Konsistenz geprüft. Der Ramachandran Graph wies keine Aminosäure in nicht erlaubten Regionen auf. 


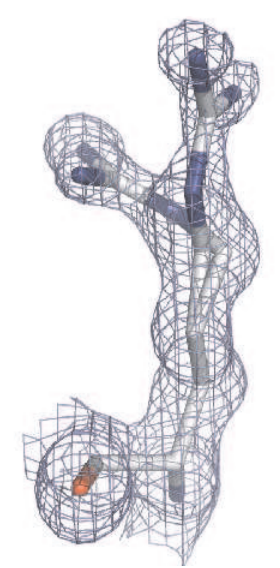

Arginin 54

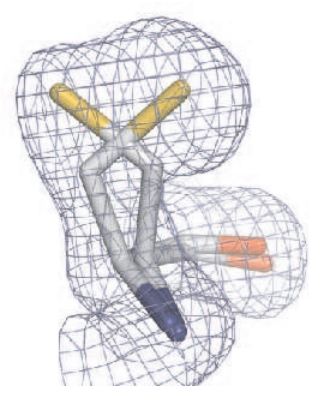

Cystein 166

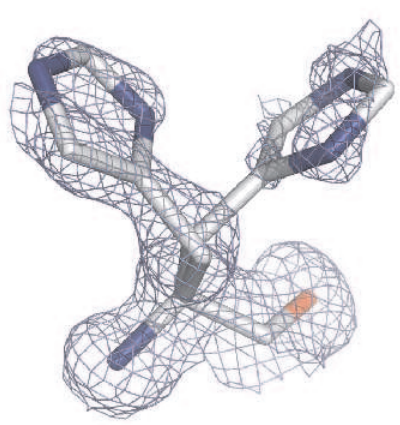

Histidin 81

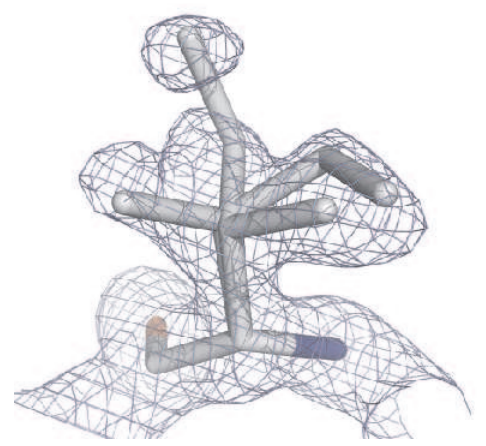

Isoleucin 180

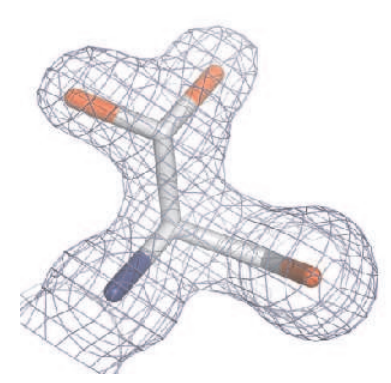

Serin 135

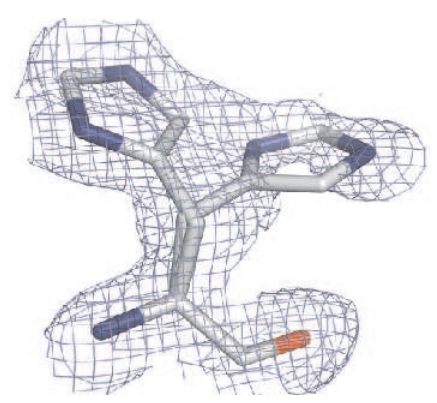

Histidin 227

Abbildung 6.20: Fehlordnungen in der tPphA-Struktur

\begin{tabular}{llll}
\hline Residue & Anteil A in $\%$ & Anteil B in \% & Fehlordnung ab dem folgenden Atom \\
\hline Arginin 54 & 57.2 & 42.8 & $\mathrm{CD}$ \\
Histidin 81 & 74.1 & 25.9 & $\mathrm{CB}$ \\
Serin 135 & 35.9 & 64.1 & $\mathrm{OG}$ \\
Cystein 166 & 26.3 & 73.7 & der gesamte Rest \\
Isoleucin 180 & 62.9 & 37.1 & $\mathrm{CB}$ \\
Histidin 227 & 68.9 & 31.1 & $\mathrm{CB}$ \\
$\mathrm{Mg}^{2+} / \mathrm{Ca}^{2+}$ & $63.4(\mathrm{Mg})$ & $36.4(\mathrm{Ca})$ & der gesamte Rest \\
\hline
\end{tabular}

Tabelle 6.6: Besetzungs- bzw. Fehlordnungsverfeinerung 


\begin{tabular}{ll}
\hline $\mathrm{R}_{\text {Kristall }}$ & 16.63 \\
$\mathrm{R}_{\text {Free }}$ & 20.83 \\
Anzahl der Proteinatome & 1822 \\
Anzahl der Heteroatome & 3 \\
Anzahl der Wasseratome & 136 \\
Mittlerer B-Wert $\left(\AA^{2}\right)$ & 27.979 \\
der Hauptkette & 25.815 \\
der Seitenketten & 30.031 \\
Standardabweichung & \\
der Bindungslängen $(\AA)$ & 0.013 \\
der Bindungswinkelabstände $(\AA)$ & 0.037 \\
Ramachandran Analyse $(\%)$ & \\
am meisten favorisierte Region & 92.4 \\
erlaubte Region & 7.6 \\
generell erlaubte Region & 0 \\
nicht erlaubte Region & 0 \\
\hline
\end{tabular}

Tabelle 6.7: Verfeinerung der tPphA-Struktur in C222

\subsubsection{Die tPphA-Struktur in der Raumgruppe $P 4_{1} 2_{1} 2$}

Die Struktur von tPphA in der Raumgruppe P4 ${ }_{1} 2{ }_{1} 2$ wurde mittels molekularen Ersatzes mit dem Programm PHASER [95] gelöst. Dazu wurde das Modell von tPphA aus der Struktur in der Raumgruppe C222 1 ohne Wassermoleküle und ohne Metallionen verwendet. Die Strukturlösung ergab zwei Moleküle der tPphA und sechs $\mathrm{Mg}^{2+}$-Ionen, die aus der soaking-Lösung stammten, in der asymmetrischen Einheit. Besonders auffallend bei den beiden Monomeren war, daß die flexible loop-Region der Aminosäuren 144 bis 159 in Monomer A bis auf drei Aminosäuren (153-155) gebaut werden konnte, und in Monomer B vollständig geordnet vorlag. Somit konnte in Monomer B der loop in die Dichte mit dem Programm COOT [80] modelliert werden. Die Verfeinerung wurde mit dem Programm REFMAC5 [85,94] vorgenommen. Da die Ramachandran Analyse für die verfeinerte Struktur viele geometrisch schlecht orientierte Aminosäuren anzeigte (s. Tab. 6.8, S. 102), wurden einerseits nur die DESY- oder nur die SLS-Daten für die Verfeinerung verwendet. Andererseits wurden aber auch beide Datensätze in XPREP [74] gemittelt, wobei sich ein $\mathrm{R}_{\text {int }}$ von $14.73 \%$ ergab. Außerdem wurde versucht, eine Verbesserung der Verfeinerung durch Hinzunahme von NCS-restraints zu erreichen, was jedoch nicht erzielt werden konnte. Aufgrund der schlechten Daten und der niedrigen Auflösung wurden alle drei Datensätze parallel verfeinert. Die Statistiken der drei Verfeinerungen sind in Tabelle 6.8 aufgeführt. 
6 Strukturbestimmung der Phosphatase tPphA

\begin{tabular}{llll}
\hline & $\begin{array}{l}\text { native Kristalle } \\
\text { ohne M } \\
(\text { DESY) }\end{array}$ & $\begin{array}{l}\text { native Kristalle } \\
\text { ohne M } \\
(\text { SLS })\end{array}$ & $\begin{array}{l}\text { native Kristalle } \\
\text { ohne M } \\
\text { (gemittelt) }\end{array}$ \\
\hline $\mathrm{R}_{\text {Kristall }}$ & 28.9 & 27.7 & 27.5 \\
$\mathrm{R}_{\text {Free }}$ & 35.0 & 34.5 & 35.2 \\
Anzahl der Proteinatome & 3187 & 3187 & 3187 \\
Anzahl der Heteroatome & 6 & 6 & 6 \\
Anzahl der Wasseratome & 21 & 21 & 21 \\
Mittlerer B-Wert $\left(\AA^{2}\right)$ & 32.952 & 56.065 & 48.171 \\
der Hauptkette & 33.011 & 56.225 & 48.314 \\
der Seitenketten & 32.870 & 55.841 & 47.974 \\
Standardabweichung & & & \\
der Bindungslängen $(\AA)$ & 0.010 & 0.012 & 0.013 \\
der Bindungswinkel $\left({ }^{\circ}\right)$ & 1.832 & 2.044 & 2.104 \\
Ramachandran Analyse $(\%)$ & & & 79.6 \\
am meisten favorisierte Region & 78.1 & 80.0 & 13.0 \\
erlaubte Region & 14.2 & 12.3 & 3.8 \\
generell erlaubte Region & 3.1 & 3.1 & 3.6 \\
unerlaubte Region & 4.6 & 3.8 & \\
\hline
\end{tabular}

Tabelle 6.8: Verfeinerung der tPphA-Struktur in $\mathrm{P}_{4}{ }_{2}{ }_{1} 2$; M: Metallion 


\section{Ergebnisse}

\subsection{Struktur von tPphA in $\mathrm{C} 222_{1}$}

\subsubsection{Strukturbeschreibung von tPphA}

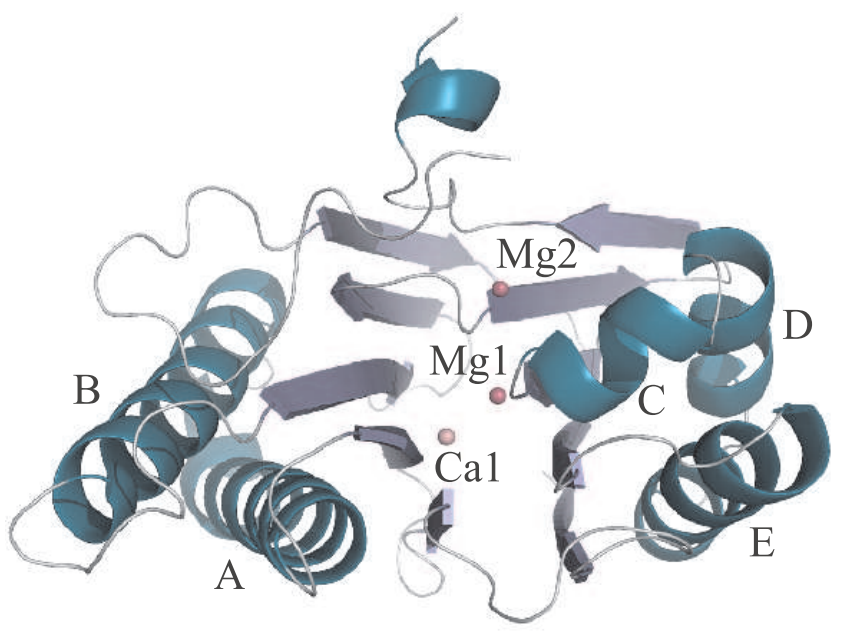

a)

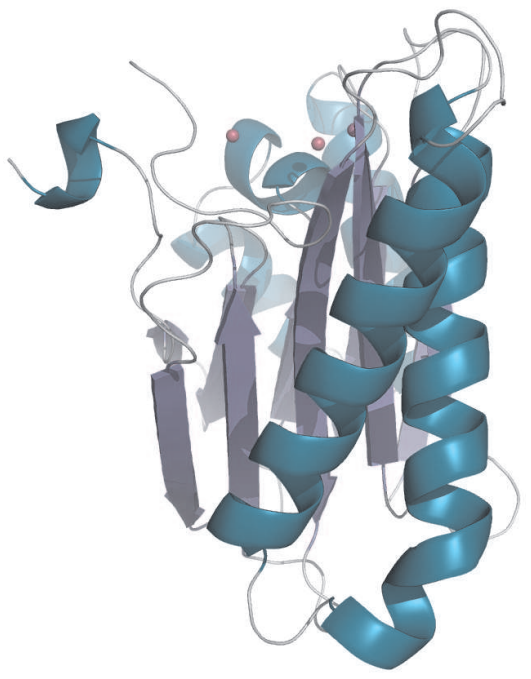

b)

Abbildung 7.1: Struktur von tPphA in C222 . Auf der Lage von $\mathrm{Mg} 1$ befinden sich sowohl $\mathrm{Mg}^{2+}$ als auch $\mathrm{Ca}^{2+}$; die $\alpha$-Helices sind mit den Indices A bis E gekennzeichnet.

In der Raumgruppe C222 1 liegt ein Monomer von tPphA in der asymmetrischen Einheit vor, bei dem die Aminosäuren 144 bis 159 nicht in der Elektronendichtekarte zu sehen sind (s. Abb. 7.1). Diese bilden eine loop-Region, die in dieser Raumgruppe sehr flexibel ist und in der Elektronendichtekarte nicht sichtbar ist. Daher wurden sie nicht in das Modell eingefügt. Desweiteren liegen in der asymmetrischen Einheit drei Metallionen vor, wobei eine Lage eindeutig mit $\mathrm{Ca}^{2+}$, eine weitere eindeutig mit $\mathrm{Mg}^{2+}$ und die dritte sowohl mit $\mathrm{Mg}^{2+}$ als auch $\mathrm{Ca}^{2+}$ besetzt verfeinert werden konnte. Die Struktur von tPphA besteht aus einer zentralen $\beta$ Faltblattstruktur, die von insgesamt fünf $\alpha$-Helices umgeben ist. Die $\beta$-Faltblätter sind anti- 


\section{Ergebnisse}

parallel angeordnet. Insgesamt liegen auf jeder Seite der $\beta$-Faltblattstruktur fünf $\beta$-Faltblätter vor.

\subsubsection{Das aktive Zentrum}

Im aktiven Zentrum von tPphA liegen drei Metallionen vor. Diese bestimmen die Enzymaktivität. Desweiteren wird die Enzymaktivität vom $\mathrm{pH}$-Wert der Lösung, der oberhalb eines Wertes von 8.0 liegen sollte, bestimmt. Ist $\mathrm{Mg}^{2+}$ oder $\mathrm{Mn}^{2+}$ im aktiven Zentrum des Enzyms vorhanden, ist das Protein in der Lage, Phosphat von einem phosphorylierten Serin abzuspalten. Liegt hingegen $\mathrm{Ca}^{2+}$ im aktiven Zentrum vor, ist das Enzym inaktiv. Es wurde daher ein Aktivitätstest mit $p$-NPP durchgeführt (s. Abschnitt Kristallisation ab S. 94), der die Aktivität der Kristalle bestätigte. Nach dem soaking in die $p$-NPP-haltige Lösung zeigte sich nach $1 \mathrm{~h}$ die gelbe Färbung des freiwerdenden $p$-NPs.

Das aktive Zentrum ist in Abbildung 7.2 (s. S. 104) dargestellt. Das Kalziumion Ca1 ist

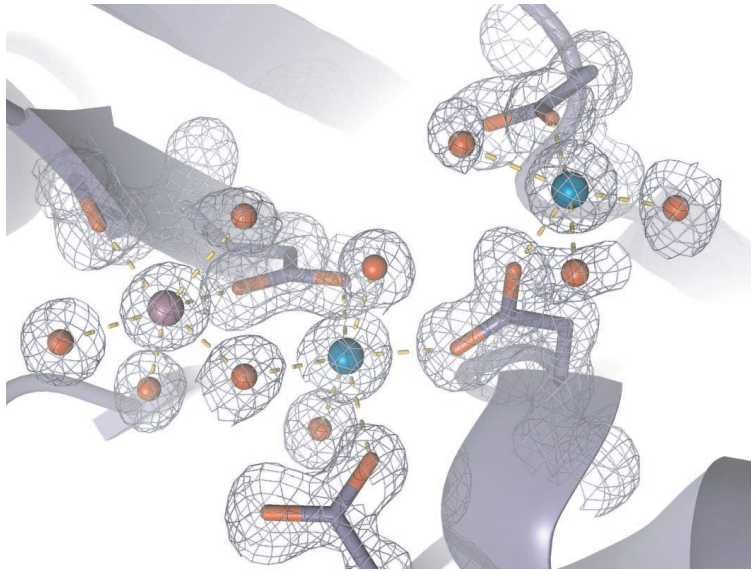

a)

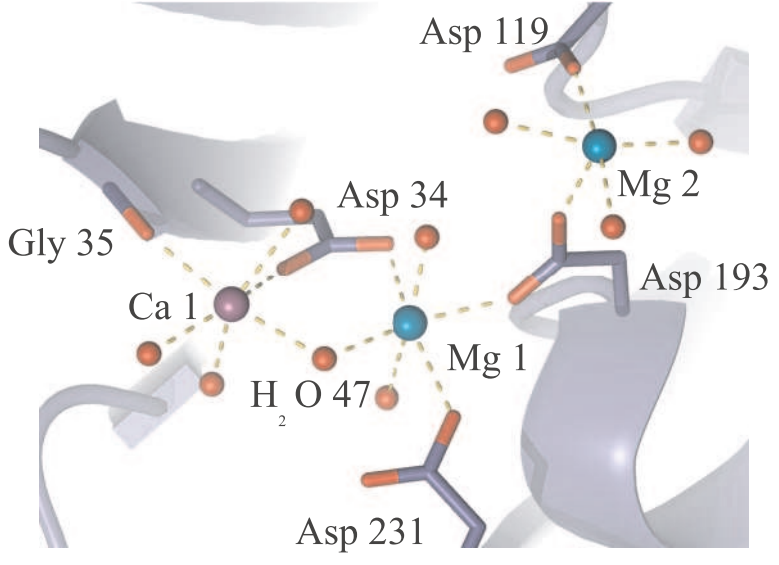

b)

Abbildung 7.2: Aktives Zentrum von tPphA: a) mit Elektronendichtekarte, b) mit Beschriftung der Aminosäuren, die an der Bindung der Metallionen beteiligt sind.

von vier Wassermolekülen $\left(\mathrm{H}_{2} \mathrm{O} 25,37,47\right.$ und 70), von einem Hauptkettensauerstoffatom des Gly35 und dem OD1 des Asp34 umgeben. Das Magnesiumion Mg1 koordiniert drei Wassermoleküle ( $\mathrm{H}_{2} \mathrm{O}$ 6, 47 und 98), OD2 des Asp34, OD1 des Asp193 und OD2 des Asp231. Das Magnesiumion $\mathrm{Mg} 2$ bildet nur fünf Koordinationen zu drei Wassermolekülen $\left(\mathrm{H}_{2} \mathrm{O} 68\right.$, 69 und 100), OD2 des Asp119 und OD2 des Asp193 aus. Die sechste Koordinationsstelle ist frei. Sie könnte von einer Aminosäure aus der flexiblen FLAP-Region gebildet werden. Da sie jedoch in die flexible FLAP-Region fällt, ist sie nicht in der Elektronendichtekarte sichtbar. Man sieht, daß die beiden Metallionen Ca1 und Mg1 jeweils das $\mathrm{H}_{2} \mathrm{O}$-Molekül 47 koordinieren. Dieses überbrückende $\mathrm{H}_{2} \mathrm{O}$-Molekül ist das katalytische Nukleophil, welches 
für die Dephosphorylierung benötigt wird. Bei den Aminosäuren, die an der Koordination der Metallionen beteiligt sind, handelt es sich um konservierte Aminosäuren, die auch in der PstP Struktur und der menschlichen PP2C vorliegen.

\subsection{Struktur von tPphA in $\mathrm{P4}_{1} 2_{1} 2$}

\subsubsection{Strukturbeschreibung von tPphA}

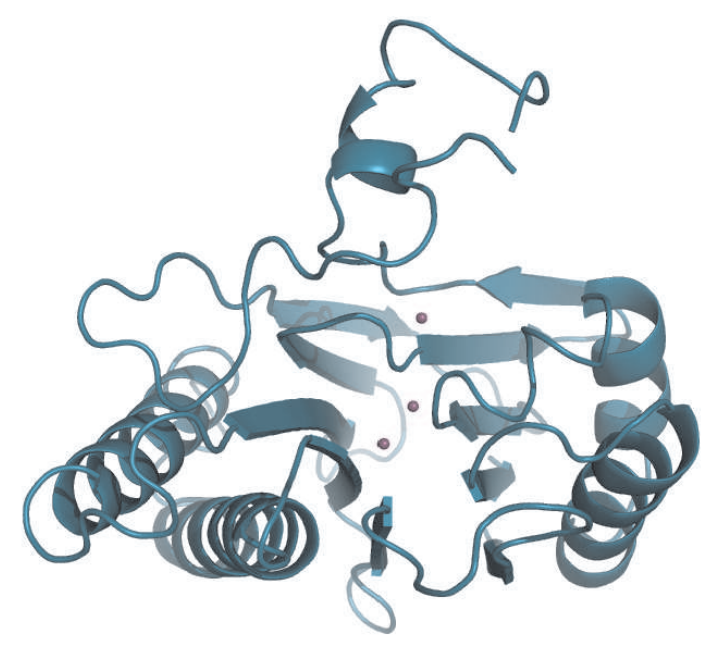

a)

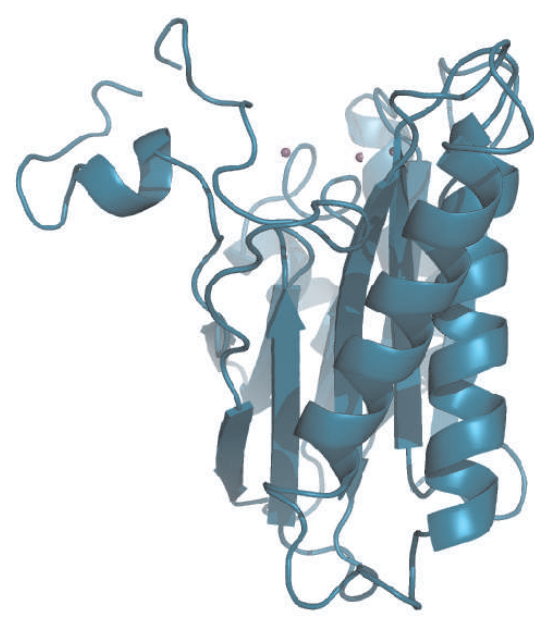

b)

Abbildung 7.3: Struktur von tPphA in $\mathrm{P}_{1}{ }_{2} 2_{1} 2$ Monomer A; die lilafarbenen Kugel stellen die drei Magnesiumionen dar

Die asymmetrische Einheit der tPphA-Struktur in der Raumgruppe P4 ${ }_{1}{ }_{1} 2$ umfaßt zwei Monomere von tPphA, sechs Magnesiumionen und 21 Wassermoleküle. In dieser Raumgruppe ist die sehr flexible FLAP-Region, die in der Raumgruppe C222 1 nicht modelliert werden konnte, in der Elektronendichtekarte sichtbar. Im Fall des Monomers A konnte sie bis auf die Aminosäuren 153 bis 155 vollständig gebaut werden. Im Fall des Monomers B konnte die FLAP-Region komplett modelliert werden, es waren jedoch die folgenden Bereiche nicht in der Elektronendichte sichtbar: Met1, Lys64 bis Gln65 und Lys105 bis Arg111. Die Tertiärstruktur von tPphA in der Raumgruppe P4 ${ }_{1} 2{ }_{1} 2$ umfaßt genauso wie die tPphA-Struktur in $\mathrm{C} 222_{1}$ ein zehnsträngiges, antiparalleles $\beta$-Sandwich, welches an zwei Seiten von insgesamt fünf $\alpha$-Helices umgeben ist. Das Besondere an den beiden Monomeren ist, daß sie die flexible loop-Region enthalten, wobei sie in beiden Monomeren leicht unterschiedlich geformt ist. 


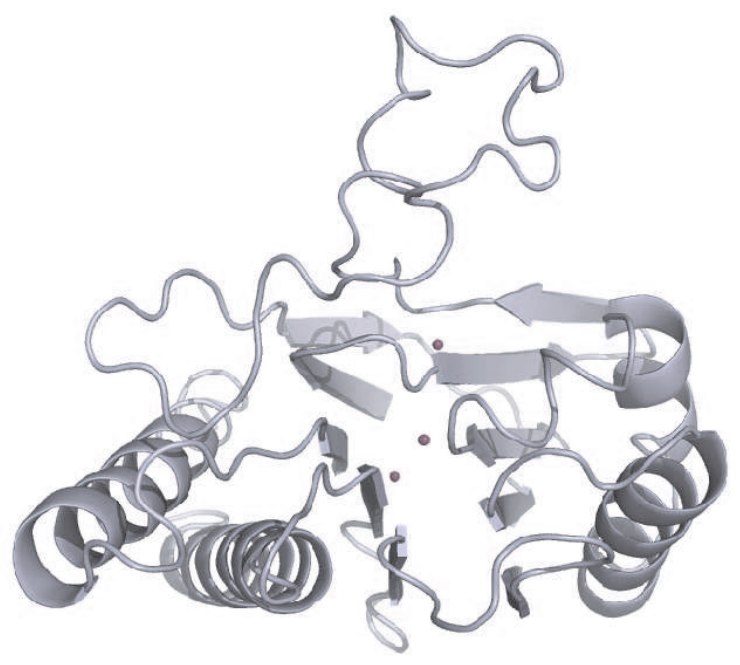

a)

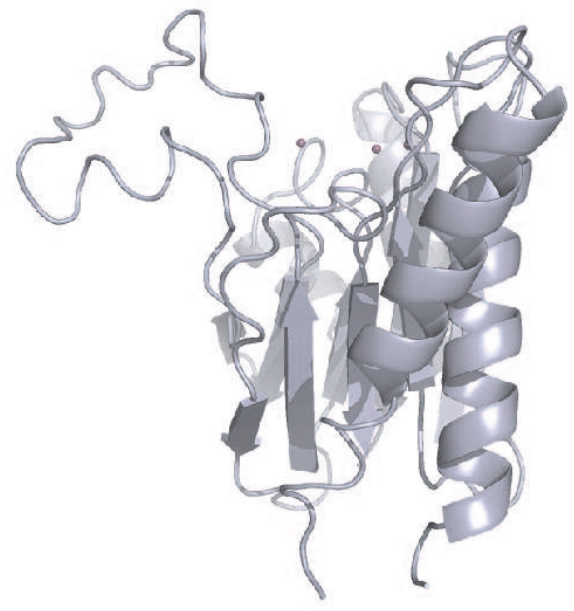

b)

Abbildung 7.4: Struktur von tPphA in $\mathrm{P}_{1}{ }_{2}{ }_{1} 2$ Monomer B; die lilafarbenen Kugel stellen die drei Magnesiumionen dar

\subsubsection{Das aktive Zentrum}

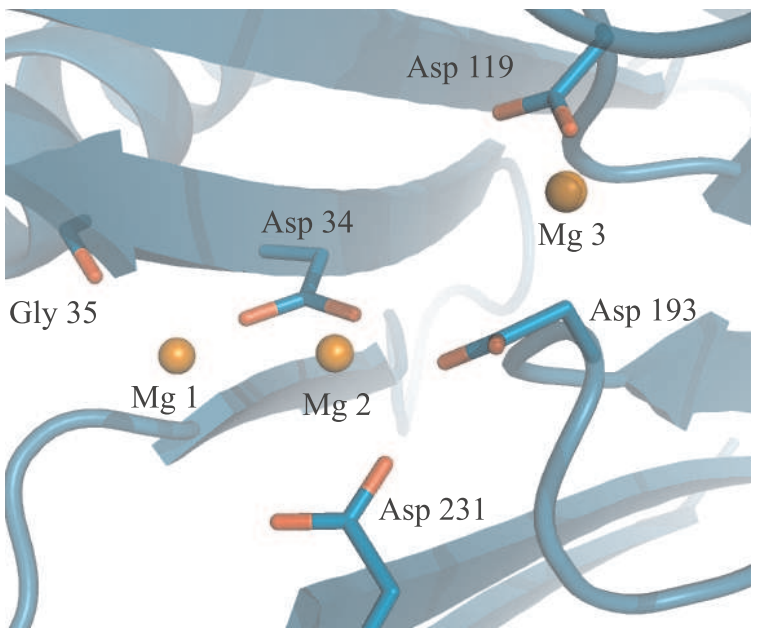

a)

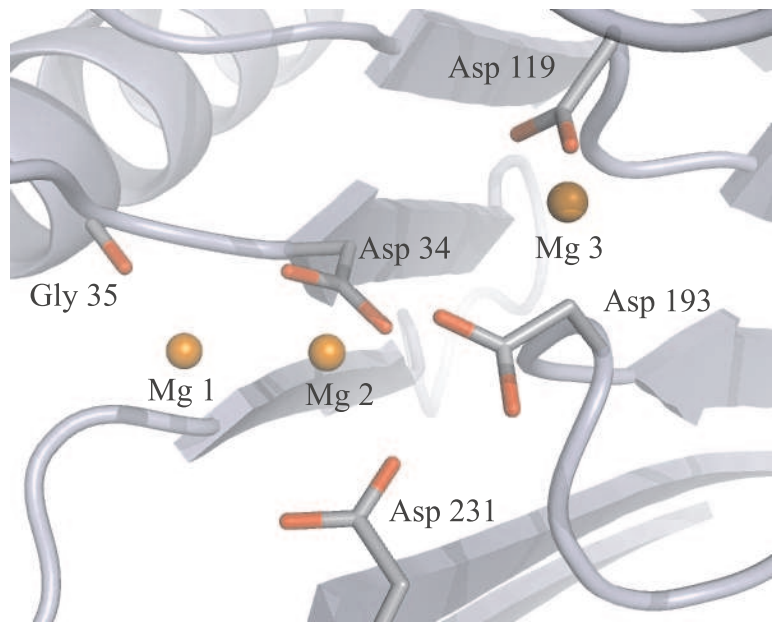

b)

Abbildung 7.5: Das aktive Zentrum in der tPphA-Struktur in $\mathrm{P} 4{ }_{1} 2{ }_{1} 2$ : a) Monomer A, b) Monomer B.

Die Kristallisation für die Strukturlösung in $\mathrm{P} 4{ }_{1} 2{ }_{1} 2$ erfolgte ohne Metallionen. Trotzdem sind in den beiden aktiven Zentren sechs Magnesiumionen gebunden. Dies ist nicht verwunderlich, 
da die Kristalle in eine $\mathrm{Mg}^{2+}$-haltige soaking-Lösung überführt wurden. Da die Kristalle nach dem soaking eine gelbe Färbung aufgrund des freiwerdenden $p$-NPs zeigten, lag somit die aktive Form von tPphA vor. In jedem Monomer sind jeweils drei Magnesiumionen im aktiven Zentrum vorhanden. Diese sind auch von den Aminosäuren Asp34, Gly35, Asp119, Asp193 und Asp231 umgeben (s. Abb. 7.5, S. 106). Es fehlen jedoch im Gegensatz zu der Struktur in C2221 die Wassermoleküle, welche die oktaedrische Koordination komplettieren. Diese sind bei einer Auflösung von ca. $3 \AA$ in der Elektronendichtekarte schlecht lokalisierbar. Außerdem sind einige Aminosäuren anders positioniert als in der C222 ${ }_{1}$-Struktur, so daß die Metallionen, wie in Tabelle 7.1 (s. S. 107) aufgeführt, koordiniert sind.

\begin{tabular}{lll}
\hline & Monomer A & Monomer B \\
\hline Mg1 & OD1 (Asp34): 2.05 & OD2 (Asp34): $2.57 \AA$ \\
& O (Gly35): 2.39 & O (Gly35): 2.07 \\
Mg2 & OD2 (Asp231): 2.21 & OD2 (Asp231): $2.41 \AA$ \\
& OD1 (Asp193): 2.13 & OD2 (Asp193): $2.25 \AA$ \\
& OD2 (Asp34): 2.01 & OD1 (Asp34): $2.27 \AA$ \\
& & OD2 (Asp34): $2.28 \AA$ \\
Mg3 & OD2 (Asp119): 2.09 & OD2 (Asp119): $2.17 \AA$ \\
\hline
\end{tabular}

Tabelle 7.1: Wasserstoffbrückenbindungen der Magnesiumionen im aktiven Zentrum 


\section{Diskussion}

\subsection{Vergleich von tPphA in den verschiedenen Raumgruppen}

\subsubsection{Tertiärstruktur}

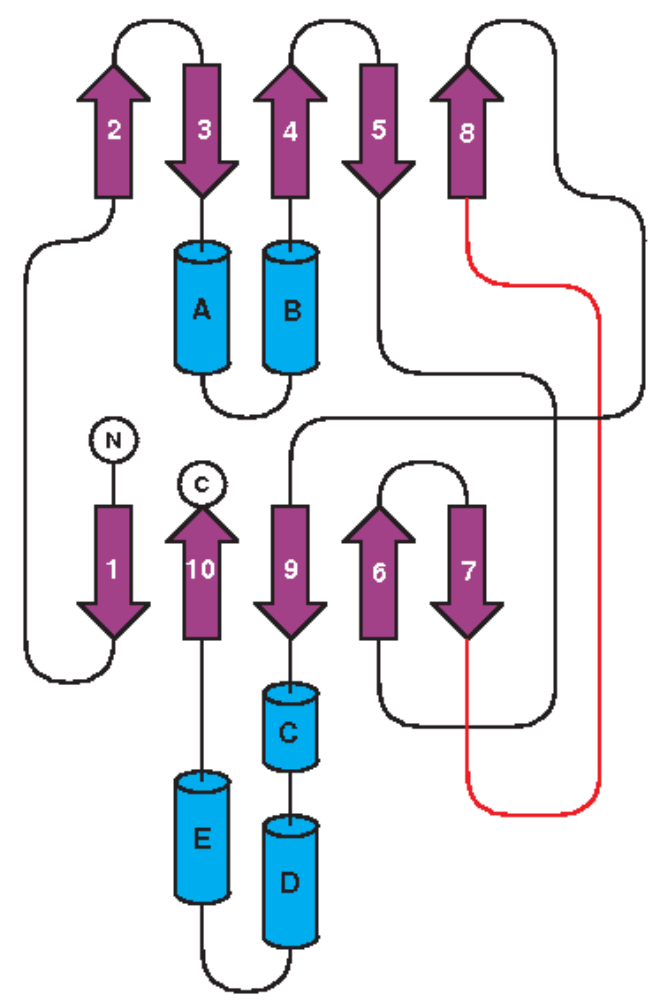

a)

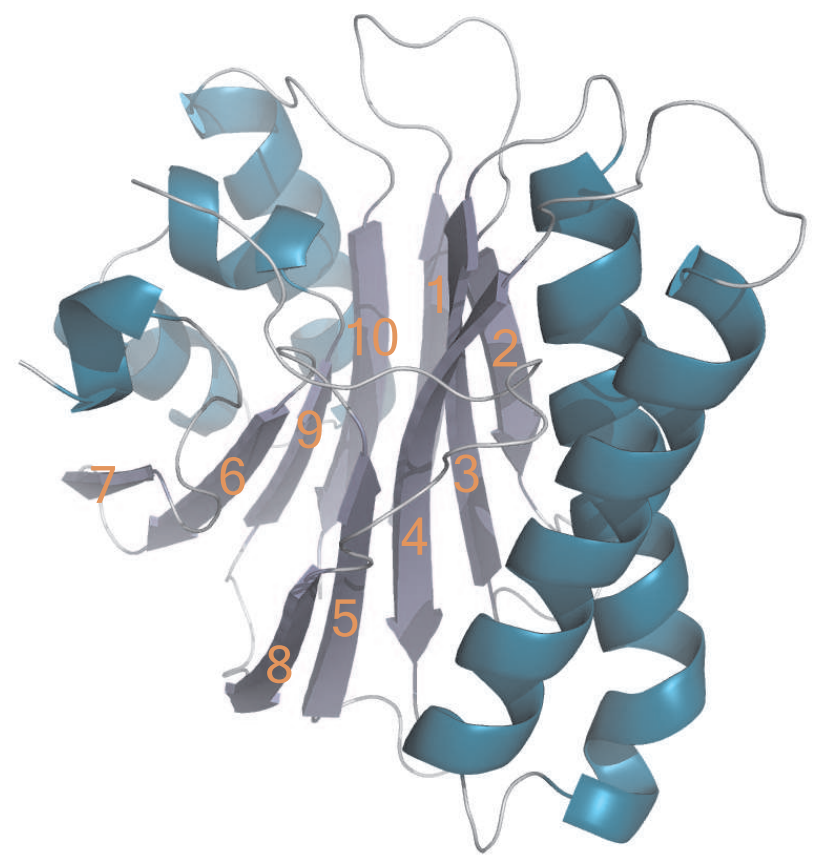

b)

Abbildung 8.1: a) Topologie der tPphA-Struktur, in rot ist die FLAP-Region markiert; b) Die Numerierung der $\beta$-Faltblätter am Beispiel der tPphA-Struktur in C222 1

Die Strukturen von tPphA in den Raumgruppen C222 ${ }_{1}$ und $\mathrm{P} 4{ }_{1} 2{ }_{1} 2$ unterscheiden sich bis auf die FLAP-Region kaum. Die Topologie, die am Beispiel der tPphA-Struktur in C222 
angegeben ist, ist für alle drei Monomere identisch (s. Abb. 8.1, S. 108). Es liegt ein zehnsträngiges, antiparalleles $\beta$-Sandwich vor, das an der einen Seite von zwei, an der gegenüberliegenden Seite von drei $\alpha$-Helices umgeben ist. Ein großer Unterschied zwischen den drei Monomeren besteht in der Struktur der FLAP-Region, welche die Aminosäuren 145 bis 165 beinhaltet. In der Struktur in C222 1 ist diese Region zu flexibel und kann daher nur ansatzweise von Aminosäure 160 bis 164 in der Elektronendichtekarte erkannt werden. Der Teil der flexiblen Region ist in allen drei Monomeren einheitlich, helikal geformt (s. Abb. 8.2, S. 109). In einem Vergleich der flexiblen Bereiche mit dem Programm Escet [97] wird ferner deutlich, daß die FLAP-Region in den beiden Monomeren der P4 ${ }_{2}{ }_{1} 2$-Struktur stark variiert. Dieser Bereich wird nicht durch Kristallkontakte fixiert, so daß die FLAP-Region frei beweglich ist.

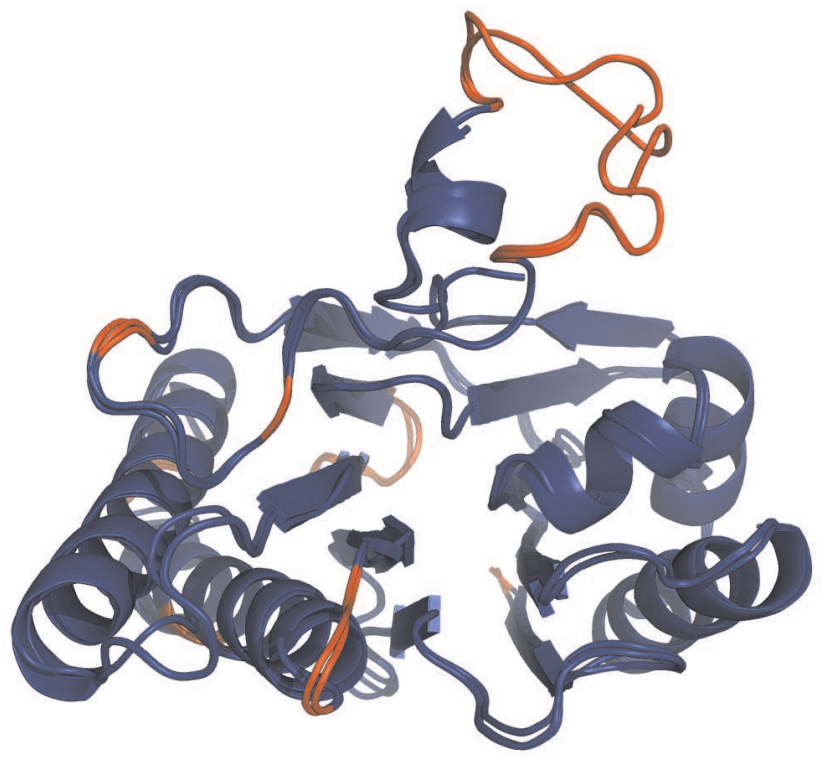

a)

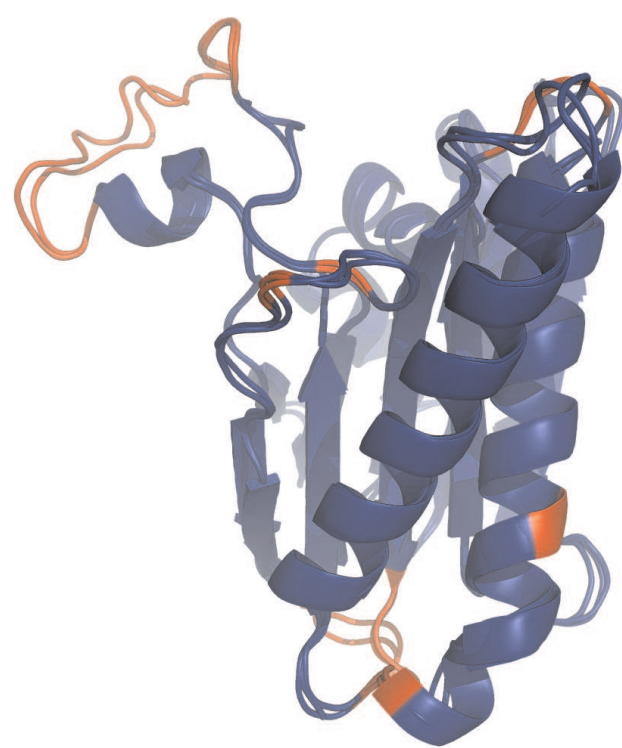

b)

Abbildung 8.2: Escet-Abbildung der Unterschiede in den drei Monomeren der tPphA-Strukturen; in blau sind die starren Bereiche gezeigt, in rot die flexiblen Bereiche

Eine weitere Abweichung in den drei Monomeren besteht in der Region der Aminosäuren 105 bis 111. In Monomer B der tPphA-Struktur in P4 $2{ }_{1} 2$ konnte dieser Bereich aufgrund seiner Flexibilität nicht gebaut werden. Ansonsten weichen die Strukturen in den folgenden Bereichen voneinander ab: Aminosäure 55, 171, 37 bis 39 und 64 bis 65 .

\subsubsection{Das aktive Zentrum im Vergleich}

In einer Überlagerung der drei Monomere wird deutlich, daß die aktiven Zentren in einigen Punkten stark differieren (s. Abb. 8.3, S. 110). Die bemerkenswerteste Veränderung ist die 


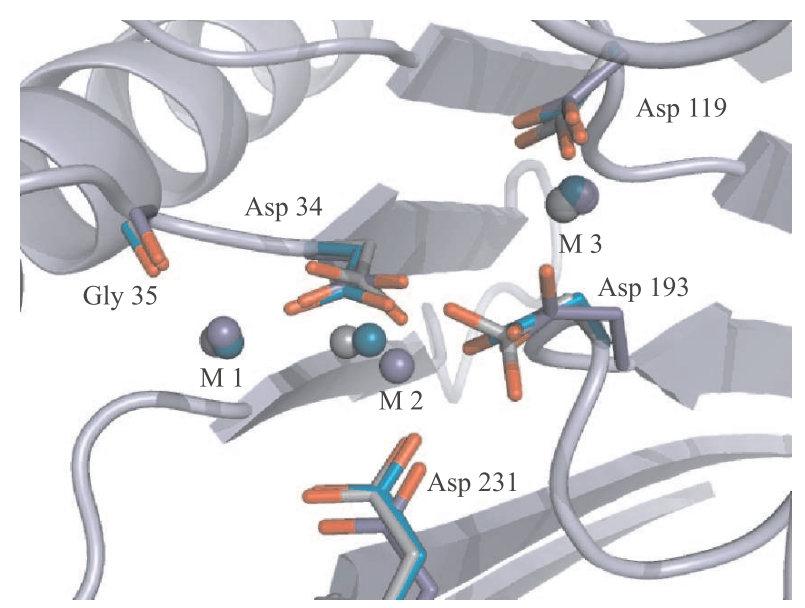

Abbildung 8.3: Das aktive Zentrum der drei Monomere, in blau die tPphA-Struktur in $\mathrm{C} 222_{1}$, in türkis Monomer A in $\mathrm{P} 4{ }_{1} 22_{1} 2$ und in grau Monomer B in $\mathrm{P} 4{ }_{1} 2_{1} 2$

Lage des zweiten Metallions (M2), die in den drei Strukturen im Gegensatz zu den anderen beiden Metallionen, welche in allen drei Monomeren eine ähnliche Position aufweisen, stark variiert. In der tPphA-Struktur in C222 liegt an dieser Position eine Mischung aus $\mathrm{Ca}^{2+}$ - und $\mathrm{Mg}^{2+}$-Ionen vor.

Die Differenz in der Position von M2 hat Auswirkungen auf die Ausrichtung der an dieses Metallion koordinierenden Aminosäuren. Am deutlichsten wird dies an der Aminosäure Asp193. Sie befindet sich in den drei Monomeren an unterschiedlichen Positionen, was ihr die Ausbildung unterschiedlicher Wasserstoffbrückenbindungen ermöglicht. In der tPphAStruktur in C222 kann Asp193 zwei Wasserstoffbrïcken ausbilden, eine zu M2 und eine zu M3. In den tPphA-Strukturen in $\mathrm{P} 4{ }_{1} 2_{1} 2$ ist es der Aminosäure Asp193 dagegen nicht mehr möglich, zwei Wasserstoffbrücken auszubilden, da die Seitenketten aufgrund der veränderten Lage von M2 näher an dieses Metallzentrum rücken und dadurch zu weit von M3 entfernt sind.

Eine weitere von der veränderten Lage von M2 betroffene Aminosäure ist Asp231. Diese besitzt in den Monomeren in $\mathrm{P} 4{ }_{1} 2_{1} 2$ eine andere Position als in dem Monomer in $\mathrm{C} 222_{1}$.

\subsection{Vergleich von tPphA mit anderen PP2C-Phosphatasen}

\subsubsection{Tertiärstruktur}

Die Tertiärstruktur von tPphA entspricht der Tertiärstruktur der menschlichen PP2C-Phosphatasen und der katalytischen Domäne der bakteriellen Phosphatase aus M. tuberculosis PstP. 
Die Überlagerung der tPphA in der Raumgruppe C222 1 (in blau) mit PstP (in grün) und der menschlichen PP2C (in gelb) ist in Abbildung 8.4 (s. S. 111) dargestellt.

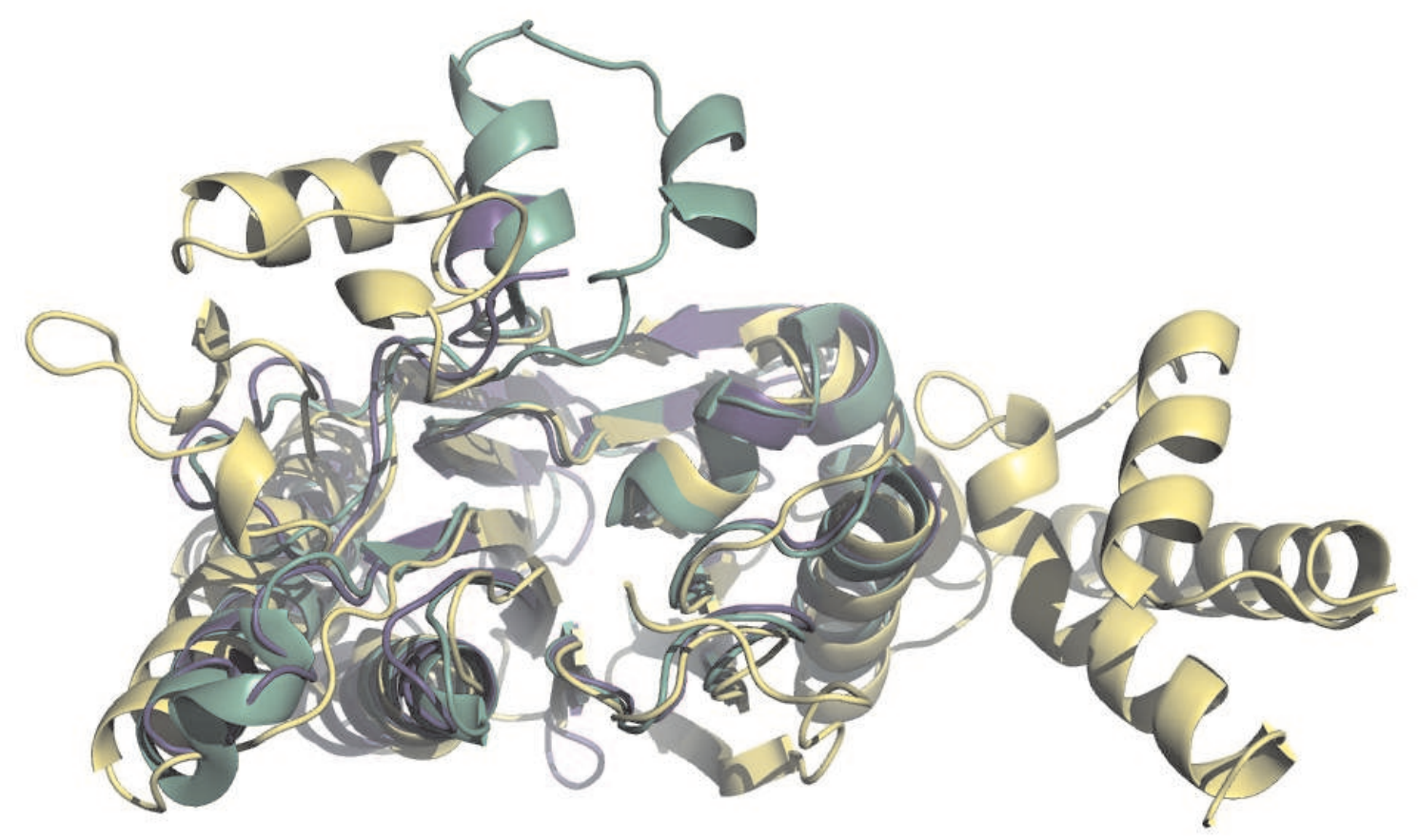

Abbildung 8.4: Überlagerung von tPphA (blau) mit PstP (grün) und menschlicher PP2C (gelb)

Im Vergleich der drei Strukturen wird deutlich, daß tPphA in seiner Struktur der bakteriellen Phosphatase stärker ähnelt als der menschlichen PP2C. Die menschliche PP2C weist am C-Terminus des Proteins drei zusätzliche $\alpha$-Helices auf, die weder in der PstP noch in der tPphA-Struktur zu sehen sind. Desweiteren ist die flexible Region der menschlichen PP2C, die in der Struktur von tPphA in C222 1 fast vollständig fehlt, viel weiter von deren aktivem Zentrum entfernt. Allerdings sind die zwei Metallionen im aktiven Zentrum, die für die Aktivität des Enzyms unentbehrlich sind, in allen drei Strukturen identisch. Hinzu kommt bei der Überlagerung von tPphA mit PstP, daß die Position aller drei Metallionen identisch ist. Die tPphA ist damit die zweite bakterielle Phosphatase, die im Gegensatz zur menschlichen PP2C drei statt zwei Metallionen im aktiven Zentrum aufweist. Hierbei ist interessant, daß die PstP Struktur ein Fragment aus einer membranverankerten PP2C-ähnlichen Phosphatase ist, die tPphA-Struktur hingegen eine vollständige, cytoplasmatische Phosphatase ist. Obwohl daher Unterschiede in der spezifischen Funktion vorhanden sein könnten, besitzen beide Strukturen die gleiche Anzahl an Metallzentren. Allerdings gibt es auch Unterschiede zwischen den Strukturen von tPphA in den unterschiedlichen Raumgruppen und zu PstP. Die erste Helix (A in der Topologie, Abb. 8.1 a, S. 108) ist in der tPphA-Struktur länger als in der PstP-Struktur 


\section{Diskussion}

(s. Abb. 8.5, S. 112). Sie geht von Aminosäure 41 bis 64, wohingegen die Helix A in der PstP Struktur nur von Aminosäure 44 bis 62 reicht.

Desweiteren erscheint die FLAP-Region in der tPphA-Struktur sehr viel flexiber, was sich einerseits in der loop-Struktur zeigt, andererseits in den unterschiedlichen Orientierungen in den drei Monomeren. Die FLAP-Region in der PstP Struktur scheint stabiler zu sein, da sie zwei $\alpha$-Helices enthält.

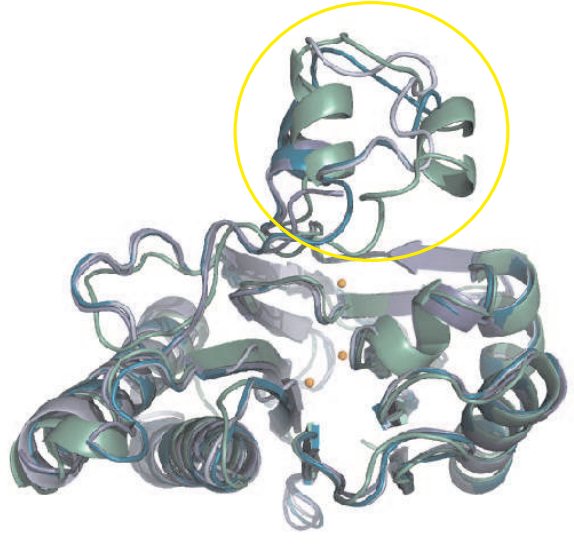

a)

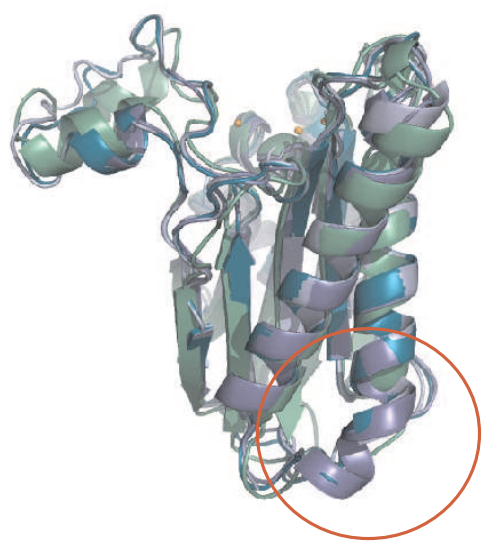

b)

Abbildung 8.5: Überlagerung von tPphA (blau) mit PstP (grün); in orange sind die drei identischen Metallzentren in tPphA und PstP dargestellt, in gelb ist die FLAP-Region markiert, in rot ist die längere Helix von tPphA markiert.

\subsubsection{Das aktive Zentrum im Vergleich}

Die aktiven Zentren in den drei Strukturen (tPphA, PstP und menschlicher PP2C) sind sehr ähnlich aufgebaut. Alle besitzen die charakteristischen, konservierten Aminosäuren, die für PP2C Phosphatasen üblich sind. Sie sind in Tabelle 8.1 (s. S. 113) vergleichend zusammengefaßt. 


\begin{tabular}{lll}
\hline Aminosäure in tPphA & Aminosäure in PstP & Aminosäure in menschlicher PP2C \\
\hline Asp34 & Asp38 & Asp60 \\
Gly35 & Gly39 & Gly61 \\
Asp119 & Asp118 & Asp146 \\
Asp193 & Asp191 & Asp239 \\
Asp231 & Asp229 & Asp282 \\
\hline
\end{tabular}

Tabelle 8.1: Vergleich der konservierten, Metall-koordinierenden Aminosäuren von tPphA, PstP und menschlicher PP2C

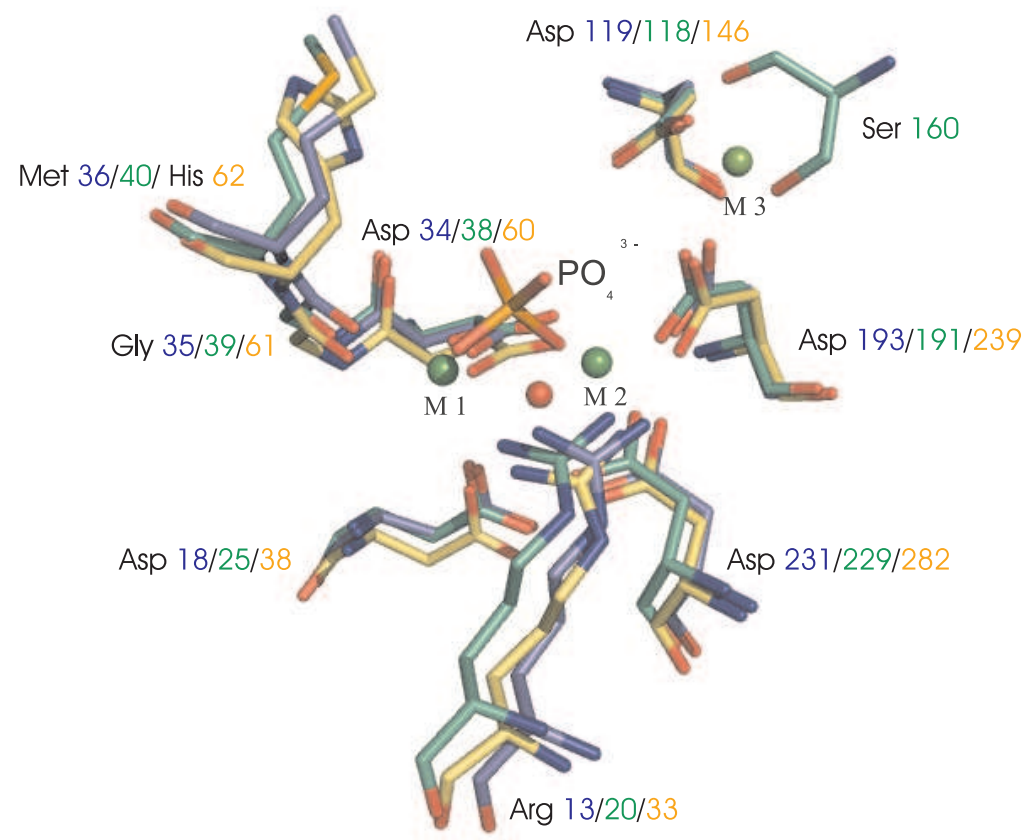

Abbildung 8.6: Aktives Zentrum der drei Phosphatasen; in gelb PP2C, in grün PstP und in blau tPphA in der Raumgruppe C222 1 ; das Phosphat stammt aus der PP2C-Struktur, die Metallionen (grün) stammen aus der PstP- und tPphA-Struktur. Das katalytisch essentielle Wassermolekül ist als orangefarbene Kugel dargestellt.

In einer Überlagerung aller drei aktiven Zentren erkennt man die Übereinstimmung der Koordination der Metallionen (s. Abb. 8.6, S. 113), wobei deutlich wird, daß die Bindungstaschen von PstP und von tPphA sich stärker ähneln als die Bindungstaschen von tPpha und menschlicher PP2C.

Ein interessanter Aspekt zwischen der menschlichen PP2C und den bakteriellen PP2Cähnlichen Phosphatasen PstP und tPphA besteht in der Aminosäure His62 in der PP2C zu der an gleicher Position gelegenen Aminosäure Met36 bzw. Met40 in den bakteriellen Phosphata- 


\section{Diskussion}

sen. In der menschlichen PP2C-Struktur agiert His62 während der Spaltung der P-O-Bindung als Säure [101]. Diese Funktion ist im Falle der beiden bakteriellen Phosphatasen aufgrund des an der dieser Position vorliegenden Methionins nicht gegeben.

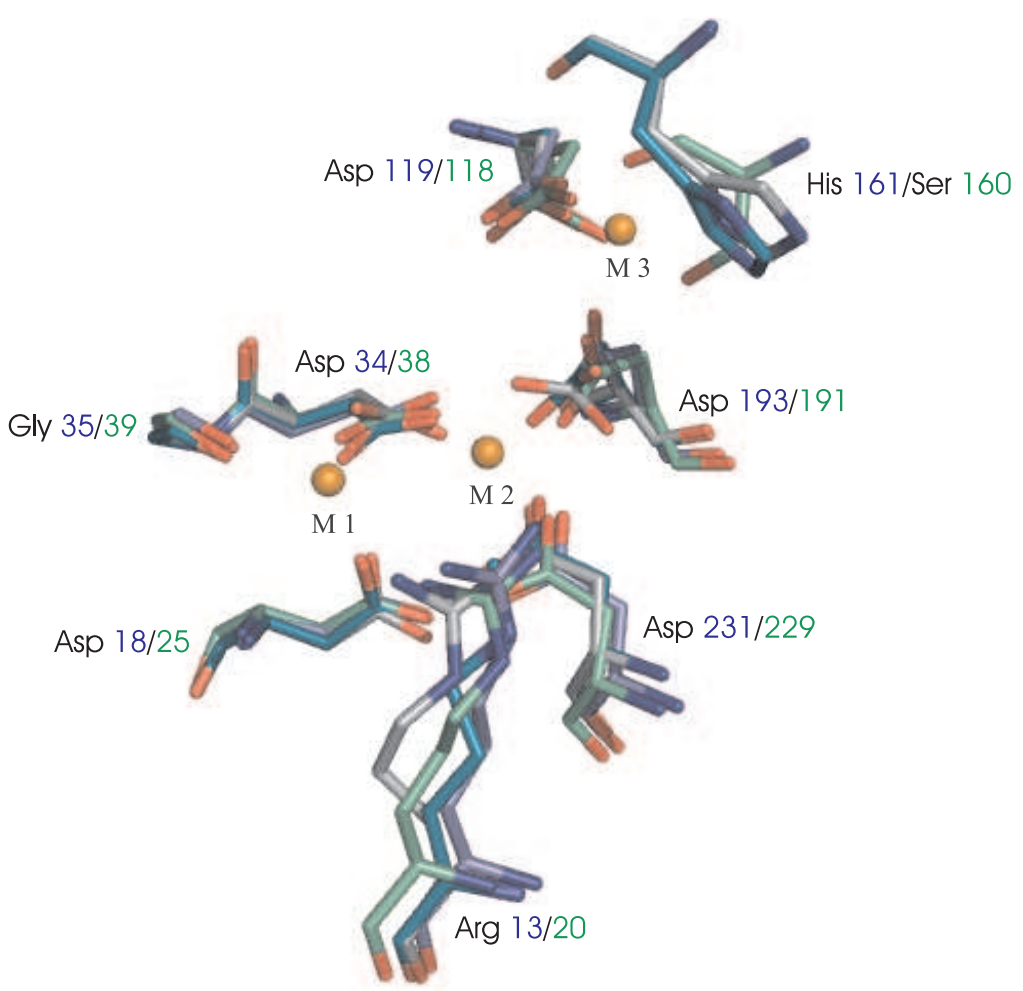

Abbildung 8.7: Überlagerung der bakteriellen PstP (grün) mit den drei Monomeren der tPphA; in blau tPphA in $\mathrm{C} 222_{1}$, in türkis Monomer A in $\mathrm{P} 4{ }_{1} 2_{1} 2$ und in grau Monomer B in $\mathrm{P} 4_{1} 2_{1} 2$; in orange sind die drei Metallionen eingezeichnet

Ein weiterer wichtiger Unterschied besteht in der Anzahl der Metallionen. In der menschlichen PP2C-Struktur sind nur zwei Metallionen vorzufinden, in den bakteriellen PP2Cähnlichen Phosphatasen hingegen sind jeweils drei Metallionen vorhanden. Die Koordination dieses dritten Metallions ist in den beiden bakteriellen Phosphatasen unterschiedlich. In der PstP-Struktur wird das dritte Metallion von zwei Wassermolekülen, Asp118, Asp191 und Ser160 oktaedrisch koordiniert. In der tPphA-Struktur ist das dritte Metallion hingegen nur von drei Wassermolekülen sowie Asp119 und Asp193 quadratisch pyramidal koordiniert. Eine Koordination des dritten Metallzentrums in Analogie zu der Koordination in PstP durch Ser160 kann in der tPphA-Struktur in C222 1 aufgrund der fehlenden Elektronendichte in diesem Bereich nicht gefunden werden. In der tPphA-Struktur in $\mathrm{P} 4{ }_{1} 2{ }_{1} 2$ weist im Bereich der FLAP-Region die Aminosäure His161 den geringsten Abstand zum dritten Metallion auf, wo- 
bei die Distanz bei ca. 4 A liegt. Die Überlagerung der verschiedenen tPphA-Strukturen mit PstP ist in Abbildung 8.7 (S. 114) gezeigt.

\subsubsection{Die elektrostatischen Oberflächen im Vergleich}

Für den Vergleich der elektrostatischen Oberflächen sind in Abbildung 8.8 (s. S. 115) die Oberflächen der bakteriellen PstP und der tPphA nebeneinander dargestellt. Hierbei wurde für die Struktur von tPphA das Monomer B aus der Raumgruppe $\mathrm{P} 4{ }_{1} 2{ }_{1} 2$ gewählt, da es als einziges Monomer die vollständige FLAP-Region enthält.

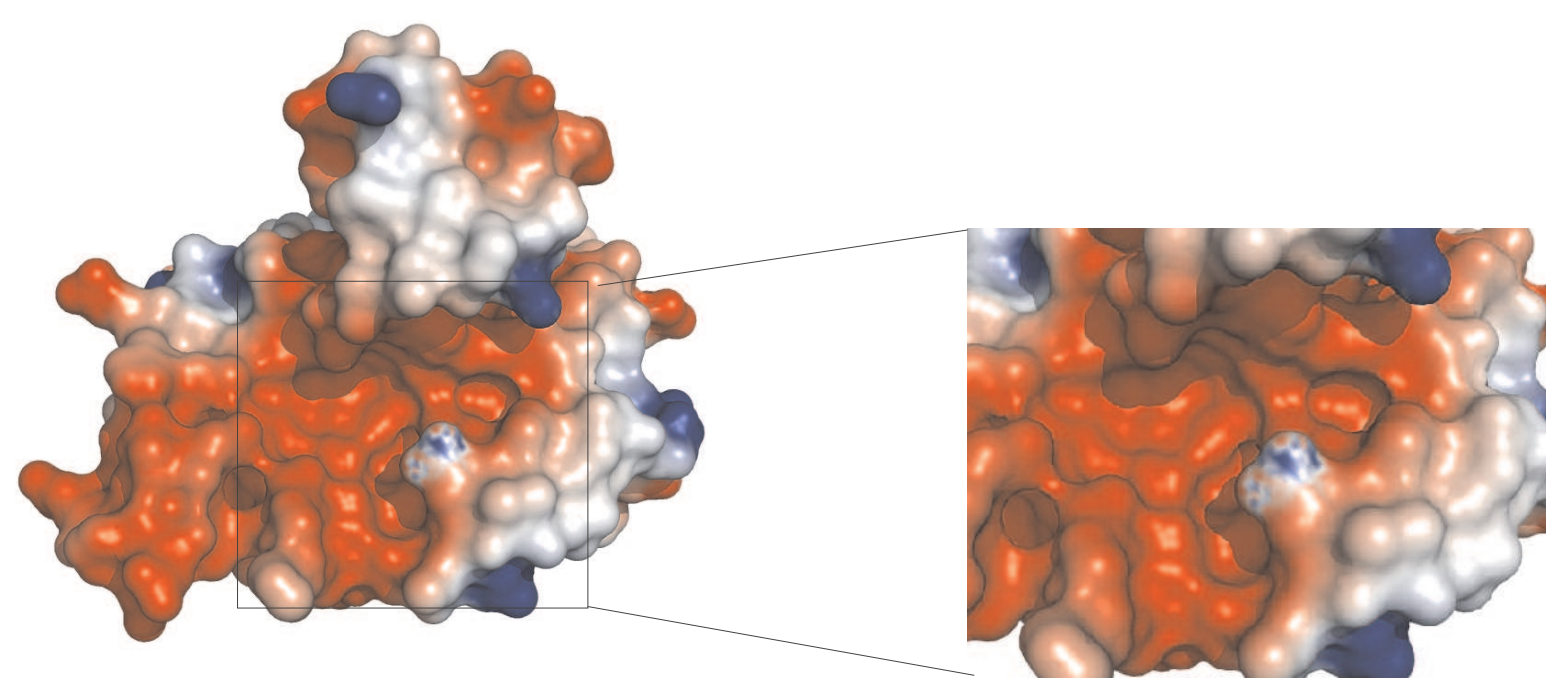

a)

b)

Abbildung 8.8: Elektrostatische Oberflächenstrukturen der bakteriellen PstP Struktur 


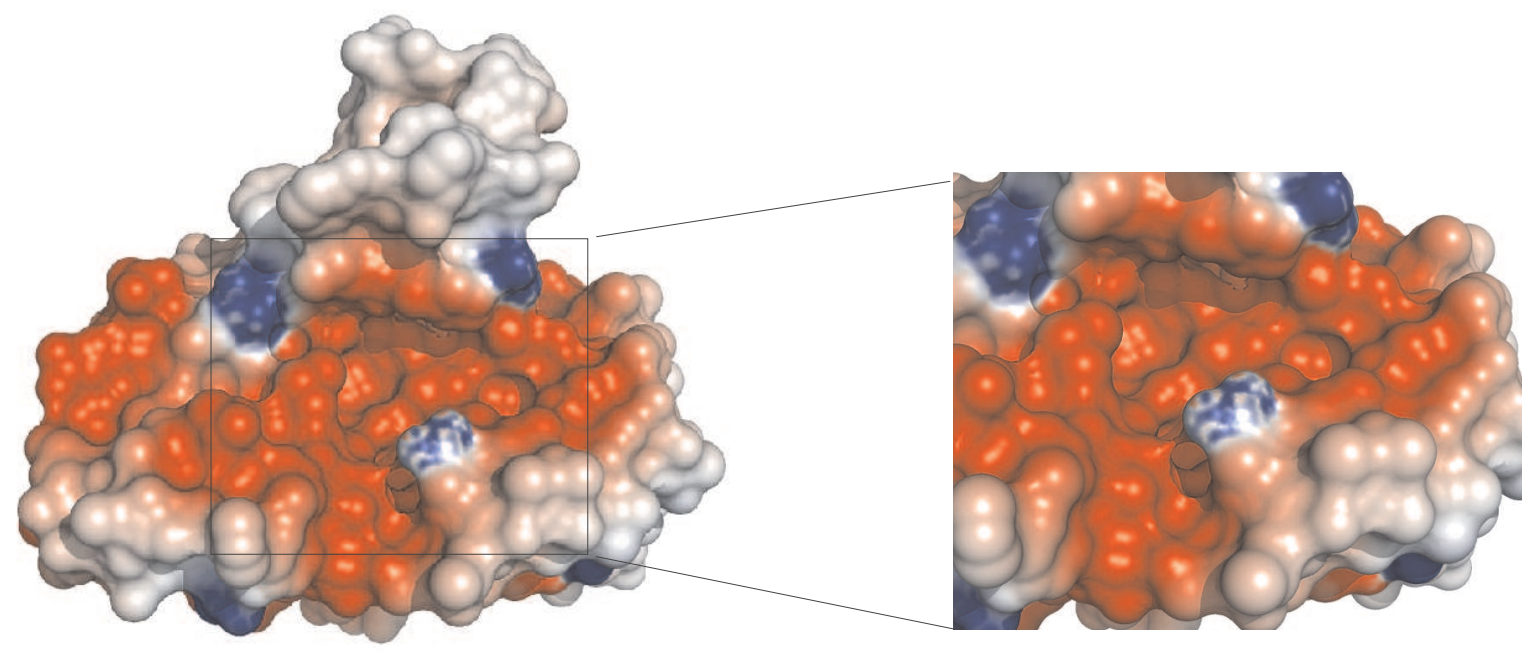

a)

b)

Abbildung 8.9: Elektrostatische Oberflächenstrukturen von tPphA des Monomers B

Besonders auffällig in den beiden elektrostatischen Oberflächen sind die Vertiefungen im Bereich der Metallionen, die in beiden Fällen eine starke positive Ladung aufweisen. Dieser Bereich ist in den Abbildungen 8.8 b und 8.9 b vergrößert dargestellt. Die starke positive Ladung begünstigt die Anziehung des negativ geladenen Substrats, welches im Fall von tPphA wahrscheinlich das phosphorylierte PII-Protein ist, welches durch tPphA dephosphoryliert wird.

\subsection{Ausblick}

Das Ziel der Arbeit war es, die Struktur von tPphA mit der bakteriellen PstP und der menschlichen PP2C zu vergleichen und Rückschlüsse auf den katalytischen Mechanismus und die Entwicklung der Dephosphorylierung in der Evolution zu ziehen. Es konnte gezeigt werden, daß das aktive Zentrum von tPphA der menschlichen PP2C ähnelt, wobei in der tPphA-Struktur drei statt zwei Metallionen vorliegen. Zudem besteht eine sehr starke Ähnlichkeit zwischen dem aktiven Zentrum von tPphA und dem der bakteriellen PstP, wobei hier die Koordination des dritten Metallions wie oben beschrieben unterschiedlich ist. Da die bakteriellen PP2Cähnlichen Phosphatasen, wie die menschliche PP2C, ein zweifach koordiniertes Hydroxid-Ion besitzen (s. Abb. 8.10, S. 117), welches als Nucleophil das phosphorylierte Substrat angreifen könnte, ist es für die beiden bakteriellen PP2C-Phosphatasen durchaus möglich, daß ein ähnlicher katalytischer Mechanismus wie für die menschliche PP2C vorliegt. Es sollten jedoch weitere molekularbiologische Tests für die Überprüfung dieser Annahme durchgeführt 
werden. Es ist angedacht, die Aminosäure His 161, die in der FLAP-Region liegt und am nahesten an dem dritten Metallion lokalisiert ist, zu mutieren, um dadurch die Bindung des dritten Metallions zu verändern. Außerdem sollte mittels molekularbiologischer Methoden

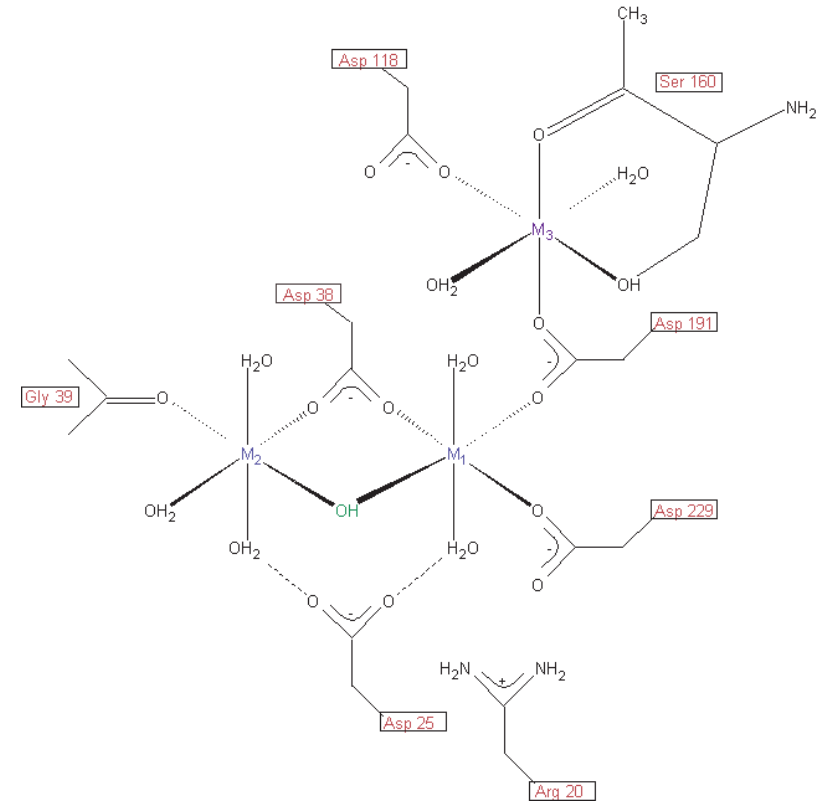

a)

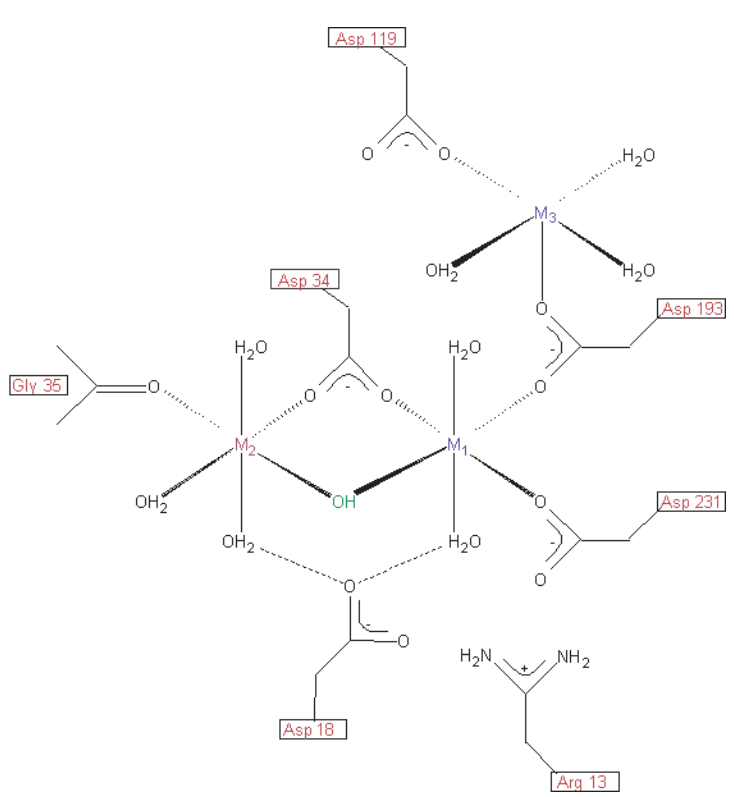

b)

Abbildung 8.10: Schematische Darstellung des aktiven Zentrums, a) der PstP-Struktur, b) der tPphAStruktur

in-vivo das natürlichen Substrat (das PII-Protein) der tPphA überprüft und weitere natürliche Substrate der tPphA identifiziert werden. 


\section{Anhang}

Fluoreszenz-Scan von C2B

Fluoreszenz-Scan

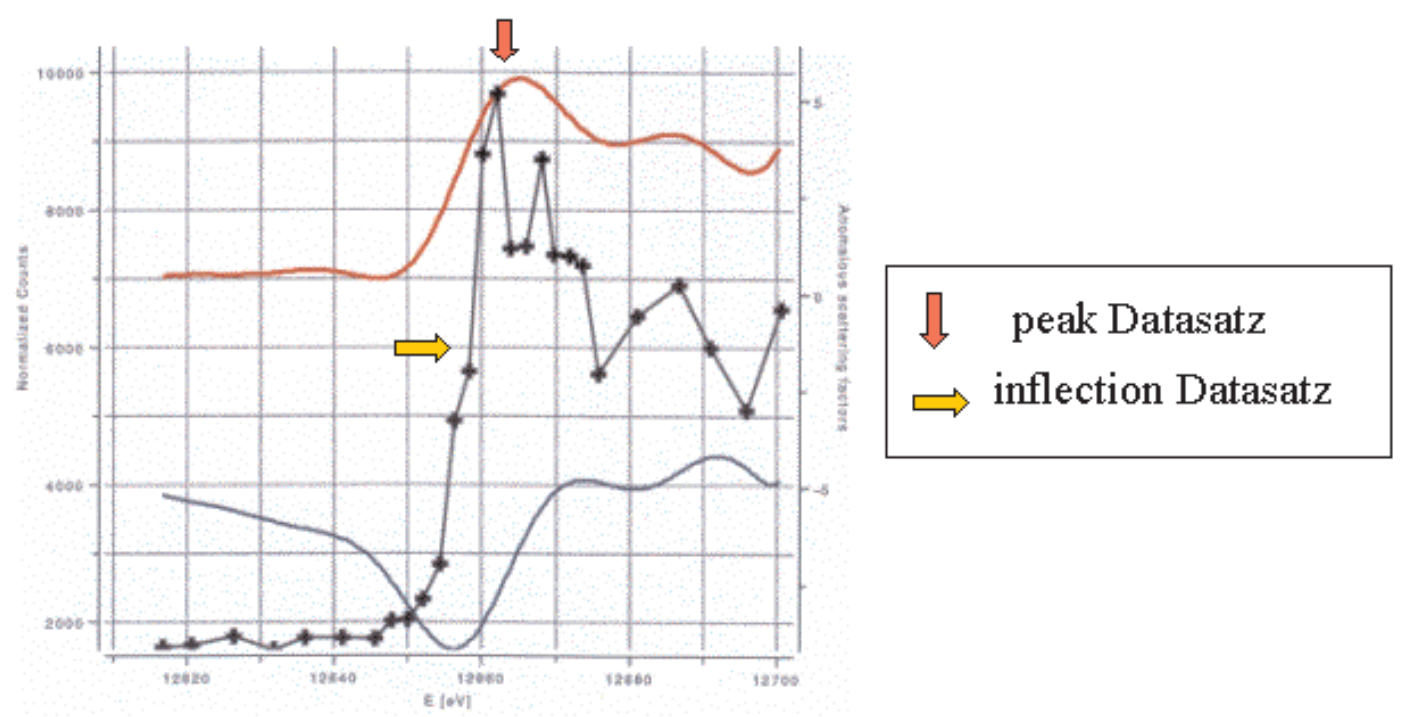

Abbildung A.1: Fluoreszenz-Scan von C2B 
Fluoreszenz-Scan von tPphA

Fluoreszenz-Scan

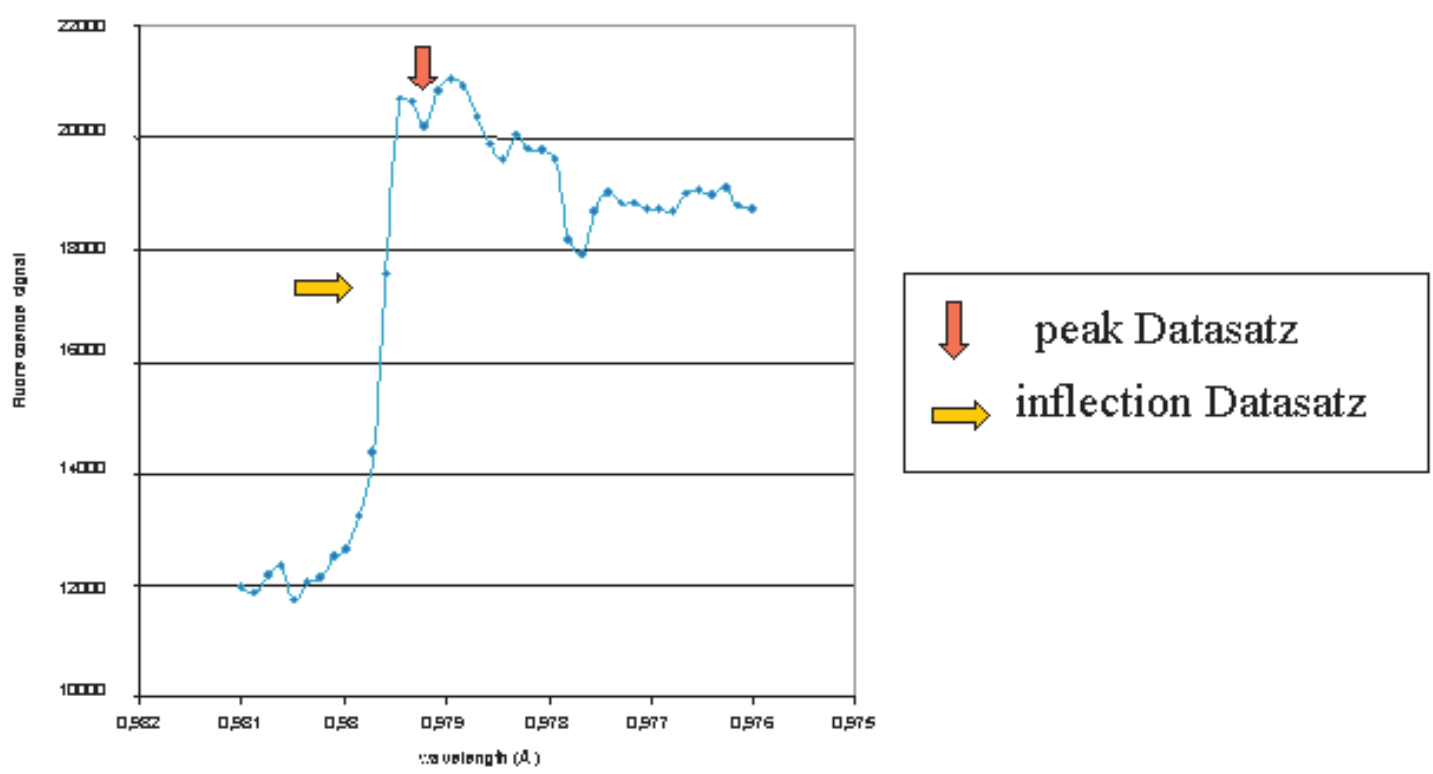

Abbildung A.2: Fluoreszenz-Scan von tPphA 
Sequenzvergleich der tPphA mit PphA aus Synechocystis sp. PCC 6803

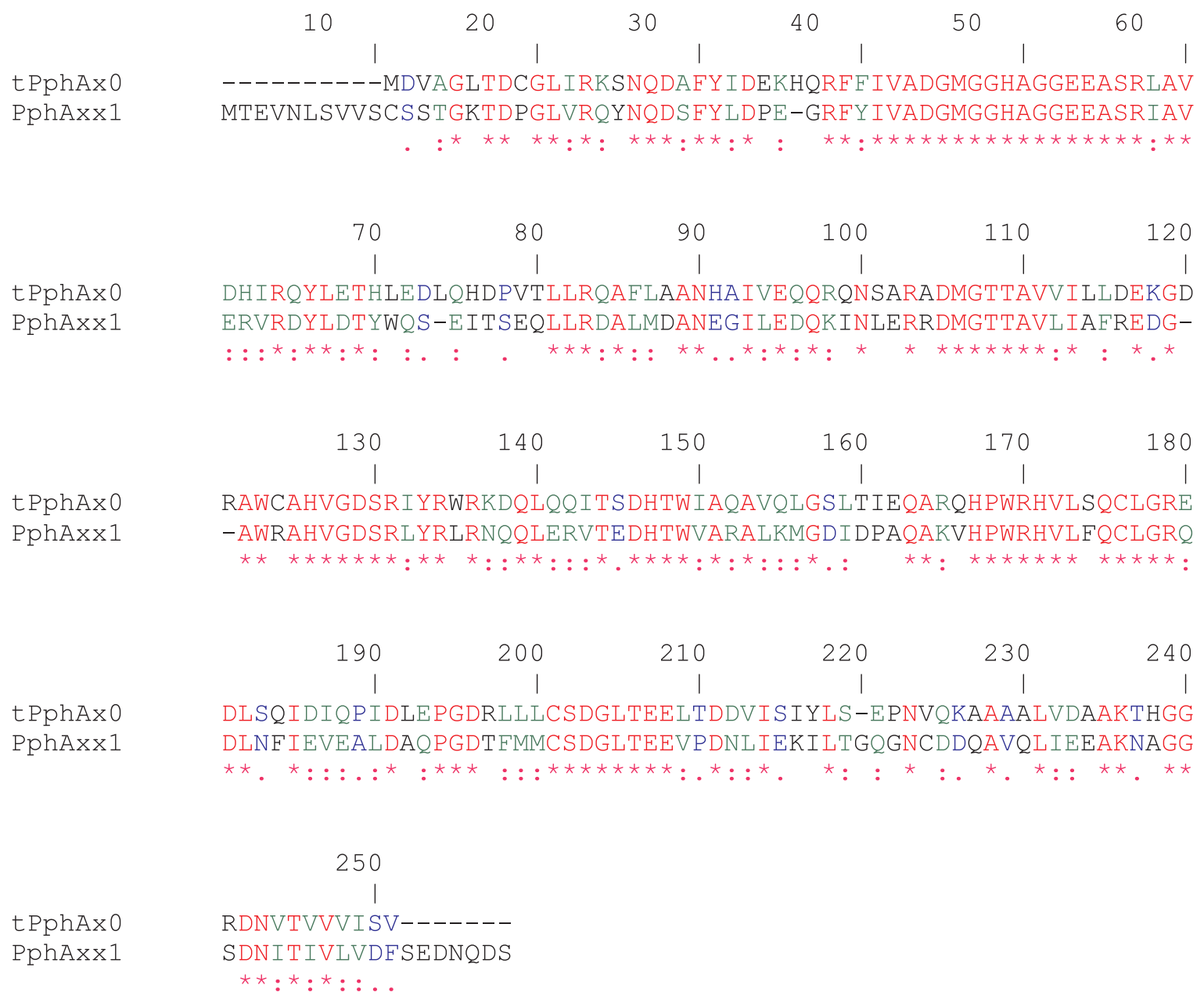

Abbildung A.3: Sequenzvergleich der tPphA mit der PphA aus Synechocystis sp. PCC 6803 aus dem Programm CLUSTALW [46]; identisch (*) : 123 Aminosäuren $47.67 \%$ (rot), sehr ähnlich (:) : 58 Aminosäuren $22.48 \%$ (grün), weniger stark ähnlich (.) : 17 Aminosäuren $6.59 \%$ (blau), unterschiedlich : 60 Aminosäuren $23.26 \%$ 


\section{Sequenzvergleich der tPphA mit PstP aus M.tuberculosis}

tPphAx 0

1 txoxx1

tPphAx0

1 txoxx 1

tPphAx0

1 txoxx 1

tPphAx 0

$1 \operatorname{txoxx} 1$

tPphAx0

1 txoxx 1

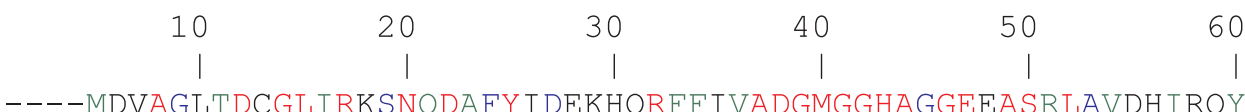
MTLVLRYAARS DRGLVRANNEDSVYAG---ARLLALADGMGGHAAGEVASQLVIAAL-AH

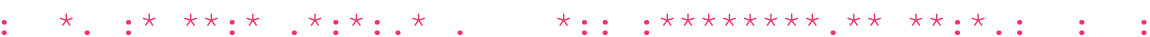

$\begin{array}{rrrrrr}70 & 80 & 90 & 100 & 110 & 120 \\ 1 & 1 & \mid & \mid & \mid\end{array}$

LETHLEDLQHDPVTLLRQAFLAANHAIVEQQRQNSARADMGTTAVVILLDEKGDRAWCAH LDD--DEPGGDLLAKLDAAVRAGNSAIAAQVEMEPDLEGMGTTLTAILFA--GNRLGLVH

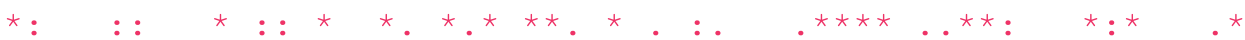

$\begin{array}{llllll}130 & 140 & 150 & 160 & 170 & 180\end{array}$ | 1 | | | | | VGDSRIYRWRKDQLQQITSDHTWIAQAVQLGSLTIEQARQHPWRHVLSQCLGREDLSQID IGDSRGYLLRDGELTQITKDDTFVQTLVDEGRITPEEAHSHPQRSLIMRALTGHEVEPT-

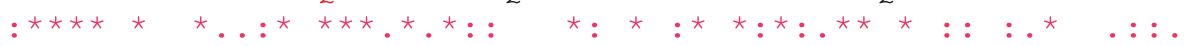

$\begin{array}{rrrrrr}190 & 200 & 210 & 220 & 230 & 240 \\ \mid & \mid & \mid & \mid & \mid\end{array}$
IQP IDLEPGDRLLLCSDGLTEELTDDVISIYLSEPNVQKAAAALVDAAKTHGGRDNVTVV LTMREARAGDRYLLCSDGLSDPVSDETILEALQI PEVAESAHRLIELALRGGGPDNVTVV

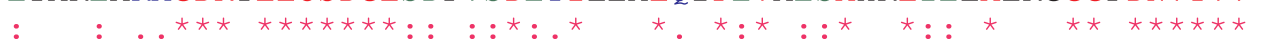

\section{VISV--}

VADLEH

* . :

Abbildung A.4: Sequenzvergleich der tPphA mit der PphA aus M.tuberculosis aus dem Programm CLUSTALW [46]; identisch (*) : 88 Aminosäuren $35.77 \%$ (rot), sehr ähnlich (:) : 46 Aminosäuren $18.70 \%$ (grün), weniger stark ähnlich (.) : 28 Aminosäuren 11.38 \% (blau), unterschiedlich : 84 Aminosäuren $34.15 \%$ 


\section{Abbildungsverzeichnis}

1.1 Der synaptische Vesikelzyklus . . . . . . . . . . . . . . . . . . 4

1.2 Das synaptische Vesikel . . . . . . . . . . . . . . . . . . . 5

1.3 Struktur des endosomalen SNARE-Komplexes . . . . . . . . . . . . 6

1.4 Modell für die Funktion der SNARE-Proteine . . . . . . . . . . . . . . . . . 7

1.5 Modell für die Funktion der SNARE-Proteine . . . . . . . . . . . . . . . 8

1.6 Der Rab Zyklus . . . . . . . . . . . . . . . . . . . . . . . . . . 9 9

1.7 Rabphilin-3A . . . . . . . . . . . . . . . . . . 9

1.8 Topologie der C2-Domänen . . . . . . . . . . . . . . . . . . . . . . . 11

1.9 Thermosynechococcus elongatus BP-1 . . . . . . . . . . . . . . . . 13

1.10 Die Stickstoff-Assimilation von Cyanobakterien . . . . . . . . . . . . . . . 14

1.11 PII-Protein aus dem Cyanobakterium Synechococcus sp. PCC 7942 . . . . . 15

1.12 Schematische Darstellung des PII-Phosphorylierungs-Zyklus . . . . . . . . . 16

1.13 Genfamilie von PPP und PPM mit den zugehörigen charakteristischen Motiven 18

1.14 Aminosäure-Sequenz-Abgleich der tPphA, PphA, PstP und PP2C . . . . . . 19

1.15 Die FLAP-Region . . . . . . . . . . . . . . . . . . . . . . . . 20

1.16 Katalytischer Mechanismus der menschlichen PP2C . . . . . . . . . . . 21

2.1 Vektorkarte des pET32a-Vektors mit dem tPphA insert . . . . . . . . . . . 24

2.2 Vektorkarte des pGEX-2T-Vektors mit dem C2B insert . . . . . . . . . . . 25

2.3 Reaktionsgleichung des p-NPPs . . . . . . . . . . . . 37

2.4 Phasendiagramm für die Kristallisation . . . . . . . . . . . . . . . . . 38

2.5 Kristallisation nach a) der hanging drop Methode, b) der sitting drop Methode 39

2.6 Anleitung für streak seeding [65] . . . . . . . . . . . . . . . . . 40

2.7 Fluoreszenz-Scan von Se-Met Protein . . . . . . . . . . . . . . . . . . . 41

2.8 Der Zusammenhang der Amplituden . . . . . . . . . . . . . . . . . . . 44

2.9 Die Harker Konstruktion für den isomorphen Ersatz . . . . . . . . . . . . . . 44

2.10 Beugung des einfallenden Röntgenstrahls . . . . . . . . . . . . . . . . . 45

2.11 Friedelsches Gesetz für a) normale und b) anomale Beugung . . . . . . . . . 46

2.12 MAD-Experiment: Theorie und Praxis . . . . . . . . . . . . . . . . . . 48 
3.1 SDS-Gel der Expression des GST-C2B-Fusionsproteins; vI: vor Induktion,

3.2 Reinigung des nativen C2B: SDS-Gel des Thrombinverdaus und der Kationenaustauschersäule . . . . . . . . . . . . . . . . 55

3.3 Reinigung des nativen C2B: SDS-Gel der Gelfiltration, die peak-Fraktionen 60 bis 72 sind aufgetragen. . . . . . . . . . . . . . . . . . 55

3.4 SDS-Gel der Expression des Se-Met Proteins; vI: vor Induktion, nI: nach Induktion. . . . . . . . . . . . . . . . 56

3.5 Kristalle der C2B-Domäne . . . . . . . . . . . . . . . . 58

3.6 Anomales I/sigma für den peak Datensatz . . . . . . . . . . . . . . . 61

3.7 Anomales I/sigma für den inflection Datensatz . . . . . . . . . . . . . . . . 61

3.8 Anomales I/sigma für den high remote Datensatz . . . . . . . . . . . . . . . 61

3.9 Korrelation zwischen peak, inflection und high remote Datensatz . . . . . . . 61

3.10 Vergleich der Elektronendichtekarten . . . . . . . . . . . . 63

4.1 Struktur der C2B-Domäne in $\mathrm{P} 2{ }_{1} 2{ }_{1} 2 \ldots \ldots \ldots \ldots 6$

4.2 Kalzium-Bindungstasche der C2B-Struktur in $\mathrm{P} 2{ }_{1} 22_{1} \ldots \ldots \ldots$. . . . . . 67

4.3 Struktur der $\mathrm{C} 2 \mathrm{~B}-$ Domäne in $\mathrm{P} 2$. . . . . . . . . . . . . . . . . . 69

4.4 Kalzium-Bindungstasche in $\mathrm{P} 22_{1} \ldots \ldots \ldots \ldots \ldots$

5.1 Topologie der C2B-Domäne . . . . . . . . . . . . . . . . . 71

5.2 Escet-Abbildung der C2B-Struktur . . . . . . . . . . . . . . . . . . 74

5.3 Überlagerung aller drei Kalziumbindungsstellen . . . . . . . . . . . . . . . 75

5.4 Vergleich der N-Terminus Region . . . . . . . . . . . . . . . 76

5.5 Überlagerung der NMR- und Kristallstrukturen . . . . . . . . . . . . . . . 77

5.6 Überlagerung der gesamten C2B-Struktur . . . . . . . . . . . . . . . . . . 78

5.7 Elektrostatische Oberfläche der C2B-Struktur . . . . . . . . . . . . . . . 79

5.8 Überlagerung der C2B-Strukturen . . . . . . . . . . . . . . . . . . 80

5.9 Koordination der beiden Kalziumionen . . . . . . . . . . . . . . . . 82

6.1 Agarosegel nach dem Restriktionsverdau . . . . . . . . . . . . . . . . . 84

6.2 Agarosegel der Hot Star Taq PCR Produkte . . . . . . . . . . . . . . . 85

6.3 SDS-Gel der Induktion des nativen tPphA; vI: vor Induktion, 6 h: nach 6 h Induktion, $22 \mathrm{~h}$. nach $22 \mathrm{~h}$ Induktion $\ldots \ldots \ldots$. . . . . . . 86

6.4 Reinigung der nativen tPphA: SDS-Gel des Aufschlusses und der Dialysefraktionen . . . . . . . . . . . . . . . 87

6.5 Reinigung der nativen tPphA: Chromatogramm der Anionenaustauschersäule 88

6.6 Reinigung der nativen tPphA: SDS-Gel der Anionenaustauschersäule . . . . 88

6.7 Reinigung der nativen tPphA: Chromatogramm der Gelfiltrationssäule . . . . 89 
Abbildungsverzeichnis

6.8 Reinigung der nativen tPphA: SDS-Gel der Gelfiltrationssäule; vor: vor der Gelfiltration, 40: Verunreinigung, 73-84: Fraktionen der nativen tPphA . . . . 89

6.9 SDS-Gel der Induktion des Se-Met-tPphA; vI: vor Induktion, 12 h: nach $12 \mathrm{~h}$ Induktion, $18 \mathrm{~h}$ : nach $18 \mathrm{~h}$ Induktion . . . . . . . . . . . . . . 90

6.10 Reinigung der Se-Met tPphA: SDS-Gel des Aufschlusses und der Dialysefraktionen . . . . . . . . . . . . . . . . . . 91

6.11 Reinigung der Se-Met-tPphA: Chromatogramm der Anionenaustauschersäule 92

6.12 Reinigung der Se-Met-tPphA: SDS-Gel der Anionenaustauschersäule; 16-29:

Fraktionen der Anionenaustauschersäule . . . . . . . . . . . . . . . 92

6.13 Reinigung der Se-Met-tPphA: Chromatogramm der Gelfiltrationssäule . . . . 93

6.14 Reinigung der Se-Met-tPphA: SDS-Gel der Gelfiltrationssäule; vor: vor der Gelfiltration, 42: Verunreinigung, 74-85: Fraktionen der Se-Met-tPphA . . . . 93

6.15 Kristalle von $\mathrm{tPphA} \ldots \ldots \ldots$. . . . . . . . . . . . . . 95

6.16 Anomales I/sigma für den peak Datensatz . . . . . . . . . . . . . . . . . . . . . . . . . . . . .

6.17 Anomales I/sigma für den inflection Datensatz . . . . . . . . . . . . . . . 98

6.18 Korrelation zwischen peak und inflection Datensatz . . . . . . . . . . . . . . 98

6.19 Harker Sektion entlang $\mathrm{y}=0 \ldots \ldots$. . . . . . . . . . . . . . 98

6.20 Fehlordnungen in der tPphA-Struktur . . . . . . . . . . . . . . 100

7.1 Struktur von tPphA in $\mathrm{C} 2222_{1} \ldots \ldots \ldots \ldots \ldots$. . . . . . . . . 103

7.2 Aktives Zentrum von $\mathrm{tPphA} \ldots \ldots \ldots \ldots$

7.3 Struktur von tPphA in $\mathrm{P}_{1}{ }_{2} 2$, Monomer A . . . . . . . . . . . . 105

7.4 Struktur von tPphA in $\mathrm{P}_{1}{ }_{2} 2$, Monomer B . . . . . . . . . . . . 106

7.5 Das aktive Zentrum in der tPphA-Struktur in $\mathrm{P} 4{ }_{1} 2_{1} 2 \ldots \ldots$. . . . . . 106

8.1 Topologie der tPphA-Struktur f . . . . . . . . . . . . . . . . . 108

8.2 Escet-Abbildung für tPphA . . . . . . . . . . . . . . . . . . 109

8.3 Das aktive Zentrum der drei Monomere . . . . . . . . . . . . . . . . . 110

8.4 Überlagerung von tPphA mit PstP und menschlicher PP2C . . . . . . . . . 111

8.5 Überlagerung von tPphA mit PstP . . . . . . . . . . . . . . . . . . . 112

8.6 Aktives Zentrum der drei Phosphatasen . . . . . . . . . . . . . . . 113

8.7 Überlagerung der bakteriellen PstP mit tPphA . . . . . . . . . . . . . . . . . 114

8.8 Elektrostatische Oberflächenstrukturen, PstP . . . . . . . . . . . . . . . 115

8.9 Elektrostatische Oberflächenstrukturen, tPphA . . . . . . . . . . . . . . 116

8.10 Schematische Darstellung des aktiven Zentrums . . . . . . . . . . . . . . 117

A.1 Fluoreszenz-Scan von C2B . . . . . . . . . . . . . . . . 118

A.2 Fluoreszenz-Scan von tPphA . . . . . . . . . . . . . . . . . . . . . 119

A.3 Sequenzvergleich der $\operatorname{tPphA}$ mit PphA . . . . . . . . . . . . . . . . 120

A.4 Sequenzvergleich der $\operatorname{tPphA}$ mit PstP . . . . . . . . . . . . . . 121 


\section{Tabellenverzeichnis}

2.1 Primer für tPphA, die Restriktionsenzyms-Schnittstellen sind mit dickeren Buchstaben markiert; for: forward, rev.: reverse. . . . . . . . . . 23

3.1 Kristallisationsbedingungen der nativen C2B-Domäne $\ldots \ldots \ldots$. . . . . 57

3.2 Kristallisationsbedingungen der nativen $\mathrm{C} 2 \mathrm{~B}-$ Domäne mit $\mathrm{Ca}^{2+} \ldots \ldots . . .58$

3.3 Datensammlung der Se-Met Kristalle der C2B-Domäne . . . . . . . . . . . . 59

3.4 Datensammlung der nativen Kristalle der C2B-Domäne . . . . . . . . . . . . 60

3.5 Verfeinerung der C2B-Struktur in der Raumgruppe $\mathrm{P} 2{ }_{1} 2{ }_{1} 2 \ldots \ldots$. . . . . . . 64

3.6 Verfeinerung der C2B-Struktur in der Raumgruppe $\mathrm{P} 22_{1} \ldots \ldots$. . . . . . . 65

5.1 Wasserstoffbrücken in der C2B-Struktur in $\mathrm{P} 2{ }_{1} 2_{1} 2 \ldots \ldots \ldots 72$

5.2 Wasserstoffbrücken in der $\mathrm{C} 2 \mathrm{~B}-$ Struktur in $\mathrm{P} 21 \ldots \ldots . \ldots 73$

5.3 Standardabweichungen der Überlagerung von C2B . . . . . . . . . . . . 81

6.1 Kristallisationsbedingungen mit Metallionen . . . . . . . . . . . . . . . . . . 94

6.2 Kristallisationsbedingungen ohne Metallionen . . . . . . . . . . . . . . . . . 94

6.3 Verbesserte Kristallisationsbedingungen . . . . . . . . . . . . . . . 95

6.4 Datensammlung für die nativen tPphA Kristalle; M: Metallion . . . . . . . . 97

6.5 Datensammlung für Se-Met tPphA . . . . . . . . . . . . . . . . . . . . 97

6.6 Besetzungs- bzw. Fehlordnungsverfeinerung . . . . . . . . . . . . . . 100

6.7 Verfeinerung der tPphA-Struktur in C222 $\ldots \ldots \ldots \ldots \ldots 1 . \ldots \ldots$

6.8 Verfeinerung der tPphA-Struktur in $\mathrm{P} 4{ }_{1} 2{ }_{1} 2 ; \mathrm{M}$ : Metallion . . . . . . . . . . . 102

7.1 Wasserstoffbrückenbindungen in der tPphA-Struktur . . . . . . . . . . . 107

8.1 Vergleich der konservierten, Metall-koordinierenden Aminosäuren . . . . . . 113 


\section{Literaturverzeichnis}

[1] T. C. Südhof, Annu. Rev. Neuroscience 2004, 27, 509-547. 3, 4, 6, 7

[2] Y. A. Chen, R. H. Scheller, Nature 2001, 2, 98-106. 5

[3] R. Jahn, T. Lang, T. C. Südhof, Cell 2003, 112, 519-533. 6

[4] C.-I. Branden, J. Tooze, Introduction to protein structure (Garland Publishing, Inc.), 1999. 6

[5] W. Antonin, D. Fasshauer, S. Becker, R. Jahn, T. R. Schneider, Nature structural biology 2002, 9(2), 107-111. 6

[6] D. Fasshauer, R. B. Sutton, A. T. Brunger, R. Jahn, Proc. Natl. Acad. Sci. USA 1998, 95, 15781-15786. 6

[7] J. B. Bock, H. T. Matern, A. A. Peden, R. H. Scheller, Nature 2001, 409, 839-841. 6

[8] R. C. Lin, R. H. Scheller, Annu. Rev. Cell Dev. Biol. 2000, 16, 19-49. 7

[9] C. Ostermeier, A. T. Brunger, Cell 1999, 96, 363-374. 8

[10] H. Stenmark, Genome Biology 2001, 2(5), 3007.1-3007.7. 8

[11] G. Baldini, A. M. Martelli, G. Tabellini, C. Horn, K. Machaca, P. Narducci, G. Baldini, J. Biolog. Chem. 2005, 280(41), 34974-34984. 9, 10

[12] S.-H. Chung, W.-J. Song, K. Kim, J. J. Bednarski, J. Chen, G. D. Prestwich, R. W. Holz, J. Biolog. Chem. 1998, 273(17), 10240-10248. 9, 10

[13] M. E. Burns, T. Sasaki, Y. Takai, G. J. Augustine, J. Gen. Physiol. 1998, 111, 243-255. 9

[14] H. Shirataki, K. Kaibuchi, T. Sakoda, S. Kishida, T. Yamaguchi, K. Wada, M. Miyazaki, Y. Takai, Molecular and cellular biology 1993, 13(4), 2061-2068. 10

[15] M. Fukuda, J. Biolog. Chem. 2003, 278(17), 15373-15380. 10 
[16] O. M. Schlüter, E. Schnell, M. Verhage, T. Tzonopoulos, R. A. Nicoll, R. Janz, R. C. Malenka, M. Geppert, T. C. Südhof, J. Neuroscience 1999, 19(14), 5834-5846. 10

[17] M. Kato, T. Sasaki, T. Ohya, H. Nakanishi, H. Nishioka, M. Imamura, Y. Takai, J. Biolog. Chem. 1996, 271(50), 31775-31778. 10

[18] E. A. Nalefski, J. J. Falke, Protein Science 1996, 5, 2375-2390. 10, 11

[19] J. Rizo, T. C. Südhof, J. Biolog. Chem. 1998, 273(26), 15879-15882. 10, 11

[20] J. Z. Zhang, B. A. Davletov, T. C. Südhof, R. G. W. Anderson, Cell 1994, 78, 751-760. 10

[21] G. Schiavo, N. J. Gmachl, G. Stenbeck, T. H. Sollner, J. E. Rothman, Nature 1995, 378, $733-736.10$

[22] Z. H. Sheng, C. T. Yokoyama, W. A. Catterall, Proc. Natl. Acad. Sci. USA 1997, 94, 5405-5410. 10

[23] R. B. Sutton, B. A. Davletov, A. M. Berghuis, T. C. Südhof, S. R. Sprang, Cell 1995, 80, 929-938. 10

[24] X. Shao, I. Fernandez, T. C. Südhof, J. Rizo, Biochemistry 1998, 37, 16106-16115. 10

[25] M. Biadene, P. Montaville, G. M. Sheldrick, S. Becker, Crystal structure of the C2A domain of rabphilin3A, acta Cryst. D, unpublished. 11

[26] K. Forchhammer, FEMS Microbiology 2004, 28, 319-333. 13, 15, 16, 17

[27] Y. Nakamura, T. Kaneko, S. Sato, M. Ikeuchi, H. Katoh, S. Sasamoto, A. Watanabe, M. Iriguchi, K. Kawashima, T. Kimura, Y. Kishida, C. Kiyokawa, M. Kohara, M. andi Matsumoto, A. Matsuno, N. Nakazaki, S. Shimpo, M. Sugimoto, C. Takeuchi, M. Yamada, S. Tabata, DNA Research 2002, 9, 123-130. 13

[28] A. L. Lehninger, D. L. Nelson, M. M. Cox, Prinzipien der Biochemie (Spektrum Akademischer Verlag GmbH Heidelberg, Berlin, Oxford), 1994. 13

[29] J. M. Berg, J. L. Tymoczko, L. Stryer, Biochemie (Spektrum Akademischer Verlag Heidelberg, Berlin), 2003. 14

[30] K. Forchhammer, N. Tandeau de Marsac, J.Bacteriology 1994, 176(1), 84-91. 14, 16, 17

[31] E. Flores, A. Herrero, Biochemical Soc. Transactions 2005, 33, 164-167. 14, 15 
Literaturverzeichnis

[32] T. Arcondéguy, R. Jack, M. Merrick, Microbiology and molecular biology reviews 2001, 65(1), 80-105. 15, 16

[33] H. S. Son, S. G. Rhee, J. Biolog. Chem. 1987, 262(18), 8690-8695. 16

[34] K. Forchhammer, N. Tandeau de Marsac, J. Bacteriology 1995, 177(20), 5812-5817. 16

[35] A. Herrero, Molecular Microbiology 2004, 52(5), 1225-1228. 16

[36] K. Forchhammer, N. Tandeau de Marsac, J.Bacteriology 1995, 177(8), 2033-2040. 16, 17

[37] A. Irmler, S. Sanner, H. Dierks, K. Forchhammer, Moleular Microbiology 1997, 26(1), 81-90. 17

[38] A. J. Ninfa, M. R. Atkinson, Trends in Microiology 2000, 8(4), 172-179. 17

[39] L. Shi, W. Zhang, Microbiology 2004, 150, 2247-2256. 17, 18

[40] L. Shi, Frontiers in Bioscience 2004, 9, 1382-1397. 17, 18, 21

[41] P. J. Kennelly, M. Potts, Frontiers in Bioscience 1999, 4, 372-385. 17, 18

[42] D. Barford, A. K. Das, M.-P. Egloff, Annu. Rev. Biophys. Biomol. Struct. 1998, 27, 133-164. 18

[43] P. Bork, N. P. Brown, H. Hegyi, J. Schultz, Protein Sci. 1996, 5, 1421-1425. 18, 19

[44] W. Zhang, L. Dhi, Microbiology 2004, 150, 4189-4197. 18

[45] K. Katoh, K. Kuma, H. Toh, T. Miyata, Nucleic Acids Res. 2005, 33, 511-518. 18

[46] H. D. G. Thompson, J. D., T. J. Gibson, Nucleic Acids Research 1994, 22, 4673-4680. $19,120,121$

[47] A. K. Das, N. R. Helps, P. T. W. Cohen, D. Barford, EMBO Journal 1996, 15, no. 24, 6798-6809. 20

[48] K. E. Pullen, H.-L. Ny, P.-Y. Sung, M. C. Good, S. M. Smith, T. Albers, Structure 2004, 12, 19471954. 20, 21

[49] N. Kloft, e-mail von Dr. N. Kloft an die Verfasserin vom 16.05.06, 2006. 21 
[50] P. T. Wingfield, Current protocols in protein science (John Wiley \& Sons, Inc.), 1998 S. 5.0.1-5.2.18. 24, 30, 35

[51] S. Harper, D. Speicher, Current protocols in protein science (John Wiley \& Sons, Inc.), 1997 S. 6.6.1-6.6.21. 24,35

[52] G. Wedler, Lehrbuch der physikalischen Chemie (WILEY-VCH Verlag GmbH), 1997. 30,37

[53] M. A. Greagg, M. J. Fogg, G. Panayotou, S. J. Evans, B. A. Connolly, L. H. Pearl, Proc Natl. Acad. Sci. U S A 1999, 96(16), 9045-9050. 31

[54] J. Hanke, S. Solinas-Toldo, J. Hoheisel, Handbuch der molekularen Medizin, Band 1, Molekular- und Zellbiologische Grundlagen (Springer-Verlag Berlin Heidelberg), 1997 S. 51-91. 31, 33

[55] J. Cline, J. C. Braman, H. H. Hogrefe, Nucleic Acids Research 1996, 24(18), 3546-3551. 31

[56] Qiagen, HotStarTaq® PCR Handbook, 2005. 33

[57] K. A. Eckert, T. A. Kunkel, PCR. A practical approach (Oxford University Press, New York), 1991 S. 225-244. 33

[58] U. K. Laemmli, Nature 1970, 227, 680-685. 34

[59] Amersham Bioscience, GST gene fusion system, 2003. 35

[60] Amersham Bioscience, The recombinant protein handbook, 2003. 36

[61] A. Williams, V. Frasca, Current protocols in protein science (John Wiley \& Sons, Inc.), 1999 S. 8.2.1-8.2.30. 36

[62] L. Hagel, Current protocols in protein science (John Wiley \& Sons, Inc.), 1998 S. 8.3.1-8.3.30. 36

[63] C. Mackintosh, Protein phosphorylation: A practical approach (Oxford University Press, New York), 1993 S. 197-230. 37

[64] M. Ries-Kautt, A. Ducruix, Crystallization of nucleic acids and proteins: A practical approach (Oxford University Press, New York), 1992 S. 195-218. 38

[65] E. A. Stura, I. A. Wilson, J.Crystal Growth 1991, 110, 270-282. 39, 40, 122 
Literaturverzeichnis

[66] E. Stura, Protein Crystallization: Techniques, strategies, and tips (International University Line, LA Jolla), 1999 S. 139-153. 39

[67] T. Bergfors, J.Structural Biology 2003, 142, 66-76. 39

[68] E. Garman, Acta. Cryst. D 1999, 55, 1641-1653. 40

[69] E. F. Garman, T. R. Schneider, J. Appl. Cryst. 1997, 30, 211-237. 40

[70] M. A. Walsh, G. Evans, R. Sanishvili, I. Dementieva, A. Joachimiak, Acta. Cryst. D 1999, 55, 1726-1732. 41

[71] G. M. Sheldrick, in group seminar, 2005 . 41

[72] Z. Otwinowski, W. Minor, Methods in Enzymology 1997, Volume 276: Macromolecular Crystallography, part A, 307-326. 42, 96

[73] G. M. Sheldrick, X2SAD, göttingen 2002. 42, 96

[74] Bruker-AXS, SADABS, XPREP, Techn. Ber., Computerprogramme, 2002. 42, 60, 62, 96,101

[75] D. Blow, Outline of crystallography for biologists (Oxford University Press, New York), 2002. 42, 43, 45, 50, 51

[76] G. Rhodes, Crystallography made crystal clear (Academic Press), 2000. 42

[77] C. Giacovazzo, H. L. Monaco, D. Viterbo, F. Scordari, G. Gilli, G. Zanotti, M. Catti, Fundamentals of crystallography (International Union of Crystallography, Oxford University Press), 1992. 43, 49

[78] Z. Dauter, Acta. Cryst. D 2002, 58, 1958-1967. 43

[79] J. L. Smith, W. A. Hendrickson, T. C. Terwilliger, J. Berendzen, International Tables for Crystallography, Volume F (IUCr and Kluwer Academic), 2001 S. 299-309. 46, 47, 48

[80] A. González, Acta. Cryst. D 2003, 59, 1935-1942. 47

[81] R. J. Read, Acta. Cryst. D 2001, 60, 432-438. 49

[82] K. Y. J. Zhang, K. D. Cowtan, P. Main, International Tables for Crystallography, Volume F (IUCr and Kluwer Academic), 2001 S. 311-324. 49, 50

[83] G. M. Sheldrick, Z. Kristallogr. 2002, 217, 644-650. 50, 62 
[84] P. Emsley, K. Cowtan, Acta. Cryst. D 2004, 60, 2256-2268. 51, 62, 64, 99

[85] G. Murshudov, A. Vagin, E. Dodson, Acta. Cryst. D 1997, 53, 240-255. 51, 62, 64, 99, 101

[86] G. M. Sheldrick, T. R. Schneider, Methods in Enzymology 1997, Volume 277: Macromolecular Crystallography, part B, 319-343. 51, 62, 63, 64, 68, 99

[87] Z. Dauter, G. N. Murshudov, K. S. Wilson, International Tables for Crystallography, Volume F (IUCr and Kluwer Academic), 2001 S. 393-402. 51

[88] A. T. Brünger, Nature 1992, 355, $472-475.51$

[89] T. R. Schneider, Tutorial on how to solve a Se-substructure using SHELXD, Techn. Ber., Dept. of structural chemistry, University of Göttingen, 2003. 60

[90] T. R. Schneider, G. M. Sheldrick, Acta. Cryst. D 2002, 58, 1772-1778. 60

[91] G. M. Sheldrick, H. A. Hauptmann, C. M. Weeks, R. Miller, I. Usón, International Tables for Crystallography, Volume F (IUCr and Kluwer Academic), 2001 S. 333-351. 60

[92] T. Pape, T. R. Schneider, J. Appl. Cryst. 2004, 37, 843-844. 62, 99

[93] R. J. Morris, A. Perrakis, V. S. Lamzin, Acta. Cryst. D 2002, 58, 968-975. 62, 99

[94] G. Murshudov, A. Vagin, E. Dodson, in Proceedings of Daresbury Study Weekend, 1996 . 62, 64, 99, 101

[95] A. J. McCoy, R. W. Grosse-Kunstleve, L. C. Storoni, R. J. Read, Acta. Cryst. D 2005, 61, 458-464. 64, 101

[96] W. Kabsch, C. Sander, Biopolymers 1983, 22(12), 2577-2637. 71, 72

[97] T. R. Schneider, Acta. Cryst. D 2002, 58, 195-208. 72, 109

[98] J. Ubach, J. Garcia, M. P. Nittler, T. C. Südhof, J. Rizo, Nature 1999, 1, 106-112. 76, 79

[99] E. Krissinel, K. Henrick, Acta. Cryst. D 2004, 60(12), 2256-2268. 77, 81

[100] R. A. Laskowski, M. W. MacArthur, D. S. Moss, J. M. Thornton, J. Appl. Cryst. 1993, 26, 283-291. 99

[101] M. D. Jackson, C. C. Fjeld, J. M. Denu, Biochemistry 2003, 42 (28), 8513 -8521. 114 


\section{Publikation}

1. Neutral and Ionic Aluminum, Gallium and Indium Compounds Carrying Two or Three Terminal Ethynyl Groups, M. Schiefer, N.D. Reddy, H. Ahn, A. Stasch, H.W. Roesky, A.C. Schlicker, H. Schmidt, M. Noltemeyer, D. Vidovic, Inorganic Chemistry, 2003, 42, 4970-4976.

2. Partially fluorinated rare earth metal complexes, A.M. Neculai, D. Neculai, G.B. Nikiforov, H.W. Roesky, C. Schlicker, R. Herbst-Irmer, J. Magull, M. Noltemeyer, European Journal of Inorganic Chemistry, 2003, 17, 3120-3126. 


\section{Lebenslauf}

\section{Persönliche Daten}

Name

Anne Christine Schlicker

Geburtsdatum

3.Februar 1979

Geburtsort

Rotenburg/Wümme

Familienstand

ledig

Staatsangehörigkeit

deutsch

\section{Studium und schulische Ausbildung}

Jul 1998

Okt 1998

Okt 2000

Mai 2003

\author{
Allgemeine Hochschulreife, Ratsgymnasium Rotenburg \\ Wümme \\ Diplomstudiengang Chemie, Georg-August-Universität \\ Göttingen \\ Vordiplom Chemie, Georg-August-Universität Göttingen \\ Diplomarbeit am Lehrstuhl für Strukturchemie \\ der Georg-August-Universität unter der Leitung von \\ Prof. George M. Sheldrick, PhD: \\ Röntgenstrukturuntersuchungen an Komplexen \\ von Acetylenen und Verbindungen der Seltenerdenmetalle \\ Abschluss: Diplom-Chemikerin
}

\section{Promotion}

Jun 2003 - Mai 2006
Dissertation am Lehrstuhl für Strukturchemie der Georg-August-Universität im Arbeitskreis von Prof. George M. Sheldrick, PhD:

Kristallstrukturen der C2B-Domäne von Rabphilin-3A und der PP2C-ähnlichen Phosphatase tPphA von Thermosynechococcus elongatus BP-1 